The Tidiness of Chaos:

Tradition and Innovation in the Sadak Nyelam Dé Zhi Ritual at Triten Norbutsé

Jonathan Edward Verity

Charlottesville, VA

M.A. History of Religions, University of Virginia, 2007

B.A. Religious Studies \& Environmental Science, University of Virginia, 1997

A Dissertation presented to the Graduate Faculty

of the University of Virginia in Candidacy for the Degree of

Doctor of Philosophy

Department of Religious Studies

University of Virginia

May, 2014 


\section{Table of Contents}

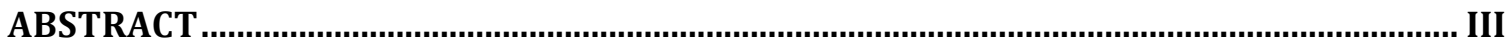

ACKNOWLEDGEMENTS

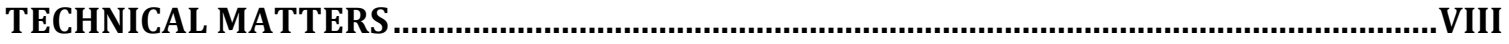

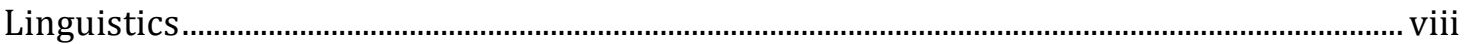

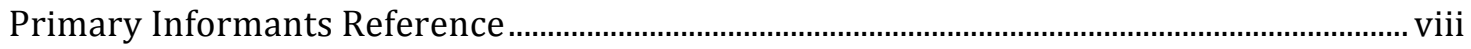

INTRODUCTION

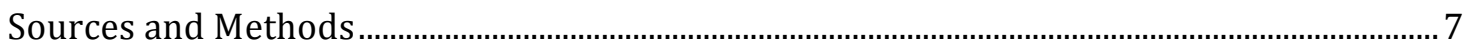

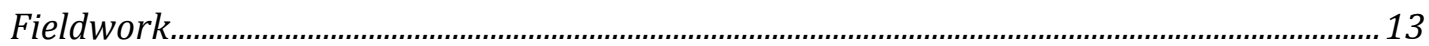

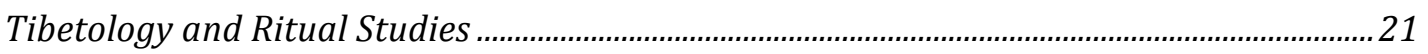

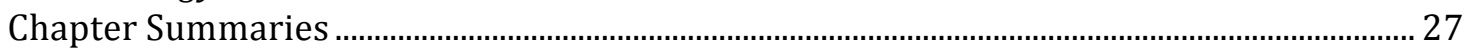

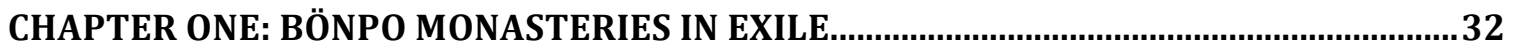

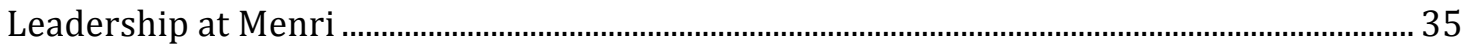

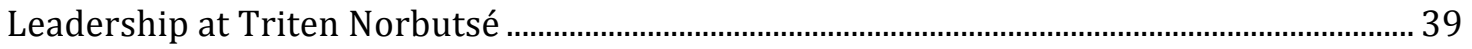

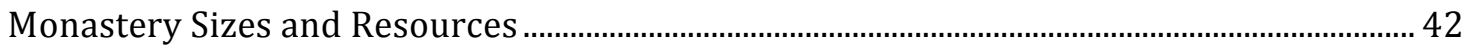

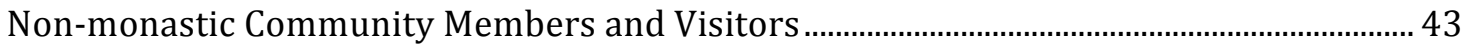

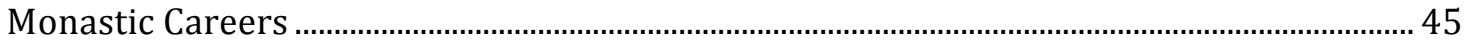

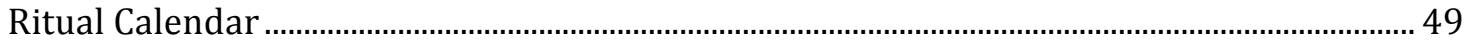

Dö Rituals

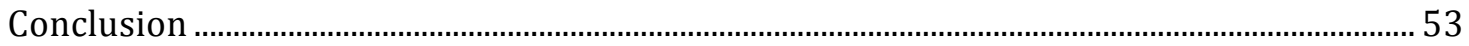

CHAPTER TWO: PERFORMANCE

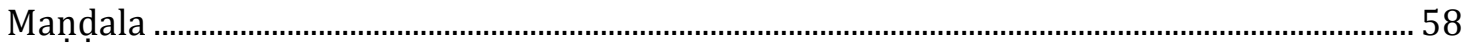

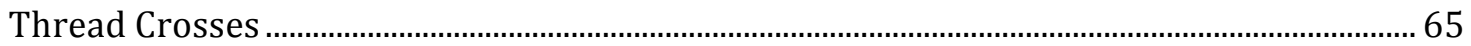

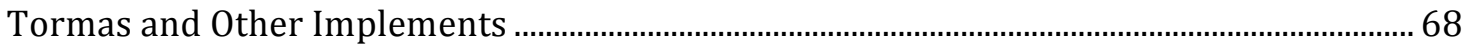

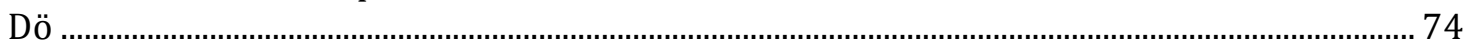

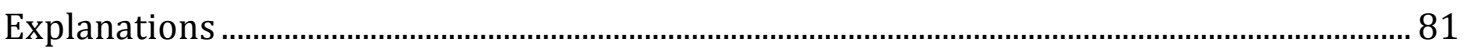

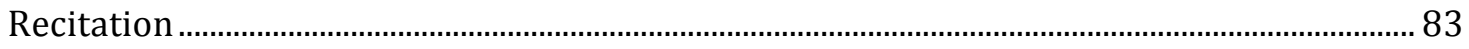

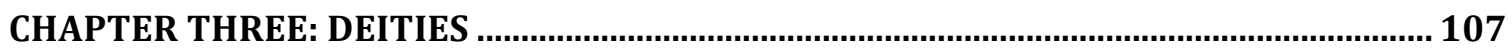

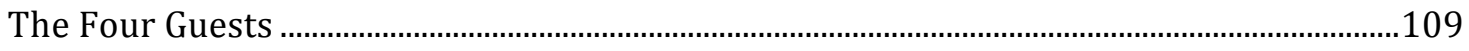

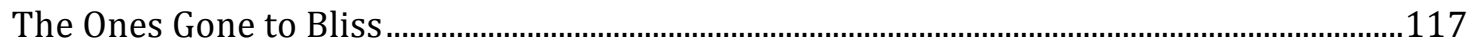

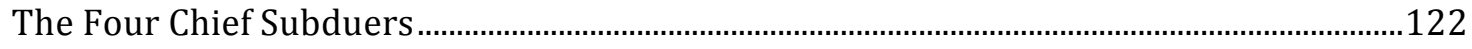

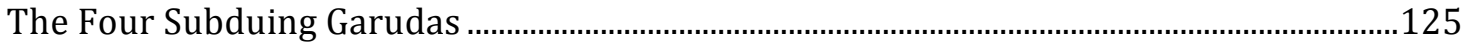

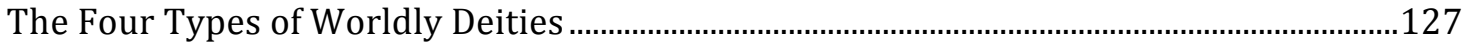

Lu

Sadak

Nyen

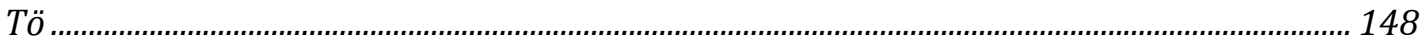

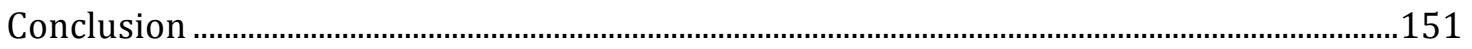

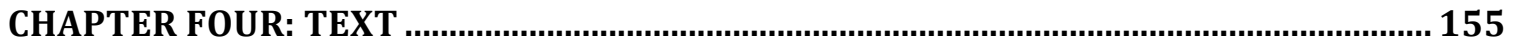

Pönsé Khyunggötsel and the Background of the Nyelam Dé Zhi ............................................156 


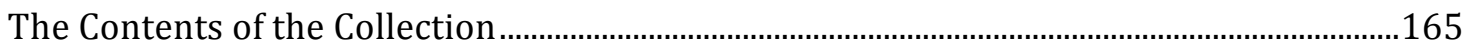

Literary Genres

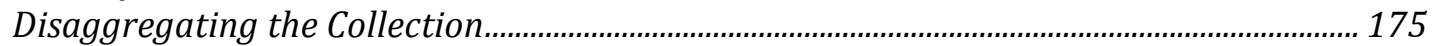

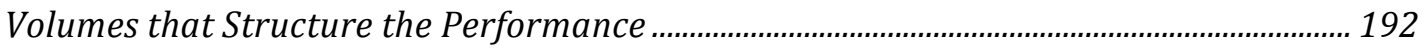

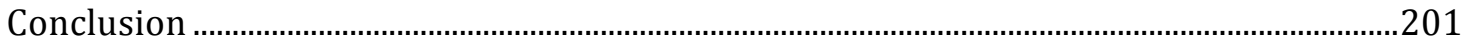

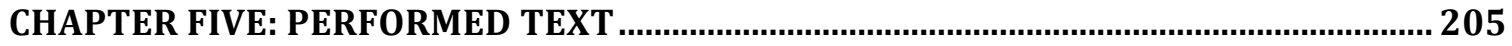

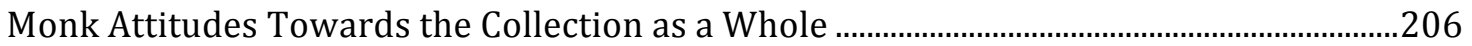

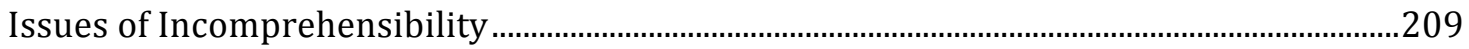

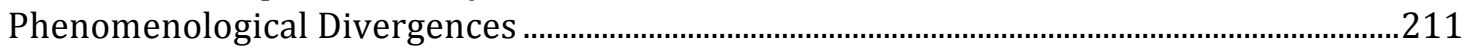

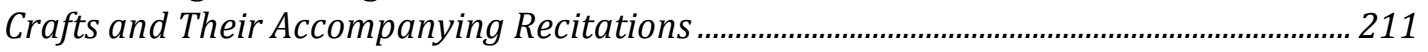

Divergence During the Main Liturgy and Recitation............................................................... 219

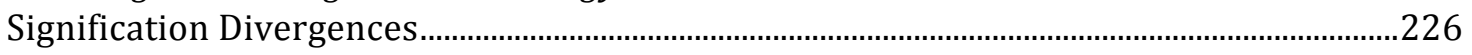

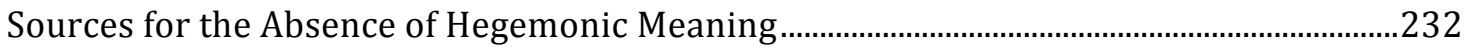

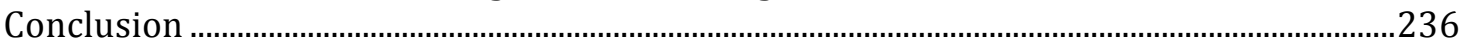

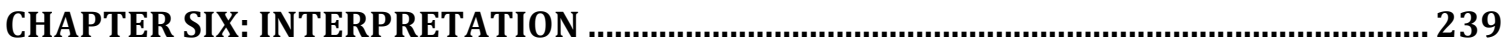

Conditions for the Inconsequence of Ritual Infidelity …….........................................................242

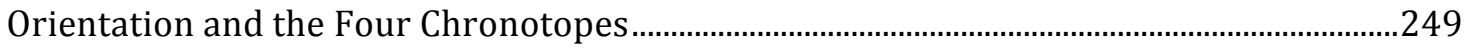

Body

Home

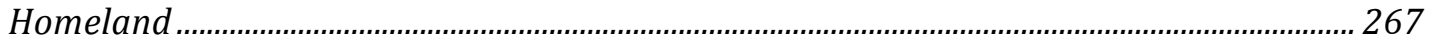

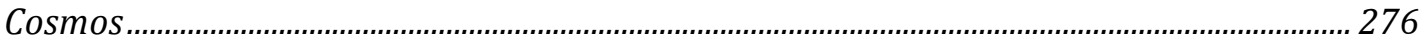

Globalization and the World Stage

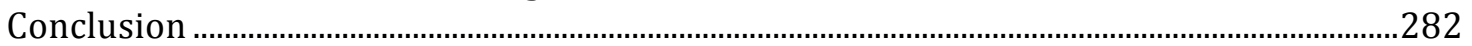

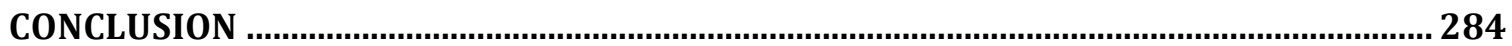

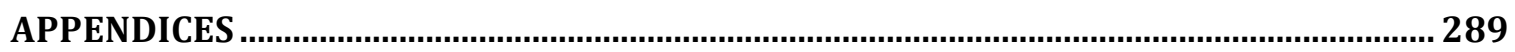

Appendix 1: Annotated List of Volumes in the Nyelam Dé Zhi Collection .............................289

Appendix 2: List of Volumes According to Genre, Ordered by Quantity, Descending .......307

Appendix 3: List of Volumes According to Inclusion in the Performance at Triten

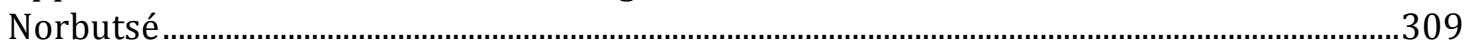

Appendix 4: Unpublished Manuscript of a Teaching Document on the Subject of Tormas,

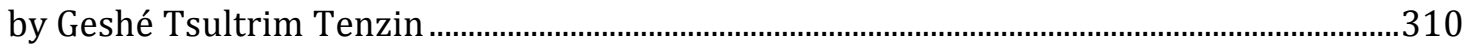

Appendix 5: Unpublished Manuscript "Tapiritsa” (ta pi hri tsa) by Tsultrim Tenzin .......318

Appendix 6: The table of contents (sa bcad) for the Manuscript (zin thu)............................330

Appendix 7: The table of contents (sa bcad) for the Upper Ritual (stod chog) volume ....331

Appendix 8: Notable title page differences across volumes ......................................................332

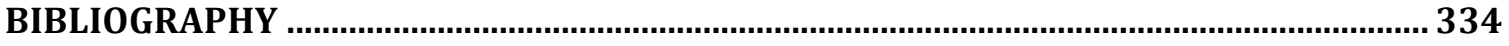

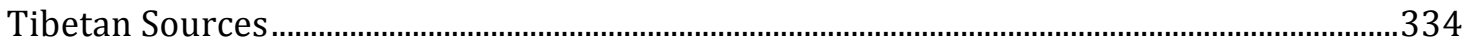

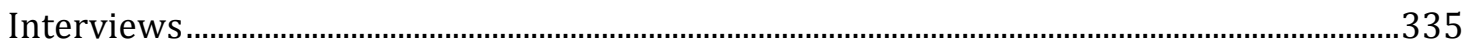

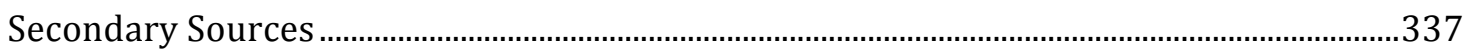




\section{Abstract}

The following monograph centers on the performance of the Sadak Nyelam Dé Zhi (sa bdag nye lam sde bzhi) ritual at the Bönpo Triten Norbutsé monastery in Kathmandu, Nepal. The study includes an evaluation of the ritual's textual bases as well as detailed ethnographic observations and interviews from in-person attendance at the performances in 2009 and 2010, and from living among the performers and other extended community members in the months before and after. This ritual, also known by monks and others as the "summer ritual," is undertaken every year in the $4^{\text {th }}$ month of the Tibetan calendar, from the $12^{\text {th }}$ to the $16^{\text {th }}$, corresponding roughly to the end of May and beginning of June of the international calendar. It is one of many annual events at the monastery, but it is unique among others for the scale of its prominent dö (mdos) mound, adorned with greenery and flowers and so on from the woods around the monastery, in lieu of a more traditional altar, as well as for its emphasis on worldly deities.

Due to this emphasis on worldly deities and thus on primarily lay concerns, the ritual is unique also in its disconnection from the priorities of an academicfocused monastery (bshad grwa) in exile, with very little laity in the immediate vicinity. This tension, combined with many others that will be explored in the pages that follow, produces a ritual performance with a conspicuous lack of concern for traditional outcomes, as defined in the texts and in conversation, and which thus begs the question of why and how this ritual and its performance persist as relevant in other ways. 
The central argument of this paper answers these questions, first by showing the various pressures that disengage the community from the ritual's ostensible goals - or their own varied understandings of the ritual's goals - and from fidelity to performance as prescribed by texts and other community standards. Second, it reveals the ways that these pressures and other phenomena create space in and through the performance for actors and the community as a whole to impute new meanings to or otherwise address diverse community imperatives. Third and last, it describes those alternative meanings and appropriations of the ritual, many of which relate to the community's exiled context, thereby illuminating a rich process of cultural creation for a new community in a new environment. 


\section{Acknowledgements}

We often hear the title "Doctor" and think of columned institutions and hours poring over books, and passing difficult exams, as if that is all that happened over the course of nine years. For me, the journey from learning my first phrase in Tibetan tashi delek! - to typing the last period of this dissertation has been one filled with adventure and misadventure, with stimulation and boredom, with tremendous happiness and heartache. I've traveled and lived around the world. I've made friends in new places and have lost friends to tragedy. I've become a married man to a woman brave enough to move with me from San Francisco to a small town in Virginia without a ring on her finger (more about her later). Then I became a father. And still, the dissertation waited patiently in a dark corner.

Every step of this journey has been taken with other people who took time and energy out of their own journeys, in one way or another, to help me with mine. The trivial words of thanks that I'm about to write to these people will never adequately convey the depths of gratitude I feel for their support, assistance, direction, camaraderie, and love over these last several years and beyond.

The first people I encountered here at UVa were my schoolmates, and so I want to thank them first for their friendship, support, feedback, and insight year after year, even as we competed for funding and, in the early days of coursework, praise from our instructors. I wish I hadn't succumbed to that but I did. I couldn't possibly list all the important people but the ones I've spent the most time with include Ben Nourse, Brenton Sullivan, Chris Bell, David DiValerio, Alison Melnick, Geoff Barstow, and Manu Lopez. I'm also tremendously grateful for classmates who were further along than I was, or had already graduated, for their friendship and guidance, especially around the subject of Bön and travel and fieldwork: Jann Ronis, Jessie Starling, Chris Hatchell, Katarina Turpeinen, Bill Gorvine, and Slava Komarovski.

Teachers who have helped along the way are also too numerous to mention, but those who were the most consistent presences in my life, shaping the way I think, helping me with big questions, and of course exposing me to wondrous worlds inside our own, include: Ben Ray, Paul Groner, Karen Lang, John Nemec, Clarke Hudson, Larry Bouchard, and John Shepherd. I'd also like to thank my talented, spirited, and patient teachers of the Tibetan language: Tinley Lama and Tsetan Chonjore.

A huge debt of gratitude goes to my dissertation committee - David Germano, Kurtis Schaeffer, Ben Ray, and John Shepherd - for their willingness to read this sometimes tired, sometimes overly excited tome on a subject they may or may not particularly care about, and for their helpful critiques and guidance along the way. Special thanks also to Samten Karmay, who provided profoundly helpful insight and guidance during our talks at Menri and at his home in Paris. 
None of this would have happened, both in terms of the opportunity to come to graduate school, and in terms of keeping me on track and supported along the way, if it weren't for my advisors, Kurtis Schaeffer and David Germano. Kurtis, who came on as a faculty member the same year that I started the Masters program, has been a persistent voice of reason, an inspiration for how to succeed as both an academic and a family man, and a great friend, offering words both kind and stern as needed along the way.

My fate has perhaps never been as intertwined with anyone as it has with David Germano, who was my undergraduate advisor, graduate advisor, professor, and employer. This dream of mine to switch careers from technology to academia would not have been realizable without his faith and direction, and thus he has almost singlehandedly changed the course of my life. This is all the more meaningful to me given how absurdly over-committed he is to a million people and a million projects (though those of us who know him well believe he relishes the insanity). In class, he often quoted a Nobel Peace Prize laureate who said something along the lines of, "It's easy to help a thousand people. What's hard is to help just one." He does both.

This particular project, not to mention my entire perspective on Tibet, religion, monasticism, and more, have been massively assisted by the Bönpo monks and others at Menri monastery in Dolanji, India, and Triten Norbutsé monastery in Kathmandu, Nepal. I want to extend special thanks to His Holiness Lungtok Tenpé Nyima, the abbot of Menri, as well as to Lopön Tenzin Namdak and Khenpo Tenpa Yungdrung Rinpoché at Triten Norbutsé, for their inexhaustible hospitality and wisdom. My time at both monasteries was dramatically improved by friends and teachers, most but not all of whom were geshés. Foremost among these were: Geshé Choekhortsang (Nyima Özer) from Dolpo, Geshé Yungdrung Monlam from Dergé, Geshé Tenzin Yangtön from Dolpo, Geshé A Trom (Sherap Lhundrup) from Khyungpo, and the Acharya Drukzé. One geshé who helped me a great deal but did not want to be named out of fear of repercussions I will refer to as Geshé Q. Thank you also to Tsultrim Gyatso, for tirelessly helping me film the proceedings at Triten Norbutsé, to Döndrup and Takla, the guestmasters at Menri and Triten Norbutsé, as well as Sunita, Suraj, and the rest of the Pant family, with whom I stayed whenever I was in Kathmandu. Finally, I want to pay special thanks to Geshé Tenzin Tsultrim, the Drupdra Khenpo at Triten Norbutsé, for his limitless patience, humor, and wisdom, in answering my thousands of questions and pointing me in the right direction. As the administrator of the Nyelam Dé Zhi ritual and my main contact at Triten Norbutsé, I owe any of this project's successes to him. To Khenpo-la and all the monks and Bönpos who helped me, I want to say this: Anything you read in this paper that is wrong is my fault, not yours. Geshé Mönlam Wangyel, you told me to "tell the truth about this ritual." I have done so to the best of my ability, but I know my truth will be different from yours. 
For exposing me to Bön before I knew what it was, and for keeping me in the loop with their activities and constant stream of visitors, I'd also like to thank Tenzin Wangyal Rinpoché of Nelson County, Virginia, and everyone at Ligmincha.

Finally, I have to extend my deepest heartfelt ineffable gratitude to my family, who have wondered and worried about me, and nevertheless supported and cheered me every step of the way. I am who am and I've done what I've done because of the steady groundedness of my dad, the excitable intellect of my mom, and a sister who reminds me all the time how weird I am.

And then there is the one person who has stood by me through all the adventure and misadventure and heartache, who has been at the source of so much of the happiness, who inspired me and took care of me and looked after our affairs and our daughter as I first buried myself in books, then went off to Asia for a year, and then drowned myself and our lives in this dissertation - my superhuman wife, Erin Malec.

Finally, I'd like to dedicate anything good about this work to our daughter, Hope, and our second child, due in a few days. I dedicate the rest to the sadak, lu, nyen, tö, and other nefarious characters of the Tibetan landscape, who sometimes like smelly things. 


\title{
Technical Matters
}

\author{
Linguistics
}

With regards to translation and transliteration I have followed a few different guidelines in order to create the most effortless experience for both casual readers and Tibetologists wanting to pursue more detailed investigations. Throughout the discussion all Tibetan words are translated into English, with Wylie transliteration in parentheses for at least the first usage of the word, unless the word or phrase satisfies one or more of these conditions:

1) The word is the name of a person, place, or other proper noun, or so well-known either as is or in its Sanskritic form that translation is more misleading than helpful. An example of the latter is "mandala."

2) The word or phrase is difficult to translate or the translation is not helpful. An example of this is the tö (gtod) classification of deities. An English translation for this particular use of this word is unknown, though some discussion will be given below.

When a word is not translated in the discussion for the reasons above it is phoneticized according to the THL Simplified Phonetic Transcription scheme. When words or phrases are not translated in footnotes or appendices, and are not phoneticized elsewhere, they are left in Wylie.

\section{Primary Informants Reference}

This is by no means an exhaustive list, but for reference here are some of the contacts at Menri and Triten Norbutsé monasteries who gave me the most citable assistance. Note that I have chosen to refer to them by their shorter names in the pages that follow to facilitate the presentation of information.

- Geshé Tenzin Tsultrim, aka Drupdra Khenpo, abbot of the school of practice at Triten Norbutsé.

- Sherap Lhundrup, aka Geshé A Trom, from Khyungpo (Hopa)

- Nyima Özer, aka Geshé Choekhortsang, from Dolpo

- Geshé Mönlam Wangyel, the disciplinarian at Triten Norbutsé

- Geshé Q: A geshé who helped me a great deal but did not want to be named

- Geshé Tenzin Yangtön from Dolpo 
- Geshé Yungdrung Mönlam from Dergé

- Lopön Tenzin Namdak, aka Yongdzin Rinpoché, founder and head teacher at Triten Norbutsé

- Sangyé Tenzin, aka Menri Trizin Lungtok Tenpé Nyima Rinpoché, abbot of Menri monastery 


\section{Introduction}

There is a strong temptation to look upon ritual as if it were one of the tidiest forms of human behavior. With an often textually prescribed set of actions, ritual actors reproduce an established program with the highest fidelity, ensuring there is no deviation from the syntax, grammar, or at the very least the commitment, that bring about the ritual's promised, or implicit, transformation. Or so ritual literature and accounts would have us believe. The performance of the Sadak Nyelam Dé Zhi (sa bdag nye lam sde bzhi, referred to henceforth by the common shortened form Nyelam Dé Zhi) dö (mdos) ritual at Triten Norbutsé monastery in Kathmandu, Nepal, and the texts that inform it, reveal a distinct lack of tidiness that is almost certainly common among rituals of similar scale - those involving a great many actors with sometimes very different skills and sensibilities, drawing from a diverse body of literature that has been aggregated over the course of many centuries - but which is further complicated by a great number of factors that include an exiled context, divergent priorities and concerns, and profound competing tensions within and around the community.

The primary goal of this project is not to establish a definitive account of the Nyelam Dé Zhi as it exists in the texts and minds and performances of the Bön tradition as a whole, nor is it to propose a theory of ritual that could be generalized to other performances beyond the Nyelam Dé Zhi, even to other rituals at Triten Norbutsé, and much less to other rituals of other monasteries or of other Tibetan 
traditions. It is also not about describing all of the minutiae that comprise Tibetan ritual - what tormas are, why performers play a conch horn, and so forth, as those kinds of pan-Tibetan details have been described at great length elsewhere (though some details will be given about implements as necessary, especially in Chapter Two, describing what performers are doing, as well as their understanding of what they are doing). ${ }^{1}$ What follows is the presentation and analysis of one ritual performed by one community, including relevant background from other texts and communities when appropriate, but focusing very much on the context provided by, on the one hand, the voluminous collection of texts associated with the Nyelam Dé Zhi, and, on the other, the community's own understandings and explanations of the ritual, of ritual generally, and of the deities and other entities, traditions, and ideas that the Nyelam Dé Zhi addresses.

Through this ritual lens, a number of other key communal dynamics, traditions, and history will come to light. One is the marginally larger issue of modern Bönpo monasticism in exile. While it is impossible to make generalizations across all such monasteries, Triten Norbutsé in Kathmandu and Menri monastery in Dolanji, Himachal Pradesh, India - the other principle monastery in exile and the global seat of the Bönpo tradition - have a great deal in common. Taken together, their commonalities illuminate the personalities, programs, and tensions of the institutions that see themselves as the primary educators, caretakers, and defenders of Bön on an increasingly global stage. The places of divergence between these monasteries, due to demographics, resources, and leadership style, among others,

\footnotetext{
${ }^{1}$ See Beyer (1978), Tucci (1980), Kohn (2001), and many others for this kind of information.
} 
are illuminating as well, revealing in some cases the ways that idiosyncrasies of place and person influence institutional priorities and ritual strategies, and in other cases the ways that monasteries with otherwise similar functions and cultures set themselves apart from each other to occupy unique and redemptive niches in their shared cultural landscape.

The ritual lens will provide insight also into literary trends and tensions in Bönpo institutional contexts, both modern and historical. With regards to specifically ritual literature, the multi-volume text that is the basis of the Nyelam Dé Zhi, presented monolithically as the product of a single treasure revelation, proves to be in actuality a complex accretion of volumes, subject matter, sensibilities, and authorship over time, culminating in - or possibly beginning with, in terms of compilation - the writing of the Manuscript of the Nyelam Dé Zhi (nye lam sde bzhi'i zin thu $)^{2}$ in the $19^{\text {th }}$ century, which synthesizes the otherwise disparate volumes or groups of volumes into a performable whole. There can be no doubt that the textual bases of comparable large-scale institutional rituals reflect a similarly diverse history, as well as a similar genius for performative synthesis.

To an extent, the collection of subjects, writing styles, historical layers and so on that marks the texts of the Nyelam Dé Zhi is a microcosm of the Bönpo canon itself, of which the Nyelam Dé Zhi collection is in fact a member. While there are a number of known Bönpo canons scattered across the Tibetan cultural region, the primary canonical texts, in the form of a Kangyur, Tengyur, and "Katen" - a collection that appears to include any text that could be found at the time of

\footnotetext{
${ }^{2}$ See Appendix 1, Volume 1.
} 
compilation - are housed, and have now been digitized, and are used every day, at Menri and Triten Norbutsé. Given that the Nyelam Dé Zhi collection is a part of this canon, and the Manuscript instructs further use of other canonical texts, a study of this ritual necessarily illuminates aspects of scriptural composition and especially compilation, as ritual texts, all the way to abbreviated ritual manuals, have been deemed worthy of the canon.

In the particular case of the Nyelam Dé Zhi, the strategies of textual compilation and synthesis, together with a subject matter consisting primarily of worldly concerns that is otherwise performed in a monastic environment that is designed to prevent engagement with such concerns, provides also a rare opportunity to glimpse into the process of the institutionalization of ritual. This extends from the tensions between text and performance, to the connection between performance context and purpose or meaning, all the way to the portability, elasticity, and capacity of ritual to bridge dramatically different time periods, communities, and tensions.

A study of the deities that are the primary focus of the Nyelam Dé Zhi - from the worldly deities like the lu and sadak that lend the ritual its name, to the buddhalike Ones Gone to Bliss (bde bar gshegs pa) that are at the center of the mandala, and of virtually every manḍala - reveals that identity and agency are by no means fixed in the context of a community's day-to-day and ritual-to-ritual experience. Even in the context of one ritual, there can be substantial disagreement around identity, though such disagreement is often not socially or even ontologically problematic within the community. Bringing this apparently paradoxical field into dialogue with 
the bounded nature of ritual, which depends heavily on a model of "guests," will yield a deeper understanding of how different cultural and historical layers within a community cohere in the lived experience of its members.

All of these dimensions - monasticism, literature, agents and identity, the institutionalization process, text and performance, ritual as a strategy to meet various imperatives, and the many others that will be discussed below - are themselves contextualized in this community, and thus in this study, by the modern Tibetan diaspora in which Triten Norbutsé is embedded. The urbanity of Kathmandu and the high degree of access it provides to global communication and travel all influence monastic resources, sensibilities, and careers, while the exile status of the community compels different interpretations and motivations for ritual and other activities that were otherwise phenomonologically similar, and possibly the same, in pre-exile contexts. For the Bönpos at Triten Norbutsé, these forces can produce an uncertain, high-pressure environment, inhabited by diverse, sometimes unfamiliar people both inside and outside the immediate community, with boundaries between the two that are not intuitively as clear as they may once have been. The people that cross into the community are often from places, and of a character or cultural orientation, that the community had little exposure to previously, and there are opportunities for community members to go to outside places and interact with outside people that were not possible, or much more difficult, in the past. Modern exile also compels different priorities and attitudes, even as community members try to stabilize around constants. Activity inside this 
community thus cannot help but address, or try to address, this new situation and these new parameters, regardless of that activity's original design.

At a deeper level, this project is thus about the creative tension that exists between contradiction and coherence, and between tradition and innovation. It is about the movement between these poles, as a force that both undermines and empowers, that both limits and expands. In the case of the Nyelam Dé Zhi performance, even the canonical texts ostensibly at its root reveal themselves to be in motion between these poles, providing a very shaky, and very flexible, foundation upon which to construct and re-construct an annual event that has evolved an everincreasing capacity to address a great variety of shifting communal imperatives. As such, the modern performance is a crucible for cultural creation, if one of many, with actors bringing older ritual and monastic forms and their embedded histories which are themselves complex adaptations to a variety of pressures over time - into dialogue with new tensions, to produce a strand of Tibetan Bönpo culture uniquely suited to the modern exiled context of Triten Norbutsé.

In the pages that follow, then, there is to be found a ritual study, but also a historical, cultural, and textual study, that together endeavor to present a portrait of a community engaged in a particular activity at a particular time, the modern performance of the Nyelam Dé Zhi, that pulls them back towards home as it pushes them forward into a different future. It is an activity that situates them in particular relationships with the principle agents that populate their worldview, and that reflects the changes in those relationships compelled by changes elsewhere. In the end, it proves to be an extraordinarily rich and complex picture, as can only be the 
case for a diverse community in a new environment that is engaged in the performance of a text-based ritual that has a pedigree stretching back many centuries.

\section{Sources and Methods}

Given the current state of scholarship, there is a tendency, or at least a temptation, with any project centering on Bön, to examine the relationship between the project's focus within Bön and any comparable subjects in Buddhism. While there is great value in such comparative projects, the present project aims for a different kind of value. Many of the components of this ritual have Buddhist analogues, but this project, except where strictly relevant or especially interesting, does not assess pedigrees, borrowings, so-called plagiarisms, or even basic differences and similarities between Buddhism and Bön. Neither does it attempt, beyond speculative conclusions, to speak to Bön as a larger tradition past, present, or future, as if it could somehow be reduced to what is happening in this one community around this one ritual. Rather, the goal of the present project is to illuminate what is happening on the ground right now in an exiled monastic community, and to illuminate the texts that inform or at least animate this ritual and related activity on the ground, hoping, as a byproduct of the process, to provide valuable data for other comparative or tradition-scale projects.

As an example of this focused approach, the local deities that the Nyelam Dé Zhi addresses, most of which are quite clearly present in Buddhist traditions and rituals as well, will not be explained from the perspective of patently Buddhist 
sources, or even, with a few exceptions, on the basis of pan-Tibetan secondary scholarly sources. There is an abundance of published and translated works on the subject of lu and their kind, some that are specific to certain sects, and others that have no particular affiliation. As the sources section below will help illustrate, this project considers perspectives on these deities as given by community members in interviews or other formats, sources they point to as definitive for the subject matter, and details from the texts of the Nyelam Dé Zhi, as well as the sources they invoke. $^{3}$

There can be no doubt that this is not the whole picture. People often have trouble identifying the precise provenance of their ideas and beliefs, and it is profusely possible and likely that other sources - oral or textual - have informed the beliefs and behavior of community members around particular subjects. Again, however, it is beyond the scope of this project, and possibly futile for any project, to trace the genealogy of ideas and beliefs as they exist within and among a particular people of a particular place and time, when those people, some exiled and some indigenous, hail from a great diversity of locations across south and east Asia, and a few from elsewhere, even when they share a common acknowledged cultural identity. The Nyelam Dé Zhi, its subjects, and its performance at Triten Norbutsé speak immediately to the concerns and dynamics of this particular community at this particular place and time.

\footnotetext{
${ }^{3}$ Note that one of the blind spots of this project is that I did not attempt to translate the gtsang ma klu 'bum that exists outside the collection of the Nyelam Dé Zhi, and which certainly provides some authoritative perspectives on these deities. I did read through much of it, however, and reference it accordingly below, though again I try to focus on the contents of the Nyelam Dé Zhi collection and informants' personal perspectives.
} 
The immediacy that this project endeavors to represent and achieve, however, does not and should not require total ignorance of historical context. Thus, the texts of the Nyelam Dé Zhi, the hagiography (rnam thar) of the treasure revealer, Pönsé Khyunggötsel (dpon gsas khyung rgod rtsal), who allegedly discovered the collection in the 12 th or 13 th century, the particular textual or oral sources - some recent, some ancient - that community members and the texts of the collection point to as the bedrocks of their knowledge and beliefs, as well as other authoritative texts beckoned by subjects at play in the Nyelam Dé Zhi, all bear scrutiny as background and context for what is happening in this community right now. This is true even and perhaps especially if the verifiable contents of that source do not or cannot speak to the knowledge that a community member claims from it, in which case the exaltation of its name alone, or its misremembered but otherwise confidently asserted contents, speaks to something important in the contemporary context that begs the same scrutiny as above.

Working with Bönpo texts can be quite a challenge, however. To quote Tenzin Tsultrim, a great scholar and my primary informant at Triten Norbutsé, "the [Bönpo] Kangyur and Tengyur are a mess." ${ }^{4}$ It is beyond the scope of this project to discuss in any detail particular issues with canonical texts unrelated to the Nyelam Dé Zhi and its supplementary sources, but it is important at least to highlight general difficulties in case any of them have contributed to errors in any of the analysis that follows. First, in terms of access, it has proven impossible to review the Kangyur and Tengyur put together by Nyima Tenzin (nyi ma bstan 'dzin), published

\footnotetext{
${ }^{4}$ Interview with Tenzin Tsultrim at Triten Norbutsé on 5/16/2010.
} 
in 1965 in New Delhi (Śatapițaka Series 37, Part II), ${ }^{5}$ as repeated attempts to procure a copy all failed. While a consultation of this publication could ultimately be a fruitless endeavor for the study of the Nyelam Dé Zhi and related subjects, it appears that a different edition of the Nyelam Dé Zhi volumes may exist therein, which would be of enormous value in ascertaining anything resembling a normative textual representation of the Nyelam Dé Zhi, and of its performance requirements, instructions, and so on. This is especially true given the current state of the Nyelam Dé Zhi volumes and supplementary texts, all of which are canonical, and many of which are often out of order, inexplicably but presumably accidentally duplicated in places, riddled with spelling or transcription errors or alternative spellings, missing chunks of text, inconsistently titled, and missing colophons, among other challenges (discussed in detail in Chapter Four). With Bönpos claiming the Nyelam Dé Zhi collection was discovered all together, and no information, or disorganized information, in the other available resources and collections, canonical or otherwise, including Buddhist sources, literary investigations of the collection necessarily become either a book-level project of their own, or, as with the present project, a matter of comparing volumes to each other and to Bönpo notions and experiences of their origins and utility.

There is also a dearth of known, detailed Bönpo histories of the caliber and clarity, for example, of Gö Lotsawa's Blue Annals. Much of our information about Khyunggötsel and related subjects comes from Khyunggötsel's hagiography, which

\footnotetext{
5 bka' 'gyur bren 'gyur gyi sde chan sgrigs chul bstan pa'i me ro spar ba'i rlung g.yab bon gyi pad mo rgyas byed nyi 'od.
} 
is one of the collected texts in Sources for a History of Bön, ${ }^{6}$ which itself has many valuable historical texts awaiting translation, publication, and/or distribution, ${ }^{7}$ and the work of Shardza Tashi Gyeltsen (shar rdza bkra shis rgyal mtshan), especially his Treasury of Good Sayings, translated and annotated by Samten Karmay (1972). In the pages that follow, this text is referred to simply as the Treasury. Other sources, such as those that help to situate Khyunggötsel in a particular time period, will be referenced directly.

Perhaps the biggest blind spot to acknowledge in terms of sources, however, is the absence of pre-exile documentation, as it would seem important to know what has developed in the process of transition or re-settlement, and what has simply been imported wholesale into a new context. Unfortunately, this will prove to be a challenging subject to address, as this community did not formerly exist in Tibet in its current configuration. The original Triten Norbutsé was a monastery established in the 14th century, destroyed in the Cultural Revolution. When Tenzin Namdak established the present Triten Norbutsé in Kathmandu in 1987, he simply attached the name of the original monastery to the new one, fostering continuity and traditionalism with the name but otherwise establishing new traditions for a new community instead of re-establishing those of the original. ${ }^{8}$

The Nyelam Dé Zhi, for example, may or may not have been performed at the original Triten Norbutsé. Nobody interviewed, and no sources consulted, could say

\footnotetext{
${ }^{6}$ Namdak 1972. Note that the table of contents lists Khyunggötsel's hagiography as an autobiography, which could be true in the sense that he dictated it to someone else, but is likely a biography.

${ }^{7}$ Especially the g.yung drung bon gyi rgyud 'bum (1-46), sgrags pa gling grags (48-71), and bstan pa'i rnam bshad dar rgyas gsal ba'i sgron ma (498-769).

8 Note that Tenzin Namdak claims that some of the traditions are the same, but he did not elaborate (Interview at Triten Norbutsé on 5/26/2009).
} 
for sure. Tenzin Namdak acknowledges that the Nyelam Dé Zhi was and is performed in many places in Tibet, both in households and monasteries, but he could or would not name any places in particular. ${ }^{9}$ Other Bönpos who are old enough to remember clearly pre-Cultural Revolution Tibet, such as Samten Karmay, also describe witnessing performances of the Nyelam Dé Zhi, though typically more in household contexts, but none of them can point to modern performances or to any specific evidence of historical performances.

All of this is to say that the part of this project that considers the issue of exile works with a very limited historical context. There are, of course, many published sources about Tibetan life and history prior to exile, and some of these can be helpful foils, for example, for the ways monastic life and the overall operation of a monastery differ in exile, and can help speak to how landscape deities are negotiated in new terrain, but such sources have little to no relevance to the Nyelam Dé Zhi itself, and thus only interviews and oral histories, as sparse as they are, can provide a backdrop of pre-exile dimensions, at least until more monastic or general Bönpo histories are unearthed.

As a result, this project cannot be one of comparison. It is not about how the ritual is different in this environment compared to former environments, but about how it is functioning now, and how it has functioned since its implementation in the late 1980's, because and in spite of its exiled context.

\footnotetext{
${ }^{9}$ Interview with Tenzin Namdak at Triten Norbutsé on 5/26/2009. When I asked him to give specific examples of other places where the Nyelam Dé Zhi is performed, he smiled and waved his hand and said I should not worry about that. "Focus on this one and do it seriously," he said.
} 


\section{Fieldwork}

I conducted fieldwork from September 2008 to August of 2009, in Dolanji, Himachal Pradesh, India, at Menri (sman ri) monastery, the surrounding village, and other nearby areas, and in Kathmandu, Nepal at Triten Norbutsé monastery, its surroundings, and other parts of the city. In order to answer lingering questions, collect additional data, and observe differences in the performance of the Nyelam Dé Zhi from year to year, I returned to Triten Norbutsé for May and June of 2010. I also drew from experiences living in Lhasa for the summer of 2006 and spending time with Tibetans in Charlottesville and elsewhere, including many Bönpos, courtesy of Tenzin Wangyal Rinpoché and his local Ligmincha Center.

At Menri, His Holiness Lungtok Tenpé Nyima, also known as Sangyé Tenzin and the abbot of the monastery, was gracious enough to permit me to stay as long as I desired. On occasion, I lodged in the monastery guesthouse at the edge of the monastery, for which I paid the typical guest rate of 175 rupees $(\$ 3.50)$ per night for room and board. More often, the monks shuffled me from room to room in the two buildings closest to the library. The building immediately next to the library was one of the nicest in Dolanji, reserved for visiting scholars and other non-tourist guests, though a poet monk from Amdo named Tri Yungdrung Marnangtsang, who had broken his arm after falling off a monastery wall, convalesced there for a month or two. The other was a multi-use building with dialectics school offices on the top floor, a few empty concrete bedrooms on the second floor - where I and the occasional non-tourist guest stayed, and also a middle-aged monk named Tenzin 
Yeshé, ${ }^{10}$ who lived there permanently - and woodworking and crafts spaces on the ground floor, where a few lay carpenters, both Tibetan and Indian, toiled day after day to produce or fix monastery furniture, ritual implements, and more. When I stayed in these buildings I still paid 75 rupees per night in order to eat three meals a day at the guesthouse. Döndrup the guesthouse master, as well as a geshé here and there, ate at the guesthouse alongside any guests. ${ }^{11}$ On occasion, I ate with the monks outside their main kitchen, and during community celebrations we all ate together, but Sangyé Tenzin's policy of every monk having a turn in the kitchen meant that some meals in the monastery kitchen were barely edible, and it was otherwise appropriate for me to be with guests rather than monks for most meals. Regardless of my accommodations I gave occasional donations, especially around larger rituals, as an expression of gratitude for their hospitality, and in support of their broader endeavors.

\footnotetext{
10 Tenzin Yeshé, who went by the nickname Shu and who had unusual skin tags on his eyelids that he said just started showing up ten years ago, was an interesting example of a very bright monk who, in marked contrast to the vast majority of other monks at Menri, had no interest in being a geshé. When I asked why, he said that so many monks only care about the geshé label, and he wants to define himself and earn individual titles from the people he helps. On more than one occasion he told me the Great Perfection was boring, and then covered his mouth and laughed. He had traveled around a great deal and was staying at Menri for three years before moving on. He was intensely interested in world affairs, listening to the radio all the time. One day, during the McCain-Palin campaign of 2008, he knocked on my door and very loudly from the hall said, "The vice presidential candidate's daughter is seventeen and pregnant!" I heard him laughing heartily as he ran back down the hall to his room and his radio. On a pocket-sized pad of paper he kept a list of difficult English words that he had heard on the radio or read somewhere, and every now and then he would come into my room and ask me to explain them in Tibetan: progenitor, nucleotide, mutiny. He was very chatty and his $A$ mdo skad was often difficult to understand, and when I once told him I was too tired to keep talking, he looked away and said, "Yes, I understand. I'm not a geshé and you have more important work to do." He was a complex and intelligent and colorful character that provided me with a lot of my basic information about Menri and its monastic conventions and daily activities, as well as providing important perspective on monk life outside the academic program.

${ }^{11}$ Over the course of a year, there were perhaps only a handful of nights with no guests at the guesthouse. It was not uncommon for all ten rooms to be booked, with tourist groups doing the Tibetan spiritual tour of India, Bön adherents, scholars, healers, lost souls and seekers of all orientations and cultures, but especially from eastern Europe.
} 
Language was a challenge, mostly because of the difficulty of bringing my particular training in Tibetan into the much more fluid environment of the monastery. I had undertaken many years of Tibetan language study, both literary and colloquial, including an intensive three-month "bootcamp" at UVa, but classes in the spoken language had been centered on the dialect of Lhasa, which is generally considered more standardized than the others, in large part because it is the official language of the Tibetan government-in-exile. Speaking with Tibetans in Lhasa and the United States often involved primarily this dialect as well. On the ground at these Bönpo monasteries in India and Nepal, however, the Lhasa dialect was anything but standard. Some monks could speak it - though almost none were actually from Ü-tsang (dbu tsang) - but the vast majority spoke the dialects of their homelands, principally the Kham dialect (khams skad) or the Amdo dialect ( $A$ mdo skad). Within these dialects, however, were a variety of regional accents and subdialects that were a further challenge to the field worker trained in the Lhasa dialect. There was in fact such a cacophony of sounds and slang at both monasteries that some monks called this unique linguistic medley "monastery speak" (dgon pa skad). I did my best to navigate this hybrid dialect and those of my individual friends and informants, having them write down words I did not understand and then entering them into a flashcard system to test myself in the evenings, but I did not develop the overall fluency I had hoped for by the time I left.

After a few weeks of observation, language fortification, and background research at Menri, I asked Sangyé Tenzin if he would approve of my working with one or more geshés to translate texts relevant to Khyunggötsel and the Nyelam Dé 
Zhi and otherwise answer questions or tell me anything else they know about the subjects of my project. He graciously offered that Geshé A Trom (dge bshes A khrom) from Khyungpo, ${ }^{12}$ one of Menri's chief astrologists, would work with me in exchange for instruction in English, of which he knew nothing. His accent proved to be very thick and difficult to understand at first, and I'm quite sure he felt the same about my stilted classroom Lhasa dialect. I sensed that he was reticent to work with me, but he dutifully showed up nearly every evening for our lessons, which started with him helping me with the most challenging abbreviations and variations of the headless ( $d b u$ med $)$ script to be found in Bönpo texts, and continued across a variety of subjects for a few months, though mostly focused on the translation of Khyunggötsel's hagiography, until his mother died and he had to begin bardo (bar do) practices.

Without specific direction from Sangyé Tenzin, I also worked with a number of others at Menri. These were Menri Pönlop Trinley Nyima Rinpoché from Dölpo, Geshé Yungdrung Mönlam from Dergé, Geshé Chökhortsang (aka Nyima Özer) from Dölpo, Geshé Tenzin Yangtön from Dölpo, ${ }^{13}$ and the Acharya Drukzé who worked in the settlement office. Some of my greatest help, however, came from a geshé that I will anonymize and refer to henceforth as Geshé $Q$, at his request.

As relevant context for this request, during my time at Menri, the monks procured a Tibetan language version of Samten Karmay's The Arrow and the

12 Geshé A Trom's monk name is actually Shenrap Lhundrup (gshen rab lhun grub) but the other monks gave him the name A Trom and this is now the name by which everyone knows him. ${ }^{13}$ Unlike the other geshés, who all wanted to learn or practice English in exchange for help, my currency with Tenzin Yangtön was my laptop and knowledge of using video editing software, which we used to edit down a dozen hours of footage from his recent trip to Dölpo into an hour long movie that he could show to colleagues, friends, and students to raise awareness about Dölpo and its infrastructure needs. 
Spindle. The backlash against Karmay, an ex-Bönpo geshé who was now viewing his tradition through the hermeneutically suspicious prism of western scholarship, was enormous and instantaneous. Karmay came to Menri at the invitation of Sangyé Tenzin, to answer monks' questions and to try to explain himself and his work. It was an extremely intense encounter that I partially captured on film. Afterwards, a number of monks who were previously helping me became suspicious of my intentions, not only refusing to help with my work, but refusing to speak to me or otherwise have anything to do with me. Geshé $\mathrm{Q}$ was chief among them, and was clearly the most devastated by what he considered to be a profound betrayal by Karmay and, by extension, all scholars of the western traditions. Thus, after many months working together - with him helping me translate and learn about Khyunggötsel and Nyelam Dé Zhi, and me helping him translate his teachings into English so that he could teach westerners more effectively - he avoided me, even at the level of eye contact, for the rest of my stay. There is no question that my fieldwork at Menri suffered as a result of his and other monks' changes of heart. 


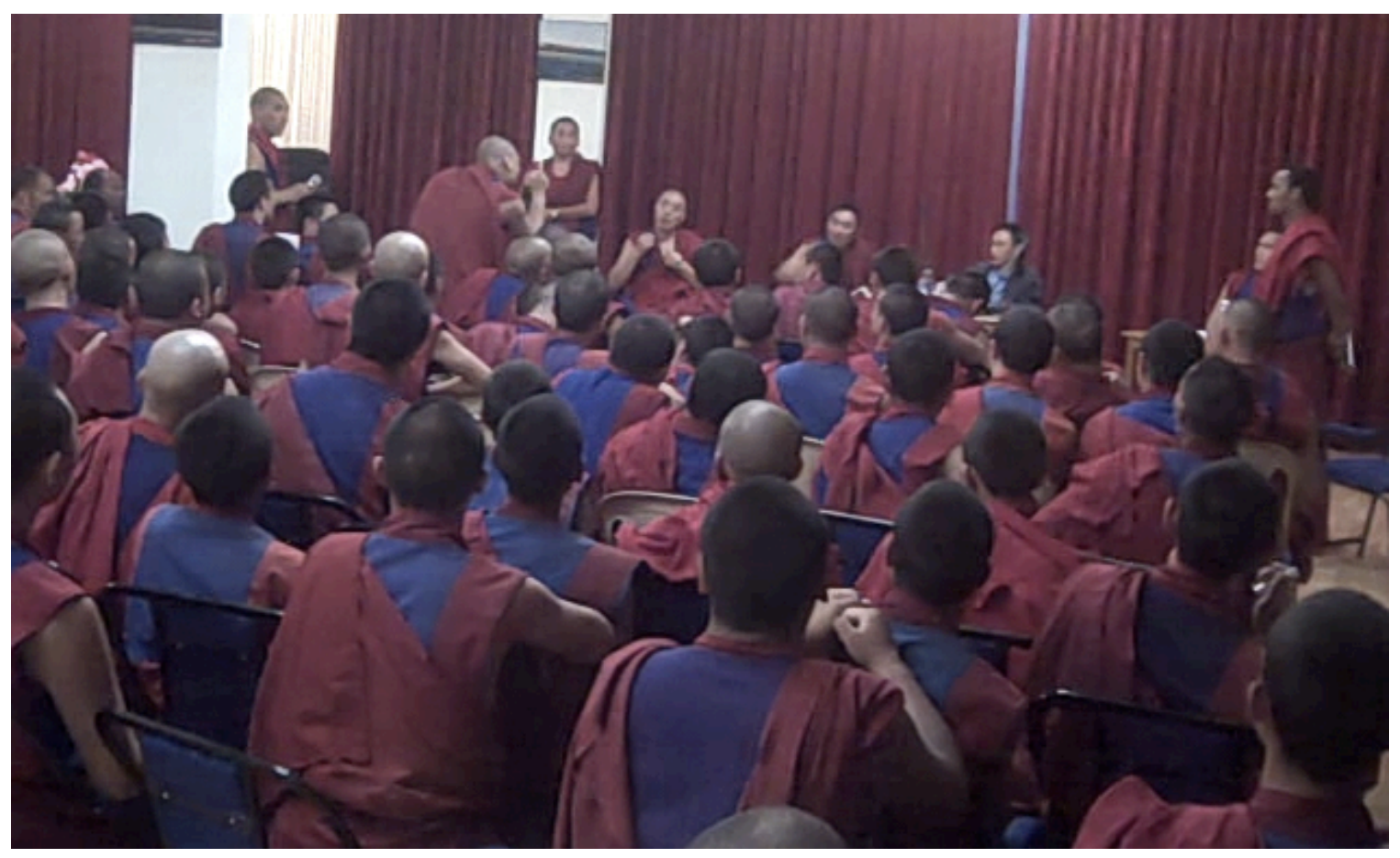

Figure 1: Menri monks confronting Samten Karmay about his book The Arrow and the Spindle.

At Triten Norbutsé, I worked with Tenzin Tsultrim, the abbot of the school of practice, far more than I did with anyone else, though Tenzin Namdak helped as his health permitted, providing invaluable information about the establishment of Triten Norbutsé and of the Nyelam Dé Zhi as an institutional tradition there, and about a variety of other subjects. Had he been well enough to see me more often, I certainly would have worked with him more closely.

At both monasteries and in surrounding areas, I conducted many dozens of formal interviews, with the informants above, other monks and laypeople in the communities, visiting Bönpos and scholars and guests from around the world, and others. I used a digital video camera to film the interviews whenever possible, and always used a portable audio recorder or my computer microphone to capture the audio. I also took profuse notes. When a formal interview was impossible or 
inappropriate, I did my best to take notes during or immediately after conversations, using a pad of paper I always kept in my pocket or a mobile version of the Evernote application on my iPhone.

Given the paramount importance of capturing all aspects of the Nyelam Dé Zhi ritual at Triten Norbutsé, I asked the disciplinarian (dge skos), Geshé Monlam Wangyel, for the assistance of a monk who could help me film, ask questions, and inform me of upcoming events, changes, and so on that I might otherwise not know about. This would ensure that we were recording as much of the event as possible, but I also knew that he would have better access and be less of a distraction than I would. This turned out to be true to extents I did not imagine possible, with monks talking naturally on camera about controversial subjects and talking about me as if I would never see the footage. Tsultrim Gyatso, my assistant, even told some monks, erroneously, that I thought the thread crosses (nam mkha) they had made for the Nyelam Dé Zhi did not look good. ${ }^{14}$ The candor of his recordings were thus helpful in unexpected ways, showing not only how they might act differently without me there, but what they thought of me, how they interpreted the work I was doing, and so on.

In all cases, I did my best to make sure that all in the community, especially my friends and informants, got a regular break from me and my questions and recording devices. Even when the momentum was in my favor and things were going well, I forced myself to step away from the monastery grounds at least once a week to translate on my own, walk down to the nunnery across the valley from

\footnotetext{
${ }^{14}$ As will be discussed later, it was actually Tenzin Tsultrim who said this.
} 
Menri, take the bus from Triten Norbutsé to Boudha for momos, or otherwise go out to experience the sights and tastes of the surrounding areas.

Given that this project relies on modern ethnographic data as much or more than on textual data, I have depended on and have cited interviews and conversation as primary. There is no doubt that reliability is always a question, even with the most knowledgeable and well-intentioned members in the community, because of the kinds of contextual influences described above and others interviewee distractedness, fatigue, and so on - and also because of my own reliability issues - perception, memory, recording devices, and so forth. To an extent, I combatted these issues by asking multiple people the same question, and even the same people the same question at different times, but ultimately I came to the conclusion that inconsistency and unreliability, when corrected as much as possible for the observer effect, were themselves critical to understanding how the community operates, what its priorities are and how individual priorities relate to those of the larger community, how the community orients to ritual generally, and to the Nyelam Dé Zhi in particular. Much more will be said about this below, but suffice to say here that I make use of interview citations and casual references to what these monks and other community members think or say not only with full knowledge of the limitations of conversations as sources but fully embracing those limitations as critical to a proper understanding of what is happening on the ground at any given moment.

There are some cases, however, where I cite interview data as evidence for something that would be better supported by a textual citation. The availability and 
accessibility of Bönpo texts is improving, due in large part to the digitization efforts currently underway at Menri, but there are still many basic questions that can only be answered in dialogue with Bönpo scholars, both Tibetan and non-Tibetan. There is a great diversity of emic and etic sensibilities among these scholars, and until answers have been given the appropriate larger-scale scrutiny they cannot be considered definitive, but they are all we have to go on in the meantime and thus will be treated cautiously, and with caveat, as authoritative.

\section{Tibetology and Ritual Studies}

While there are far too many influences in this study to name, the analysis that follows draws upon or takes as its point of departure a few key works in the fields of Tibetology and ritual theory. In terms of the former, foremost among all secondary publications on the subject of Bön is the immense wealth of material authored, edited, and/or translated by Samten Karmay. Karmay, an ex-Bönpo geshé and the most prolific ethnically Tibetan scholar of our time to participate explicitly in nonTibetan intellectual scholarship, shows a predictable shift over the course of his career from being principally concerned with cataloguing and translation to unpacking the former with exposition and analysis. Some caution is required when using especially the earlier works, as Karmay's unique perspective often placed him in limbo between different cultural perspectives - for example, claiming a date for the Buddhic Tönpa Shenrap that is too late for orthodox Bönpos to accept and perhaps too early for international scholars. In all cases, however, the data from catalogues and translations, the insights from his various analyses, and the breadth of his cultural experiences and observations of Bön and Tibet, are crucial to this 
study and arguably to any study of Bön. In almost all cases below, they are cited as authoritative, with an occasional note of caution or divergence as appropriate.

Though not cited heavily, Georges Dreyfus's seminal The Sound of Two Hands Clapping (2003) provides the implicit baseline foundation of Tibetan monasticism from which all of this study's observations and analyses of monks and monasteries spring. While it is difficult to establish anything resembling a normative Tibetan monasticism across Buddhism and Bön, inside and outside of Tibet, Dreyfus's work, combined with other observations of monasteries and monks in the field, as well as other secondary sources on specifically Bönpo monasticism, ${ }^{15}$ provided enough context and contrast to suggest that what was happening at and between Triten Norbutsé and Menri monasteries was unique and compelling.

There is much secondary Tibetological scholarship that engages at some level in the evaluation of Tibetan ritual, but not many studies that have undertaken a comprehensive and systematic analysis of a particular ritual, and even fewer that have done so with a substantive ethnographic orientation. Stephan Beyer's The Cult of Tara (1978) and Richard Kohn's The Lord of the Dance (2001) stand as perhaps the two most significant secondary scholarly assessments of Tibetan ritual, ${ }^{16}$ with the former describing a host of rituals centered around the deity Tara, and the latter focusing on the Mani Rimdu festival. Both are towering achievements, with spectacular detail, exposition, and synthesis across Buddhist doctrinal and cultural modes of thinking and acting, and both derive a great deal of authority and impact

\footnotetext{
${ }^{15}$ See for example Cech (1987), Dagkar (1994), Karmay and Nagano (2003), Skorupski (1981), and Yamaguchi (2005), among others.

16 There are many other valuable studies, such as those done by Bentor $(1996,2000)$, which cannot and should not be discounted. Beyer and Kohn were simply the most relevant.
} 
from their origins in field observation and research. Despite or because of this latter dimension, however, the dominant scholarly agendas of both works appear to be translation, emic exposition and synthesis, and amplification. Unlike Beyer, Kohn does engage in cultural analysis in the last few pages of his book, and includes ethnographic discussion throughout, but it is clear this was not the goal of either work. With the solid foundations of Tibetan ritual phenomena and agency that they and others ${ }^{17}$ have now laid, the present study can afford to focus less on what the texts say, but on how they say it; less on what ritual actors say and do, but on how we might make cultural sense of what they are saying and doing; and in all cases how it all fits into a context of Bönpo monasticism in exile.

There is, of course, a spectacular abundance of scholarship in the loosely defined discipline of ritual studies. While a great many of these works would be relevant in one way or another to this study, ${ }^{18}$ there are a few theorists and works that speak most specifically to the dynamics on the ground at and around Triten Norbutsé's performance of the Nyelam Dé Zhi. To illuminate ritual motivation and action at a fundamental level, it has proven useful to draw on the work of Caroline Humphrey and James Laidlaw as represented by The Archetypal Actions of Ritual (1994). Therein the authors present a theory of ritual drawn from research into a

\footnotetext{
17 See Bentor (1996, 2000), Blondeau $(1990,1998,2005$, and the many others listed), Cabezon (2009), Cantwell (2005), Denwood (1983), Gardner (2006), Garrett et al. (2013), Ishii (2005), Ramble (2005), and a great many others.

18 There is no doubt that aspects of the work of Mircea Eliade and Clifford Geertz, to take two of many possible examples, would have some relevance to ritual discussions herein. The choice to exclude them was not made lightly, but it was made nonetheless, with the intention of making use of a couple of more modern theories that were more immediately relevant in more dimensions than the others. Again, this is by no means to discount Eliade or Geertz or anyone else, and in fact it could certainly be argued that Humphrey and Laidlaw and Tweed (discussed below) are building off a tradition that was itself built by these former scholars of ritual and religion.
} 
Jain puja, the touchstone of which is the idea that the primary mechanism of ritual action is the actor's adoption of a "ritual commitment," which requires only that the agent "get things right" in order to create a space for meaning and interpretation that is otherwise highly plastic and flexible. This commitment is an attitude characterized by the irrelevance of the agent's intentions or thoughts, with all focus directed towards performing stipulated ritual acts that are elemental/archetypal and apprehensible. There was a time when such rites had a clear and dominant meaning, but they were "practices" at that time. Ritualization is the process of objectifying such practices and ascribing different and new meanings to them (pp. 151-155). In fact, custom or practice does not become ritual until people disagree about the meaning (p. 12). One of the concluding assertions of this study is that the evolution of the Nyelam Dé Zhi and its performance at Triten Norbutsé can be explained, in part, in precisely these terms.

Jonathan Z. Smith's works, especially Map is not Territory (1993) and To Take Place (1992), have educated the aspects of this analysis that deal with issues of inhabiting new spaces and relating the peripheral to the central (borrowing here also from Victor Turner's seminal "Betwixt and Between" [1986]), uprooting traditions from endemic environments and installing them in foreign ones, and so on. There are, however, some points of departure from his theories that have limited their overall applicability to this study. Primary among these is his occasional emphasis on fidelity to text or tradition in ritual performance. While there can be no doubt that some degree of fidelity is diagnostic of ritual as a category of behavior, observations of the performance of the Nyelam Dé Zhi, like many such rituals, will 
reveal that rigorous adherence to detailed prescriptions for thought and action is by no means necessary for success, at least not in the ways that success is being redefined for an evolving modern community.

Perhaps the most influential theoretical work for this study, however, is that of Crossings and Dwellings: A Theory of Religion, by Thomas Tweed (2006). His theories will be unpacked in greater detail in Chapter Six, where they can provide more immediate context for the interpretations of the Nyelam Dé Zhi performance that follow, but it bears summarizing here the particulars of their applicability. As will be shown, many of the dynamics operative in the performance of the Nyelam Dé Zhi can be understood best in the context of a community that has been persistently engaged in a process of orientation to new landscapes, new cultures, and new political situations. Tweed's work explicitly frames religion as a force for orientation, situating one in relationship to one's body, home, homeland, and the cosmos. While he describes religion in general terms, relegating ritual to one of many devices in the employ of the religious to advance the process of orientation, the present study promotes ritual and its actors to the primary orienting agents, thereby co-opting the strength of his theories for slightly different ends. Tweed also couches his theories in more modern and, sometimes, exiled, communities, such that his perspectives cannot help but be more applicable to Triten Norbutsé than older and often more textual perspectives on traditions that have in many cases been more deeply situated in their environments over longer periods of time.

In terms of the pressures of and adaptations to modernity from the Tibetological side, this study travels to the threshold of, and otherwise points to, the 
observations and analysis presented by David McMahan in The Making of Buddhist Modernism (2008) and in the many works by Donald Lopez, Jr. $(1994,1998,2002)$. While it was beyond the scope of this project to describe in any detail the kinds of larger-scale dialogue and adaptations developing between Tibet and Tibetan Buddhism and the rest of the modern and western world - which McMahan and Lopez address with great success - the modern pressures that inform and compel attitudes toward and instances of performance, interpretation of the same, and broader community decisions and priorities at Triten Norbutsé are of much the same ilk. As will be shown, relatively wealthy visitors to the monastery from elsewhere in the world are generally seeking a particular version of Bön that emphasizes practices and experiences that are anything but common among the vast majority of Bönpos over time, while scholar monks strive for sophistication and prestige that elevate them above polemical rhetoric and misunderstandings that are many hundreds of centuries old, but all the more relevant and immediate on the broadening world stage. Thus, a speculative seventh chapter in the present study would do well to go into much greater detail about how these pressures are arriving at the foot of Triten Norbutsé's hill in Kathmandu and where they came from, but for now the analysis will content itself to leave the more sweeping versions of those perspectives to the likes of Lopez and McMahan.

For the more theoretical, less Tibetological perspectives on modernity and globalization, especially those that involve diasporic or exiled communities, this study draws to a great extent on Tweed's work described above, and to a limited extent on the work of Manuel Vasquez, whose Globalizing the Sacred: Religion Across 
the Americas (2003) provides a number of relevant perspectives. While Vasquez is admittedly focusing on different cultural contexts, he addresses in a more general way the growing enmeshment of the local and the global given the availability of information and the intermingling of previously far-flung cultures, as well as the deterritorialization and reterritorialization of discourses and practices in diasporic communities now inhabiting more modern environments, which engenders and compels new interpretations of old forms. This discussion points further to the inevitable complexity and contradiction resulting from these dialectics of homogenization and heterogenization, which help to explain inconsistencies in the field, and to illuminate processes of cultural formation and reformation in modern contexts generally.

\section{Chapter Summaries}

Aside from the introduction and conclusion, there are six primary sections that examine different aspects of the Nyelam Dé Zhi ritual and its background: 1) Brief portraits of Triten Norbutsé and Menri monasteries; 2) The performance of the ritual at Triten Norbutsé; 3) The deities that the ritual principally addresses; 4) The texts that provide the foundation and organizing structure for the performance; 5) Divergences between text and performance; and 6) Interpretations of how the Nyelam Dé Zhi functions in the community as a whole.

Chapter One seeks to provide a thumbnail sketch of the two modern Bönpo monasteries in exile - Menri monastery in the village of Dolanji in northern India, and Triten Norbutsé in Kathmandu, Nepal. This is not meant to be an exhaustive 
representation of either - there are a number of such studies already published (referenced below) - but rather an overview of how these institutions and their communities converge and diverge in exile in ways that help to explain the salience of the Nyelam Dé Zhi ritual performance beyond the achievement of its ostensive goals.

Chapter Two is a thick description of the performances of the Nyelam Dé Zhi as observed at Triten Norbutsé in 2009 and 2010. It starts with the various preparations that must be done in advance of the recitation and then describes, step by step, the four days that comprise the main liturgy. Much of the activity across the four days is redundant, so it is not a complete accounting of events, and nor were the preparations and recitation different enough from year to year to treat them separately, and thus the narrative reads like an accounting of a single event. At various places, monks provide perspectives and explanations about what they are doing and why. It becomes clear over the course of the observation and interviews that there is not much rigor or fidelity or enthusiasm in the performance of the ritual, and thus the chapter ends by asking the question that is the key driver of this investigation: Why do this ritual when it does not appear, at first glance, to be relevant or interesting or useful to this community?

Chapter Three goes into detail about many of the various deities that are addressed by or otherwise have agency in the Nyelam Dé Zhi ritual. The diverse beings that "attend" rituals in their various capacities are known consistently as one or more of "the four guests" (mgron bzhi), and thus this scheme is examined in detail and applied to the Nyelam Dé Zhi. Doing so, and also attempting a taxonomy and a 
highlighting of worldly deities, which are the primary addressees of the ritual, reveals a slipperiness of identity that is in fact characteristic of many of the agents involved in the Nyelam Dé Zhi. In addition to exploring one of what will be many zones of inconsistency in the composition of the Nyelam Dé Zhi, I suggest briefly that one of ritual's functions is to help create coherence in the field out of these shifting identities that are based on interpenetrating layers of culture, geography, history, and idiosyncrasy.

Chapter Four is an evaluation of the various volumes comprising the Nyelam Dé Zhi collection, as well as the supplementary texts that inform the ritual performance. Not much is known about the history of the collection or individual volumes, but background is provided in the form of a portrait of the purported revealer of the collection, Pönsé Khyunggötsel (dpon gsas khyung rgod rtsal). In addition to placing the volumes within generic designations, one of the main goals of this chapter is to show the profound inconsistency in style and content and function across the collection, which can only point to multiple authorship over large time periods - despite Bönpo claims to the contrary and the lack of corroborating information elsewhere in literature - as well as the utility and probable origins of the collection as a series of independent or loosely grouped, thematically similar remedial manuals for addressing immediate community problems like sickness or drought. This inconsistency also explains, in part, inconsistency or lack of concern regarding preparations and performance. At the end of the chapter I highlight three of the most important texts to the performance, especially the Manuscript (volume 1 of the collection), a recently added instructional and liturgical organizational 
manual that makes the institutional performance of the ritual possible, while connecting the specifics of the liturgy to the traditions of the Dru ('bru) clan.

Chapter Five looks at the various ways that the performance of the Nyelam Dé Zhi diverges from the textual instructions. It does this by first examining how monks relate to the collection of texts and ritual as a whole and examining the problem (and opportunity) of preparations and performance based on generally incomprehensible texts. It follows this up with an examination of divergences from text from both an aesthetic perspective - doing things differently - and a signification perspective - understanding things differently. This particular part of the analysis includes issues of performance - like chant melodies - that are difficult to describe in texts and thus point to a host of assumed skills and knowledge that the text authors, especially the author of the Manuscript, expected performers to have. All of this leads naturally into a discussion of the ways these divergences, and others, clear the way for substantive imputation of other communal and personal meanings and values into the voids or gray spaces left in their wake.

Chapter Six then attempts to fill those voids with the various ways that the community and individuals at Triten Norbutsé have re-appropriated the Nyelam Dé Zhi performance to other ends. To do this, it starts by both using and critiquing Jonathan Z. Smith's work to recapitulate and expand on the various ways and reasons this ritual and its performers are not concerned with ritual fidelity in the way that many rituals and performers apparently are. It also reintroduces the importance of exile, and to a lesser extent globalization, to a proper understanding of the ways the Nyelam Dé Zhi has been re-appropriated. To provide an 
organizational framework for this critical part of the analysis, and to leverage the insight and cachet of a recent theory of religion, it makes use of Thomas A. Tweed's notion of "crossings and dwellings" (2006), and his four chronotopes of body, home, homeland, cosmos. Taking the controversial liberty of substituting "ritual" for "religion" in his theories shows the variety of domains in which the Nyelam Dé Zhi operates for individuals and a community, and reveals the important ways that they are all essentially forces of orientation, which makes an otherwise seemingly irrelevant ritual persistently useful, especially in an exiled context. The chapter closes with a brief exploration of the ways in which globalization and the world stage, as opposed to the narrower issue of exile, play into dynamics around the Nyelam Dé Zhi and among community members more broadly.

Finally, in the conclusion, I pull back the scope to see both how the Nyelam Dé Zhi fits into a broader theory of ritual - the one espoused by Caroline Humphrey and James Laidlaw (1994) - and to revisit the primary issue of the creative power afforded by inconsistency, and the ways it relates to the Triten Norbutsé community and to all of us. 


\section{Chapter One: Bönpo Monasteries in Exile}

Menri monastery in Dolanji, Himachal Pradesh, India, and Triten Norbutsé in

Kathmandu, Nepal, are the principle caretakers of the Bön tradition in exile.

Together they serve also as the monastic seat of Bönpo scholarship, engaged in a variety of research projects, the publication of journals and texts, the digitization of canonical texts, the housing of any known texts from and about the Bön tradition, and, most conspicuously, the education of monks. At the core of both institutions are academic schools (bshad grwa) where Bönpo monks are trained to become geshés and teachers and leaders. Observations of the daily activities of the monastery and conversations with the monks themselves leave little doubt that this education is the primary focus and mission of these monasteries, and that the coveted title of geshé confers considerable prestige upon its bearer. Despite these similarities and the others to be described below, however, there are a number of key differences as well, as must be expected for monasteries of different sizes, in different countries, under different leadership. These domains of overlap and divergence prove to be critical context for an understanding of ritual function and performance dynamics in the context of the Nyelam Dé Zhi, and thus a few of the most salient among them bear scrutiny prior to examining the ritual itself. ${ }^{19}$

\footnotetext{
${ }^{19}$ Note that what follows is hardly a complete portrait of these vibrant institutions. It includes only the details perceived as relevant to this particular analysis of the Nyelam Dé Zhi. For more detail about internal monastic operations at Menri, see in particular Cech, 1987 and Karmay and Nagano, 2003, pp. 736-38; at Triten Norbutsé, see in particular Yamaguchi, 2005, and Karmay and Nagano, 2003, pp. 731-35.
} 
The communities at both Menri and Triten Norbutsé include monks from all over the Tibetan cultural region, ${ }^{20}$ with a few members from elsewhere, many of whom will visit one monastery from the other, sometimes briefly for an event, sometimes for years to pursue a particular course of study, contribute particular skills in need at the other monastery, or for practical reasons such as being closer to family or sources of financing. ${ }^{21}$ Both monasteries also have very small lay communities supporting them compared to what they might have enjoyed in preexile Tibet - though Menri may never have had a large local lay community. ${ }^{22}$ This is also one of many ways that the two communities diverge, however. Menri has a much larger built-in lay community in its settlement village, ${ }^{23}$ and as a result lay engagement is more frequent and prolonged. Triten Norbutsé only has a handful of lay individuals in its immediate vicinity, but its location, in Kathmandu, a thriving international hub that is also very close to ethnically Tibetan regions of Nepal, some of which are heavily populated by Bönpos, means that laypeople and monks from other monasteries are often visiting or passing through.

\footnotetext{
${ }^{20}$ Exact numbers of resident monks are difficult to ascertain because the population is often in flux. No one, including the institutional administrators could give confident numbers, though the the ballparks were 200 for Menri and 100 for Triten Norbutsé.

${ }^{21}$ Indian and Nepalese monks, or any others that have passports have the option of flying between Delhi and Kathmandu if they are in a financial position to do so, while monks with a Tibetan refugee status and without the proper papers will take the bus, a sometimes long and arduous journey that, while generally successful, has occasionally resulted in being denied entry at the border, turning around to make the journey back.

22 This is from Cech, 1987, of which more will said below.

${ }^{23}$ The population fluctuates from 50-400 according to Cech, 1987, p. 168, though Sangyé Tenzin told me in an interview at Menri monastery on 4/16/2009 that there were currently somewhere between 50-75.
} 


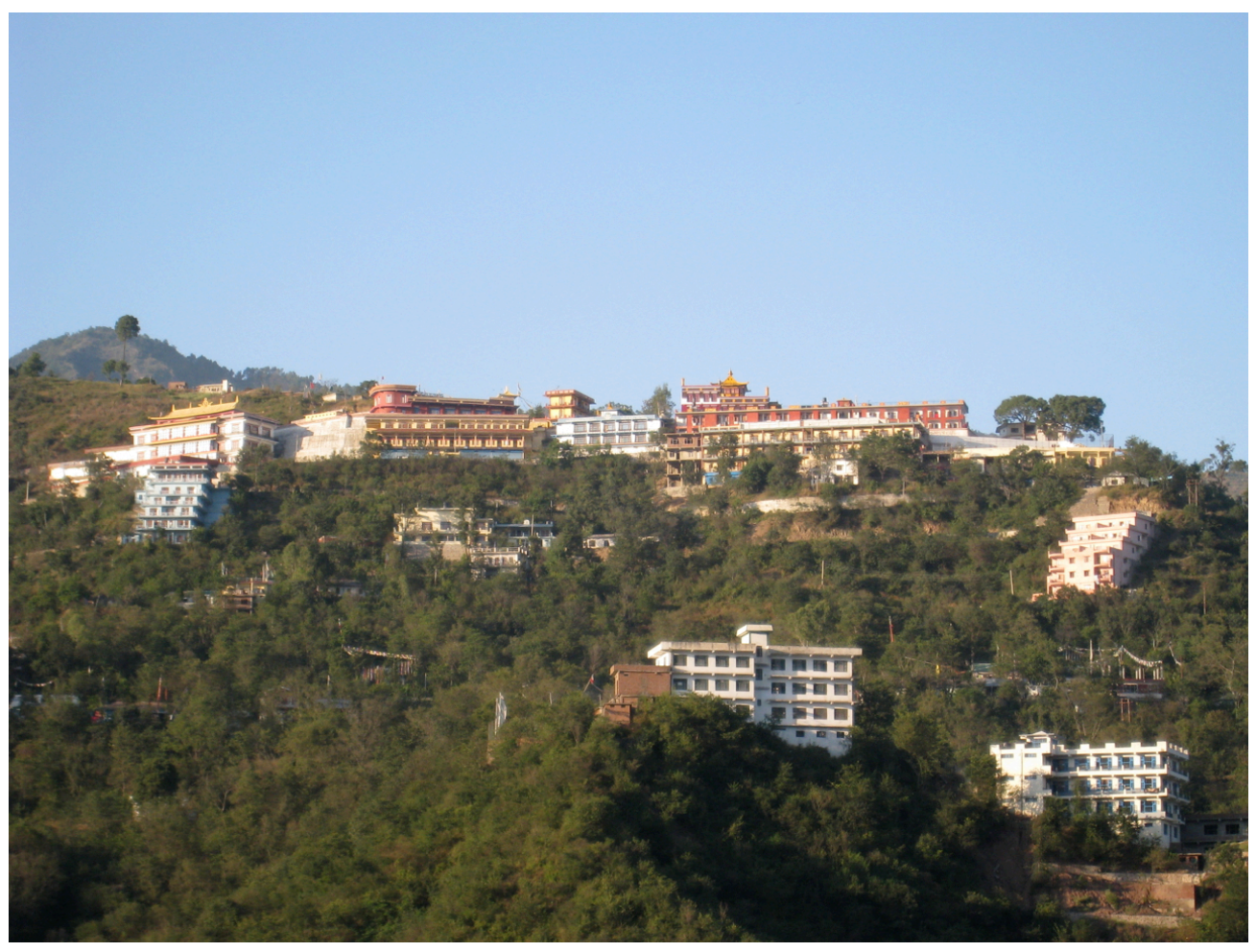

Figure 1.1: Menri monastery

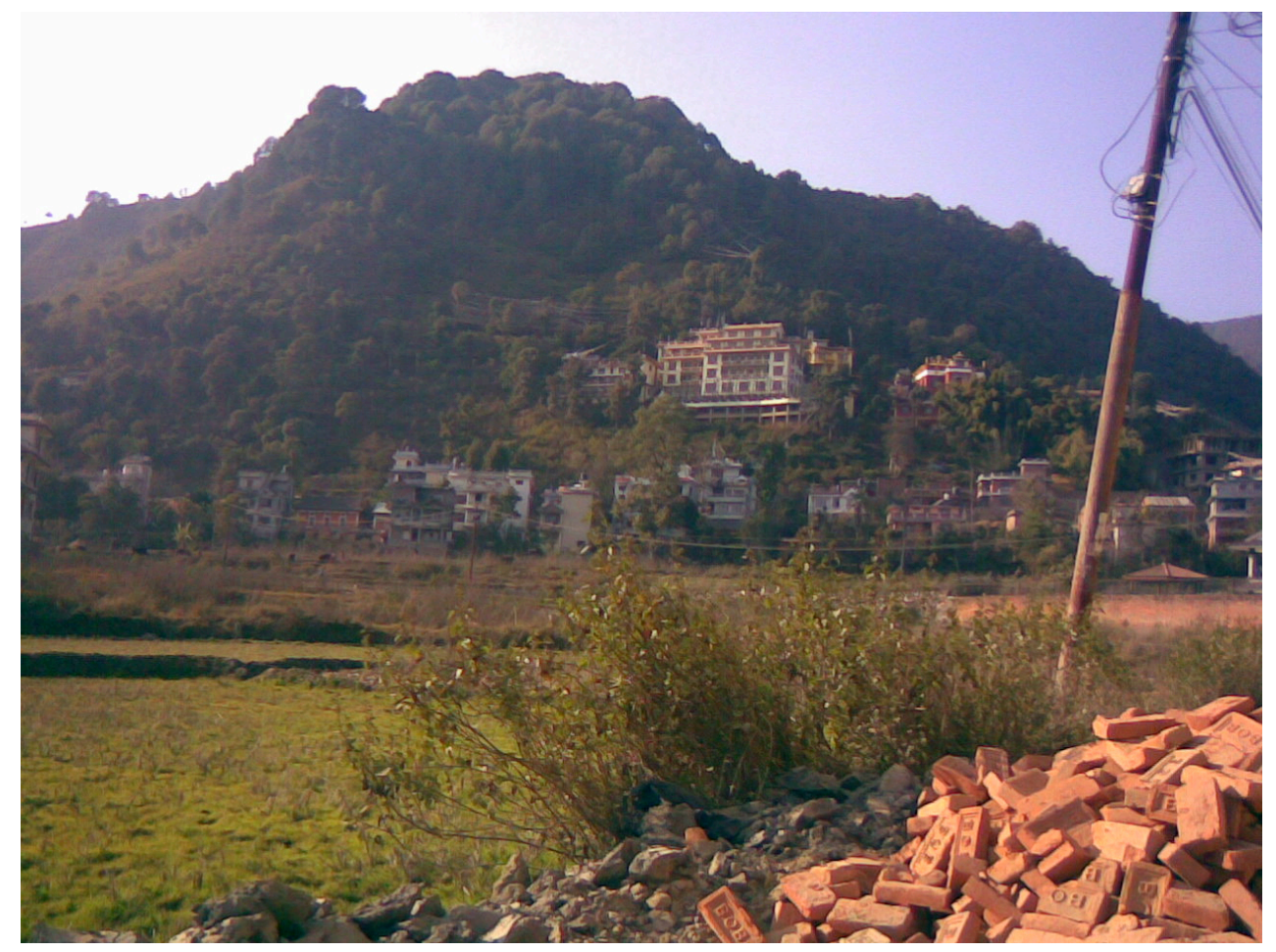

Figure 1.2: Triten Norbutsé monastery 
The political situation - in terms of relations between local government and exiled Tibetan populations - is also less delicate in Kathmandu. The Menri community, both lay and monastic, is constantly under the Indian government's magnifying glass, doing their best to follow the rules of the refugee arrangement, to be on their best behavior, and so on. Though the political situation in Nepal was quite unstable in the times that I was there, their orientation towards the Bönpos was much less strict and less formal. Combined with the monastery's proximity to metropolitan amenities, this laxity entails that monks and other community members are much freer to come and go and otherwise carry on in their lives as they normally would.

\section{Leadership at Menri}

The difference in rigidity between the two environments of the monasteries is reflected in, and perhaps influenced or reinforced by, the difference in leadership styles and personalities at each. Lungtok Tenpé Nyima Rinpoché is the abbot of Menri and is now in his early eighties. Though his health is deteriorating a bit, ${ }^{24}$ he is still very much involved with and in charge of the day-to-day operation of the monastery. When he is not traveling, teaching, or looking after monastery affairs from his office, assisted from the next room by his personal secretary, an exceedingly polite and affable monk from France named Dominique (monastic name

\footnotetext{
${ }^{24}$ For most of my stay at Menri he was sharp and mobile, but about a third of the way into my time there he had an episode that he later said was brought on by "sugar sickness" (ci ni na tsha), presumably a local term for diabetes ( $c i n i$ is a transliteration of the Hindi word for sugar). During this episode, which lasted a couple of days, he seemed confused, had trouble remembering who I was and why I was there, and so on.
} 
Yungdrung Tenzin [g.yung drung bstan 'dzin]), he is strolling around monastery grounds, checking on the progress of various construction or craft projects, listening in on debates, ${ }^{25}$ making sure monks with specific jobs are at their stations and engaged with their work, scolding younger monks for climbing on walls or otherwise horsing around - "They are like goats!" - taking a moment to lean on his cane in the shade and smile at a fresh litter of stray puppies rolling around in the sun by the monastery kitchen, answering questions for and entertaining visiting Indian officials, fielding drama from the lay settlement, school, or nunnery, and a multitude of other quotidian management tasks to ensure everything is running smoothly.

Word of Sangyé Tenzin's impending arrival spreads at the speed of sound, startling monks into tight-lipped action. On more than a half-dozen occasions, my casual conversation with a monk would screech to a halt when his eyes narrowed towards the horizon and the words, "Is that Rinpoché? It is!" fell from his mouth. He would then leave in a mad dash. Indeed, many monks and western students or followers of Bön describe Sangyé Tenzin's personality and teaching style as "wrathful" or "rigid" or "strict." Many western visitors to the monastery arrive expecting to meet a man with the almost child-like glee of the Dalai Lama - and Sangyé Tenzin does have those moments - but his style, in emic terms, is much more one of "radical compassion." He will not hesitate to raise his voice and use strong language if he thinks it is the best or only way to help. In etic terms, he is a no-nonsense, take-charge personality with no time for tomfoolery, and under

${ }^{25}$ For many years, Sangyé Tenzin would join in on the occasional debate, but he has long since declared himself too old for this now. 
significant pressure from the Indian government, the Tibetan government, and the larger world, to show that Bönpos are or can be serious and worldly scholars, respectful of all cultures and schools of thought, disciplined in all their pursuits and behaviors. He is very clear about his role, beyond teacher and administrator and spiritual leader, as the principle caretaker of the Bön tradition, and about Menri as the principle residence and showcase of the same, embodying also a tradition of rigorous discipline that stretches back some 600 years. ${ }^{26}$

In addition to being a driving force in the expansively inclusive approach to the canonization of Bön, Sangyé Tenzin has helped to design the geshé program so that every monk in the academic program undertakes segments dealing in ritual, practice, craftsmanship and other ostensibly less scholastic content so that they are each inculcated, to the degree possible, with the entire breadth of Bön. Every monk must also rotate in and out of positions around the monastery in order to have experience cooking, ${ }^{27}$ cleaning, looking after records, and so on. ${ }^{28} \mathrm{He}$ is eager to show appreciative visitors his residence (bla brang), which is furnished with meticulously crafted statues, paintings, implements, and more, most of which, especially in the small shrine therein, represent or are thematically aggregated around Purba (phur ba), the principle tutelary deity (yi dam) of Sangyé Tenzin's lineage.

\footnotetext{
${ }^{26}$ Old and new Menri alike placed a heavy emphasis on discipline - Karmay, 2005, pp. 160-162, but also confirmed in fieldwork and interviews.

${ }^{27}$ Monks often expressed dissatisfaction with this arrangement, given that if the monk whose turn it is to cook does not make the rice well, leaving it too raw, the whole meal is ruined and everyone must go hungry or find other food to eat. But perhaps this is just part of the education.

${ }^{28}$ Note that there are a number of exceptions to this - jobs that you have to earn the privilege to do, including the chant master ( $d b u$ mdzad), disciplinarian (dge skos), and so on.
} 
When he talks about the importance and primacy of Bön among Tibetan traditions, however, he most often points to ritual. Every substantial ritual of the annual calendar commands elaborate craftwork, which may be actualized by lay Tibetan and Indian carpenters, ${ }^{29}$ but more often by the monks themselves, most of whom have learned how to do the work via a ritual crafts segment of the academic curriculum.

During my stay in 2008-2009, Sangyé Tenzin decided to do a massive Medicine Consummation (sman sgrub) ritual around his birthday, a ritual of a scale that will only happen once or twice in an abbot's lifetime. He commanded another one many years ago - the "mind" version, while the recent one is the "activity" version - but will not have the opportunity to command another. For parts of the ceremonies, geshés wore rare, pristine sky blue robes and large white hats with blue stripes, and wielded finely crafted implements. All activity orbited around a massive mound of powdered medicine that, allegedly for the first time in history, had been concocted from materials that Sanskrit, Tibetan, and Zhang Zhung sources variously identified as the most powerful substances in the world. The total cost of collecting and processing these ingredients in such volume was 200,000 rupees, or roughly $\$ 4,083$. On this and other occasions - including a walk around the massive, highly impressive dö (mdos) of the summer Sky Expanse ( $\left.m k h a^{\prime} k l o n g\right)$ ritual - Sangyé Tenzin said to me variations of, "This is the legacy of Bön. This is what Bön has brought to the world."

\footnotetext{
${ }^{29}$ These employees of the monastery are usually most involved with the construction of structural elements - wood or steel frames that monks then adorn with the more delicately crafted implements. Highly complicated or time-consuming craft projects are delegated to specialty shops in Kathmandu.
} 
Meanwhile, Sangyé Tenzin has worked hard to elevate the level of scholastic rigor at Menri, to better match what is expected of Buddhist geshés. There are certainly monks at Menri who are not in the academic program, but the vast majority are, or want to be. The abbot and others explain that there is a practical school (sgom grwa) ${ }^{30}$ at Menri, but it is mostly just for laypeople or others who want to do some focused practice. "Most important," he says, "is dialectics (mtshan nyid). You have to learn dialectics first, through debate - it must be through debate, it's the only way to really learn it - and then you can do practice."31

\section{Leadership at Triten Norbutsé}

This emphasis on dialectics and scholasticism is evident also at Triten Norbutsé, and is one of the most compelling similarities to suggest common dimensions across Bönpo monastic communities in exile, but otherwise there is a different culture at Triten Norbutsé, for reasons given above, but also because of the configuration and personalities of ranking resident lamas. Lopön Tenzin Namdak, also known to followers as Yongdzin Rinpoché, is the founder of and ranking lama at Triten Norbutsé. He is nearly equal in stature to Sangyé Tenzin among Bönpos, and perhaps even greater in stature in scholarly circles given his prolific publication history and scholastic engagement. Like Sangyé Tenzin, he is the principle teacher of his community, 32 and they do share common values that emphasize scholarship and tradition, but otherwise his personality and role at the monastery are quite

\footnotetext{
${ }^{30}$ Monks often used sgom grwa and sgrub grwa interchangeably.

${ }^{31}$ Interview with Sangyé Tenzin at Menri monastery on 5/21/2009.

32 This is not to be confused with the official position and title of head teacher, given to the highly learned Pönlop Trinley Nyima Rinpoché.
} 
different. He is a couple of years older than Sangyé Tenzin, into his eighties, and is in worse health. He is often confined to his residence to recover from an illness, and when he walks through the monastery grounds he generally has to be assisted by one or two younger monks. ${ }^{33}$

Even when outside and visible, Tenzin Namdak's role vis-à-vis the monks is very different from Sangyé Tenzin at Menri. He is their teacher and not their administrator, and this dynamic means that, combined with his arresting blue eyes, infectious boyish smile, and great sense of humor, the monks that he encounters around grounds are always at ease around him, smiling and laughing at his jokes or at the playful way he interacts with them.

The substantially younger abbot of the monastery, since 2001, is Tenpa Yungdrung Rinpoché. Also highly affable, the abbot splits his time between Triten Norbutsé and the French Bönpo monastery of Shenten Dargyé Ling, founded in 2005, and also spends a good deal of time traveling around the world to teach. Though he obviously handles the monastery's affairs competently, his absence creates a very different, more relaxed dynamic for monks than at Menri.

This leaves Geshé Tsultrim Tenzin from Amdo - the abbot of the practical school (sgrub grwa'i mkhan po, henceforth Tenzin Tsultrim) - as the most present, in some ways most visible, ranking lama. Though his appointment to the practice school might suggest a particular affinity or capacity for practical pursuits above all others, the truth is that he is an extremely competent and engaged scholar, a teacher

\footnotetext{
${ }^{33}$ Part of the reason for this, compared to Menri, is the much more challenging terrain. Triten Norbutsé is situated on the side of a very steep hill, and going from one building to the next can require considerable leg and lung power. Menri is also on a hill, but is laid out more gradually and laterally.
} 
of a variety of subjects, ranging from monastic discipline ('dul ba) to the tradition of the Great Perfection (rdzogs chen), and the primary ritual administrator. He is a recognized authority figure in the community, well-known at Menri also, but it is not his job to get involved in larger monastery affairs or academic careers. Much like the lamas above him, Tenzin Tsultrim has a very generous and agreeable persona, with an expansive sense of humor and a relatively carefree attitude. Add to this picture Geshé Mönlam Wangyal, the disciplinarian at Triten Norbutsé, who is far more gregarious and less stern than those ${ }^{34}$ at Menri, and it becomes clear that, compared to Menri, the culture of Triten Norbutsé is for better or worse much more permissive and relaxed.

The effect of all of this on the monks' dispositions and careers is palpable. At the risk of over-generalizing, reduced oversight and more relaxed leadership at Triten Norbutsé means more gregarious and less industrious monks, at least when it comes to ritual crafts, which are further reinforced by Sangyé Tenzin as critical at Menri, and somewhat neglected at Triten Norbutsé, where Tenzin Tsultrim, as will be discussed in more detail below, explains that there are not enough monks to do everything they would ideally do, and where the ritual administrator himself does not engage much in teaching or disciplining the construction of ritual crafts, and where ritual activity is given an especially low priority compared to other pursuits.

\footnotetext{
${ }^{34}$ Since Menri is larger, there are two disciplinarians, compared to Triten Norbutsé's one, which also engenders different dynamics in the community. At Menri, the disciplinarians often look to each other (especially the younger to the older) for guidance and hold each other accountable. Even so, the higher tensions and idiosyncratic interpersonal dynamics at Menri led, on one occasion during my stay, to a fist fight between the older disciplinarian and one of the geshés. They were sitting outside of Sangyé Tenzin's office to discuss mounting conflicts when one threw an orange with great force at the other. The other monks present quickly broke up the fight, but tensions remained indefinitely. When I asked some of the monks and Sangyé Tenzin what all the conflict was about, they brushed it off, saying that some people just have more trouble getting along than others.
} 


\section{Monastery Sizes and Resources}

This issue of size is also an important difference between the two communities. The larger population of monks at Menri requires greater oversight, and beckons the kind of authoritarianism that Sangyé Tenzin embodies, but it also allows for monks and other community members to get involved in more specialized work, and to devote as many resources as necessary to a given task. Triten Norbutsé has a smaller population that is easier to manage, but which also limits the breadth and depth of the activities in which monks engage. For example, monks at both monasteries agree that the Expansive Sky ritual done at Menri is essentially a superior version of the same kind of summer dö ritual as the Nyelam Dé Zhi. This is an issue that will be discussed in greater detail later, but for now it is relevant merely to point out that virtually all monks interviewed at both monasteries agree with this sentiment. When I asked Tenzin Tsultrim why, given this widely acknowledged inferiority of the Nyelam Dé Zhi, they did not do the Sky Expanse ritual at Triten Norbutsé instead, his response was that there are not enough monks or other resources at Triten Norbutsé for the construction of the Sky Expanse ritual's much larger dö and the other more intensive requirements. Menri is substantially larger, with many more monks. This was a common answer, from him and others, to questions that addressed deficits between the two otherwise similar communities. 


\section{Non-monastic Community Members and Visitors}

This issue of size and resources relates also to the relative lay and guest populations surrounding both monasteries, and the support that they provide to monastic activities. Menri is situated above an official, politically sanctioned settlement of Bönpos, with a large orphanage, a school for kids of all ages, shops, offices, and residences of all sorts. Sangyé Tenzin and his administrators manage the money that comes from the central government-in-exile in Dharamsala, the distribution of this money to settlement officers for the purposes of settlement livelihood and maintenance, and oversight of the funds from there. Some of this money returns to the monastery in the form of ritual patronage or other donations, but mostly the monastery relies on different sources of funding, from income-earning lay Bönpos in the settlement, from guests to the monastery, some of whom are relatively wealthy western practitioners of Bön, and others. The stature of Sangyé Tenzin and Menri, as well as the capacious and comfortable accommodations in the Menri guesthouse, and the great natural beauty of the monastery and its surroundings, attract a constant stream of visitors from around the world - tourists, practitioners, filmmakers, volunteers, and NGOs among them. The income from these guests alone can be substantial. ${ }^{35}$

\footnotetext{
35 Many thousands of dollars arrived at Menri over the course of my stay there, but one telling story Sangyé Tenzin told me was about a wealthy Russian Bönpo adherent who had recently visited the monastery, offering to donate an extremely large sum of money. Sangyé Tenzin turned him down because it had become clear to him that this practitioner was expecting to have, in return, some influence over the direction of the monastery. As much as the monastery administrators complain about the tightness of funds, financial affairs must be relatively well in order to reject such an offer outright.
} 
At Triten Norbutsé, there is virtually no lay population in the immediate vicinity of the monastery, aside from a few shopkeepers, but there is a relatively steady stream of visitors from elsewhere in Kathmandu and elsewhere in the world. Tenzin Tsultrim explains that it is exceedingly rare that rituals earn enough patronage to pay even for themselves, but the monastery's income would be dramatically reduced without these visitors. In the pages that follow, the relative lack of laity is assumed to be a limiting factor that may not have been the case in pre-exile contexts, but the truth is that the pre- and post-exile delta is unknowable. There are fewer laypeople nearby, and greater distances from "headquarters," but foreign visitors are almost certainly wealthier than pre-exile local Bönpos. Though it is unintuitive and unlikely, it may very well be that Triten Norbutsé is better off with its current patrons than it ever could have been in Tibet. There are some formidable obstacles in the way of this assessment that, along with other difficulties in comparing Triten Norbutsé to anything similar in Tibet, will be discussed in more detail in the final chapter.

One crucial difference in exile that is better known, given the lack of an everpresent local laity, is the relative lack of opportunity for engagement with the lay people. Requests occasionally come in from afar to do rituals for the deceased or to improve agricultural conditions or yields, but the pre-exile practice many older monks describe, of walking down into the village to do any number of rituals on any given week, barely exists for Triten Norbutsé in exile. ${ }^{36}$ Monks spend the majority of

\footnotetext{
${ }^{36}$ Though, as will be described later, this practice is a bit more persistent at Menri, where the monastery stands immediately over the official Bönpo settlement of Dolanji, but even so it is much more often reactive, rarely as proactive and entrepreneurial as it once might have been.
} 
their time on the monastery grounds, studying or engaging in administrative responsibilities, and on the streets and shops just below when they have some free time. This means that there is a deeper disconnection than in pre-exile environments between monastic careers - especially in their pre-geshé years - and lay benefit. The spiritual economy is certainly still in effect, but the academic monks at these great institutions are for the most part focused on attainment of the academic degree and what follows. ${ }^{37}$

\section{Monastic Careers}

The day-to-day lives of the monks at Triten Norbutsé do vary, however, based on their trajectory of their careers. ${ }^{38}$ While Menri is home to a sizable orphanage that supplies the monastery with a substantial influx of very young monks who attend school during the day and dress in robes and partake in basic monastic community life much of the rest of the time, Triten Norbutsé has few to none of these adolescent monks, with the youngest typically being teenaged. ${ }^{39}$ Of the $100+$ monks that are in residence at Triten Norbutsé at any given time, $90 \%$ are or were in the academic program. ${ }^{40}$ Most of the remaining $10 \%$ are in the practical

\footnotetext{
${ }^{37}$ Note that, to an extent, this is a characteristic of academic monks everywhere. It is a rigorous pursuit and requires focus and dedication. But the lack of lay engagement and opportunity only enhances the isolation.

38 For an hourly outline of typical monk activities, as well as details about the academic program, see Yamaguchi 2005, especially pages 556-559, though it is important to recognize that aspects of their lives and the program have changed since - the total duration of the geshé program, for example, discussed elsewhere.

${ }^{39}$ I say "few to none" and "typically" because I did occasionally see very young monks around the monastery, but all of the ones I asked about were visiting from other parts of Nepal with other monks or family members.

${ }^{40}$ Interview with Tenzin Tsultrim at Triten Norbutsé on 5/25/2009.
} 
school, with a handful of others in neither. ${ }^{41}$ Monks in both programs follow the basic structure of life in the monastery, eating with the other monks, participating in the community-scale rituals and other events, and helping out with a variety of jobs around grounds - as caretakers (gnyer $b a$ ), treasurers, assistants to older lamas, photographers, and so on. While most monks are engaged in their curricular activities in the academic program or in their practice in the practical school, these other monks are free to do as they please, as long as they are following the basic monastic rules. ${ }^{42}$ They read, take walks, practice, go into town for tea or to run errands, and so on. One such monk at Menri, described in more detail later, would often say, "The monk life is great. I have three jobs: eat, sleep, and shit." While this is an underrepresentation of the many activities in which such monks would engage on a given day, there is no doubt that the choice not to participate in the academic or practical programs often stemmed from a desired lifestyle. Monks who were not interested in studying or practicing most of the day every day for many years, ${ }^{43}$ or who wanted spend more time traveling, ${ }^{44}$ or were otherwise interested in different subjects or methods of learning, had the option of simply participating in the

\footnotetext{
${ }^{41}$ Menri had more monks in this "neither" category, if only because it is larger, but also because the Menri practical program is less developed and/or pursued than the one at Triten Norbutsé, and thus non-scholastically inclined monks generally just opt for their own regiment.

${ }^{42}$ I never saw a monastic code ( $b c a^{\prime} y i g$ ) or any other official document outlining such rules, but Tenzin Tsultrim taught the vinaya ('dul ba) to all monks, and it was otherwise clear that at least the vast majority of rules - no singing or dancing, for example - were the same as other monasteries. ${ }^{43}$ It is important to note that this lack of interest sometimes related to the capacity (or lack thereof) to succeed in these programs, but sometimes these monks were very bright indeed and certainly could have been successful in the academic program, at least from an intellectual perspective, if not from the perspective of dedication and commitment.

${ }^{44}$ One of the defining differences among monk subpopulations at both Triten Norbutsé and Menri was whether they originally haled from the TAR, in the sense that the Indian and Nepalese monks, for example, had little difficulty getting passports, permits, and whatever else they needed to travel from place to place. Monks from the TAR had a harder time, though traveling by bus allowed must of them to travel between Nepal and India without too much difficulty (though the difference between flying in and out of Kathmandu and going by bus is, of course, substantial).
} 
community at a reduced level of engagement. As the statistics show, however, this third category was far from common at Triten Norbutsé and Menri, because of intense focus on and prestige associated with the academic program and its promise of a geshé degree.

To move upwards through the academic curriculum in pursuit of this prestigious degree, academic monks are engaged in near constant study. When they are not in class, debating in the courtyard or assembly hall, attending a ritual, or otherwise tending to quotidian tasks like eating and cleaning and washing their clothes, they are strolling around the monastery grounds with their dialectics school texts, reading and reciting and memorizing key points and whole texts over and over again so as to have them instantaneously at their disposal during debates and exams. These recitations are done at such high speeds, and are so monotonous, that in my early days staying at Menri, I mistook a few such academic monks reciting on the roof of the building where I was staying for large winged insects buzzing around the ceiling.

After anywhere from twelve to fifteen years of study, geshés are eligible to graduate, to much fanfare. The geshé graduation ceremony (dge bshes mdzad sgo) lasts anywhere from nine to fourteen days. Each day, one of the geshé candidates recites an entire philosophy text from memory in the morning, followed by an auspicious throwing of grain (bkra shis) and another recitation from memory in the afternoon. Before he starts, the rest of the monks do a recitation for the deity Chamma (byams $\mathrm{ma}$ ) to dedicate all subsequent activity for the benefit of all sentient beings, and, after he finishes, they recite a prayer from Tönpa Shenrap's teachings. 
When all geshé candidates have completed their recitations from memory, they participate in a final exam (dam bca'), followed by three days of debate. Assuming all has gone well - and Tenzin Tsultrim says it always does ("They have passed all exams for the previous thirteen years, so they will not fail now." ${ }^{45}$ ) - they receive their geshé certificates and the title of "karampa" ( $b k a^{\prime}$ rams pa), which is essentially equivalent to a doctorate of divinity. There is tremendous excitement around all of these proceedings that alternate year to year between Menri and Triten Norbutsé, unparalleled by any other activity or event throughout the year.

The practical school monks, on the other hand, spend most of their time engaged in the study and practice of the Great Perfection, which principally involves meditation. Tenzin Tsultrim is their primary instructor and administrator, and he spends much of the day engaged in teaching them these and related subjects, and teaching all monks about monastic discipline. Monks in the practical school tend to be older on average than monks in the academic program and generally have no particular degree or change in status in mind, choosing instead to advance their practice in a structured environment, though they do receive a title of "Yogi of the Shen" (gshen kyi rnal 'byor ba) after four years of study.

\footnotetext{
45 Interview with Tenzin Tsultrim at Triten Norbutsé on 3/3/2009.
} 


\section{Ritual Calendar}

Monks from both schools, and those in no school, come together to prepare for and otherwise participate in rituals and celebrations of the annual calendar. These rituals are (according to the Tibetan calendar):46

- $1^{\text {st }}$ month

- Nyamé Sherap Gyeltsen's (mnyam med shes rab rgyal mtshan) birthday ( $\left.4^{\text {th }}-5^{\text {th }}\right)$

- Cham ('cham) dances ( $\left.8^{\text {th }}\right)$

- Honoring the Completely Pure Virtuous Acts of the Shen (gshen gyi dpe spyod rnam par dag pa'i mdo, on the $14^{\text {th }}-15$ th)

- Mawé Senggé ( $r m a$ ba'i seng ge) wisdom deity ritual (for the academic community only, $23^{\text {rd }}-30^{\text {th }}$ )

- Ritual in honor of Drenpa Namkha (for practical school monks only, $23^{\text {rd }}-30^{\text {th }}$ )

- $4^{\text {th }}$ month

$\circ \quad$ Nyelam Dé Zhi $\left(12^{\text {th }}-16^{\text {th }}\right)$

- $8^{\text {th }}$ month

$\circ$ Observation of monastic discipline $\left(1^{\text {st.- }} 7^{\text {th }}\right)$

- $9^{\text {th }}$ month

○ Commemorating the death of Tönpa Shenrap $\left(30^{\text {th }}\right)$

- $12^{\text {th }}$ month

- The Gutör Chenmo ritual (dgu gtor chen mo, 26 $6^{\text {th }}-29^{\text {th }}$ )

There are a great many other smaller rites that happen on a daily basis, and special occasions for rituals or celebrations that happen less often, but these are observed every year, and attendance is, in theory, compulsory for all monks, though there will be important caveats to this, examined in more detail in the chapters that follow.

\section{Dö Rituals}

Given that both Menri and Triten Norbutsé have one major dö (mdos) ritual on the annual calendar - the Sky Expanse ritual and the Nyelam Dé Zhi, respectively - a

\footnotetext{
${ }^{46}$ Note that this is based partially on Karmay and Nagano, 2003, pp. 732-733, with in-person confirmations with Tenzin Tsultrim during an interview at Triten Norbutsé on 5/29/2009.
} 
brief evaluation of this category cum ritual implement is appropriate here. The dö itself is a large, roughly pyramidal mound that represents the world or universe, outfitted with mud, greenery, flowers, thread crosses (gnam $m k h a$ ), torma (gtor $m a$ ), wood drawings (shing ris), and a variety of other substances and objects to help complete the simulacrum. Over the course of its ritual, the dö is systematically transformed into the actual world or universe and offered to deities. ${ }^{47}$

The word mdos itself is of unknown origin. Karmay has trouble locating it, ${ }^{48}$ while Blondeau shows some slipperiness in the distinctions between mdos and $g$ to. ${ }^{49}$ A highly learned geshé at Menri believes that it refers to "condensation," condensing the universe and worldly issues into a single monument and ritual. ${ }^{50}$ In terms of content, there is also some slipperiness between dö and lü (glud), implements that function in many rituals more or less like ransoms. Karmay suggests that the two are often confused because lü is the basis of dö, but dö is different because it represents a palace or universe, compared to the lü, which takes on many other forms. ${ }^{51}$ Ramble confirms this with the simple but important insight that the dö is always offered, not expelled as lü usually are. ${ }^{52}$ Later, however, Karmay writes that a lü is represented by a dö, and describes an occasion in which a powerful lü leads the dö out of the house ${ }^{53}$ which would seem to backtrack a bit. Blondeau complicates the matter by explaining that there are three kinds of lü - for men, women, and

\footnotetext{
47 This explanation from Blondeau, 2005, p. 251 is slightly loftier than average monks' understanding of the dö but is otherwise compatible.

48 Karmay, 2009, p. 339.

49 Blondeau, 2005, p. 251.

50 Interview with Nyima Özer at Menri monastery on 2/16/09.

51 Karmay, 2009, p. 339.

52 Ramble, 2005, pp. 301-302.

53 Karmay, 2009, p. 341.
} 
children - each with 10 dö, of which there are three kinds - inner, outer, and secret. $^{54}$ She notes also that Karmay places it in the second vehicle of Bön - The Vehicle of the Shen of Phenomena (snang gshen theg $p a$ ) - and classifies it as a means of achievement (sgrub thabs), not worldly ritual, because it is one of the nine ritual acts connected to the Heap of Universals (spyi spungs) tantric cycle. ${ }^{55}$ This is not the case for the Nyelam Dé Zhi, however, which is considered "outer tantra" and more worldly in its sensibilities, thus showing that dö rituals themselves have a more fundamental origin and are widely applicable implements/strategies for a variety of types of rituals.

In terms of origins, the Treasury shows dö rituals like the Nyelam Dé Zhi, Sky Expanse, and the Dö of the Appeasement, Repulsion, and Slaying of Welsé (dbal gsas kyi skong zlog bsad gsum gyi mdos) being actively revealed in the $12^{\text {th }}$ and $13^{\text {th }}$ centuries. $^{56}$ The mythic origins are traced in the Sky Expanse text, ${ }^{57}$ which also talks about procedures for any Bönpo dö ritual, ${ }^{58}$ signifying that such rituals were already well in place by the time the Sky Expanse was discovered. Indeed, the evidence suggests that dö rituals are as Buddhist as they are Bönpo ${ }^{59}$ and may even be more Buddhist in origin. ${ }^{60}$

\footnotetext{
${ }^{54}$ Blondeau, 2005, p. 252. Though this is misleading because the dö itself and many of the rites it entails are strongly in the "outer" category.

55 Blondeau, 2005, pp. 251-252.

56 Karmay, 1972, p. 123 is one.

57 Blondeau, 2005, p. 256.

58 Blondeau, 2005, p. 253.

59 Blondeau, 2005, p. 273 says that the Sky Expanse was discovered as part of a tradition that is both Bönpo and Buddhist, and also says that there is no difference in the basic conception (252) or performance (268) of dö rituals, though she had never actually witnessed the Sky Expanse ritual at the time this was written.

${ }^{60}$ Karmay, 2009, p. 354 shows that lots of dö ritual texts were attributed to Pehar (pe har), known generically as the dö of the gyel[po deities] (rgyal mdos), but more convincingly, Blondeau (2005, pp.
} 
Menri and Triten Norbutsé are not, of course, the only places where dö rituals have been done in recent history. The Sky Expanse is done or was recently done at Trotsang (khro tshang) monastery near Dergé (sde dge), the Tengchen (steng chen) monastery in Tengchen, ${ }^{61}$ the Patsang (spa tshang) monastery in Yeta Xiang (ye tha xiang), ${ }^{62}$ and the monastery of Doting (rdo rting) in Bönlung Kamo (bon lung ska mo) in Gyelshö (rgyal shod), ${ }^{63}$ though each with different periodicity and scale. Other Bönpo dö rituals could be found at Kowo (ko bo) monastery in Tengchen,${ }^{64}$ Tingngu (rting ngu) monastery in Trowo La Xiang (khro bo la xiang), ${ }^{65}$ and in the village and monastery in Ludrak $(\mathrm{klu} \mathrm{brag}){ }^{66}$ There is even a dö text behind aspects of the Lügong Gyelpo (glud 'gong rgyal po) ritual in Lhasa, ${ }^{67}$ and both Buddhist and Bönpo dö rituals are apparently quite common among the Himalayan laity at large, for private exorcisms, family problems, and protective ceremonies. ${ }^{68}$

$264,268,272$ ) discusses how the origin of the dö cosmology is more Indian/Buddhist/Hindu than Bönpo, and how the dö construction is clearly mandalic. For those who have witnessed the ritual and heard the rhetoric about Bönpos being more concerned with worldly issues and folk implements, this is all somewhat surprising. To look upon the collected assembly of earthy ingredients, animal portraits, threadcrosses, torma, and so on is to have the feeling of seeing something uniquely Bönpo. And maybe you are, not in the sense of origins, but in the sense of modern craftsmanship and stewardship.

61 Karmay, 2003, p. 164.

62 Karmay, 2003, p. 131.

63 Karmay, 2003, p. 116.

${ }^{64}$ Karmay, 2003, p. 170.

65 Karmay, 2003, p. 90.

66 Ramble, 2005, p. 301 and Karmay, 2003, p. 678.

67 Karmay, 2009, p. 350. The text is called rgyal po rtse mdos.

68 Blondeau, 2005, p. 249. While this is no doubt true, I think there may be some confusion with lü happening in some of these cases. 


\section{Conclusion}

Examining these areas of convergence and divergence between two Bönpo monasteries in exile with ostensibly similar missions reveals a number of dynamics that influence, and that are then perhaps further influenced by, ritual performances and priorities. At both monasteries, monks come from all over the TAR and beyond, forming small groups within the monastery based on geographic provenance. This is not by any means unique to these monasteries - pre-exile governmental monasteries of central Tibet, for example, had a long history of membership from across the Tibetan cultural region - but it has a couple of additional implications in these exiled environments. One is that it is essentially a foregone conclusion that many of the monks will disperse at some point after receiving their geshé degrees. A number of them do stay as teachers, researchers, and so on, but it was not at all uncommon to hear monks expressing a desire to go back to their homeland, or elsewhere if it would be impossible to return to the TAR, to teach, set up or lead monasteries, become scholars, or otherwise inhabit other places and roles. Programs at the monastery are thus configured to rotate monks in and out of nonscholastic roles to educate them with the breadth of the Bön tradition, and not the depth. ${ }^{69}$

The other implication of the diverse populations across monasteries is a kind of restriction on the previous implication - Menri's situation in India, in relatively close proximity to the government-in-exile, means that it houses more refugee

${ }^{69}$ More will be said about this in Chapter Six. 
monks who are incapable of traveling outside of India because of their refugee status and lack of documentation. Triten Norbutsé in Kathmandu is in a much more permissive situation with more fully documented monks, which, together with the other dynamics at these monasteries, especially those related to leadership, translates to a greater sense of constancy and residency at Menri, compared to a greater, if still subtle, sense of ephemerality and transience at Triten Norbutsé. Leaders at both monasteries consider themselves the stewards of Bönpo traditionalism but the monastic communities in general emphasize scholarship above all other pursuits. Both enjoy patronage from international visitors, which is especially welcome given the relatively paltry lay presence at both, but especially at Triten Norbutsé. Menri is supported by a village that is the official settlement of Bönpos in exile, and as such it receives annual income from the central governmentin-exile in Dharamsala. The proximity of Triten Norbutsé to a major international travel hub makes it an accessible and desirable destination for wealthier patrons, but this may be offset by the current greater facility with visa procurement for longer durations in India, and the gravitational pull of the ranking Bönpo lama and "headquarters" orientation of Menri. In any event, the relative sizes of the monasteries, in terms of monks and infrastructure and income, naturally encourage different activities of different scale, especially given the relative exposure, and lack thereof, to a community of beneficiaries in the immediate environment. The relative pressures from national governments and the government-in-exile, combined with relatively different leadership styles even if the values at the root of both are the 
same, further affect the character of monastic activities, performances, and priorities.

Some of these issues will be revisited in Chapters Five and Six, where they will be brought into direct dialogue with the texts and performances of the Nyelam Dé Zhi, particularly in terms of the tensions between ritual and scholarship. In the meantime, the above will suffice as context for the emergence of the unique ritual dimensions of the Nyelam Dé Zhi at Triten Norbutsé, the performance of which we turn to now. 


\section{Chapter Two: Performance}

From the 12 th to the 16 th of the $4^{\text {th }}$ month of the Tibetan calendar year - the end of May or beginning of June on the western calendar - the monks at Triten Norbutsé monastery begin preparations for the annual Sadak Nyelam Dé Zhi (sa bdag nye lam sde bzhi, henceforth referred to as Nyelam Dé Zhi) ritual, what they call their "summer ritual." The pocket-sized calendar of monastery events that monks sell in the tiny shop below the kitchen, alongside dialectic school text books, khatak ( $k h a$ btags) scarves, yogurt, prayer flags, sleeves of crackers, incense, and other goods, shows the Nyelam Dé Zhi spanning these four days at the beginning of the summer, and translates it as, "ritual and practice to harmonize and purify all the spirits of the universe."70 Not one of these English words can be found in the Tibetan title of the ritual, and indeed monks and scholars at all levels have difficulty explaining the literal meaning of, much less translating, the title, ${ }^{71}$ but this English translation gives a clear indication of monastery administrators' understanding of the ritual's motivation and its intended outcome. As discussed in more detail below, however, monks give a variety of answers regarding the motivations or goals of the ritual,

\footnotetext{
70 From the Triten Norbutsé 2009-2010 calendar.

${ }^{71} \mathrm{~A}$ literal translation of sa bdag nye lam sde bzhi might be "The four sections [of] shortcuts [to worldly deities like the] sadak," but it is clear that sde bzhi (four sections or types) really should refer to the deities, so that a more coherent title might be something along the lines of sa bdag sde bzhi nye lam - "shortcuts [for] the four types [of ] sadak." In a personal interview (Paris, France on 5/31/2011), Samten Karmay agreed with this assessment of the title and, separately, claimed that the Treasury of Good Sayings (legs bshad mdzod) listed the treasure revealer Shubön Genyen (shu bon dge bsnyen) as having revealed a text called "something like 'sa bdag klu gnyan sde bzhi,'" suggesting that perhaps both the title and the purported revealer - Pönsé Khyunggötsel (dpon gsas khyung rgod rtsal) - were wrong or at least controversial. An examination of the Treasury, however, shows Shubön Genyen as the revealer only of the 'bum texts for each of the four deities addressed by the Nyelam Dé Zhi - klu 'bum dkar nag khra gsum and klu gnyan sa bdag gtod kyi 'bum (Karmay, 1972, p. 124 [287.21-24]). It is true that four 'bum volumes for each of the deities are included in the Nyelam Dé Zhi collection, but it is unclear and unlikely that these four volumes in the Nyelam Dé Zhi are the same as those revealed by Shubön Genyen.
} 
usually different from the "official" explanation, such that general consensus is elusive.

Regardless, as April turns to May, everyone knows the time for the summer ritual is coming, and though there is a great diversity of attitudes and personalities among the ranks, there is a palpable and intriguing sense of indifference overall. Soon there will be manḍala making, torma ( $g$ tor $m a$ ) shaping, and dö construction underway in different parts of the monastery. Some monks will appear to be highly engaged in the crafting of these preparations, eager to do it well, but many will not. By the time recitation gets fully underway, most former energetic engagement will have subsided into a sober, stoic, and occasionally monotonous and somnolent toil.

Before the main liturgy can commence, however, there are four full days of preparations. Monks must construct a sand maṇdala and dozens of torma dough effigies, thread crosses, wood drawings, and a number of other implements and offerings. They will gather mud and greenery from the monastery surroundings, and construct the dö that is the centerpiece and platform for all of the other materials, and that is, analogically, the axis of the cosmos and abode of all sentient beings. Monks must get their ritual texts in order, interspersing the primary instructions and verses with supplementary ones. And everything - grounds, materials, and bodies - will need to be cleaned. None of these require half as much time and concentration as the mandala, however, and thus this is where preparations begin. 


\section{Maṇdala}

The first day of preparations arrives at the end of May and, in the prayer wheel temple, a teenaged and a twenty-something monk flip through loose, yellowed pecha (dpe cha) pages and, through clouds of incense, point to a picture of a colorful sand maṇạala ${ }^{72}$ in a modern book titled Mandalas of the Bön Tradition (Namdak, 2002). After some debate, one of them starts to draw subtle white lines in chalk and pencil on a large square piece of plywood, painted black and supported by four red Coca-Cola bottle crates covered with a saffron sheet. The most fundamental, axial lines of the mandala ${ }^{73}$ - those that generally require lengths of powdered string between poles at the extremities of the board for measurement purposes or that are snapped to imprint a whisper of perfectly straight, guiding white - were in place before I arrived to observe. I ask the monk if he drew those lines and he says no. The other one says that those lines are always there because every maṇala needs them. He then picks up a metal horn with a serrated ridge running its length, fills it with black sand pulverized almost to silt, carefully points it at the center circle of the maṇdala, and with a tightly controlled vigor, urges the sand out, grain by grain, by rubbing a metal stick over the serrated ridge. The line-drawing monk continues in his work, using a clear plastic triangular set-square as his straight edge and a compass to draw circles. Occasionally, he gets up to go look at the text and picture that have now been placed on the altar, before sitting back down to continue drawing the lines. It takes almost five solid, intensely focused minutes of sand-

\footnotetext{
72 rdul tshon gyi dkyil 'khor

${ }^{73}$ These are the plumb lines (gnam thig), boundary lines (sa thig), and directional lines ('dzing thig).
} 
slinging to produce a half-inch black circle of uniform color at the center of the board, and there is already sweat beading the monk's brow. This is the easiest part of the job, with clear instructions, with no other sand to displace, no layering of color, and so few other bodies in the room to complicate the work. It will only get more challenging from here.

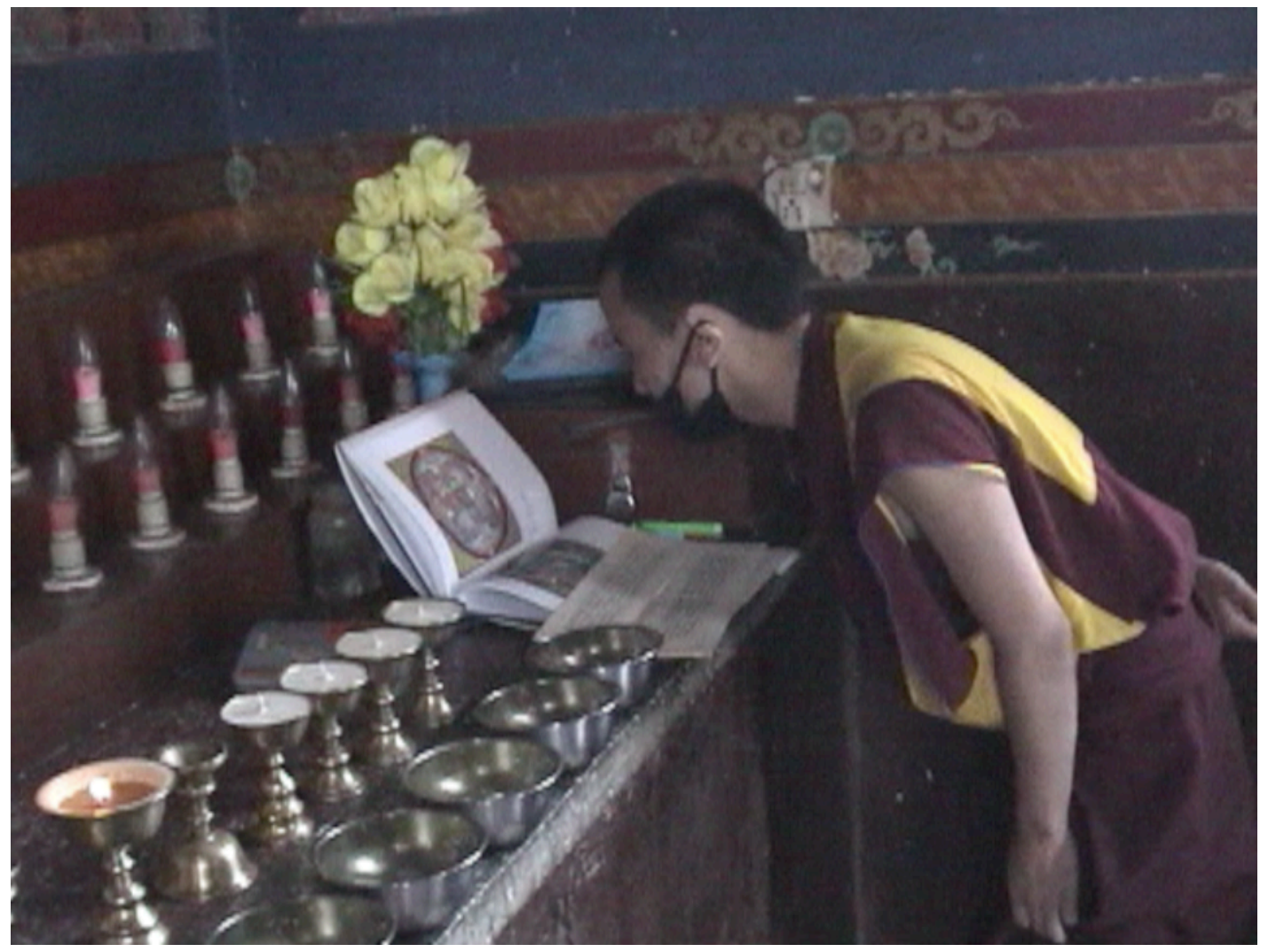

Figure 2.1: Mandiala-maker using the picture book and Manuscript pages.

After an hour or so, two more monks join the first two and all four kneel or sit on burlap-covered pillows, necklaces tucked into undershirts or swung over their backs, hunching over the guiding lines of the mandala to urge sand of all colors out of their metal horns. To achieve the precision that the mandala requires, they use different sized horns for different densities of detail, and further shape the piles or 
wrangle stray grains of sand with plastic rulers, stiff pieces of paper, and the tip of a pencil. Sometimes they sprinkle a little sand on the ground and practice drawing lines in it with a pencil before doing the same to the mandala. They all wear surgical masks to keep the clouds of sand out of their lungs and to keep their breath from disturbing the delicately laid grains. Even so, they have to stop every now and then one Khampa (khams pa) monk in particular, who announces on more than one occasion that he has a headache - to go outside and spit and rub their eyes and otherwise take a break before starting again.

Sand of every imaginable shade fills the glass jars and plastic cups covering one half of the temple floor. ${ }^{74}$ In places it is hard to walk comfortably, for fear of knocking one over. When the instructions or picture call for a particular color, the monks debate over which of their jars is the best match, sometimes mixing two or more colors together with the tip of a pencil in a jar lid to approximate a new one. Overall, they debate color more than they discuss any other subject. Even so, one monk will start filling in a section of the mandala with a particular color, only to be corrected soon thereafter by another monk, who reads something or looks again at the illustration or other parts of their maṇdala and declares a mismatch.

The correction of such errors requires a delicacy even greater than the cautious laying of grains. A monk will wrap the large open end of the horn - where the sand is loaded - with a khatak scarf, place the smaller spout end over the errant grains, and then suck them up into the scarf with pure lung power. The potential for

\footnotetext{
${ }^{74}$ Most of this sand is purchased in town. Monks were generally not sure how the sand or colors get made, with some suggesting that the sand is actually powdered rocks and that the color comes from plants or spices. While this may have been traditionally true, and may still be true to an extent, the neon colors suggest a more synthetic manufacture.
} 
netting some of the wrong grains alongside the right ones is high, as the lines of the maṇdala are sometimes no more than a couple of grains wide, and it is difficult to modulate the force of the vacuum. Even with great care, including an occasional attempt to double wrap the horn with a khatak folded over on itself, sand comes straight up through the horn and into the mouth and lungs. It is a strong incentive not to make a mistake.

Maṇdala-making is grueling, relentless work that extends nearly from sunrise to sundown. ${ }^{75}$ One of the monks is obviously much steadier and more skilled than the others, who often seem irritated or exhausted, and thus he becomes the de facto leader of the group, referring more than the others to the description of the maṇdala in the pecha pages and at least as often as the others to the picture in the modern book. He is much quieter, joking less, concentrating more than the others. Over a short lunch of bananas, tea, and chapati, ${ }^{76}$ he says he wants to be a scholar of Bön history and correct the erroneous view of Bön shared by so many in the world. The others eat in silence, occasionally stealing glances at us as we talk.

Throughout the day, people come into the temple to see the progress. The monastery disciplinarian Geshé Monlam Wangyel, who chose which monks would create the mandala this year - monks rotate in and out of the job from year to year leans in at one point to see that the maṇala is well underway, and Tsultrim Tenzin

\footnotetext{
75 Their actual schedule goes something like this:

7:00am: start work

10:00-10:30: noodle and tea break

12-2pm: lunch break

4-4:30: tea and biscuits break

6:30pm: done for the day

76 The monks use this Hindi word to describe the flat, pan-fried bread that is a staple at virtually all meals.
} 
(tshul 'khrims bstan 'dzin), the Drupdra Khenpo (sgrub grwa'i mkhan po, aka sgom grwa'i mkhan po), principle administrator of ritual activity and my primary contact and resource at the monastery, comes in after lunch, silently looks things over as he strolls around the room with his hands clasped behind his back, and leaves, not to return again at any time during the manḍala's construction, or, for that matter, at any time during the remainder of ritual activities. At one point late in the day an elderly nun tries to come in and spin the mani wheel, but the monks explain that they are working on this mandala and there is no room to walk around the wheel. She throws up her arms and walks out. Young monks come and go throughout the day, craning to get a look. A spectator monk in his twenties starts to spin the wheel as he stands watching. The mandala leader tells him to stop.

During their afternoon tea break, one of the mandala makers looks over their collective work for the day and his grave expression suggests that the enormity of the task ahead is dawning on him. He says, "One whole day." Another one solemnly says, "Three more to go." The Khampa who frequently gets headaches is outside the temple, lying on his back on the concrete stoop, covering his face with hands that are cloudy with white and blue and pink dust.

Over the course of three days, the mandala fills in grain by grain, yielding a map of the cosmos with details tailored to the Nyelam Dé Zhi and the deities and ideologies it addresses. Many elements are common to all mandalas - lotus seats, doorways in the four directions, seed syllables, and so on - but then there are prominent leaves and other vegetation, not just in the periphery as a trivial adornment, but integrated into the core architecture of the mandala. 
On the last day, monks rub their arms and look over their work while others come in to admire it. One older monk that has seen many western visitors come and go turns to me and says, “Tibetan culture is amazing, isn't it?” I ask the mandala makers why they made this mandala and one of them says, "It's for the altar." The others are silent until the leader says, "It's the seat of the gods. The sadak and lu come and sit here, very close to where Tönpa Shenrap (ston pa gshen rab) and the other Ones Gone to Bliss (bder gshegs) sit. Then we give them offerings to keep them happy." The manḍala makers can not or do not tell me more than this, but Tenzin Tsultrim later reiterates that the mandala is a "palace of the gods"77 and they all come and stay in it when they are invited during the recitation. It is not just the main gods of the ritual who come, he emphasizes -- it is all of them, and all sentient beings. The four syllables on lotus petal leaves in the center -- $b a, A$, hum, and $O m$-are seeds ${ }^{78}$ for the four principle Ones Gone to Bliss: Satrik Ersang, ${ }^{79}$ Tönpa Shenrap, Sangpo Bumtri, ${ }^{80}$ and Shenlha Ökar. ${ }^{81}$ The $k a, k h a, g a$, and $n g a$ syllables in the primary directions are the seats of the chief subduers ('dul dpon) -- Lu Bön

\footnotetext{
77 lha yi pho brang. It is clear from the context of this conversation that he is suggesting that the central part of the mandala, to be inhabited by the deities, is the most important element and purpose of the mandala.

78 When talking about the mandala independently, prior to the ritual, monks refer to the syllables variously as "seats" (gdan) or "seeds" (yig 'bru or sa bon) of the deities, which are two functionally different definitions, but they both point to the same understanding of the role of syllables in the mandala, as supports for the invoked deities.

${ }^{79}$ Satrik Ersang (sa trig er sangs) is the Zhang Zhung translation of Sherap Chamma (shes rab byams $m a$ ), who is a deity often equated with virtually all of the other female deities in the Bön pantheon as well as the Buddhist Drölma (sgrol ma) or Tara. More will be said about this and the other deities in the next chapter.

${ }^{80}$ Sangpo Bumtri (sangs po 'bum khri) is often described as the father of existence or of the universe, having given rise to all beings via his union with Chucham Gyalmo (chu Icam rgyal mo), who is often equated with Satrik Ersang. Ontologically, he is a "perfected body" (rdzogs sku).

${ }^{81}$ Shenlha Ökar (gshen lha 'od dkar) is ontologically described sometimes as a "perfected body" (see the ta pi hri tsa document) or as a "Bön body" (bon sku, comparable to chos pa'i sku in Buddhism).
} 
Yeshé Nyingpo, ${ }^{82}$ Nyen Bön Tangtang Krölwa, ${ }^{83}$ Tö Bön Bati Sungyen, ${ }^{84}$ and Sadak

Bönpo Küntu Khyappa. ${ }^{85}$ The khrom syllables just beyond that are the syllables of the garuda, and the four lotus seats with $p h u, n y a$, sa, and $k h a$ are for the sadak, lu, nyen, and tö. These are the sixteen "guests" (mgron), ${ }^{86}$ and while the ritual involves other beings, these - and especially the chief subduers and the sadak, lu, nyen, and tö - will be the primary addressees of the liturgy.

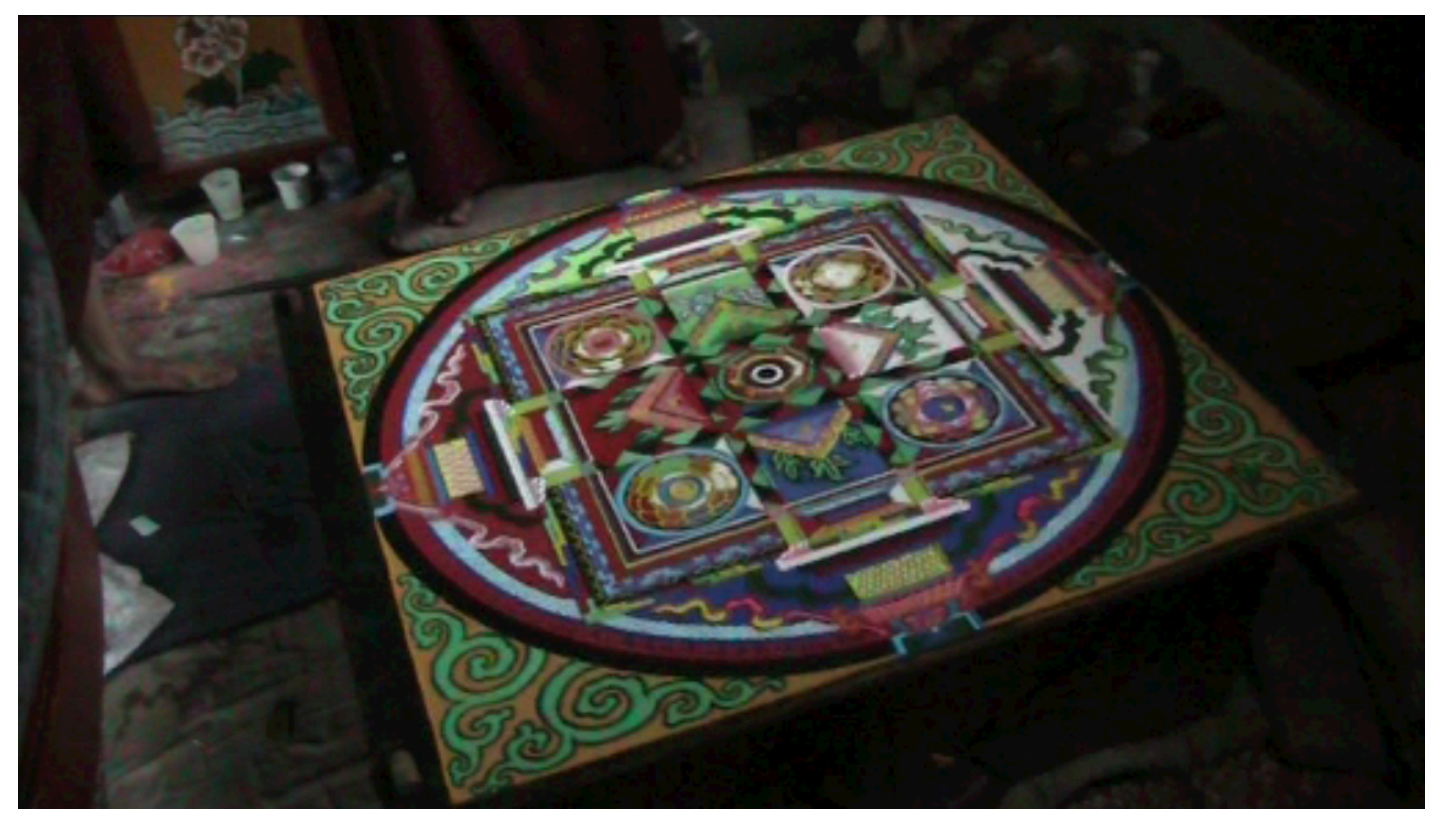

Figure 2.2: The completed manḍala.

When asked about the significance of other elements in the mandala, Tenzin Tsultrim says that one can read about that in one of the many references out there about maṇalalas, one of which he wrote - an unpublished document titled ta pi hri

\footnotetext{
82 klu bon ye shes snying po, arguably the most important king and subjugator of the masses of lu. ${ }^{83}$ gnyen bon thang thang khrol ba. Note that some of the texts - and some lines within texts - have gnyen, while others have gnyan. The latter is the most commonly accepted spelling.

${ }^{84}$ gtod bon ba rti gsung bsnyen

${ }^{85} \mathrm{sa}$ bdag bon po kun tu khyab pa

${ }^{86}$ Guests at ritual proceedings are often divided into four types or two types, all of which will be discussed in greater detail below, but the former can be roughly seen here in the form of the four groups - the four Ones Gone to Bliss, four chief subduers, four garudas, and four types of worldly deities.
} 
$t s a .{ }^{87}$ The message is clear: The syllables and the deities they represent are the unique and important elements of this mandala and this ritual. Everything else is convention, adornment, trivial.

\section{Thread Crosses}

As the mandala work winds down, the thread cross (gnam mkha) work winds up. In a bare, non-descript space at the edge of the monastery grounds, a dozen monks sit together on long rugs or cushions with bags of yarn and sticks, weaving. With the noise of boisterous debates outside as a backdrop, these older monks - generally in their thirties - pull sticks out of taped bundles, shape and notch them with pocket knives, and then start by crossing the sticks and binding them together with black thread, until they attain a diamond shape approximately the size of a quarter. Some of them line this black center with white. Then there are threads of pink, orange, green, purple, blue, yellow, and many shades between. Some of them show or otherwise advise others on aspects of the process, but the atmosphere here is decidedly different from that in the manḍala shrine. They are not making use of any reference materials, balls of yarn fly through the air as they request certain colors, and they are all talking constantly. Emaciated cats stroll through the space, sniffing around the indifferent monks' feet for food, batting the balls of yarn, and meowing loudly. As the day wears on, the banter turns into hearty joking.

\footnotetext{
87 The ta pi hri tsa, named after an important Bönpo scholar, is a short unpublished reference guide that explains the basic identity and appearance of important Bönpo deities, and describes in a more general fashion the purpose and variations of mandala, torma images (gtor par), and related themes. See Appendix 5 for the full text.
} 
"Look at this one," a monk in his late thirties says, holding up a justcompleted thread-cross. "This one is special."

All the other monks laugh hysterically. Another monk joins the fun and says, "No, look at mine. Mine is really unique."

A third monk points to his neighbor's thread-cross and says, "And this one! This one is perfectly ordinary."

The laughter in the room reaches new heights, and the joke continues in this way for nearly an hour, with all but a few bashful monks participating. At one point, mid-laugh, a monk in his late thirties looks right at my camera and me, scowls the smile right off his face, and shakes his head. This, combined with the nervous looks of the shy monks, is one of many times I wonder if I have worn out my welcome, or if I'm skewing norms simply by observing - if the whole joke about ordinary and extraordinary is a mockery of my intense interest in something they find so mundane - or if the monks have anxiety about what I am going to say about them. Either way, there are moments of genuine appreciation where one monk holds up his completed thread cross and another monk, all joking aside, nods his head and says, "That one really is good." 


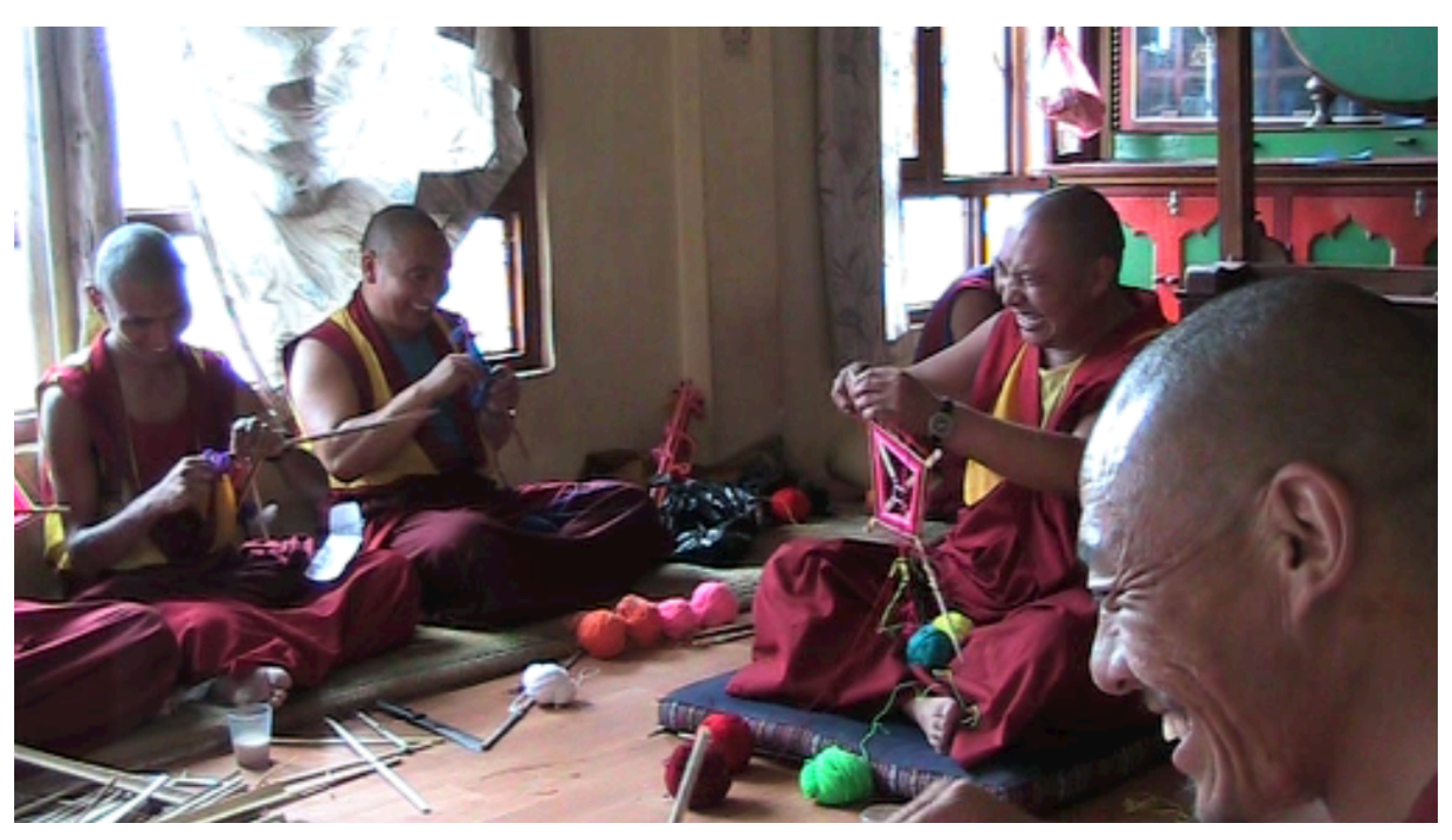

Figure 2.3: Thread cross makers.

The pile of completed thread crosses grows and grows, yarn all colors of the rainbow standing out in stark contrast against the brown and gray of the sticks. The monks have also made changbu (chang bu) - individual sticks wrapped with and featuring protruding loops of yarn - that they describe as a variety of thread cross. By the end of the day, there are many dozens of thread crosses and changbu, and the monks call their work done.

Explanations on the spot of the symbolism and purpose of thread crosses vary nearly as much as the colors used to construct them. The diversity of responses reflects both monks' individual understandings of thread crosses and the numerous traditional uses of thread crosses in ritual. Some monks say they are all-purpose offerings to gods, either as respectful offerings to higher deities or as ransoms to lower deities, and that sometimes certain beings will reside inside the thread crosses after they come to get the offering. Others respond that the construction of 
thread crosses is motivated purely by the wish to generate good merit for oneself, for a particular benefactor who is sick or otherwise in need, or for the community as a whole. Others still - the majority - cannot or will not say what they represent, aside from saying they are part of the ritual, instead directing me to ask Tenzin Tsultrim, who explains in a bit more detail: The center of all thread crosses is black to represent eyes, since buddhas and sentient beings all have eyes. Some thread crosses are the "support" for buddhas, some are offerings, some are the support for demons and ghosts, some are ransoms. The colors principally represent earth (yellow), water (blue), fire (red), air (green), and sky (white). For the ransom thread crosses, the main color is black and the shape is square. Offering thread crosses are diamond-shaped. Wrathful thread crosses are the shape of a purba (phur ba). The changbu function exactly like the other kinds of thread crosses. When asked for more detail, Tenzin Tsultrim points to the same ta pi hri tsa document that he referenced for detail about the mandala.

\section{Tormas and Other Implements}

The next morning, the monk assistant ${ }^{88} \mathrm{I}$ had engaged to help me video the ritual wakes me up at 5:00am to say a group of monks have started constructing tormas. A group of a dozen monks of various ages stand around a large concrete work table outside the monastery kitchen in the pitch black morning, scooping tsampa (tsam $p a$ ) dough out of a massive metal bowl and shaping them according to instructions in the same Manuscript pecha pages used by the mandala making monks. At this

\footnotetext{
${ }^{88}$ Tsultrim Gyatso (tshul khrims rgya mthso)
} 
hour, among these monks, there is little to no conversation beyond the occasional request for information about what other tormas are needed that have not already been created, the response read from the pecha pages or recited from memory. Trays start to fill up with tormas of a great variety of shapes and sizes. A few have been made to look like yaks, deer, or other animals, others are long and conical, some are in the shape of purbas, and some are constellations of different sizes and shapes that require plates to hold them together. The five-offering torma is very common, featuring the five offerings - water, flowers, incense, butter lamps, and tormas $^{89}$ - pressed together. Large rectangular blocks with detailed images carved into molds (gtor par) are pressed into the dough of certain tormas to impart more specific meanings to them. There are yungdrung (g.yung drung) symbols, lotuses, wheels, jewels, arrows, spindles, and many more. Some monks use wood sticks shaped like knives to draw designs - sometimes just patterned lines, sometimes leaves or other explicit images - on the sides of some of the larger tormas. One looks like a lotus flower with petals spread. A number of the cones have eight smaller cones like horns at the top. Some are brushed with a yellow liquid, indicating that they are to be used for higher deities, while others are painted red, including the purba-shaped tormas, indicating that they are to be used for lower deities. In a corner of the outdoor space is another large metal bowl filled with water, in which are floating balls of a stiff colored butter mixture - primarily white, but also pink, blue, green, red, brown, and yellow. Two monks extract the balls and shape them

\footnotetext{
${ }^{89}$ In larger rituals, it is essential to have each of these items in hand for the five-fold offering, but in smaller rituals and as an affordable way to increase the volume of these materials even in larger rituals, it is common to construct tormas that combine and represent each of the five of these.
} 
into adornments that will later be affixed to the tormas. Some are just flattened into circles of various sizes and colors, while others are carefully shaped into flower petals or meandering green vines with leaves of many additional shades of green. Sometimes these adornments are layered, with white dots providing the foundation for a blue flower, inside of which is pressed a pink flower.

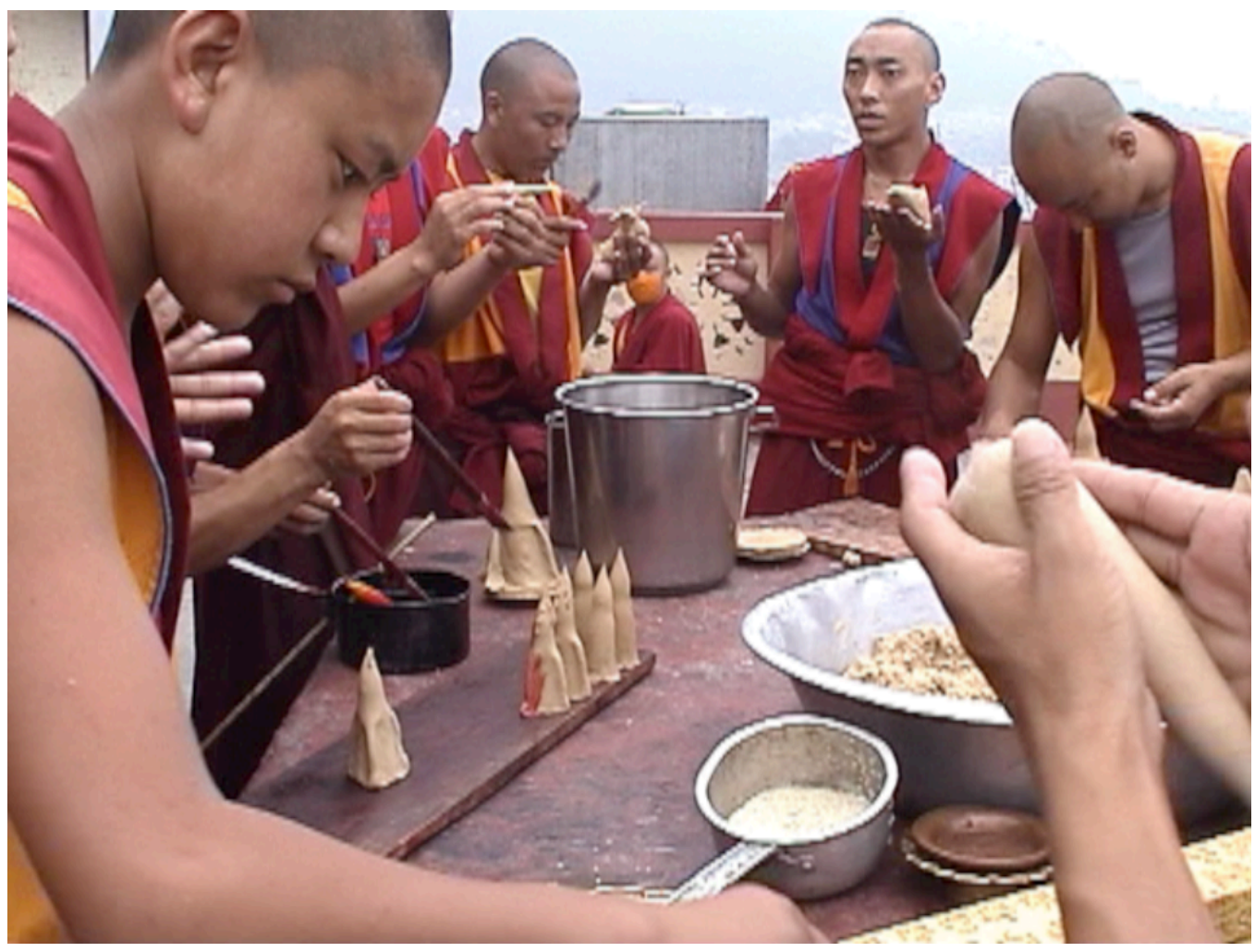

Figure 2.4: Making tormas. 


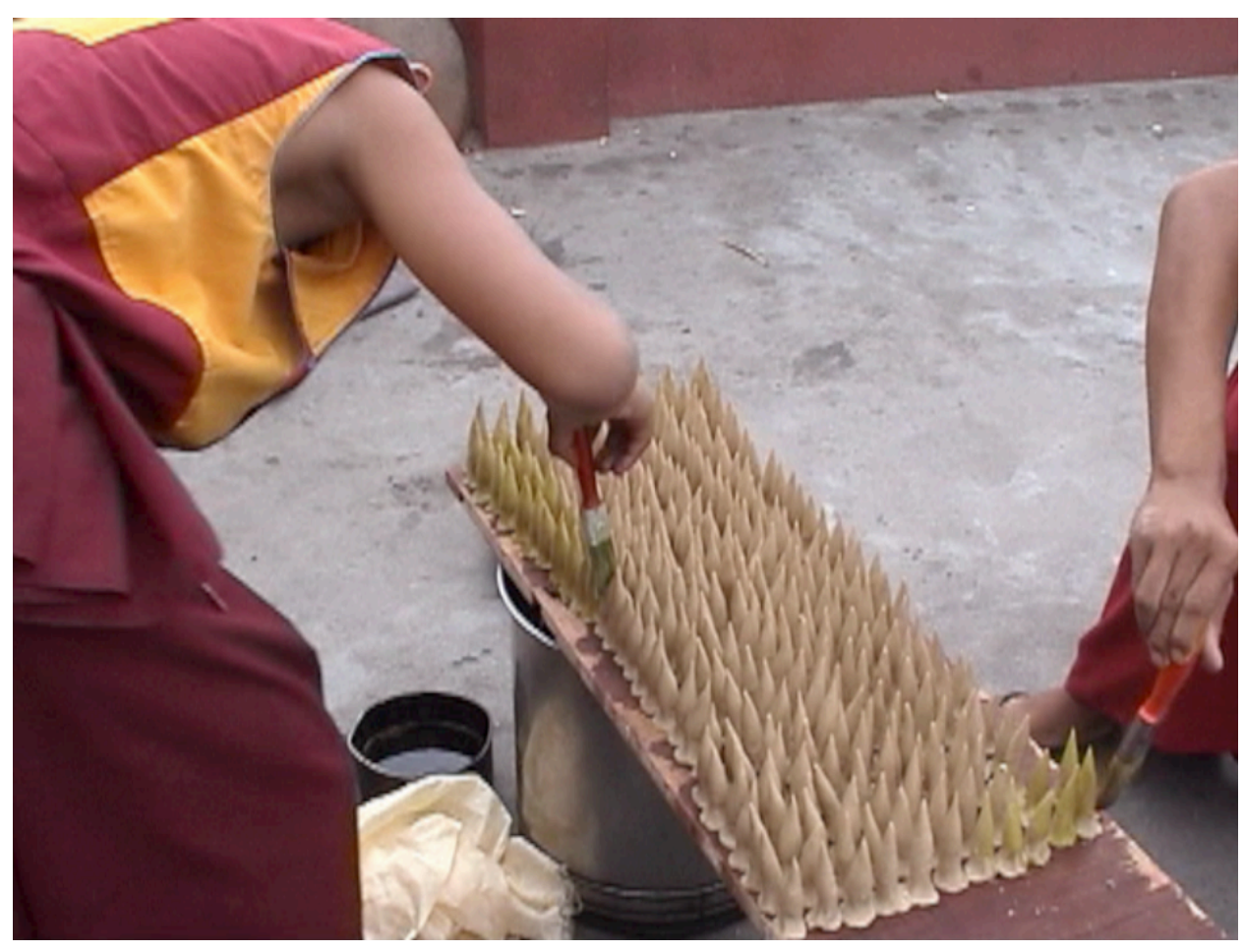

Figure 2.5: Tray of tormas.

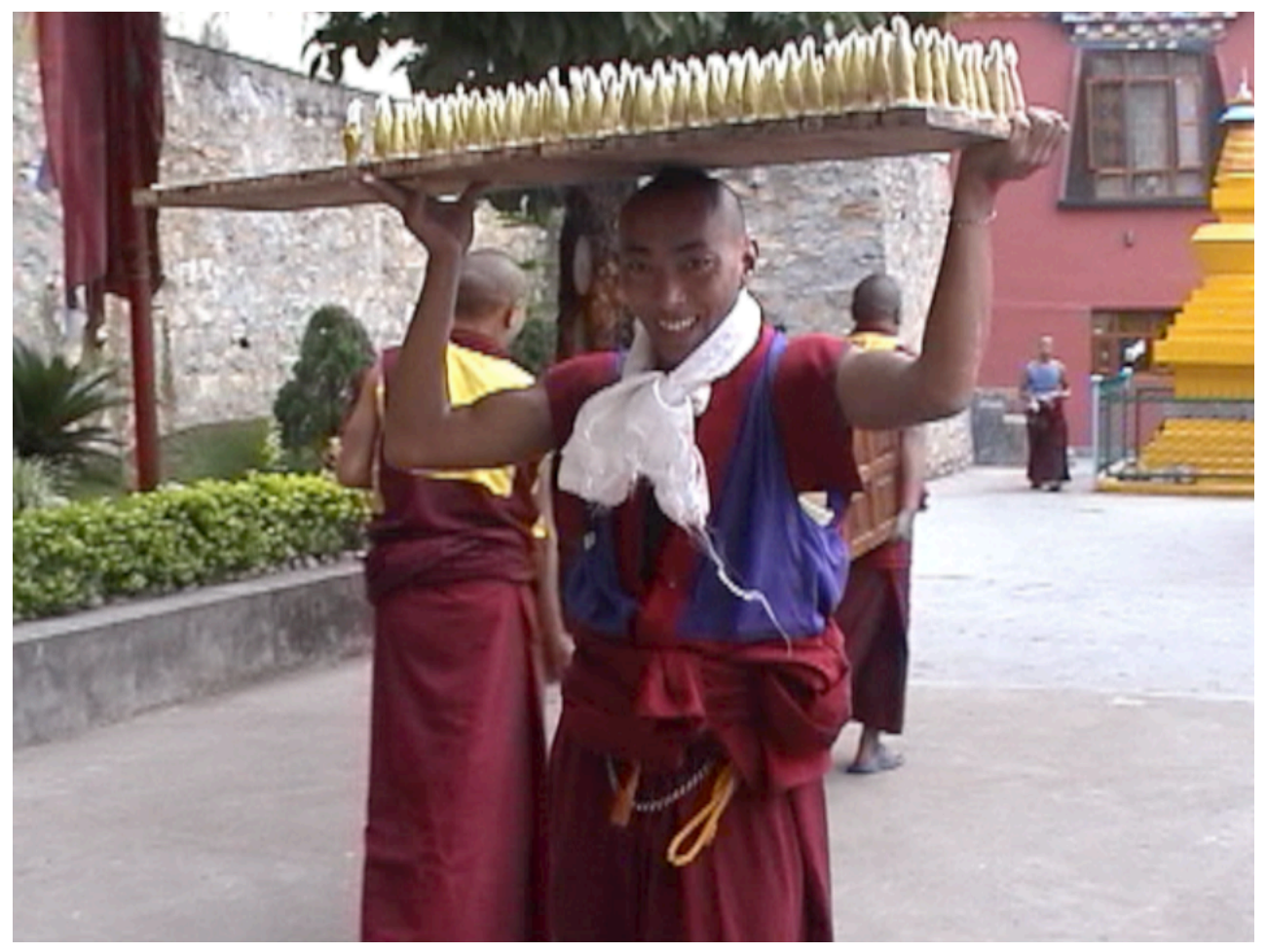

Figure 2.6: Carrying tormas to assembly hall. 
In another corner of the torma-making space are monks constructing other supporting materials. Three monks glue white beads that resemble pearls into the center of paper flowers glued to sticks, while another monk scotch tapes drawings featuring animals, people, and other valuable objects to small wooden poles (shing ris). Everywhere in this part of the monastery there is the feeling of industriousness, with everyone energetically dedicated to putting together the various implements of the ritual, most of which will end up on the dö.

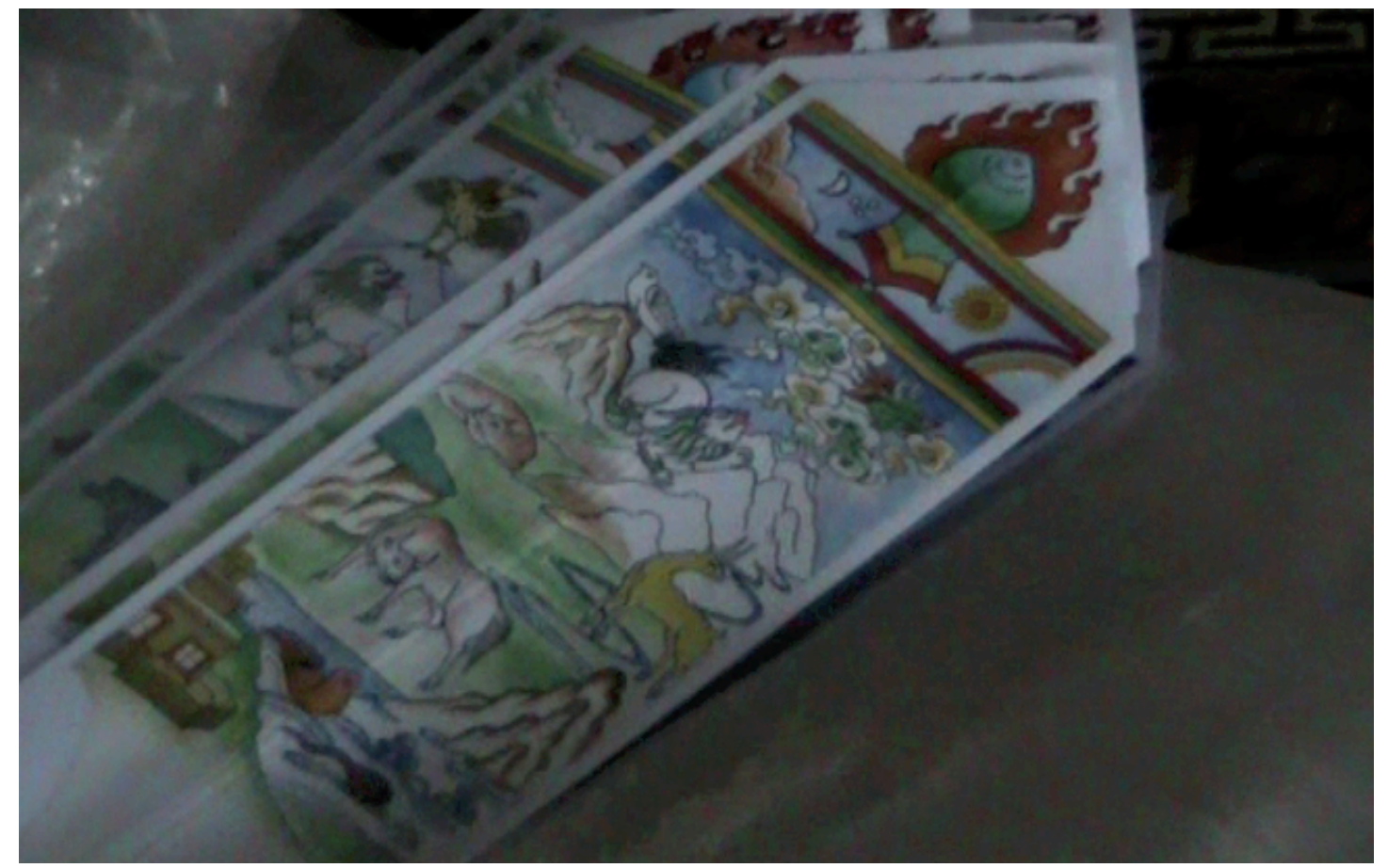

Figure 2.7: "Wild animal" (ri dwags) wood drawings for the dö.

When monks describe the importance or meaning of particular tormas, their responses are of much the same character as those for the mandala and thread crosses. Some cannot or will not say anything beyond a basic statement of the importance of tormas in the ritual, and in most rituals, and that if I want more details I should talk to Tenzin Tsultrim. Others say that tormas can serve a variety of 
purposes - offerings to "high" deities, ransom for "low" deities, vessels or supports, substitutes for other items or people that cannot be there for whatever reasons, and a way to generate merit. One monk says some of them are food for the sadak and lu. Another monk from Amdo explains that tormas were first created and taught by Tönpa Shenrap many thousands of years ago, that it is an important part of the Bön tradition, and that all Tibetans - Buddhist or Bönpo - now use them for many different reasons. The flowers and other ornaments affixed to tormas or used elsewhere are usually explained as ways to make offerings more attractive to the deities they target.

Consulting Tenzin Tsultrim results also in answers similar to those he gave for other ritual implements. He gives a one or two word description of a couple of them - the small roughly circular ones packed with detail are the five-fold offering tormas, the triangular ones are for garudas - and then refers me to ta pi hri tsa. I agree to read it, explaining that it will take a little time to translate, but in the meantime could he tell me something about a deftly rendered yak torma one of the monks made, or a little bit more about how and why Tönpa Shenrap thought it necessary to invent tormas? He looks at me with the smiling bespectacled eyes that have begun to accompany every answer, and says, "No. Read ta pi hri tsa. Everyone must read ta pi hri tsa." He hands me another printed document and says, "And here is something else I wrote with more detail about tormas." 90

\footnotetext{
90 See Appendix 4.
} 
With the mandala and tormas made, all attention shifts to the construction of the dö, literally the mound upon which all other implements will be placed - and all ritual attention focused - and figuratively a model of Mount Meru, the axis of the cosmos. The pace of preparations has picked up as the first day of recitation draws near with much work left to do. Monks scatter throughout the verdant, jungly hillside to break off long branches of leaves, pick flowers, and collect small scoops of mud. Outside the assembly hall, three monks pull large wet blocks of clay out of yellow burlap bags, splitting them into smaller, more manageable pieces. Inside the assembly hall, a few monks begin to put together the altar (mchod shom), covering it in swaths of saffron, blue, and maroon sheets, and the wooden two-tiered frame - the lower tier covered in saffron sheets and the upper in maroon - that will act as the foundation of the dö. Other monks count and examine the wear and tear of the various peaked and printed images of the wood drawings varying from six to twenty inches in length that monks made or assembled over the last couple of days. The largest and widest of these drawings features an ornate garuda spreading its wings, while the smaller, narrower ones depict a number of iconic images in profile: A man, an arrow, a woman, a spindle, a variety of animals and birds, images of wealth, and so on. One monk starts to shape the clay from outside the assembly hall into fist-sized mounds, and inserts the wood drawings into each, so that they remain propped upright. I ask him to confirm these are the wood drawings, using the word "shingri" that I've read so much about in the Nyelam Dé Zhi root texts, and he says, "No, these are just 
images (gzugs brnyan)." ${ }^{91}$ Because I am quite confident they are wood drawings, matching the descriptions from the Manuscript exactly, and because I am concerned my Tibetan is merely incomprehensible, I ask again. As before, he shakes his head and says, "No, not wood drawings. Images." Taken together with the great diversity of explanations - and absence of explanation - I heard about other ritual implements and their meanings, this incongruence begins to impart the impression that many of the monks have not read the texts, that the implements or at least their names or possibly anything about them beyond their presence as constituents of the ritual aesthetic are not important, or all of the above.

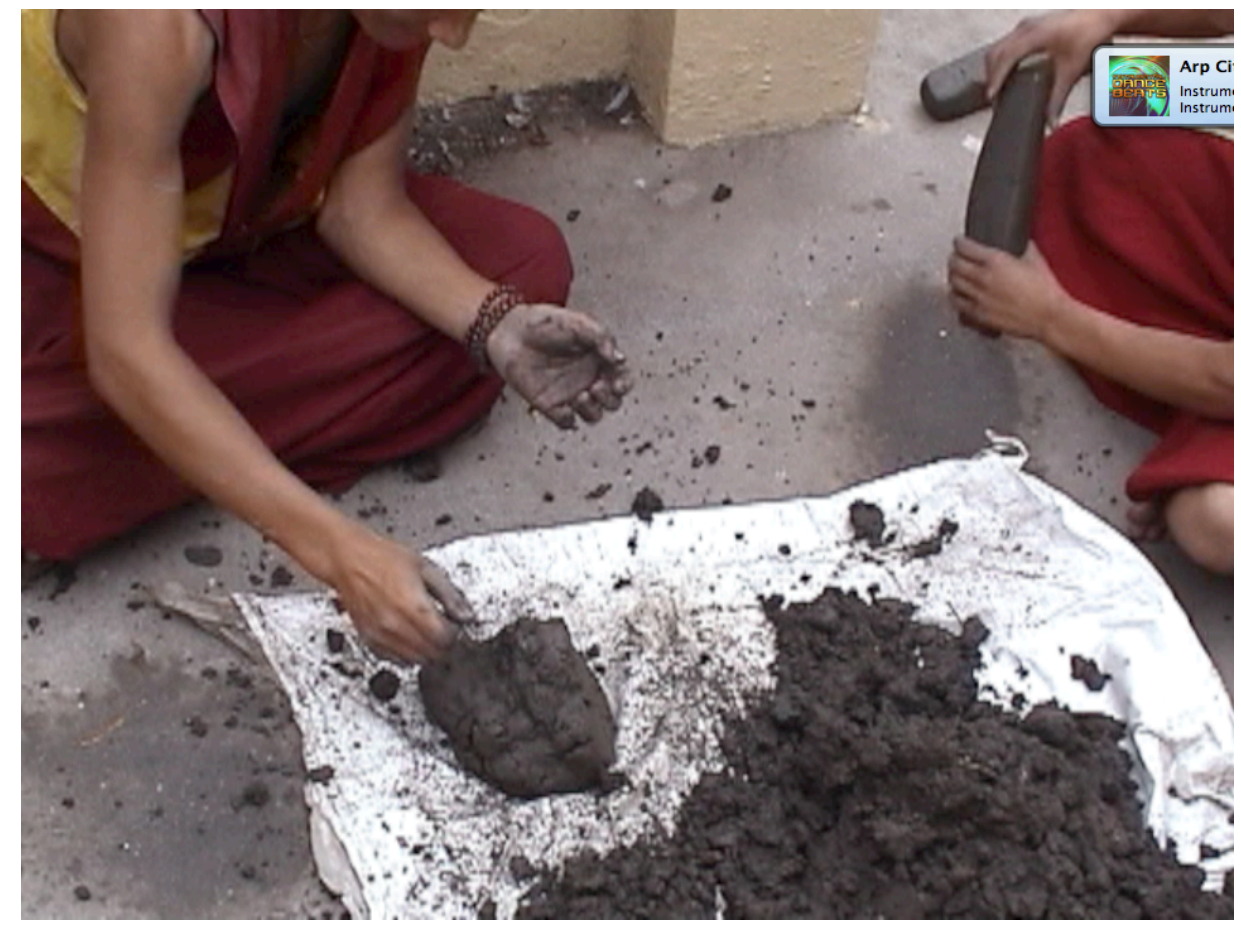

Figure 2.8: Putting together the mud bases for greenery, wood drawings, and so on.

\footnotetext{
${ }^{91}$ While there are many subtly different definitions of gzugs brnyan, the standard gloss of "images" clearly applies here. I didn't ask if he meant to communicate the more nuanced and contextually appropriate definition of "likeness that acts as a substitute for the subject it represents," but it's reasonable to assume so.
} 


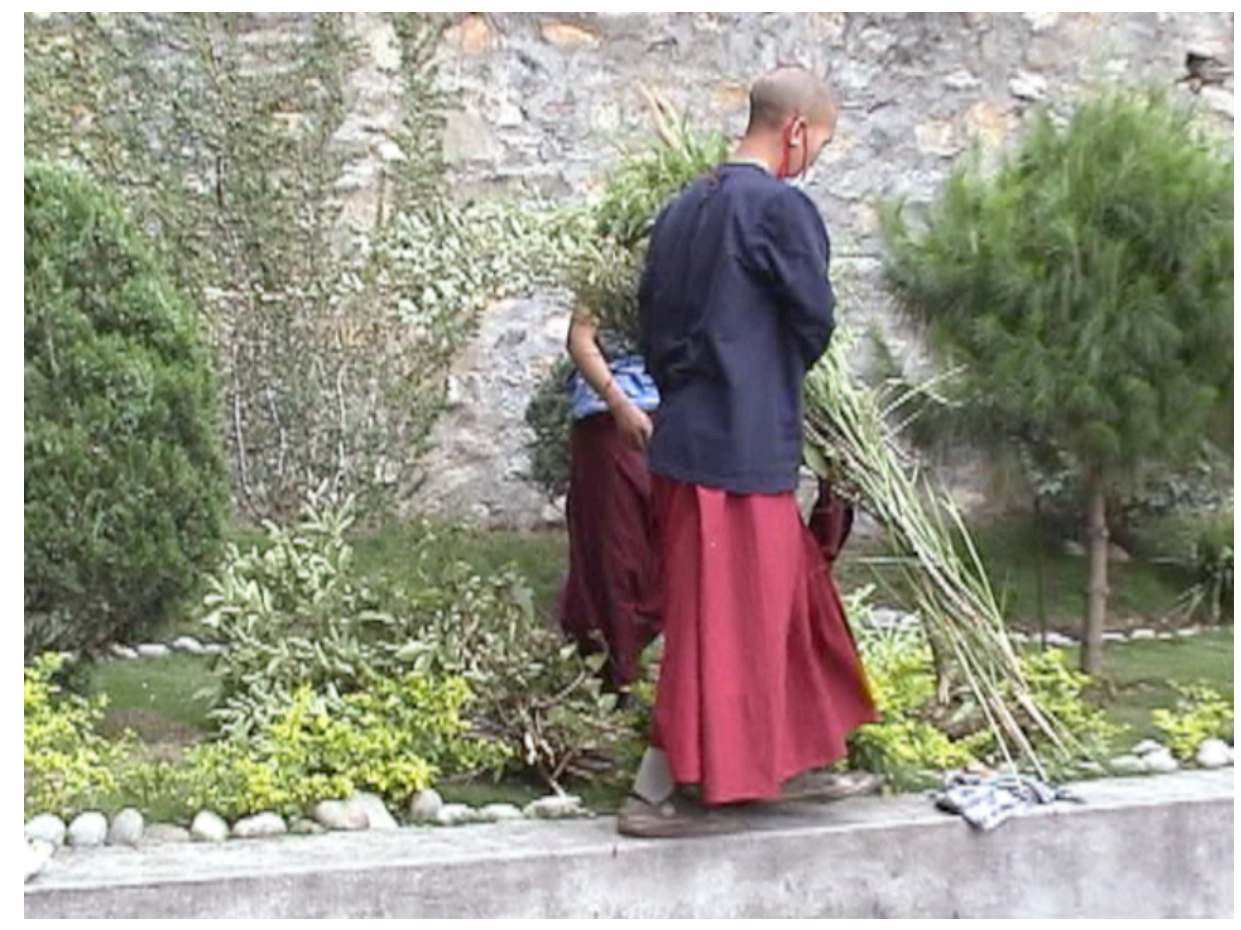

Figure 2.9: Collecting greenery for the dö.

Two monks very carefully lift the mandala and move it from the prayer wheel temple, up the stairs to the assembly hall - stopping and hunching protectively over it for a moment as the wind picks up - and inside to the top of the dö. They lay a cover of glass over the mandala and, at the direction of the recitation leader who reads from notes in a notebook that were taken from the Manuscript and the Upper Ritual (stod chog) volumes of the Nyelam Dé Zhi, begin to place tormas and other implements strategically on top, to correspond to the sections of the mandala below. The innermost lotus petals of the mandala corresponding to the four principle Ones Gone to Bliss are topped with scroll painting (thang $\mathrm{ka}$ )-like cards depicting the respective deity, taped to wooden sticks, anchored in small conical tormas painted yellow and tipped with a pinch of butter. Garuda images of an identical style are anchored in butter-tipped red purba tormas and placed atop the khrom syllables of 
the mandala, in a ring around the Ones Gone to Bliss. One by one, monks pass up large constellations of tormas to place over the regions of the mandala corresponding to the sadak, lu, nyen, and tö. The lu constellation is uniformly red, while the others are uncolored. All are heavily adorned. Outside of these tormas are thread crosses, five-offering tormas, yak tormas, and a variety of others. Down by the base of the dö, near the recitation leader's drum, is the ransom and offerings for the "driving away misfortune" rite (byur phud) - to be done early on the first day of recitation. It is a plate with cut onions and burned leaves around a red humanoid torma and red chak (chags) tormas.

If there is debate over where an implement should go, or the recitation leader does not have notes for a particular implement, other monks examine the Manuscript, looking for instructions. Everywhere in the assembly hall are large trays of different kinds and shapes of tormas, yellow and red and uncolored, with pinches of butter on top or not, encrusted with dots and discs and adornments of colors of dozens of shades. Some of the trays are more like platters, with piles of nuts and dried fruits and vegetables encircling the tormas.

Yet more greenery is brought in and arrayed around the sides of the dö, some of it large enough to qualify as small trees, while monks place all the other components of the dö in tiers. The wood drawings stand interspersed with thread crosses - which have now been accented at their points with feathers - on the second tier, except for the large, colorful garuda drawing that stands over the manḍala, above everything else. Colored strands of cotton, mostly pink and blue, are strung across the branches of the greenery, all around the dö, in a way very much 
reminiscent of Christmas tree decorations. Monks debate which implements should go where and discuss what else needs to be done, directing each other based occasionally on instructions from pages in the Manuscript, sometimes looking to the chant master for guidance, ${ }^{92}$ sometimes looking to the older monks. On occasion during these general preparations, the chant master and another monk sit down by the drum and do brief recitations from the Upper Ritual primary volume of the Nyelam Dé Zhi and from Expansive Space, an important supporting text drawn from the Zermik (gzer mig) biography of Tönpa Shenrap, to purify the environment and the various implements.

One tall, wiry monk is focused on setting up the altar and a number of other tables clothed in elaborate khatak scarves. On top of the colored swaths he places a clear plastic sheet and then bowls of all sizes, a variety of offerings, and the pearlstudded flowers on sticks that monks assembled in a corner near the torma making, lining the back. The other tables have trays of tormas - one of them has a tray of nearly a hundred - and other offerings, as well as ladles and spoons of all kinds. When these bowls of ablutionary water have been filled, he floats in them a handful of grain and a few flower petals.

The monks work throughout the day preparing the dö and the rest of the assembly hall for the official start of the ritual - the recitation - the following day. By dinnertime, the monks are showering the dö with grain, the final step in its preparation. As monks sweep up the heavily littered floor around the dö, the

\footnotetext{
92 Though the recitation leader may or may not have special knowledge of a larger ritual context, he is the one most acquainted with the text, and as will be discussed in more detail later the Manuscript was written more for his benefit, to facilitate preparations and smooth recitation, than for any other reason.
} 
recitation leader and another monk recite and perform mudras from Expansive Space, though this particular recitation is so well-known to them that they scarcely, if ever, look at the text.

I will soon see another dö for the Sky Expanse ritual at Menri monastery in Dolanji, India, that will dwarf this one in scale and sophistication of craftsmanship a comparison that will prove to be an important dynamic in how monks at both monasteries perceive the Nyelam Dé Zhi ritual more broadly - but until then I am impressed by this large, verdant, fragrant mound at the front and center of the assembly hall, and the hundreds of supporting implements around it. 


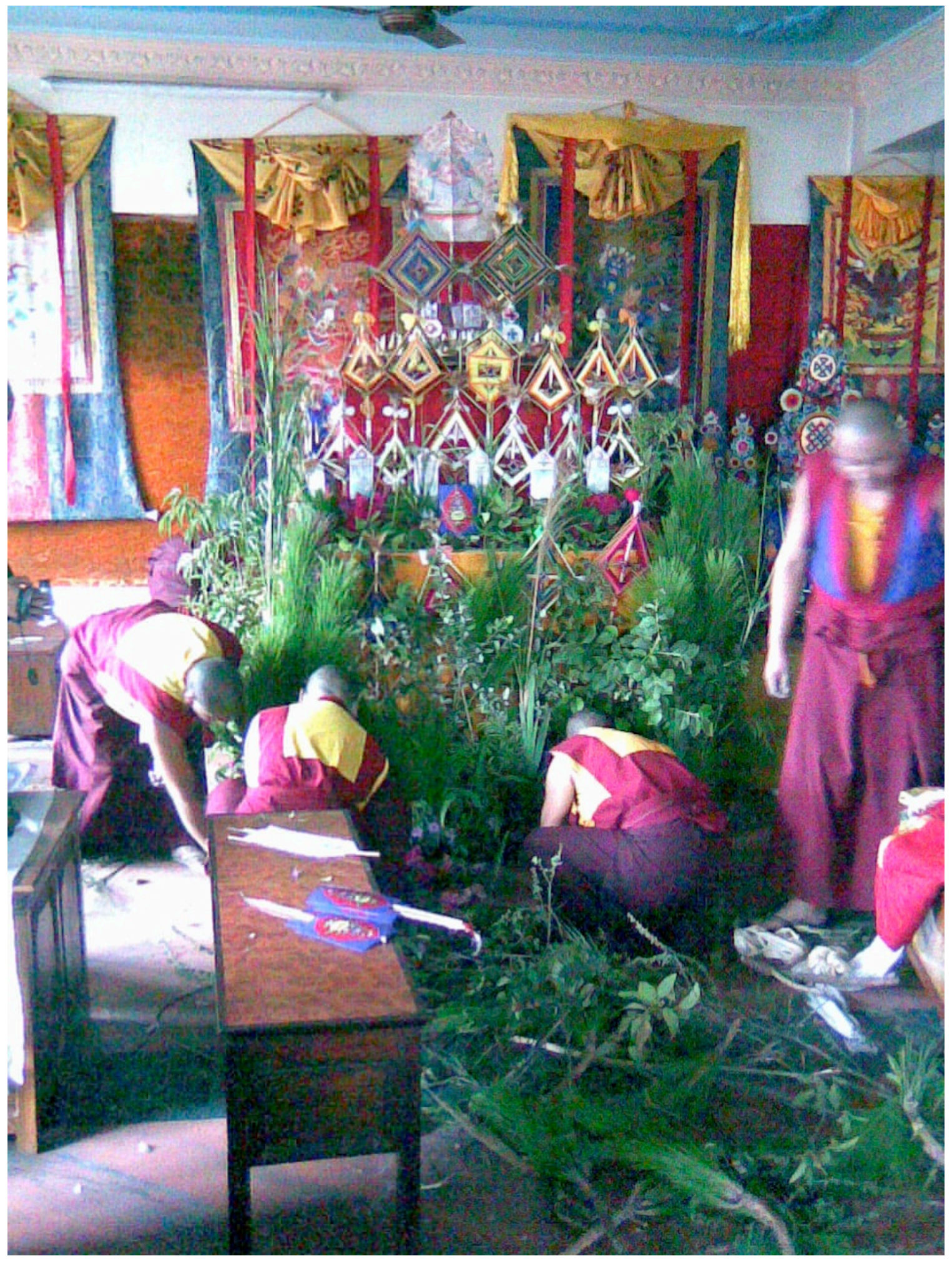

Figure 2.10: Assembling the dö in the assembly hall. 


\section{Explanations}

All calendared rituals require a thorough cleaning of the monastery grounds and of monks before getting underway, and outside, as the dö is being put together, young monks can be seen around every corner, wiping down assembly hall windowpanes, polishing lamps, and sweeping walkways. In front of the bathroom shack, two monks sit on wooden chairs as if at a barbershop, with their heads covered to varying degrees by shaving cream, and two monks above them wielding straight razors.

The palpable excitement - or at least intense absorption - that characterized the final stages of the preparatory work begins to subside now, giving way to the more routine demands of monastery life, tying up odds and ends before the ritual itself begins tomorrow, before dawn. Throughout the day, and now, in the very brief downtime before dinner, a number of monks offer a great diversity of explanations for the purpose of the ritual. As one monk outside the assembly hall works large blocks of dark gray silty clay into smaller, more manageable fist-sized pieces, he explains that this ritual is for the lu, to urge them to make it rain, which is important for farmers. A monk and friend named Tenpa Dargyé (bstan pa dar rgyas) says that the purpose of the ritual is to bring luck and fortune to benefactors. Indeed, another monk says nothing more than that it is for the benefit of lay people. A few say that it heals sick people. Others answer that it is to send away the lu so that they do not cause problems. I ask who and where these lay people and sick people are, to which monks shrug, wave generically outwards, or, in most cases, say, "Tibet." The 
disciplinarian and a number of other monks explain that the Nyelam Dé Zhi is an annual opportunity for everyone - including and especially the earthly sadak and lu deities, but extending out to all sentient beings - to come together and apologize to each other for any wrongdoings, to promise to do better for the coming year, and to request that no harm be done to anyone. "It's a nice explanation, isn't it?" he says with a smile. At least a half-dozen monks say they do not know why they do it, or they redirect my questions to Tenzin Tsultrim or Tenzin Namdak, or, as my videographer assistant says, "I just go because Rinpoché says we have to." Tenzin Tsultrim, who has become accustomed to these kinds of questions and, perhaps, to the kinds of answers that I most respond to, says that they do it because it is tradition and people will be upset if they do not. When asked about the particular people who would be upset, he responds, "Everyone." Of all the answers, it is the disciplinarian's that matches most directly with that "translation" of the event name given in the 2009-2010 monastery calendar of events: "Ritual and practice to harmonize and purify all the spirits of the universe."

A great many monks echo these sentiments and more, such that it becomes clear that different aspects of the ritual resonate in different ways with different monks, and that there is a conspicuous lack of consensus among actors about the reasons why they do it. 


\section{Recitation}

At 4:30am on the first day of recitation, conch horn ${ }^{93}$ blasts fire from the roof of the main temple. Normally the two monks blowing the horns would be visible, but this morning there is a thick shroud of fog hugging the hill, obscuring one monastery building from the next. Bleary-eyed monks stroll and then hurry to the assembly hall with wrapped pechas in hand and find their places among the four rows,,$^{94}$ or at the perimeter, against the walls. The recitation leader is at his drum at the front left of the dö, and geshés take other privileged positions close to the dö and altars. The disciplinarian sits on his elevated mat at the back of the room, by the door, overlooking the rank and file. Tenzin Tsultrim, Tenzin Namdak, Khenpo, and Pönlop are not in attendance. In total silence, all the monks settle into their cushions, adjust the pecha pages from the various required texts, ${ }^{95}$ and pull their robes up and over their shoulders against the chilly morning air. They stare out the windows, yawn, rub their eyes, and otherwise fight the lingering fatigue as they wait for everyone to get situated, and for the recitation leader to give them their cue.

Promptly at 5:00am, that cue arrives in the form of a deep droning intonation from the recitation leader. His amplified voice bellows through the assembly hall over a speaker system, and all except several monks at the perimeter - tasked with reading, and, to the extent possible, silently reciting, the Lubum, Sadakbum,

\footnotetext{
93 The conch horns are generally known as dungkar (dung dkar) or chödung (chos dung), though some monks called them Böndung (bon dung).

${ }^{94}$ The assembly hall currently has two single rows of monks along the side walls and then two double rows - with monks back to back - down the middle of the room.

${ }_{95}$ Before beginning the recitation, monks read the Manuscript - or are instructed by those who have - to see what texts are needed and how to stagger them so that they can smoothly follow along with the recitation leader, in and out and back again from text and text.
} 
Nyenbum, and Töbum - join in, slowly and erratically at first, and then all together.

With the initial tone set, the recitation begins in earnest.

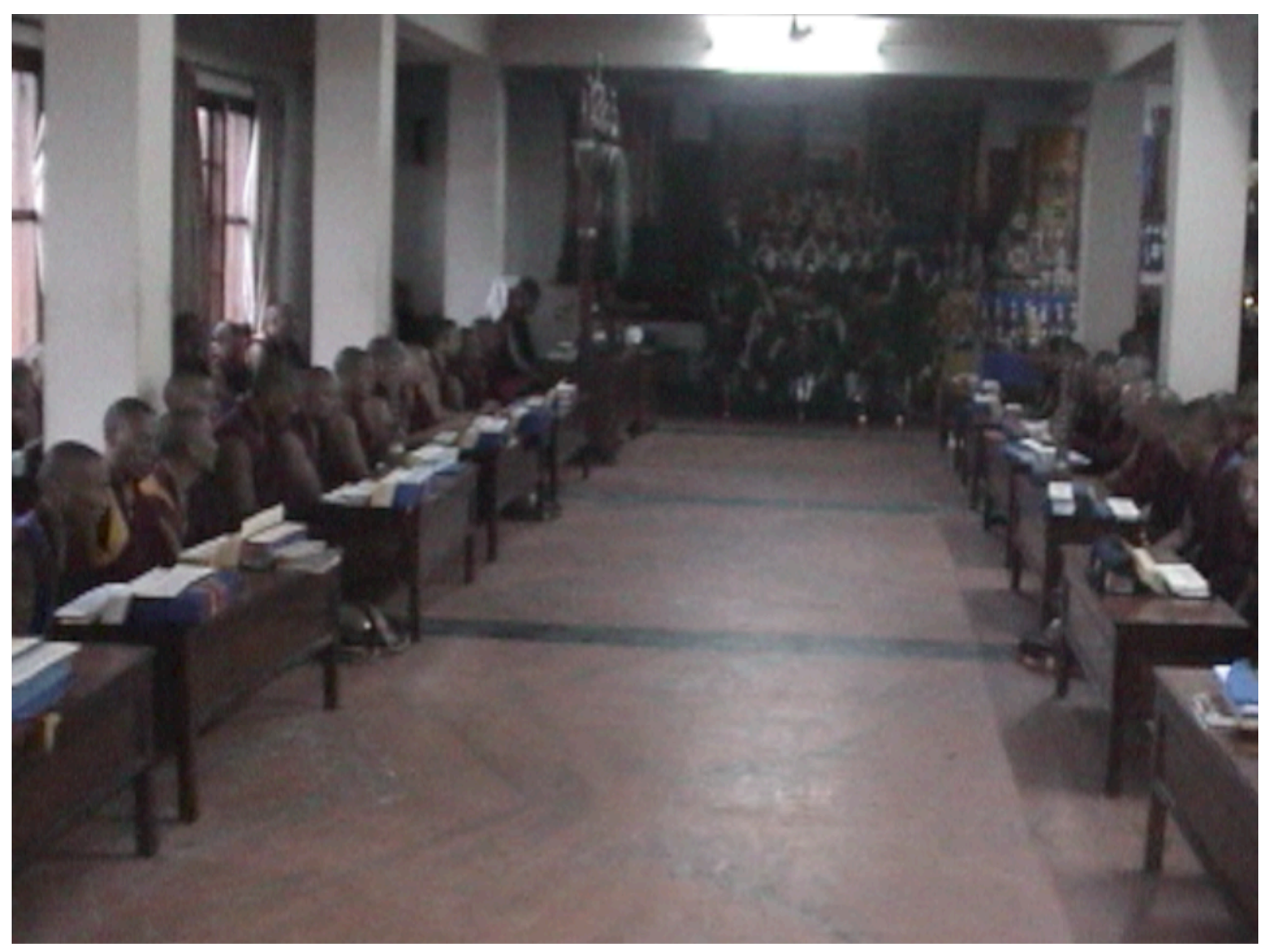

Figure 2.11: Early morning recitation in the assembly hall, with dö at front center.

Before anything else can be done, monks perform the purificatory rites that precede the principle liturgy in virtually all rituals: ${ }^{96}$ the "removal of poison" ( $d u g$ phyung) rite, using "poisonous" smoke and ash to drive away wicked spirits and otherwise purify the environment, ${ }^{97}$ ablution, and fumigation. The first of these entails the master of offerings (mchod dpon) putting poisonous herbs into a ladle,

\footnotetext{
${ }^{96}$ I observed this to be the case in all major rituals I observed at Menri and Triten Norbutsé, and it is confirmed by Karmay, 1998, p. 142.

${ }^{97}$ Monks gave predictably different explanations for what it was that was being purified - generic demons, "the yé (ye) that send misfortune" (which accords with the Manuscript), impurities in the ritual implements, bad thoughts, and more. Note also that the way this rite is understood and performed appears to be different in some respects from that described by Karmay, 1998, p. 142, which is in the context of a household ritual.
} 
burning them, and then carrying the ladle around the assembly hall. The burning poison is supposed to draw or cast out the poisons and impurities of the space, implements, monks, and so on. After making a round of the room, the poison is taken outside and discarded. For ablution, the master of offerings uses a "sprinkler" made of kuśa grass that looks like a hand broom. ${ }^{98}$ He dips it in lustral water (chab) and flicks it in the direction of the altars, dö, monks, and implements, sending droplets of water flying. For fumigation (bsang), there are two kinds: The first and most effective involves the master of offerings igniting a bowl of juniper incense at the end of a long chain and swinging it back and forth as he walks up and down the aisles and past the dö and altars. This method produces so much fragrant smoke that the entirety of the assembly hall becomes hazy, and near the windows there are sunlit walls of swirling smoke that make it difficult to see the monks a few yards away. The master of offerings also lights incense sticks (spos) and gradually makes his way around the room, waving them briskly back and forth in a "U" shape over the monks, mats, pechas, and instruments. ${ }^{99}$

\footnotetext{
${ }^{98}$ I use the word "sprinkler" because there is no agreed-upon Tibetan word for it or other more precise way to describe this implement, and Beyer uses it in his descriptions of the same (see Beyer, 1978, pp. 179, 266, 269, 271, 410, 415). There is also no Tibetan word known to my interviewees for the grass of which the sprinkler is constructed. They all use the Sanskrit/Hind word kuśa, which is the name of the grass. The texts have no explicit instructions about what kind of implement is to be used - a dynamic discussed in more detail in chapter four - leaving communities to use whatever ablutionary tool is most convenient and effective. The kuśa sprinkler is the most common, but they may use, for example, peacock feathers or a bundle of leaves.

${ }^{99}$ The fumigation rite generally calls for just swinging the sang (bsang), but the pö (spos) incense sticks brings additional purificatory power. In other contexts, the pö may stand in for sang because they are cheaper and easier to procure and deploy.
} 


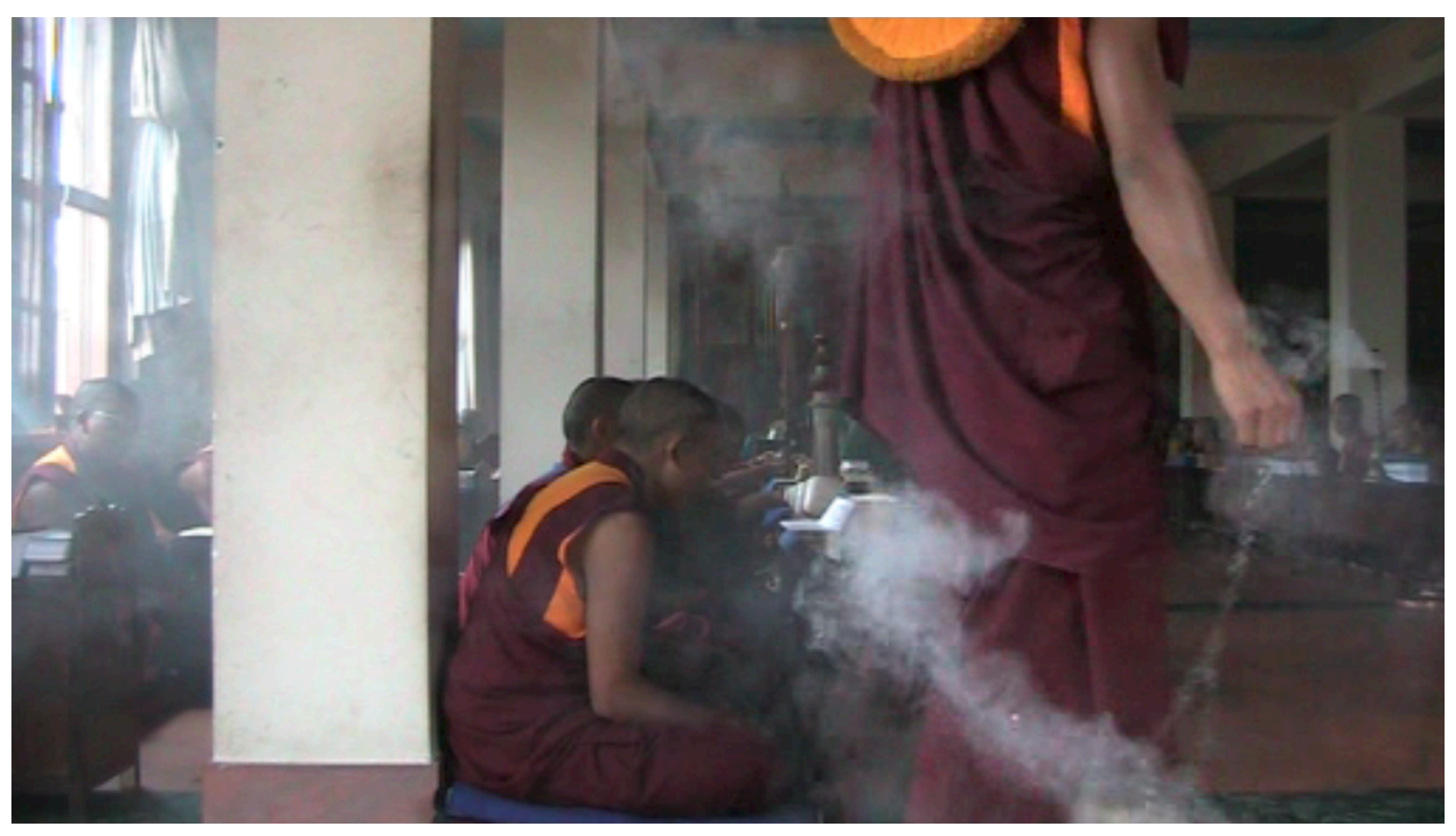

Figure 2.12: Fumigation of the assembly hall.

Meanwhile, the rest of the monks recite the verses in the dug phyung volume of the Nyelam Dé Zhi collection, and the ablution and fumigation rites from the rnam dag text that they have interspersed with their Nyelam Dé Zhi pages, though many do not need to look at the rnam dag verses because they are short and used in every ritual, and thus most monks have memorized them. Many of the monks, especially the geshés and elders, perform the mudra hand gestures that accompany these rites, the verses and mantras, in order to "seal" them. ${ }^{100}$

Next comes the earth ritual ( $s a$ chog), which is also common to many rituals but not as common as the preceding three rites. ${ }^{101}$ The master of offerings scatters

\footnotetext{
100 Younger monks often do not do these mudras, presumably because they have not yet learned how to do them.

${ }^{101}$ For more on the sachok ritual, see Cantwell, 2005; Gardner, 2006; Bentor, 1996, p. xxi; Gyatso, 1979, pp. 73-75; mkhas grub rje 1968, pp. 278-285. Note that these generally discuss the ritual from the Buddhist perspective, but it is not within this project's scope to compare Bönpo and Buddhist versions of the same ritual.
} 
"golden beverage"102 and the monks recite both from the earth ritual (sa chog) verses in the Upper Ritual volume of the Nyelam Dé Zhi, ${ }^{103}$ and from the more generic earth ritual section of Expansive Space, sealing them with "A dkar sa le 'od" and other mantras. Though a number of the monks may not understand the content of the recitation - a dynamic discussed at length in the chapters that follow - they are offering "golden beverage" as well as generic confessions of guilt to the lu, nyen, sadak, tö, and all the spirits of the land and elements, for the sake of clearing away obstacles, bringing fortune and prosperity, and generally harmonizing with, and harnessing the power of, the land. These recitations are accompanied by the offering of a particular kind of torma as a gift to the lords of the ground. ${ }^{104}$

The monks then recite the blessing (byin brlabs) from Expansive Space, and then the byur phud misfortune-sending rite of the Nyelam Dé Zhi, for which they had constructed the unique lüyé (glud yas) torma covered in red, along with a full plate of pungent and burnt offerings, described above. ${ }^{105}$ The recitation includes selfinstructive declarations that they are visualizing a substantial offering of lenchak (lan chags) tormas ${ }^{106}$ as certain powerful subjugatory figures - Lu Bön Yarnya ${ }^{107}$ or Yeshé Nyingpo, ${ }^{108}$ with Tönpa Shenrap at the heart and a garuda at the crown. ${ }^{109}$ Of

\footnotetext{
102 Serkyem (gser skyems) "golden beverage" is a frequently employed means of ritual purification and offering, usually just chang, but tea works as a substitute if chang is not available.

103 See pages 113.1-118.4.

${ }^{104}$ gzhi bdag, the "lords of the ground." This is a general term that, depending on who you ask, may or may not include the sadak, lu, and the others.

105 See figure 2.13 below.

106 These are a type of torma shaped like a spine by squeezing a segment of dough inside a fist. They are very often used as ransoms for lower spirits.

107 klu bon dbyar snya (89.2). Not much about this deity is known, aside from his being a subjugator of spirits - see the mdo 'dus volume (W21872-6170) of the Kangyur, p. 54.4, with context in the preceding two pages, though in this case the name is klu bon dbyar snyen. 108 ye shes snying po, short for klu bon ye shes snying po, the greatest lu king.
} 
course, it is impossible to observe who is undertaking the visualization and who is not, but it will become quite clear later, when some monks admit to not doing it, or to not understanding the text, and so on. Regardless, it is a short recitation, consisting of a few pages of prose, followed by the ejection of the lüyé and plate of odious materials from the assembly hall. Monks explaining this rite later take care to explain that the lüyé is not simply "thrown" or "discarded," however. The master of offerings places it carefully in a location out of sight of the assembly hall.

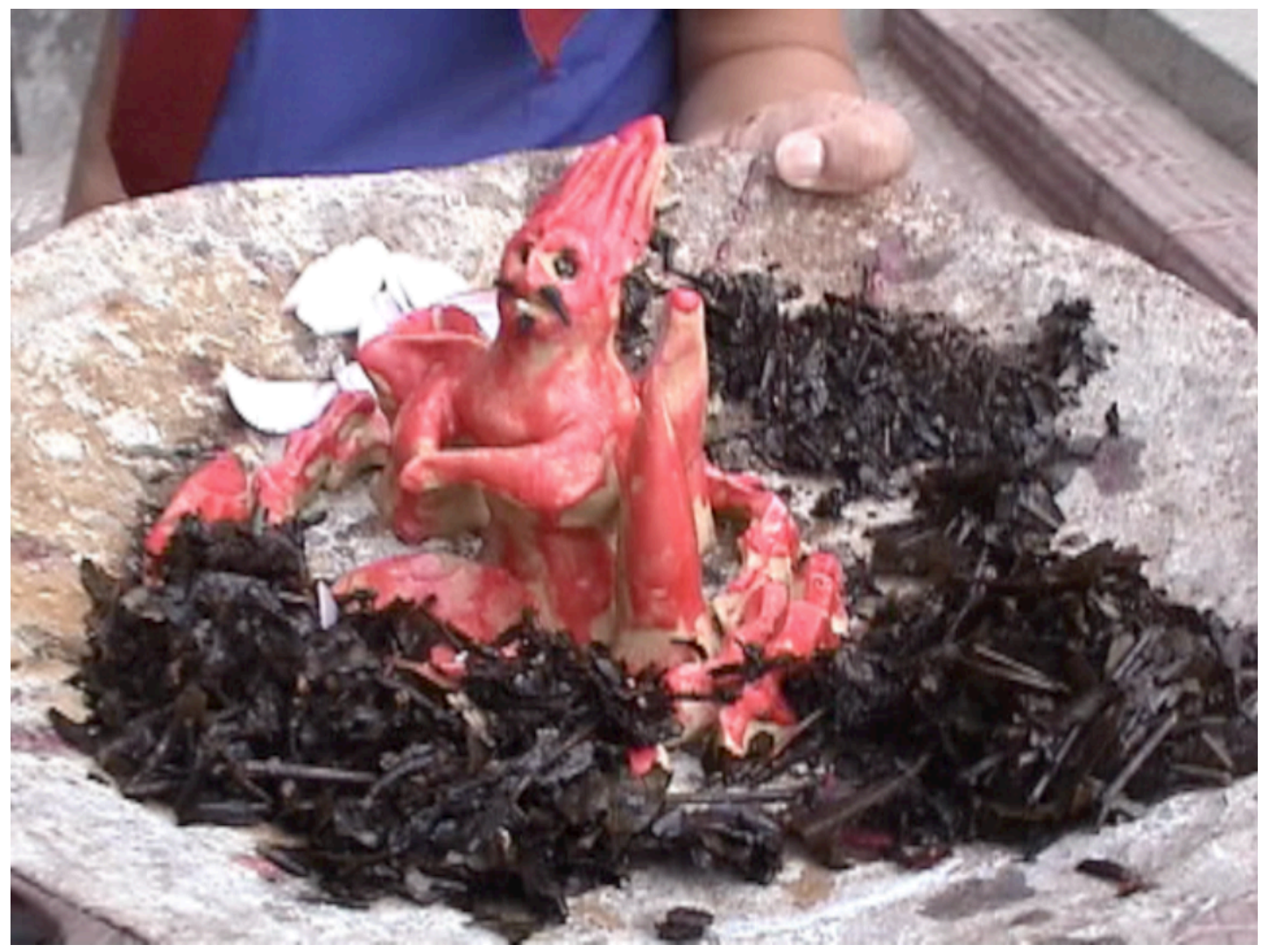

Figure 2.13: Special lüyé torma and pungent substances for Misfortune Sending.

At this point, the monks recite another rite from Expansive Space that is common to every ritual performance, the setting of boundaries (mtshams bcad). As

109 bdag nyid klu bon dbang dbyar snya 'am// ye shes snying po thugs kar ston pa gshen rab bsgoms// spyi gtsug bya khyung bskyed// (89.2-3) 
with many of these trans-ritual rites, there are five constituent components, all of which set boundaries in different ways: the performance of mudras (phyag rgya); the recitation of "essence" mantras (snying po); the placement of boundary-making materials (rdzas) like daggers (ral gri) in the four primary directions, arrows ( $m d a$ ) in the four intermediate directions, and victory banners (rgyal mtshan) above and below; the recitation of verses (tshig bshad) that narrate the process and desired effects of boundary-setting; and finally a kind of meditative absorption that commonly involves visualization of implements and actions (ting nge 'dzin), starting with equation of the materials in the ten directions - primary, intermediate, up, and down - with the ten wrathful ones (khro bo bcu), accompanied by the beating of the drum, the ringing of the shang (shang), the scattering of evergreen needles (mtshe), ${ }^{110}$ and the recitation of mantras. Again, many monks conspicuously, in the case of mudras, and inconspicuously, in the case of contemplation, undertake these component rites, and many do not.

Following boundary-setting are the recitations associated with preparing the ground for the dö and purifying and empowering the principle ritual implements, the mandala in particular. Some of these recitations that are supposed to be done while preparations are being made have indeed already been performed in isolation during the construction of the dö, but others - for example, those that are to accompany the creation of the mandala - are only performed now. Recitations anachronistically describe the casting of the various lines of the mandala,

110 This appears to be the Ephedra plant. See Karmay, 1998, p. 341 and his sources. 
connecting each of them and the mechanics of their rendering with deities, ${ }^{111}$

requesting that everything be distinct (lhang nge), bright (lham me), and stable

(brtan po), dedicating them to the benefit of patrons, ${ }^{112}$ and so on. Flipping back and

forth between Expansive Space and the Upper Ritual volume of the Nyelam Dé Zhi,

monks use the same five sub-rites as with boundary-setting and many other rites:

mudras; an essence mantra repeated four times; ${ }^{113}$ materials like incense (spos),

clean water (gtsang chu), foliage ( $m$ tshe), and a vase; recited verses imploring

deities to reside in the implements and help stabilize and clarify the mandala and

meditation and so on;114 and meditation/visualization. The recited verses for the

rest of the ritual implements and preparations are anachronistic, declaring that they

will make offerings and otherwise make use of these prepared ritual implements

and spaces the following morning, and thus request deities to reside in them

"tonight."115

111 The basic connections of types of lines with deities are made, for example, with "the [plumb] line of the emanation of Sangpo Bumtri" (128.9, sangs po 'bum khri'i sprul pa'i thig/) and "the [boundary] line of the emanation of Chuchak Gyelmo" (129.1, chu lcags rgyal mo sprul pa'i thig/), while the mechanics are connected to deities, for example, with "The various lines are pulled by Lucham Karmo and planted by LuBön Yeshé [Nyingpo]" (129.3, thig sna klu lcam dkar mos 'then/ btab ni klu bon ye shes $b t a b /$ ).

112 don ni yon bdag bkra shis don/ (131.5-132.1) is one of many examples.

${ }^{113} \mathrm{~A}$ he ho mu ling ling spros pa 'od dpag mu rgyas bdal khyab gsal

114 The recitation is quite extensive for the preparations compared to other sub-rites of Expansive Space.

115 For example, "In order to counteract the causes of obstacles/ of myself, the patrons, and all sentient beings/ And to augment lifespan, merit, and progeny/ [We] will make offerings in the morning to purify the obstructions [of] all sentient beings/ Please reside in [these] preliminary ritual preparations tonight (bdag dang yon bdag sems can thams cad kyi/ bar chad rkyen rnams bzlog pa dang / tshe dang bsod nams chung srid spel ba'i phyir/ nang par sems can sgrib sbyang mchod 'bul gyis/do nub sta bon la ni bzhugs su gsol/). There is some important debate over whether nang par and do nub literally means "in the morning" and "tonight" or metaphorically refers to "the future" and "the present." For more on this, see chapter four. This phenomenon of divorced action and recitation is not uncommon among modern institutional ritual performances in exile, with some going as far as creating a proto-mandala, with nothing but strings on a board, that a ritual actor will engage, during the relevant recitation, with a series of pantomimes that mimic the actual mandala construction, but here the monks merely recite the verses. 
The recitation of essence mantras and verses to the four principle deities the sadak, lu, nyen, and tö - as well as the four chief subduers ('dul dpon bzhi) and the garudas that subdued the four deities is the first of many rites that will be repeated every day for the remainder of the ritual performance. These mantras, which are encoded invocations and exhortations to the deities to join the proceedings, to listen, to act, to empower, or simply to be pleased, are repeated thousands of times over the course of the ritual. ${ }^{116}$ For every two mantras that are recited, the master of offerings (mchod dpon) blows on grains of rice and other offerings and ritual implements and substances to imbue them with the power of the mantras. ${ }^{117}$

A few first-day preliminaries remain, which the monks undertake with ease, as they are again so common to the variety of ritual performances throughout the year. These include the vase ornamentation and binding, different in the Nyelam Dé Zhi only in the targeting of the dedications - in addition to the four Ones Gone to Bliss, it addresses the four chief subduers and garudas and sadak, lu, nyen, and tö. The recitations dedicate certain offerings, "indivisible from the body" (sku dang gnyis su med) of each of these deities, as the contents of the vase, ${ }^{118}$ which is then

\footnotetext{
116 Each monk in the assembly hall reciting a mantra once counts as one recitation. If there were 100 monks in the assembly hall, all of them reciting the mantra once in unison would count as 100 recitations.

117 I did not observe this but a geshé described the practice to me and later pointed me to the relevant instructions in the Manuscript: snying po len gnyis re sngags (23.2), with snying po referring to the actual mantra and sngags referring, in this case, to this practice of "charming" substances with the mantras, as in sngags chu.

118 The four chief subduers are equated with that which is endowed with the five good qualities and the five grains (yon tan Inga ldan 'bru Inga), the garudas with grasses, mustard seeds, and fragrant powder ( $m$ tshe nyungs phur ma), the lu with clean water and ambrosial white milk (chu gtsang 'o $d k a r$ bdud rtsi), nyen with the completely pure essence mantras and five-fold offering (yang dag snying po rnam lnga), tö with that which possesses the five kinds of precious silk (rin chen dar sna
} 
visualized at the center of the mandala as the first step in installing them there, which itself is unlike some of the other rituals of similar scale in that this "incomparable palace of the gods" (lha yi gzhal yas khang) is constructed and connected with requests for specific worldly benefits that will reappear again and again during the Nyelam Dé Zhi: long life (tshe), wealth (nor), cha and yang (phywa g.yang), ${ }^{119}$ children generally (chung srid), and especially male children (rtsa dkar).

Following this, the monks undertake a variety of additional preliminaries, including the generic seven-branch practice, ${ }^{120}$ the Nyelam Dé Zhi-specific preliminary prostrations, confessions, and offerings, and then the more generic going for refuge, "downward offerings,"121 the scattering of grain and flowers and mustard seeds and such, together with the recitation of accompanying mantras. ${ }^{122}$ Offerings and the vase are bolstered or created with contemplative and visualization practices: Clear realization (mngon rtogs), front-generation (mdun bskyed), and selfgeneration (bdag bskyed), all of which have clear mantric and recitational bases

\footnotetext{
Inga ldan), and sadak with the self-arisen wood of the wish-fulfilling tree (dpag bsam ljon shing rang 'byung).

119 These two are especially common throughout the Nyelam Dé Zhi, and there is in fact a volume dedicated to them, the Beckoning of Fortune (g.yang 'bod). The words themselves can be difficult to translate. Tenzin Tsultrim and others defined them not as wealth and property but as the "essence" of these things, though they disclaimed their definitions as insufficient. Bellezza, 2005 (p. 420n6) defines phywa as "the general state or basis of good fortune," and g.yang as "the capability or fortune potential of individuals and sacred objects." For much more detailed information, see karma lha 'brug rgyal, 1996.

120 The seven branch practice (yan lag bdun) is comprised of: 1) prostration (phyag 'tshal ba'i yan lag), 2) offering (mchod pa'i yan lag), 3) confession (bshags pa'i yan lag), 4) rejoicing (rjes su yi rang ba'i yan lag), 5) requesting teachings [from the enlightened ones] (bon kyi 'khor lo bskor bar bskul ba' $i$ yan lag), 6) praying for those still suffering (mya ngan las mi 'da' bar gsol ba gdab pa'i yan lag), 7) dedicating merit to the enlightenment of all sentient beings (dge ba rdzogs byang du bsngo ba'i yan $\mathrm{lag}$ ). Most monks will have occasion to do this preliminary practice virtually every day of their careers.

${ }^{121}$ See below for more information about this.

122 The downward offering and what follows are somewhat generic, done across rituals, from Expansive Space.
} 
suggestive of the practices but no externally performable components, except when accompanied by mudra seals.

When all the preparations of the environment and implements and vessels and performers have been completed, it is time to invite the presiding and subduing deities into the vessels and request that they remain through the proceedings. Monks invite the four Ones Gone to Bliss first, addressing them and all of their retinue, beseeching them to come from their divine abodes and join the proceedings for the benefit of all sentient beings, but the focus of most of these recitations is the four chief subduers, and to a lesser extent the four subduing garudas. The eight of them, and all of their retinue, are invited via recitations similar to the Ones Gone to Bliss. With these powerful deities in place, the lu, sadak, nyen, and tö are invited according to specific instructions in individual volumes dedicated to each of them. They are called en masse and by name, ${ }^{123}$ requested to come with good intentions to help create favorable outcomes for everyone, helping to remove afflictions and diseases, augmenting longevity, merit, and the potential for male children for any benefactors, and leaving their malice and illness and so on behind.

To complete the installation of these sixteen guests - the four Ones Gone to Bliss, the four chief subduers, the four garudas, and the lu, sadak, nyen, and tö - the monks undertake eight additional rites highly standardized across rituals: Requesting that they remain (bzhugs su gsol), producing delight (dgyes pa bskyed), paying homage (phyags rtsal lo), confessing misdeeds (sdig pa bshags), making offerings (mchod pa 'bul), reciting essence mantras (snying po drang), praising them

123 They call illustrious members of the individual deity communities, usually kings who have control over the larger populations. 
(sku bstod), and enjoining enlightened activity (phrin las bcol). Unlike other rituals, however, that generally limit the confession sub-rite to the more genericized instructions in Expansive Space, which directs confessions to higher deities, and possibly accompanied by some more targeted confessional verses in the ritual's principle liturgical text, the monks performing the NDLZ add to this an entire volume of verses dedicated to confession, focused primarily on the sadak, lu, nyen, and tö. The rest of the rites also have Nyelam Dé Zhi-specific verses and activities, all of which implore the worldly deities to bring fortune in the form of (male) children and cha and yang and favorable weather and so on, sending away illness and bad omens and curses and unfavorable weather, converting to good the wickedness in enemies and graveyards and corrupted funereal rites (dur gyi cho 'phrul ngan pa),124 and so on.

The Beckoning of Fortune (g.yang 'bod) rites are next, for which the monks had prepared the wood drawings depicting various animals, arrows and spindles, and other symbols, as well as highly decorative tormas, many of them also depicting animals like yaks and deer. For the sake of increasing cha and yang for and bestowing other powers on practitioners and benefactors, they call out to the sixteen guests, as well as to the protector deities of the years (lo lha dpal mgon) and a host of other deities in these principle deities' retinues or otherwise capable of influencing cha and yang. They offer incense, the arrows with lamb's fleece and streamers, the various animals and greenery - all the plush materials arrayed

\footnotetext{
124 This last one is an interesting and perhaps unexpected addition to the list. Nyima Özer explains that funeral rites are susceptible to being intercepted by wicked spirits, who can then cause a variety of problems.
} 
around the dö and altars. The recitation of these verses are noticeably different from all of the others, calling out frequently with "Kuyé!" (khu ye), incorporating onomatopoeic words and expressions like kyi li li, ga ra ra, pung sé pung, and u ru ru, ${ }^{125}$ and making constant reference to samadrok (sa ma 'brog) ${ }^{126}$ concerns and materials - cattle and sheep and other livestock, grain and abundant wealth, arrows and armor and so on.

The last rite of the preliminary segment of the ritual, but one that is repeated often throughout the remainder of the Nyelam Dé Zhi, as well as in the daily lives of the performers throughout the year, is the aspiration prayer (smon lam). Less than a minute's worth of verses, it recapitulates the preceding rites and emphasizes requests and hopes that obscurations and obstacles and afflictions of the monks and benefactors will be purified or reversed.

After the aspiration prayer, the monks have accomplished the preparatory, first-day recitational rites, and what follows, and in fact much of what they have already done, reconfigured, will be repeated to some extent every day for the remainder of the ritual performance. There will be no more of the generic rites from supplementary texts ${ }^{127}$ - at least, not until the last day - and rites like the Drawing of Poison (dug phyung) and Misfortune Sending (byur phud) are done only at the

\footnotetext{
125 kyi li li means "spinning around and around." There is some debate about ga ra ra, with Bellezza suggesting that it is the sound of drala (sgra bla) warriors on the move (2008, p. 386n55), while Yungdrung Mönlam explains that it is the sound of moving around in a figure-eight (Interview at Menri monastery on 5/12/2009). dpungs se dpungs is the sound of things billowing. u ru ru can refer to the sound of wind or water, but in the context of the Beckoning of Fortune it describes the sound of cascades of grain and precious metals.

126 Translating roughly as "neither agriculture nor pasture," this refers to the common Tibetan lifestyle of nomads who also cultivate land.

127 There is, however, a series of preliminaries associated with "outer tantra" (phyi rgyud), like the mandala branch practice, that does not come from the Nyelam Dé Zhi, which monks are expected to know.
} 
beginning of the ritual, on the first day, but much of the rest of what they have already performed from the Nyelam Dé Zhi verses will be performed again, sometimes multiple times per day, in order to reach the goal of 1,000 times for each of the Ones Gone to Bliss, chief subduers, and subduing garudas, and 100,000 times for each of the sadak, lu, nyen, and tö. These repeated rites include the boundarysetting, generating meditative absorption, invocation, requesting deities to remain, producing delight, confession, offerings, essence mantras, praise, enjoining enlightened activity, beckoning fortune, and aspiration prayers.

In the days that follow, the monks in the periphery of the assembly hall will continue silently to recite the 'bum texts, while the rest of the monks repeat the same verses in order to achieve the many thousands of individual recitations required by the ritual instructions. They often recite without interstice for two hours or more, when they take a five-minute break for bananas and bread and tea, or a couple of hours for lunch and to tend to other responsibilities. Breaks are entirely quiet, except for the sounds of mass mastication. The performance continues throughout the day until five o'clock, a total of twelve hours, including the breaks. It is the same every day for the four days of performance. 


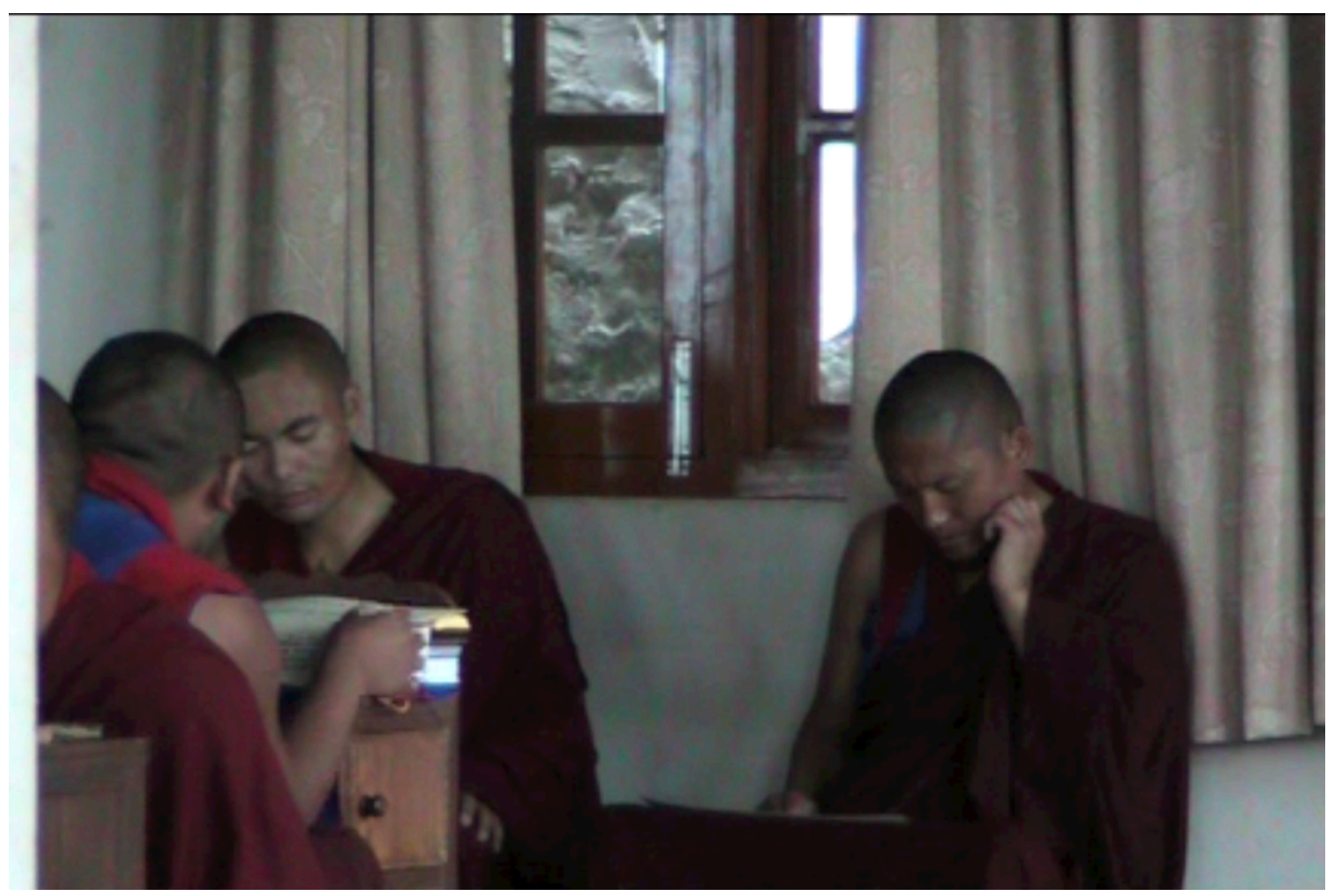

Figure 2.14: Reciting the 'bum volumes silently at the periphery.

On the last day, however, there are new concluding rites to be performed.

Additional confessions are made, both generic and specific to the Nyelam Dé Zhi, reiterating prior confessions and also addressing any offenses made in the course of the ritual performance itself. As the master of offerings walks up and down the aisles swinging the bowl of smoking juniper, monks recite the substantial smoke offering of the Nyelam Dé Zhi, before performing the Beckoning of Fortune rites one last time. All remaining offerings are dedicated to the guests, who are then sent away (skyod pa) as the master of offerings, with some assistants, begins to carry tormas, thread crosses, greenery, and other implements out in the four directions, to the trickle of water draining out of a pipe below the monastery for the lu, to a patch of ground by the monastery for the sadak, to the woods behind the monastery for 
the nyen, and to an outcropping of small rocks nearby for the tö. The higher deities like the Ones Gone to Bliss are requested to go via generic verses that are common to all comparable rituals. The sadak, lu, nyen, and tö are then sent, with the different bands of lu (according to their kings) being dispatched in the different directions, according to whence they came, and the sadak, nyen, and tö, in less detail, being sent back to their respective abodes. The language is courteous at first (skyod pa is considered a polite conveyance), but becomes more forceful as the rite proceeds (gshegs cig). The monks then address the sand mandiala that has been the "seat" of the deities throughout the ritual, again starting with a generic sending away of the higher deities from their seats, and then calling out each of the seed syllables for the specific deities of the Nyelam Dé Zhi, saying over and again that this mandala has been a momentary (skad cig ma), impermanent (mi rtag) seat and that the deities should vacate it. The master of offerings and a number of the monks throw grain and recite the generic and specific auspicious (bkra shis) verses, acknowledging that anything auspicious that happened as a result of the presence of the divine guests and the proceedings is welcome, but also declaring that the specific enjoinders to the deities shall be done. Finally, the recitation is concluded with aspiration and dedication (sgo dbye dbang bskur smon lam) prayers that dedicate all rites to the benefit of practitioners, patrons, and all sentient beings.

On this last day of recitation, the tone and consistency of voices, often wavering with fatigue over the course of the four days, normalizes and strengthens to greet the end of the event. One twelve-year-old monk, who had been gazing out the window, joking with friends, or otherwise less participant than the others much 
of the last three days, is now belting out the recitations at full volume, such that outside the temple one can hear his voice over all others.

When the recitation finally ends, monks energetically launch from their mats and begin deconstruction of the temple. Any remaining crafted implements and greenery and mud are removed from the dö and returned to earth, stored, or discarded. The mandala is carefully lifted off the top platform and carried into another shrine and kept for a while - no one seems to know why, including Tenzin Tsultrim, and there is much disagreement about how long it will remain there. Piece by piece, the dö comes apart, until there is only a scattering of grain and other ritual materials strewn across the floor. Two monks with grass and horse-hair brooms hunch over and diligently sweep everything out the door or into hands. Around the monastic grounds there is a palpable sense of levity and contentment, with an initially unclear provenance. Is it from a feeling of a job well-done, observed positive outcomes, simple relief that it is over? Over coming days, weeks, and months, this will start to become clearer.

The ritual steps and recitations described above are generally clear enough when one reads the texts of the Nyelam Dé Zhi and follows along closely, or when one has much experience observing the ritual or other rituals with similar elements. For outside observers, and even for many monks, the commonality of recitation strategies and accompanying rites means that following along with texts is the only or best way to distinguish one particular liturgy from the next, one hour from the next, one day from the next. The recitation leader and some older monks and geshés know, for example, that only the first day of the recitation includes Drawing of 
Poison and Misfortune Sending, and only the last day includes aspiration and dedication prayers and sending away. All or most monks recognize the auspicious rites on the last day, by the recognizable language or at minimum by the telltale showering of rice. All or most of them know that at some point during the recitation the deities being addressed come to reside in the mandala and then vacate it. But to the casual observer and a great many of the monks, who admit that they do not understand much of what they're reciting, it appears to be one long, fairly uniform liturgy. There are some variations in tone and melody based on the content of the recitation, but most of it is not specific to the Nyelam Dé Zhi or rituals of its type - it is "great ritual language" (chog chen skad). ${ }^{128}$ Rites are occasionally accompanied by and delineated with instrumentation - the conch horns, long horns (dung chen), gyaling (rgya gling, trumpet or clarinet-like instrument), both the larger rölmo (rol $m o$ ) and smaller shang cymbals, and of course the drum (rnga chen) - which do provide some punctuation to this otherwise long sentence, as does the activity of the master of offerings, who is in near-constant motion, taking tormas, the mandal "cake," the "golden beverage" (gser skyems), and other offerings to and from the altar, in and out of the assembly hall, prostrating as he comes and goes, but otherwise there is a constancy to the proceedings that borders on drudgery. At various times throughout the day, every day, a number of monks fall asleep, stop reciting, goof around, and so forth. Some monks, typically the geshés or older monks or those with other jobs at the monastery, stay only for the morning segment of the recitation. Some geshés, and all of the ranking members of the

128 I say "most" because there was some debate among monks about whether there was a particular melody for outer ritual, and "great ritual language" sounds overly generic. 
community - Tenzin Tsultrim, Tenzin Namdak, Khenpo, and Pönlop - do not attend at any time. Most of them have other work to tend to, though Tenzin Tsultrim repeatedly offered to meet during recitation hours because he said he would have much more free time then. When asked why he did not attend a ritual for which he is the chief administrator, he smiled and responded, "Lazy."129

It is ostensibly up to the disciplinarian to approve or deny absences in the afternoon or at any other point during the recitation, and at his discretion he polices misbehavior in the temple. Every disciplinarian at every monastery is different, and to an extent different rituals have different requirements, but in this case Mönlam Wangyel does not wake up sleeping monks or stop others from joking around. This is in marked contrast to the behavior of, for example, the two disciplinarians at Menri at every ritual I witnessed. Monks do occasionally look over at him and at the video camera if others around them are being especially demonstrative in their talking and joking. Presumably the disciplinarian would reprimand them if they became truly disruptive or otherwise went on too long, but for the most part they do not check for his judgment and he ignores them. At one point during a break, the disciplinarian steps out of the assembly hall, and three young monks begin to talk loudly, alternating between anger and laughter. It escalates and the three of them get up and quickly exit the assembly hall, punching each other (playfully?) as they go.

\footnotetext{
${ }^{129}$ I received this answer many times from him, asking in Tibetan and English, and even asked if he thought this was the answer I should give in my "book." He just smiled and repeated himself, "Yes, lazy."
} 
Despite the lack of explicit disapproval from Mönlam Wangyel, however, a number of monks ask later if I saw that some monks were sleeping. Tsultrim Gyatso, my assistant, also asks me at the end of the day to delete any footage of sleeping or joking monks because it will not look good and it will reflect poorly on him for having filmed it. Tenzin Tsultrim explains that it is not a major problem if they sleep. They are just ashamed of themselves. Mönlam Wangyel does not wake them because it is ultimately up to each of them individually, and their actions will have karmic consequences, good or bad, later.

Of all the behaviors that monks seem to judge as inappropriate for the assembly hall during recitation, however, none receive as much apparent, immediate anxiety as the spilling of tea during breaks. A splash here and there while pouring or drinking is not an issue, but when a particular monk spills his whole cup on the floor, which happens on more than one occasion, everyone near him looks nervously at the camera, and at Mönlam Wangyel, who is unfazed.

Outside the performance hours, starting at approximately 5:30pm each day, the monks eat dinner and go about their other duties and activities. Academic monks might study their dialectics, while monks with administrative jobs, like the treasurer or library manager, catch up on delinquent tasks. There is also a good deal of blowing off steam, with monks walking down to the restaurants just past Namgyel School, ordering dumplings and fried rice and other dishes that they generally do not get at the monastery. As the days of recitation progress, however, they all start to look exhausted by the time evening rolls around. Over a plate of oily 
sautéed green vegetables (sngo tshal) ${ }^{130}$ at a restaurant with no name that is a favorite of the monks, I ask a twenty-something monk if he is enjoying the recitation. He smiles wearily and says, "Yes, of course. When we are all together in there, chanting in unison, my heart becomes happy."131 Other monks around him laugh and look at me and then go back to their food. I am not sure if he is being sarcastic or not, so I say, "Really?" This time, he just nods without looking at me.132

Outside the assembly hall, near the kitchen, there is a board that lists the names of patrons who have donated something for the performance of the Nyelam Dé Zhi, along with the amount in rupees. Some of them also list specific wishes or hopes for their donation: For the benefit of one patron's family and friends, to bless the building of a house, and one donation from a group of monks from Tromtsang monastery ${ }^{133}$ for the benefit of the people of the countryside, wishing that they enjoy abundant rain, crops, and livestock. Every major ritual of the calendar beckons sponsors - local individuals or families, visitors to the monastery from around the world, people related to monks at Triten Norbutsé, well-connected Bönpos not residing in Kathmandu, and so on - and every ritual sees their names in chalk on

\footnotetext{
${ }^{130}$ Literally "green vegetables," the monks always use this word to refer to a kind of leafy, lettuce-like plant used in many dishes.

${ }^{131}$ Interview with an unspecified monk at Triten Norbutsé on 6/7/2009.

132 I do not offer additional interpretation of his answer here because it is representative of a common trend in the tone of monks' responses to my questions, or in the way I receive them. The ambivalence of this and many other comparable situations can point to many things: Ambivalence in the way a monk feels about the thing I am asking about, in the fact of my asking him about it, in the way my language and cultural skills affect the presentation of the question and the understanding of the answer, in the way he feels about me and my project and my ubiquity at the monastery, and so on. I will draw larger conclusions later, but for now I will let the ambivalence of this interaction speak for itself.

133 The board shows "khrom btsun thun mong," and a geshé confirms that this refers to monks from the monastery khrom tshang dgon g.yung drung kun grags gling.
} 
this board, but there is a marked contrast in the quantity of names and rupees between the Nyelam Dé Zhi and other rituals of similar scale..$^{134}$

This corresponds to the relative absence of lay visitors to the monastery, compared to rituals of comparable scale, like the 100,000-fold offering to Sipé Gyelmo (srid pa'i rgyal mo 'bum tshogs) or the celebrations of Tönpa Shenrap, which always attract more lay visitors, though still far fewer than rituals of comparable scale at Menri, an issue that will be addressed later. Tenzin Tsultrim explains that the donations are not nearly enough to pay for all the materials necessary to construct the ritual implements and offerings. They are therefore required to withdraw from the monastery treasury to make up the difference. Regardless of how many names there are, monks always crowd around the board during breaks to read the names and count the money donated so far.

For this particular performance, the last day of the ritual is also the first since it began that it has not rained at any point during the day. A man who used to be a monk but is now a lay practitioner - the most frequent and visible non-monastic visitor to Triten Norbutsé135 - grabs my upper arm and says, "You see? It rained every day that they were making offerings and singing praises to the lu, and now that they've stopped, the rain has stopped." I suggest that it had also rained almost every day in the two weeks prior to the ritual, and he responds quickly by saying that the monks had already been preparing their apologies and pulling out the texts, building up their good intentions, and the lu were aware of this, and in fact the

\footnotetext{
134 By similar scale, I mean multi-day rituals that require the participation of all or most of the community.

135 Sonam Kundrup (bsod nams kun grub)
} 
monks have done this so well every year that the lu have become accustomed to granting blessings this time of year regardless.

Reflecting on this answer later, I wondered if there might not be an important emic truth to it, if only because so much else about this performance of the Nyelam Dé Zhi suggested to me that the lu and other deities would not have been successfully propitiated. Indeed, the mandala did not match either the text or the photo that the monks were using as reference. "The sadak and lu will not be happy about this," Tenzin Tsultrim said in response. Upon seeing the thread crosses in my video, he said that these also were not well done, and that the deities would not like them as much. Many monks were asleep and goofing around, or otherwise not reciting in the temple, and a number of them admitted to or were described by higher ranked monks as not doing, or being capable of doing, the visualizations prescribed in the texts, despite visualization being one of the allegedly most powerful transformative tools in the ritual arsenal, so critical to effecting real change. Many of the more experienced, elite monks, those most capable of deploying ritual technologies like visualization, either left early or, in the case of the most elite monks - the abbots and rinpochés and so on - never attended at any time. When asked about whether the prospects for ritual success would not be improved by the participation of the most capable members of the community, Tenzin Tsultrim responded that it did not matter.

Indeed, while Tenzin Tsultrim was troubled by the inferior thread crosses and the mismatching of maṇalalas - "Annoying," he said ${ }^{136}$ - neither he nor anyone

136 Interview with Tenzin Tsultrim at Triten Norbutsé on 6/5/2009. 
else at any level of accomplishment expressed any real concern about this absence of fidelity to textual prescriptions. Everyone agreed that it is impossible to know for sure whether this ritual "works" to bring rain or fortune or luck or merit or happiness. "It is a ritual for laypeople, for lay concerns," some of them said. "We don't get the benefit." But there were no laypeople in attendance or otherwise aware of the ritual, it seemed, and the benefactors were lower in quantity than for comparable rituals. None of the actors or passive administrators seemed to care much about the outcome, nor was there much concern about strict adherence to prescribed parameters for performance. In many cases, they did not seem to care even about being there, preferring not to be there, and actually not being there if their communal status afforded them a reprieve. And this defied my last and lowest expectation, that the ritual actors and others involved would, at some level, for whatever reasons, want to undertake the ritual. Of course, there was a great variety of moods, enthusiasms, explanations, and so on among the monks, and there can be no doubt that some of them found the Nyelam Dé Zhi, and especially its preparations, more engaging and interesting than others. But the net evidence compelled a question that was inescapable: Why were they doing this ritual that no one seemed to care about? 


\section{Chapter Three: Deities}

The ritual of the Nyelam Dé Zhi primarily addresses four groups of deities: The four Ones Gone to Bliss, the four chief subduers, the four subduing garudas, and the four types of worldly deities for whom the ritual is named - sadak, lu, nyen, and tö.137 It is not at all uncommon for rituals of the annual calendar to include such groups of deities, and indeed every ritual of a scale large enough to include a manḍala necessarily includes the four Ones Gone to Bliss at the center, but the Nyelam Dé Zhi is unique among other rituals in the calendar first and foremost because of its emphasis on worldly deities, but by extension also because of the emphasis on nonprotector subjugators like the four chief subduers. All of these deities have some relevance to the daily activities and longer term careers of the monks at Triten Norbutsé, but an understanding of what is happening with the Nyelam Dé Zhi ritual and its performance in the context of this place and time hinges on the simple and fundamental notion that the worldly deities that are the primary concern of the Nyelam Dé Zhi are the least relevant among all the four groups to the day-to-day concerns of the monks. Much will be said about this in the following chapters, but the core dynamics of this tension come to light via the grafting of a deity taxonomy including the contradictions and slipperiness between the literary and the ethnographic, as well as among literary sources themselves - onto the cultural and idiosyncratic dimensions of monastic life at Triten Norbutsé, as described above.

\footnotetext{
${ }^{137}$ Note that there is a substantial distinction to be made between the first three and the last of these groups, in that the first three each include four individuals while the last includes four unknowably large groups of deities.
} 
Doing so also begins to reveal the ways in which the Nyelam Dé Zhi, and rituals generally, help to make sometimes diverse identities of cosmic and local agents coherent in the lived experience of the community.

The pantheon of deities in the Bön tradition, even when refined to include only those relevant to the yearly concerns of the community at Triten Norbutsé, is so vast and multifarious that it may be impossible ever to articulate a unifying taxonomic scheme that includes all agents in all contexts. A number of binary schemes, both emic and etic, have been proposed to encapsulate the expanse, most concisely presented by José Cabezon in his introduction to Tibetan Ritual:138

- gods and demons (lha 'dre)

- peaceful (zhi ba) or wrathful (khro bo)

- tutelary (yi dam) or protector (srung ma, bka'skyong)

- supramundane ('jig rten las 'das pa'i lha) or mundane ('jig rten pa'i lha)

- local or translocal139

While these are helpful groupings to understand different qualities, roles, and so on of the various deities, their multiplicity alone speaks to the insufficiency of each individually. But it is not the multiplicity alone that is the problem. Many deities shift identity from context to context, whether through an explicit emanation or association, or through divergent narratives from different cultural-historic layers within the community and tradition.

It is beyond the scope of this project to go deeper into the taxonomic logic of deities across the Bön tradition, but for the purposes of understanding the Nyelam Dé Zhi and its performance, as well as other comparable rituals, it is immediately

\footnotetext{
138 Cabezon, 2009, pp. 4-6.

139 This last is an etic scheme, with possible Tibetan translations but no effort is made to connect them here because it is out of scope to do so.
} 
clear that binary schemes are hardly useful, much less sufficient. Of much greater value, though still fraught with problems that are themselves revealing, is the emic framework of the "four guests" (mgron bzhi).

\section{The Four Guests}

A common rubric for organizing and understanding ritual agents, aside from those explicitly performing the ritual, the category of the four guests can be found in virtually every Bönpo ritual that has an offering component. Though the Nyelam Dé Zhi texts reference the four guests as a whole in places, they reveal no specific assignments of agents to guest types, and indeed such explicit assignments are rarely if ever made in the context of a ritual itself. Rather, the "four guest" framework is an organizing scheme that all educated monks ${ }^{140}$ carry with them into a variety of (mostly ritual) contexts, and as such it is as widespread and consistent an emic taxonomy of beings, especially those related to ritual activity, as can be found in the community. ${ }^{141}$

The four groups of deities in the Nyelam Dé Zhi listed above roughly - and it is important to note that it is imperfect - map onto three of these four types of guests that are invited to every substantial ritual, which themselves are grouped and ordered by magnitudes of respect:

\footnotetext{
${ }^{140}$ I do not have an explicit level of education required in order to be facile with the knowledge of the four guests, but interviews suggested that teenage or older monks who had been in the academic program or otherwise participating in rituals for at least three years were able to name the four and describe the basic kinds of deities in each.

${ }^{141}$ Aside from the being in the six realms of existence, which is of course useful in general, but not for ritual contexts.
} 
Guests of Reverence (srid zhu'i mgron): ${ }^{142}$ Transcendent deities like the Ones Gone

to Bliss, tutelary deities, and Everlasting Mind Heroes (g.yung drung sems dpa ). ${ }^{143}$

1. Guests of Good Qualities (yon tan gyi mgron): Protectors of Bön and the teachings, as well as other powerful virtuous beings.

2. Guests of Karmic Debts (lan chags kyi mgron): Sentient beings who do harm to or can be hostile to others.

3. Guests of Compassion (rnying rje'i mgron): Those of lesser fortune and power like beings of the six realms of existence, including those in the bardo (bar do) state.

All four kinds of guests are invited to the Nyelam Dé Zhi proceedings, but only the first three occupy the privileged seats in the mandala, in concentric rings that reproduce the guest hierarchy. The four Ones Gone to Bliss are Guests of Reverence at the center of the mandala. The four chief subduers and the four subduing garudas are Guests of Good Qualities in the next ring. ${ }^{144}$ The masses of worldly deities in the last group of the Nyelam Dé Zhi are generally Guests of Karmic Debts but also considered Guests of Compassion, in a ring outside of the Guests of Good Qualities. Though they are not installed onto specific syllabic seats in the mandala in the Nyelam Dé Zhi, the other Guests of Compassion, which include the patrons, are invited to the proceedings and outer layers of the mandala en masse, and are the primary recipients of dedications and any positive outcomes.

Given the emphasis of the ritual, it is perhaps unsurprising, but nevertheless unusual, that the Guests of Karmic Debts occupy explicit seats in a ring so close,

\footnotetext{
142 Note that the more common spelling of this is sri zhu'i mgron, but Tenzin Tsultrim's unpublished document has srid zhu'i mgron, and while it may be a mistake, I leave it as is out of uncertainty. 143 This is the Bönpo equivalent of the Buddhist byang chub sems dpa'.

144 There is lack of agreement among monks and geshés about where in the classification of guests the four chief subduers and the four subduing garudas fit, with a couple of my informants pointing out that the kings of the sadak and lu and so on are still just members of the larger sadak and lu clans, but the majority opinion is that they are Guests of Good Qualities, protectors of Bön. There are other guests of Good Qualities in the mandala, however, visualized generically as the noble protectors (dpal mgon) seated on the square subcontinents of the mandala.
} 
relatively speaking, to the center of the mandala. In other rituals at Triten Norbutsé and Menri they are invited as guests, given the appropriate torma offerings and so on, but they do not occupy such privileged perches in the mandala. There are undoubtedly other rituals being done elsewhere that privilege worldly deities in this way, ${ }^{145}$ but there is an immediacy to the presence of the worldly deities in most of those contexts that is absent in an exiled monastic community like Triten Norbutsé. As will be discussed in greater detail later, the monks generally do not feel, for a variety of reasons, that their destinies are as intertwined with these deities as laypeople or others in closer contact with them do, and thus in the context of their yearly ritual calendar this is an anomalous treatment indeed of otherwise less important and less relevant deities.

The different types of guests receive different types of offerings, which are further determined by whether the ritual is classified as outer tantra (phyi rgyud or sngags phyi pa), inner tantra (nang rgyud), or secret tantra (gsang rgyud). ${ }^{146}$ Given that the Nyelam Dé Zhi is an outer tantric ritual, the offerings made are as follows, including reasons for making offerings to these guests: ${ }^{147}$

\section{Guests of Reverence}

- offerings

○ The five-fold offering (both real and visualized)

(a) butter lamps made from grain oil, sesame oil, and/or cattle butter

(b) oblations of rain water, ocean water, and/or milk from a white cow

\footnotetext{
145 See for example the Mongolian mountain rites described in Lindahl, 2009, p. 238.

146 The kinds of tantra will be discussed in a little more detail from a literary perspective in the next chapter and from an ethnographic perspective in the chapter after that.

147 This information comes from observation of the ritual, conversations with Tenzin Tsultrim, and Tenzin Tsultrim's unpublished gtor ma manuscript (see Appendix 4).
} 
(c) incense of camphor (ga pur), sandalwood (tsan dan), aloe wood ( $A$ ka ru), tagara (rgya spos), pang (spang spos), drak (brag spos), and/or others.

(d) food offerings (tormas of specific types) ${ }^{148}$

(e) flowers of all kinds from clean ground that are not poisonous

- reasons

- dispelling the karmic traces (bag chags) and pollution (sgrib) of all sentient beings, and perfecting their great accumulation of merit (bsod nams tshogs chen rdzogs pa). ${ }^{149}$

2. Guests of Good Qualities

- offerings

○ white tormas arranged with three smaller, four-petaled tormas, adorned with grain and flowers.

o oblations (water and/or milk)

- reasons

○ augmenting the happiness and well-being (bde skyid) of sentient beings, and in particular causing obstacles (bar chod) on practitioners' path to liberation to subside, and increasing the benefits of merit for patrons.

3. Guests of Karmic Debts

- offerings

o white foods

○ three-petaled tormas adorned with grain and flowers

○ oblations

- reasons

- casting out poisonous aversion, pacifying sentient beings that harm others, beseeching them to take care of all the worlds and the teachings, and making wishes come true. 150

4. Guests of Compassion

- offerings

○ changbu (chang bu) tormas ${ }^{151}$

- displeasing images or other forms of animals and people

- malodorous smells

$\circ$ fine silk and skins and woolen and cotton cloths

- reasons

○ making rain, causing suffering to subside, reaching liberation..$^{152}$

\footnotetext{
148 See Appendices 4 and 5 for details on these tormas.

149 This comes from page 511 of an unspecified edition of the canonical legs spyod smon lam, via page 6 of Tenzin Tsultrim's unpublished manuscript.

150 This is from page 218 of an unspecified edition of the kun dbyings, cited on page 7 of Tenzin

Tsultrim's unpublished manuscript.

151 These are tormas the height of the palm of the hand, shaped by squeezing a length of dough inside the fist.

152 This is from page 219 of an unspecified edition of the kun dbyings, cited on page 8 of Tenzin Tsultrim's unpublished manuscript.
} 
A great many monks know about this basic classification of guests at least superficially, though some speak more often of two kinds of guests - buddhas and non-buddhas - and yet it is not at all common knowledge, or at least commonly agreed, what group specific deities or invitees belong to, much less what each should be offered and why, and much less still in the context of outer tantra versus inner or secret tantra (discussed in Chapters 3 and 4). Conversations with both novice monks and geshés about the four chief subduers, for example, was especially difficult. In the narrative of the Nyelam Dé Zhi they are the ministers of the sadak, lu, and so on, and as such they are usually understood among monks to be human (or transcendent) lamas, but are also sometimes understood to be exceptional but ethnically identical individuals among their subjects. In many cases, this latter understanding came from younger monks who pointed to the presence of the deity names in each - lu, sadak, and so on - as indications of their identity. In other cases, the understanding came from the idea that transcendent figures took on the aspect of these deities in order to better command them. This is all further complicated, though some may say clarified, by the fact that the ministers, according to the Nyelam Dé Zhi narrative, are actually Tönpa Shenrap's son-disciples, the "four immeasurable youths," who are transcendent. A number of monks also suggested that if the chief subduers are ministers, they are likely powerful but unenlightened beings, ${ }^{153}$ and all unenlightened beings have to fit somewhere in the schema of six realms of existence, and thus it could be that both the chief subduers and worldly

\footnotetext{
${ }^{153}$ Note that the Upper Ritual volume of the Nyelam Dé Zhi says that the four subuers brought even the sadak, lu, nyen, and tö to enlightenment, or at least created the conditions for it (see 111.2 and preceeding context), so they would clearly be enlightened in this context, and thus enlightenment, a slippery designation itself, cannot be used as a distinguishing criterion for guests.
} 
deities are Guests of Compassion in this case. Geshés were clear that the chief subduers could not be included as Guests of Reverence, which is a category reserved for the four Ones Gone to Bliss, but from there the lines began to blur for novices and geshés both. They speculated that it could make sense for chief subduers to be either Guests of Good Qualities, in the case of the four immeasurable youths, or Guests of Karmic Debts, if they took the form of actual sadak, lu, nyen, and tö, or possibly even both at the same time. At some point during these conversations, most novices and pre-geshé monks admitted that they did not know or fully understand the four-guest classification, deflecting questions to Tenzin Tsultrim, and many geshés acknowledged that the guests are very clear for some rituals and not so clear for other rituals, with the Nyelam Dé Zhi fitting into the latter..$^{154}$ Indeed, membership in more than one category of guest became the most common and apparently satisfactory explanation for the chief subduers' and other ritual invitees' ambivalent identities. In addition to shading between categories in the context of this one ritual, the same beings may be treated as different kinds of guests across rituals. This is not the case for the Guests of Reverence - though their various incarnations may participate in other categories - and it is unusual, though not unheard of, ${ }^{155}$ for well-known protector deities to be anything but Guests of Good Qualities, but otherwise the groups of sadak and lu, if not called out

\footnotetext{
154 Interview with Tenzin Yangtön at Menri monastery on 2/5/2009, and with Nyima Özer in personal correspondence on 10/3/2013.

155 Sipé Gyelmo (srid pa'i rgyal mo) has a multiplicitous identity that compels membership in different categories across rituals. In most contexts she is considered the protectress of Bön, but she can also act as a tutelary deity, and is considered very clearly to be a buddha in other contexts, all of which stems from her understood identity as a manifestation of Satrik Ersang. According to Tenzin Tsultrim, some lamas believe that the otter-riding protector Midü ( $\mathrm{mi}$ bdud) can also be a tutelary deity in some contexts, but he did not agree and did not know or would not say what contexts would find him treated as a tutelary deity.
} 
specifically as such, may get grouped in with Guests of Compassion or Karmic Debts in some rituals, while certain individuals among them may be celebrated in a particular ritual as a Guest of Good Qualities.

This slipperiness in categorization reflects a couple of important dynamics on the ground at these monasteries. First, the institutional construction of these categories, which plays an important role in structuring ritual activity, is not at all relevant to monks' daily lives or important for them to know explicitly, even among ritual performers. Like many taxonomies, there is a clear sense that the categories arose originally from an independent impulse to systematize or document the formerly chaotic or ambiguous, which had otherwise not been problematically so, at least not from the perspective of ritual performance. ${ }^{156}$ Second, these beings' identities, and the texts and rituals and prayers that address them, do not lend themselves well to simple classification. While only Sipé Gyelmo is unanimously and explicitly understood to play multiple roles within the community - as both protectress and tutelary deity - boundaries between other deities are always shifting. Different narratives produce confusing and sometimes conflicting understandings of identities. These differences stem from differences in texts, kinds of rituals, monks' familial and geographic backgrounds, events in the life of the monastery, teachings of the elite in the community, and any number of other influences. Some of these sources speak explicitly about the slipperiness of identity

\footnotetext{
156 It is beyond the scope of this project to investigate how these categories came to be, but they are present in similar form in Buddhism as well, and present in early ritual literature in both traditions, and thus it is obvious that it is not a recent innovation.
} 
among the various, especially worldly, deities - sometimes conferring fortune, sometimes misfortune.

A helpful analogy to make sense of this slipperiness, at the risk of trivializing the subject, is that of guests at events in other contexts. An individual or group of individuals may be celebrated as the "guests of honor" at one event, occupying the center of a kind of mandala, with other guests gathered around, in approximate rings of decreasing status or closeness or relevance to the guests of honor, while another event may find the previous guests of honor somewhere in the outer rings in support of new guests of honor. This can be complicated by guests of a particular social status who occupy positions in this hierarchy based not on their proximity to the honorees, but on their communally acknowledged status outside the context of the event. This is the case both for dignitaries of high status, who occupy positions close to or at the center, and the ignoble, who occupy positions at the periphery, in both cases regardless of affiliation. ${ }^{157}$

This is obvious enough when it is a common phenomenon. Observers quickly come to understand this shifting of status. The difficulty in a highly structured community such as Triten Norbutsé's is that the statuses of most guests, or of the most visible guests, do not change from event to event, as in the case of the Ones Gone to Bliss. Others change on rare occasions, sometimes subtly, as with the four chief subduers shifting between disciples of Tönpa Shenrap and "kings" or

\footnotetext{
157 One example of this is an American wedding, in which the bride and groom are the guests of honor, with tables arranged such that other important guests are arrayed most closely around them, followed by other guests beyond. At other weddings, that bride and groom will find themselves at a variety of tables representing different statuses, based on their relationship to the guests of honor. A dignitary at that event, invited out of reverence instead of closeness, may trump this order.
} 
"ministers" of worldly deities, and sometimes dramatically, as with the ignoble worldly deities becoming important guests in the Nyelam Dé Zhi. At both orders of magnitude, the shifting of identity is not happening often enough, and is not emphasized enough, to earn an intuitive acceptance of this phenomenon as a dynamic aspect of an otherwise relatively fixed, hierarchical system.

\section{The Ones Gone to Bliss}

The least ambiguous of all the deities addressed by the Nyelam Dé Zhi are the Guests of Reverence, the four Ones Gone to Bliss. Every ritual at Triten Norbutsé or Menri that includes a maṇạala has seats at the center of that mandala for the four Ones Gone to Bliss. ${ }^{158}$ These four - Shenlha Ökar, Satrik Ersang, Sangpo Bumtri, and Tönpa Shenrap - are the most common, most important transcendent deities in the Bön tradition in general, ${ }^{159}$ known, respectively, as the god (Iha), the mother (yum), the father of existence (srid $p a$ ), and the teacher (ston $p a$ ). In the context of the Nyelam Dé Zhi, they are associated with the following qualities, implements, and so

on:

- Shenlha Ökar

○ seat direction: northwest ${ }^{160}$

\footnotetext{
158 It is important to note that even in cases where other deities occupy the priviliged seats at the center, these other deities are widely considered to be different emanations or forms of the main four.

159 See Karmay, 1998, pp. 132-133 and Kvaerne, 2001, pp. 24-28, as well as virtually any primary ritual manual, as well as the many primary and secondary sources, too numerous to list, that describe each of the four individually. Note also, as Karmay points out on 133, that Satrik Ersang is excluded in a number of contexts, elevating the other three.

${ }^{160}$ Note that all direction specifications for the Ones Gone to Bliss are from the Nyelam Dé Zhi textual instructions. The mandala produced for the ritual performance, which mimics in this regard an image presented in the book Mandalas of the Bön Tradition, placed these seats in cardinal instead of intermediate directions. This and similar departures from the text will be discussed in more detail in Chapter Five.
} 
○ mandala line direction: north ${ }^{161}$

○ associated worldly deity: nyen

○ color: green

- syllable: $A$

○ vase offerings: the five incenses (spos lnga)

0 virtue: tutelary deity for all beings

- Satrik Ersang

o seat direction: northeast

- mandala line direction: east

○ associated worldly deity: lu

- color: white

- syllable: $b a$

○ vase offerings: the five medicines (sman lnga)

- virtue: mother of all beings

- Sangpo Bumtri

○ seat direction: southwest

- mandala line direction: west

○ associated worldly deity: tö

○ color: red

○ syllable: $\mathrm{Om}$

$\circ$ vase offerings: flowers (me tog)

- virtue: father of all beings

- Tönpa Shenrap

○ seat direction: southeast

- mandala line direction: south

○ associated worldly deity: sadak

o color: blue

○ syllable: Hum

- vase offerings: the five completely pure natural substances from the eight precious items (rin chen sna brgyad [kyi] yang dag lhun grub lnga)

$\circ$ virtue: refuge for all beings

Tönpa Shenrap appears much more often than the other three, as many of the rites begin by paying homage to him, and he is the focus of most of the narrative elements across and behind rites as the one who originally taught his followers, ${ }^{162}$ who then

\footnotetext{
161 The Upper Ritual (129-131) describes the drawing of lines of the mandala as being drawn from the compassion of each of the Ones Gone to Bliss, and thus as each line is drawn in each direction, it is connected to one of the Ones Gone to Bliss.

162 Foremost among these followers is Yidkyi Khyeuchung (yid kyi khye'u chung) but many others are listed in the texts.
} 
taught others, about the origins of the worldly deities like the lu and the ritual technologies for taming or otherwise negotiating with them.

As the Bönpo equivalent of the Shakyamuni Buddha, Tönpa Shenrap is ubiquitous in the activities and lives of Triten Norbutsé and its monks. He and his various emanations grace scroll paintings in the temples, pendants worn on necklaces, and postcards in the gift shop. Monks pay homage to him every day as part of their daily rites, multiplied many times during substantial annual rituals like the Nyelam Dé Zhi, culminating in a commemoration of his death on March 10th of the western calendar, for which monks set up an altar and large scroll painting outside, recite verses of prayers and homage to Tönpa Shenrap, light many dozens of candles in the evening, placing them around the altar and monastery grounds, at one point each holding a candle and circumambulating the temple en masse via the primary monastery circuit.

Tönpa Shenrap's presence in the Nyelam Dé Zhi, and to a lesser extent that of the other three Ones Gone to Bliss, with whom monks still engage regularly, at least at the level of homage - especially when considering emanations or alternate forms - is thus taken entirely for granted. No one is surprised to read or hear the narratives of his teachings - he is the original teacher of all subjects and all beings and asking why he is part of the ritual proceedings, installed at the center of the mandala, is akin to asking why monks live at monasteries. There is no Nyelam Dé Zhi without Tönpa Shenrap, both in the sense of its origin and its performance.

Everyone in the community understands Tönpa Shenrap to be the founder of Bön and teacher of all, but the other Ones Gone to Bliss are less clear to a significant 
percentage of the community, if not to the geshés. Shenlha Ökar and Sangpo Bumtri play prominent roles in Bönpo mythology, especially Shenlha Ökar as a kind of analogue to the Buddhist Küntu Zangpo (kun tu bzang po, whom Bönpos otherwise include in their pantheon), and their ubiquity in origin stories and as members of the Ones Gone to Bliss in other narratives translate to a relatively clear statuses and roles in the community. ${ }^{163}$

The same cannot be said of Satrik Ersang, however. Better known as Sherap Chamma, of which "Satrik Ersang" is simply the Zhang Zhung translation, she is the Bönpo equivalent of the Buddhist Tara. Chamma is a frequent subject of ritual and prayer, found often on amulets and scroll paintings and elsewhere, to the extent that she strikes monastery visitors right away as one of the most important deities in Bön. Tenzin Namdak explains without ambiguity that Satrik Ersang and Sherap Chamma are one and the same, to be distinguished only by language, but this is not at all clear to the larger community, who have regular engagement with Chamma and who generally hear about Satrik Ersang only in exalted contexts like ritual mandalas, where she plays an obviously important role, and where she may even receive elucidating context in the form of semi-narrative recitations, ${ }^{164}$ but where she mostly remains veiled behind the often inscrutable language of the verse ${ }^{165}$ and limited iconography and emphasis, especially compared to the other three Ones Gone to Bliss, whose common grouping as a triad across contexts compels the belief

163 More information can be found about both in the Ziji and Zermik, as well as in Karmay, 1998, pp. $109,130,133,267-8$, and elsewhere.

164 By "semi-narrative recitations," I mean those that provide some description of the deity they address - for example, "The great mother of the expanse, Satrik Ersang, is mother of all" (Nyelam Dé Zhi Upper Ritual, p. 119.3).

165 This will be discussed in the following chapters. 
that they must be more important. ${ }^{166}$ Sipé Gyelmo, another purported emanation of Satrik Ersang and one of the most popular deities in Bön, also gets much more attention and has much greater daily relevance to and agency in the lives of the monastic and larger community. Tenzin Tsultrim's ta pi hri tsa teaching document, ${ }^{167}$ which provides basic descriptions of some of the most important, most common deities in Bön, also does not include any mention of Satrik Ersang. It does include "Yumchen Sherap Chamma," however, describing her as "A goddess who is the Enjoyment [Body] that emanated from the Bön Body [that is] the very mind of the Perfected Body Shenlha Ökar,"168 before going on to talk briefly about her iconography, and it also makes significant reference to Sipé Gyelmo on a couple of occasions without drawing any connections to Satrik Ersang.

This all raises a question about the varied forms of this otherwise singular feminine being: Why is she called by one name and not the other in any given context? In the case of Sipé Gyelmo and other explicit emanations, different forms are understood to exist for different purposes, to play different roles, in which case there can be ritual clarity about Satrik Ersang herself as a Guest of Reverence and her emanation Sipé Gyelmo as a Guest of Good Qualities. It is less clear in the case of Sherap Chamma, however, who is thought of sometimes as an emanation and sometimes as an epithet of Satrik Ersang. It is beyond the scope of this project to go deeply enough into Bönpo history and cosmology to examine all the possible answers to this question - whether they were separate entities conflated later

\footnotetext{
${ }^{166}$ See Karmay, 1998, p. 109 for a description of this triad.

167 See Appendix 5.

168 yum chen sher rab byams ma ni rdzogs sku gshen lha 'od dkar gyi thugs nyid bon sku las las sprul pa'i longs spyod rdzogs pa'i lha mo zhig yin la/ (1.12)
} 
because of their common femininity, whether the Zhang Zhung name enhances

mystique and therefore power in contexts where she wields authority on par with

the other Ones Gone to Bliss, and so on - but the lack of clarity addressed by the

question is itself important to understanding how community members'

relationships to deities, and to the types of guests, differ from those proposed by any given definition or teaching.

\section{The Four Chief Subduers}

The four chief subduers, also known as the four taming shenpos ('dul ba'i gshen po bzhi), are the "ministers" of each of the sadak, lu, nyen, and tö. They are, along with their mandiala seats and directions:

- Lu Bön Yeshé Nyingpo (klu bon ye shes snying po) ${ }^{169}$

○ direction: east

○ syllable: $k a$

- Nyen Bön Tangtang Drölwa (gnyan bon thang thang 'grol ba) ${ }^{170}$

o direction: north

○ syllable: $k h a$

- Sadak Bönpo Küntu Khyappa (sa bdag bon po kun tu khyab pa)

○ direction: south

○ syllable: $n g a$

- Tö Bön Bati Sungnyen (gtod bon ba ti gsung snyan)

o direction: west

○ syllable: $g a$

${ }^{169}$ Lu Bön Yeshé Nyingpo is also known by the names klu grub ye shes snying po, klu las grub pa'i ye shes snying po, and ye shes snying po, according to Bellezza, 2005, p. 528, and is also described in a treasure text revealed by Dechen Lingpa (bde chen gling $p a$ ) as the "gShen of the Nagas," who practiced in the ocean and subjugated the lu therein (Achard, 2004, p. 50). Shenchen Luga (gshen chen klu dga') is his incarnation (in a translation by Martin, 2001, p. 72). There are more details in Bellezza, 2005, pp. 362-367; Namgyal Nyima Dagkar, 1998, p. 16; Achard, 2004, p. 102, note 5, 141; Martin, 2001, p. 96; and of course in the klu sgrub ye shes snying pos gsung pa'i gtad bkrol of the mdo section of a Bön Kangyur (for condensed information see Kvaerne et al, 2003, p. 45).

170 Nyen Bön Tangtang Drölwa is also known as Tangtang Gyerkhé (thang thang gyer mkhas) in the klu 'bum (Nebesky-Wojkowitz, 1956, p. 289) 
The Upper Ritual volume of the Nyelam Dé Zhi gives a brief mythology of these four that explicitly connects them, respectively, to the famous "four excellent youths," the chief disciples (and sons, in some contexts) of Tönpa Shenrap - Yidkyi Khyeuchung (yid kyi khye'u chung), Tobu Bumsang (gto bu 'bum sangs), Sebu Yulo (gsas bu g.yu lo), and Lhabu Malo (lha bu rma lo) ${ }^{171}$ - who received teachings from Tönpa Shenrap on the nature of and methods for dealing with the sadak, lu, nyen, and tö, and then went to the lands of each to subdue them.

The "Bön" in each of their names points to the pre-modern, foundational meaning of the word, which roughly translates to "priest" or "minister."172 This meaning is bolstered by the naming of the four of them as the "four taming shenpos," with shen being a common synonym or closely related term for Bön or Bönpo, as well as the name of one of the most important mytho-historical clans in the Bön tradition, the one that includes its founder, Tönpa Shenrap. While there can be confusion among modern community members as to the identity and classification of these ministers of the four classes of worldly deities, the very names of each - Yeshé Nyingpo, minister of the Lu; Tangtang Drölwa, minister of the Nyen; and so on - not to mention the stories that identify them as the four excellent youths, make it clear enough, in literary contexts, including those wholly within the

\footnotetext{
171 The best source of information for these figures is the Zermik, in which Yikyi Khyeuchung, Tobu Bumsang, Malo, and Yulo are presented as the famous "Four Excellent Youths" (via Karmay, 1972, p. 35, note 4). Tobu Bumsang is also one of the four manifestations of Shenrap Miwo, aligned with the teaching of ritual, and often listed along with the other manifestations as Confucius and Shakyamuni (Karmay, 1972, p. xxxiv). Karmay further explains on page 106 that Tobu Bumsang's monastic name is Drangsong Gyelwa (drang srong rgyal ba), whose further incarnation is Danma Gyelwa Tsukpü ('dan ma rgyal ba gtsug phud). There is also a Tobu Bumtri Lokyi Chechen (gto bu 'bum khri glog gi lce can) in the Zermik that seems a likelier match, but he is then called Totri (gto khri, see Franke, 1930, p. 307).

172 There is a great deal of controversy around what Bön may have meant in early Tibetan contexts. See Sam van Schaik 's Dunhuang-based analysis (2013) for a recent, compelling assessment.
} 
Nyelam Dé Zhi collection, that they are ethnically unrelated to the worldly deities themselves. They are higher beings - humans or gods or other - with particular knowledge of and dominion over the masses of sadak, lu, nyen, and tö.

In both literary and monastic community contexts, Yeshé Nyingpo is, by a wide margin, the most well-known of the four chief subduers. Information about the other three can in fact be quite difficult to locate, both in texts and in conversation with monks, many of whom could not name or identify any of the other three. ${ }^{173}$ This is perhaps unsurprising given that the same general pattern exists with the lu among the four types of worldly deities, with everyone knowing a great deal about lu, much information to be had in texts and in the community, and much less known - or at least much less clarity and consensus - about the other three. The most famous of all Bönpo treasure revealers, Shenchen Luga (gshen chen klu dga', b. 996 CE), is also believed to have been an emanation of Yeshé Nyingpo, ${ }^{174}$ which further bolsters his recognizability and status.

In the context of the Nyelam Dé Zhi, the four chief subduers have seats in the mandiala just outside those of the Ones Gone to Bliss, which speaks to their considerable import, at least in conceit, to the proceedings and the efficacy thereof. Various rites of the larger ritual entail generation of oneself as each of the subduers, but especially as Yeshé Nyingpo, ${ }^{175}$ to command the worldly deities to do the bidding of the ritual actors. From an emic perspective, the power of those original

\footnotetext{
173 Many younger monks did not know anything about Lu Bön Yeshé Nyingpo, either, but this is to be expected given his absence in the standard educational curriculum and the relatively secondary role he plays in ritual dramas.

174 Tenzin Tsultrim and many geshés made this connection, which is supported by primary texts such as be ro tsa na'i lde mig chung ba: klu bon ye shes snying po'i sprul pa ni// rga rigs klu dga' bya ba byung// (Martin, 2001, pp. 227-228).

175 See for example, the Affecting Lu (klu bcos) volume, p. 190.
} 
myths of domination over the domains of the worldly deities, and of these

transcendent figures more generally, bolsters the subjugatory ethic of the performance, while, from an etic perspective, as will be discussed in more detail in Chapter Six, the identification of performers with these intermediary beings between humans and the Ones Gone to Bliss, and between humans and the worldly deities - collapses the distances between both, orienting monks gradually upwards in their ideology, away from, but without losing their dominion over, the worldly.

\section{The Four Subduing Garudas}

Not much emphasis is placed on these particular garudas in the ritual texts or performance, nor are there any known distinguishing characteristics between the four, inside or outside of the ritual context, aside from their subjugatory associations with the four kinds of worldly deities - one garuda for each type of deity. They will thus not be discussed in detail here. It is worth noting, however, that they have a simple role and conceit that yields less ambiguity or controversy than most of the other beings addressed by the Nyelam Dé Zhi. They are defined early in the Upper Ritual in the context of the four chief subduers having just gone to the realms of each of the four groups of worldly deities to subjugate them:

For the fierce destructive ones who could not be tamed by peaceful means, Garudas emanated into the four realms,

And brought the harmful and cruel among the sadak, lu, nyen, and tö to peace. ${ }^{176}$

176 zhi bas ma 'dul drag po'i tshar gcod pa rnams la/ bya khyung 'jig rten bzhi ru sku sprul nas/ klu gnyan gtod dang sa bdag gis gnod pa gdug rtsub rnams bde la bkod/. Note that there is considerable ambiguity here. One alternate reading is that the four subduers emanated as garudas in the four worlds. The lack of particle after bya khyung makes it ambiguous, and indeed particles are loosely 
They are given almost no other description throughout the rest of the texts - the one bit of extra detail, also in the Upper Ritual, merely reaffirming the earlier description. ${ }^{177}$ Their associations with the ritual implements and procedures are as follows:

- The drawing of the lines of the mandala is conceived of as being done by the four garudas, where each part of the basic mandala structure being connected with beings - the four dzang lines emerge from the compassion of the four chief subduers, the mandala support is analogized to the four guests, and so on. ${ }^{178}$

- The seat of the garudas in the mandala are khrom syllables.

- The vase contents associated with garudas are grasses ( $m t s h e)$, mustard seeds (nyungs), and fragrant or medicinal powders (phur ma).

- The ornamentation of the mandala associated with garudas is the peacock feather victory banner (rmya rgyal mtshan).

The one salient detail about these associations is the first, that of garudas being associated with boundary setting, a dynamic present more explicitly in the Banishing Rock Demons (brag srin bkar ba) volume that is not used in the institutional performance of the Nyelam Dé Zhi but otherwise provides support for the function and conceptualization of garudas in the following:

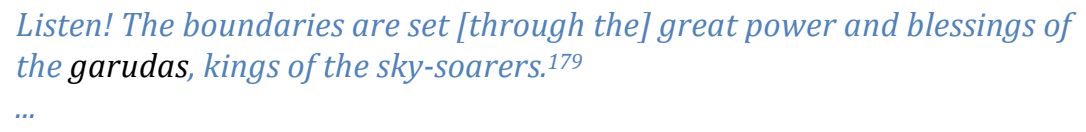

employed throughout the text. Nowhere else is there reference to the four subduers emanating as garudas, however, and they are treated appositionally throughout all the texts. The agentive particle in the last phrase suggests that the ones brought to peace/happiness could be those harmed by the worldly deities and not the deities themselves, but the presence of cruelty right afterwards makes it clear that these are qualities of the the worldly deities. The choice to translate that particle as "among" allows for the possibility that it was intended to be genitive without sacrificing the meaning if it was indeed intended to be agentive.

177 This is in the recitational part instead of the narrative part of the text, and reads: "Since the four great garudas, kings of the sky-soarers, tamed hatred and brought all under their power..." ( $m k h a^{\prime}$ lding rgyal po bya khyung chen bzhi/ thams cad dbang bsdud 'khu ldog 'dul ba'i phyir/ [121.4]). 178 See the Upper Ritual, pp. 131.3-132.1.

179 kye mkha' lding rgyal po bya khyung gi/ mthu stobs byin rlabs 'tshams bcad do/(1040.3-4). Note that here and elsewhere I have chosen to connect khyung directly to "garuda" because of the abundance of geshés that used the terms interchangeably. 
I send an exhaustively extensive offering to the Sadak, Lu, Nyen, planets, and

constellations. Lusin, do no harm or mischief. The boundaries are set by the

kings of the garudas. ${ }^{180}$

The emphasis on boundary setting through these declarations, the association of the garudas with the drawing of boundary lines in the mandala, and their strategic positioning on seats in the mandala that divide the "good deities" (Ones Gone to Bliss and chief subduers) from the "bad deities" (sadak, lu, nyen, tö) point to a characteristic ritual function that may not be otherwise explicit, especially in conversation, and to a broader and very important orientation to the Nyelam Dé Zhi ritual that will be discussed in more detail later: While the overall ethic of the ritual is understood to be one of universal harmony, and the worldly deities are invited into relatively privileged positions in the mandala, the ritual complex also reinforces boundaries by pushing or keeping classes of deities to one side or the other.

\section{The Four Types of Worldly Deities}

The sadak, lu, nyen, and tö are the primary focus of the Nyelam Dé Zhi, addressed in the very title, and together they are the agents or executors of worldly fortune and misfortune. In the manḍala and other ritual specifications, their associations are:

- lu

- seat direction: southeast

- syllable: $p h u$

- associated Ones Gone to Bliss: Satrik Ersang

○ element: blue ocean

- nyen

○ seat direction: northeast

${ }_{180}$ sa bdag klu gnyan gza' dang rgyu skar rnams/mchod pa yongs su rgya che bag cig /gtong la/ klu srin gnod pa dang rgyal ka ma byed cig /bya khyung gis rgyal pos tshams gcad do/ (1041.3-4). Note that rgyal ka should be [r]kyal ka and the last agentive particle should be a genitive. 


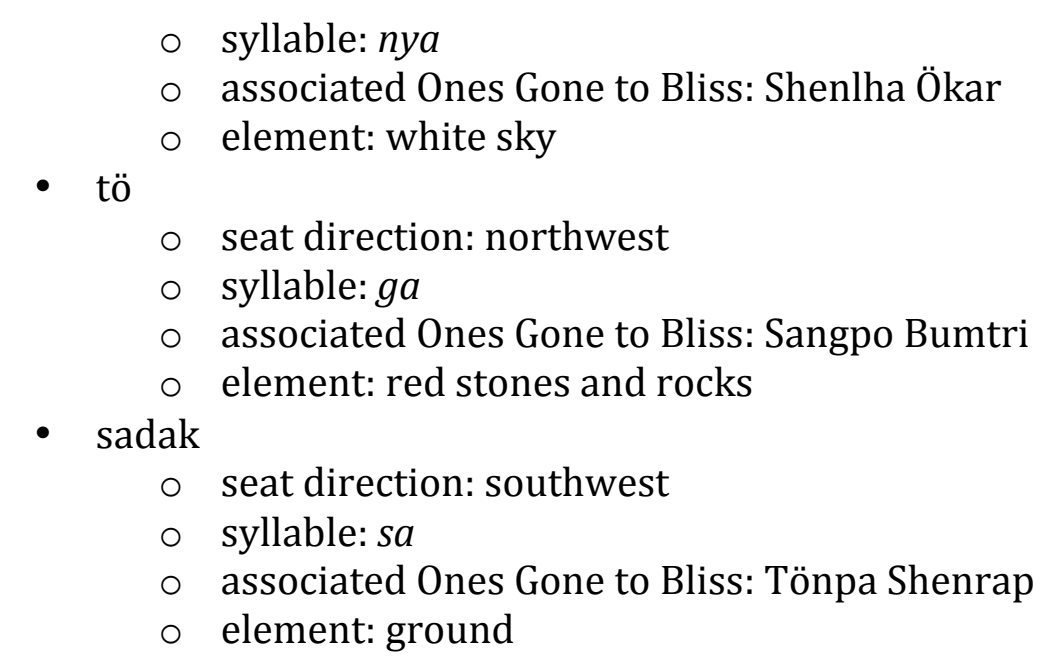

From the perspective of the Nyelam Dé Zhi, these four are clearly meant to represent a vast majority of worldly deities, but there are others, and thus one might expect to find among monks or related literature a larger category that includes all or even one that encapsulates the four principle deities mentioned above - but such a category does not uncontroversially exist. The term "lords of the ground" (gzhi bdag) denotes a category that, for many monks, includes the sadak, lu, nyen, and tö, but which also begins to hint at some confusion arising at least in part from the diversity of monk backgrounds and sensibilities at Triten Norbutsé. Asking whether the sadak and so on were lords of the ground or local gods (yul lha) - monks variously answered one or the other or both, with both being the most common answer. Those who answered that they were lords of the ground but not local gods generally explained that the local gods were named deities that existed only in one place, unlike the sadak and lu, which were everywhere. The only named deities among them were the kings of each category, which had a definite translocal character. Those that answered that they were local gods but not lords of the ground often made the same claim reversed, that lords of the ground were 
individual, named deities and local gods were generic local deities, or they claimed the lords of the ground were protector deities and/or lived in mountains, and thus lu and sadak living below the monastery would never be lords of the ground. ${ }^{181} \mathrm{~A}$ purificatory offering text given to me by Sangyé Tenzin, ${ }^{182}$ also purportedly by Khyunggötsel and used generically in an ad hoc fashion whenever such deities need to be propitiated, ${ }^{183}$ explicitly addresses the four kinds of deities of the Nyelam Dé Zhi, on page 1.1, with: sa bdag klu gnyan gtod dang gzhi bdag la/ gtor ma 'bul...

While this could be read as communicating that the four deities are part of the lords of the ground group or category, the retention of gzhi bdag from the text title, and the substitution of the four deities for $y u l$ lha, can only equate these latter two. This is further supported by other sources, including a hymn dictated to Karmay (2005,

\footnotetext{
181 These differences in understanding lords of the ground, local deities, and so on are partially explained or supported by Karmay, 1998, pp. 442-443, who suggests that the category "lords of the ground" is more common in literary contexts and in Amdo, whereas "local gods" is more common in central Tibet. I did not discover this regional explanation until after conducting surveys, and had thought monk answers were more generically idiosyncratic, and thus I did not think to ask each monk where he was from and connect that information to his answer. I do know, however, that very few monks were from central Tibet, and certainly not as many as there were "local gods" answers. Note also the support for distinctions between lords of the ground and lu specifically in a variety of sources, including the 17th century text cited in Ramble, 2007, p. 316 (citing Schuh, 1995, p. 10), and Nebesky-Wojkowitz, 1956, p. 413, though it is also worth noting the various cases where deities included as lords of the ground may not be called lu per se but have a lu appearance, as in NebeskyWojkowitz, 1956, p. 222.

182 gar 'dug yul lha gzhi bdag gi bsgrub mchod phun tshogs bde legs kun 'byung. There is a text by this name referenced on page 1024.1 of the "Tantra" section (sngags sde) of the Bönpo Kangyur catalog entitled rgyal ba'i bka' dang bka' rten rmad 'byung dgos 'dod yid bzhin gter gyi bang mdzod la dkar chags blo'i tha ram bkrol byed 'phrul gyi lde mig by bla ming g.yung drung tshul khrims dbang drag, published by bod ljongs shin hwa par 'debs bzo gra in 1995 but allegedly composed in the late 19th century. There is another comparable text called the gar 'dug yul sa'i bsang mchod in sangs rgyas g.yung drung bon gyi zhal 'don dang lo rgyus nyung bsdus zhang zhung snying tig, which is notable mostly because it highlights the interchangeability of $y u l$ lha and $y u l s a$, which is described in more detail in Karmay, 1998, p. 442.

${ }^{183}$ I never witnessed this text being performed, but Sangyé Tenzin assured me it is not at all uncommon.
} 
p. 392) that describes lu as the female types of local deity. In other places, however, Karmay suggests that it is "normally understood" that nyen are lords of the ground (1998, pp. 441-442) and that sadak are not (1998, pp. 442-443), and a Dunhuang manuscript puts the nyen and lu together and explicitly in a different category from local gods. ${ }^{184}$

In fact, it is not common from a literary perspective to find these worldly deities organized according to lords of the ground or local gods. More often one finds lists of deities with either the name of one of the deities used to represent the group or the whole group condensed into one apposite term to represent all. The most common and relevant of these is the grouping sa bdag klu gnyan, ${ }^{185}$ together comprising a category of worldly deities that is itself often listed as one of eight categories of deities - the lha srin sde brgyad, ${ }^{186}$ but many other explicit and implicit classifications exist throughout the literature and common knowledge. These include:

- lu, nyen, and gyel (rgyal) as a subgroup of the eleven sa yen (sa g.yen)..$^{187}$ - lha, lu, and men.188

- lha in the skies or upper world, nyen in the middle, and lu below. ${ }^{189}$

184 The Dunhuang text is PT 1047, via Karmay, 1998, p. 443, referencing others.

185 There are countless examples of this across texts, some of the most relevant being in Blondeau's examination of dö rituals and specifically the $m k h a^{\prime}$ klong gsang mdos (2005, p. 256), the Treasury of Good Sayings (p. 141a, from Karmay, 1972, p. 227), Cabezon, 2009, pp. 4-6, and those referenced in the next note as part of the larger classification.

${ }^{186}$ See Karmay, 1998, p. 444, and also Stein, 1972, p. 208, for a specific and older usage in a Bönpo ritual text.

187 Primarily from the Zermik (Franke, 1924, p. 340), but see also Karmay, 1998, p. 450 for a table that shows five additional classification schemes from three sources - the $m k h a^{\prime}$ klong gsang mdos, the bstan srung mtshon tho by klong rdol ngag dbang blo bzang, and the IHa 'dre bka' thang in bka' thang sde Inga, by o rgyan gling pa.

188 This is primarily from the Zermik (see Franke, 1924, p. 338) but is also in the Treasury of Good Sayings (pp. 145b and 148a, from Karmay, 1972, pp. 231 and 233, respectively), and could be idiosyncratic to certain narratives that are not meant to be classificatory, but geshés and others explained that much of their understanding of these deities originates in these stories and thus classification is a byproduct of the narratives even if unintended. 
- $\quad$ mu, dü, tsen, lu, nyen, sadak, gek, sin, chungpo. ${ }^{190}$

- lha, lu, mi, mu, tsams, gek, nö chin.191

- lu, tsen, dü. ${ }^{192}$

It is important to note, however, that in the context of the Nyelam Dé Zhi, none of the four kinds of deities are explicitly positioned in relationship to lha or any other deities, only in relation to each other. ${ }^{193}$

Identification of a classification scheme that pertains on the ground is complicated by the narratives of the Nyelam Dé Zhi, which further describe these deities in terms that are occasionally at odds with most monks' understandings of them. The primary ritual text of the collection, the Upper Ritual, describes the sadak and lu as cosmogenetic agents or at minimum primordial actors who were not only present at the time of the creation of the world, but whose very bodies comprise the earth and sentient beings. Monks believe that these beings have been around a long time, but when they heard or were directed to parts of the text that said all sentient

189 See Karmay, 1998, pp. 254, 382 (translating the incense ritual text bsang gi dag gtsang sngon 'gro, compiled by mnyam med shes rab rgyal mtshan), and 441, where he points to this being so common as to have become an "expression"; Tucci, 1949, p. 717, also referenced by Bellezza, 1997, p. 34; and Blezer, 2005, p. 136, referencing the Gesar epic via Stein, 1959.

190 dmu, gnyan, sa bdag, bgegs, srin, 'byung po (Karmay, 1998, p. 344n34, from the rnam bshad gsal ba'i sgron me by skyab ston rin chen 'od zer).

191 lha, klu, mi, dmu, tshams, bgegs, srin, gnod sbyin (Karmay, 1998, p. 344n34, from the same text as the previous note but two pages later).

192 This is via Mumford, 1989, p. 84 and elsewhere, who claims that these three types of "area gods are defined in a highly standardized way both in Bön cosmology and Nyingma Tibetan Buddhist ritual" (84), though it would appear that he is describing the individual categories and not the three together. As for the three together, they can often be seen comprising the retinue of powerful local deities - see, for example, Nebesky-Wojkowitz, 1956, pp. 225, 248.

193 There is one interesting exception to this, which is that a number of places in the Nyelam Dé Zhi volumes group the stars and planets in with the four worldly deities. While there is no explanation for this within the volumes, and even Tenzin Tsultrim could not explain why they are all grouped together, suggesting that maybe it was because they were condensed earth (interview with Tenzin Tsultrim at Triten Norbutsé on 5/25/2010), Beyer (1978, p. 294) quotes an anonymous Buddhist text called the dpal phyag na rdo rje 'byung po 'dul byed kyi sgrub thabs (block print with no edition, $\mathrm{p}$. 8a) that suggests the planets and constellations are the harmful spirits above, the sadak, lu, and nyen are the harmful spirits below, and the harmful spirits on surface of earth are the ghosts, kings, and tsen. 
beings were originally sadak, lu, nyen, and tö, or that described, for example, chopping wood as cutting into the ankles of these beings (see below), a number of them attempted to correct these assertions or were confused, or just said, "There are many different stories." ${ }^{194}$ For these monks, the "true" identity of these beings came from experiences they had in their families before they became monks, or from incidents in their villages, or from the stories that comprised the local lore.

These experiences or stories and monks' comments about them were often of much the same character. A particular lu or group of lu inhabited a stream or other water body nearby. An illness or other community-level misfortune occurred, the lu were thought to have caused it because they had in some way been offended by the community's treatment of their abodes - pollution, misuse, and so on - and the community members thus propitiated them to alleviate the misfortune. This coincides very much with classic textual descriptions of lu, including those in the Nyelam Dé Zhi, but monks went on to emphasize, or otherwise clearly implied, that these were a fundamentally different and unique type of being, unlike other sentient beings. Where they resided, in terms of the six realms of existence, was not at all clear or consistent, but they were certainly not human. Some monks thought they could be hungry ghosts, some thought they were a kind of god, but the idea that they were somehow more fundamental beings that gave rise to the rest of the sentient beings was unpopular indeed. ${ }^{195}$ The stream or water body was also clearly understood to be their abode, not their body, and the offenses against them were

\footnotetext{
194 Interview with Tenpa Dargyé at Triten Norbutsé on 2/17/2009.

195 They did acknowledge, however, that some lu were powerful enough to take on different forms, and that there were stories of human or hybrid offspring of lu that were able to interact with or command lu in special ways.
} 
thus not assaults on misunderstood body parts but on the environments that were the bodies' medium, and a possibly temporary one at that, as a great variety of factors compelled lu to come and go.

As for particulars about the four kinds of deities, a few salient details about each will be offered in sections below, but in relation to each other the sadak and lu are commonly known among all Bönpos, and among all Tibetans, while the nyen and especially the tö are much less well understood. Some monks, including geshés, could not name these latter two when discussing the Nyelam Dé Zhi, even after participating in the recitation. Other monks and some laypeople say that they have heard of nyen and have a general sense of their identity, but no one aside from Tenzin Tsultrim and the most well-read of geshés and rinpochés knew anything about the tö. Even then, those who maintained a familiarity with these elusive deities often described them only as a kind of lu that lived in the rocks or in the atmosphere. ${ }^{196}$ Indeed, the simplest explanation for all of the deities was that they are merely different kinds of lu, distinguished only by their habitat, with tö as above, sadak inhabiting the earth, and nyen inhabiting forests. Though no one makes specific reference to it when discussing the subject, this sentiment is mostly supported by a section of the Upper Ritual, ${ }^{197}$ which reads:

Generally, when lu live in water they are called "lu of the ocean depths."

When lu live in the earth they are also called "great powerful sadak." When

196 The "rocks" ( $\mathrm{rdo}$ ) and "atmosphere/air" (gnam) answers rarely came simultaneously from a single source. Most monks expressed an opinion that tö deities lived in one or the other. Only Tenzin Tsultrim and Nyima Özer explained that there were at least two kinds of tö, those that lived in rocks and those that lived in the atmosphere, which is supported by texts cited in this chapter.

197 Volume 6 of the Nyelam Dé Zhi, pp. 99-176. 
The only substantial difference in this context is that nyen are described as inhabiting the atmosphere, which some informants agree with, but which is not consistent across sources and informants that locate the nyen in the forests and the tö in the rocks and/or atmosphere.

Pushing further for detail with informants, however, yields a very clear additional set of distinctions between at least the sadak and lu, with the former taking on the aspect of a bug or scorpion with a humanoid head, ${ }^{199}$ responsible for landslides and earthquakes and such, and the latter taking on the aspect of a serpentine or fishlike body with a humanoid, usually female head, responsible for all water-related fortunes and misfortunes - floods, droughts, timely or untimely rain, and so on. Some of the monks and laypeople mentioned that the lu cause leprosy and other diseases, but no one believed (or at least did not mention) that the other deities were involved in anything except fortune and misfortune as it pertained to their respective natural abodes - earthquakes, rock slides, forest fires, and so on. This popular conception of the lu as more powerful and more relevant than the others is a departure from the Upper Ritual, which reads:

\footnotetext{
198 spyir ni klu rnams chu la gnas tsam nas/rgya mtsho gting gi klu zhes bya/klu rnams [sa] la gnas tsam nas/sa bdag dbang chen zhes kyang byas/klu rnams nam mkha' gnas tsam nas/bar snang khams kyi gnyan zhes bya/klu rnams brag dang rdo la gnas tsam nas/drag po mi mthun gtod kyi bya/ (106.5-107.2). Note that all the tsam nas would more typically be tsam na, kyang byas is better and more consistent as kyang bya, and kyi bya at the end should be kyang bya.

${ }^{199}$ A laywoman who runs a shop just down the hill from the Menri guesthouse displays a large print of a sadak on the inside of her front door - a many-armed, scorpion-like creature with the head of an unshaven man with fiery red eyes - but she admitted that she had never actually seen a sadak before and did not know if they all looked like this. Nevertheless, it seems likely that some at Menri who described the sadak in this way were influenced by this powerful image.
} 


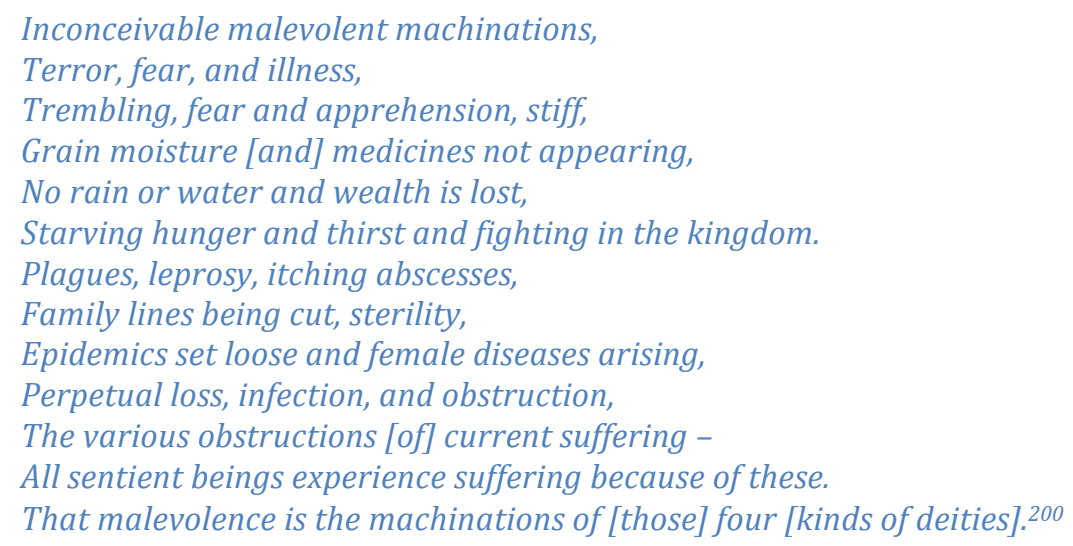

It is thus unambiguous, in this context, that all four types of deities are responsible for all kinds of calamities.

The ontological status of these deities is a predictably slippery subject. Of all the Bönpos interviewed, only one, a layman at Triten Norbutsé, claimed to have seen

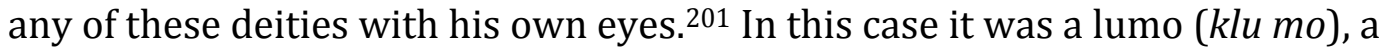
female lu, in the form of a fish with a strange head that looked vaguely reminiscent of a woman's head, with hair streaming alongside the fish-body. It was in a river in India, he said, and there was a glass box for donations on the rickety bridge above the lumo. He thought it might have been - and here he searched for and unexpectedly found the word in English, despite the rest of the conversation being in Tibetan - a "sideshow," but he worried about the consequences if he was wrong, and thus gave a few rupees.

\footnotetext{
200 gdug pa cho 'khrul bsam mi khyab/ 'jigs shing skrag dang na tsha zhi/'dar zhing skrag dang bred cing ring //'bru bcud sman rnams mi 'byung zhing / char chu med cing longs spyod zad/ bkres skoms ltog cing rgyal khams 'khrug/ nad yams mdze shu g.yan pa dang / skye rgyud bcad cing mngal rgyud skam/ nad rim gtong dang mo nad 'byung / god yams bar chad rgyun mi 'chad/ da lta'i sdug bsngal bar chad sna tshogs kyis/sems can thams cad sdug bsngal spyod// gdug pa de bzhi'i cho 'phrul yin/ (103.14). Note that cho 'khrul should be cho 'phrul, na tsha zhi should be na tsha zhing, skoms ltog should be skoms ltogs, and nad rim should be nad rims.

${ }^{201}$ Interview with Sonam Drakpa at Triten Norbutsé on 6/6/2009.
} 
While the absence of first-hand accounts casts suspicion on the empirical existence of the deities, a great many Bönpos can cite evidence of their activities. The most obvious and abundant of these are natural disasters. Just before my stay at Menri monastery in the summer of 2008, a landslide destroyed part of an unfinished tantric (sngags pa) temple at the edge of the monastery. Geshé $Q$ and others expressed concern that they had not properly conducted the land consecration ritual (sa chog) or had otherwise failed to ask proper permission from the local sadak. They brought in a layman who specialized in geomancy (sa dpyad) to reassess the suitability of the location and, with his approval, worked together to repropitiate the sadak. ${ }^{202}$

202 By the time I left in the summer of 2009, the temple was still incomplete but there had been no further setbacks of the magnitude of the landslide, which locals hoped was an indication of a satisfied sadak. Note that no one seemed to know anything about this lay specialist, however, who was not a member of the community. Sangyé Tenzin referred me to two geshés, including Geshé Q, who said they remembered him but did not have any particular details about him. 


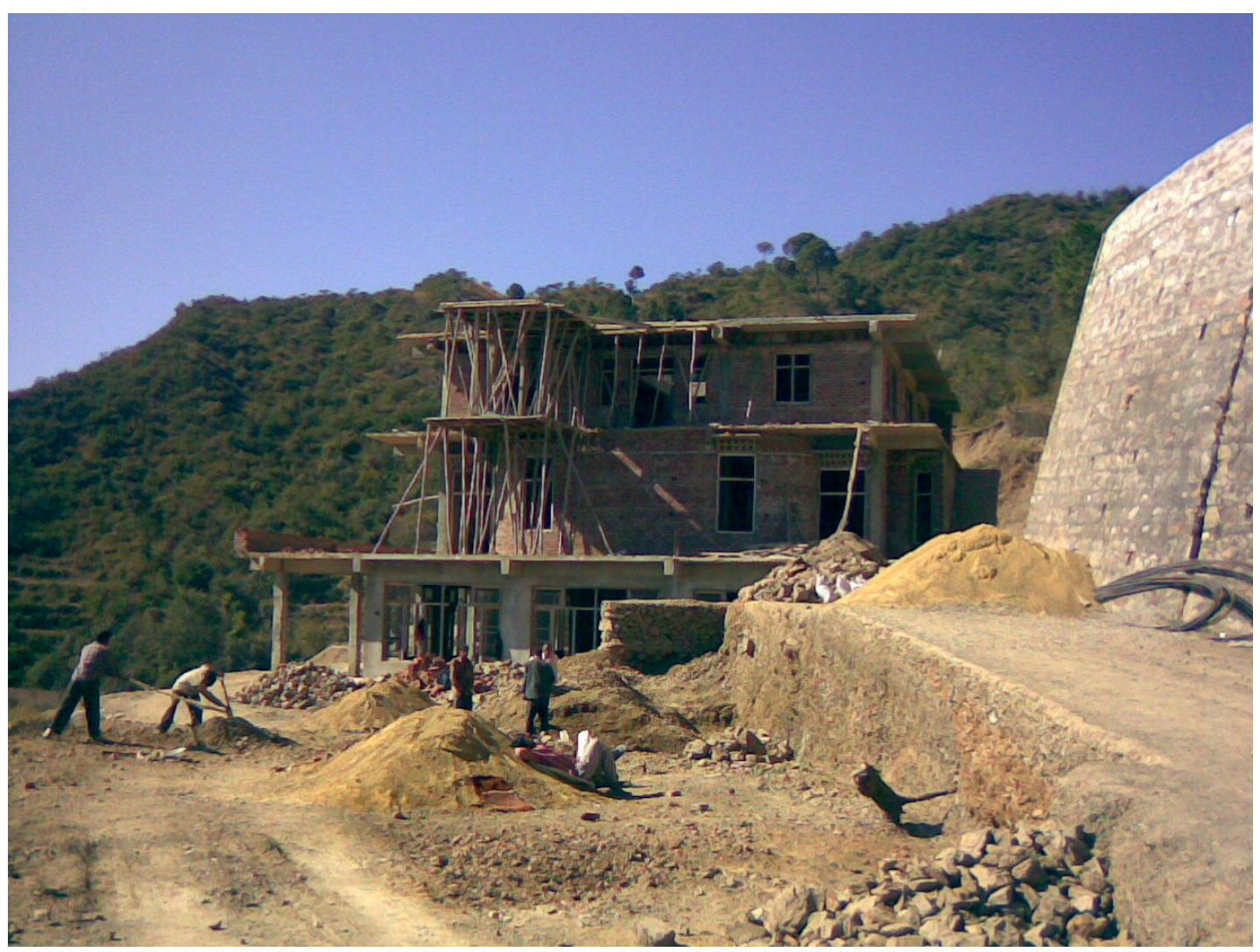

Figure 4.1: The tantric temple at Menri that was partially destroyed by a landslide that may or may not have been the work of the sadak.

At a more subtle level, a number of people described the physical signatures of these deities' abodes, important in the assessment of land suitable for inhabitation or cultivation. Nyima Özer, for example, said that it is very clear when the lu have made a home at the base of a tree near a water body - a common location for lu. In these cases, the ground around the tree will become like a marsh, and the tree trunk will start to discolor with a moldy or algal substance. ${ }^{203}$

There is a great deal of disagreement among even the most educated monks about whether it is possible to see these deities in any circumstances. Tenzin Namdak likened them to "people living in the jungle" - most of the time they are

${ }^{203}$ Interview with Nyima Özer at Menri monastery on 2/16/2009. 
hidden, camouflaged, but in the right conditions, from the right angle, if you are close enough, you can see them. ${ }^{204}$ Some of the geshés explained that, while these deities are unquestionably real, ${ }^{205}$ it is not possible to see them. Tenzin Yangtön, for example, said that they are formless, and that they have to be or there would be no room for all of us. They are so abundant that we would all be shoulder to shoulder on the earth. This does not mean, however, that it is impossible that people have seen them. They may have the power to reveal themselves to certain people at certain times, but it is rare. ${ }^{206}$

As agents of both fortune and misfortune, with powers greater than the average human, requiring material offerings, apologies, and flattery in order to maintain harmony in the community, their classification within the six realms of existence is not immediately clear. Are they gods, powerful hungry ghosts? Tenzin Tsultrim explains that they do not fit neatly into the model of the six realms of existence. They share some common characteristics with other beings - they have some physical traits and desires that are similar to humans and some that are similar to animals, with powers that are similar to gods - but ultimately they exist in a kind of "between space" that is hard to understand. ${ }^{207}$

Different monks and geshés nevertheless had different ideas about which realm these deities belonged to, but even when the question was asked in the context of the Nyelam Dé Zhi not one of them referred to the Upper Ritual volume

\footnotetext{
204 Interview with Tenzin Namdak at Triten Norbutsé on 5/26/2009.

205 No one I spoke to expressed any doubt about these deities being real, though I asked Sangyé Tenzin if they were real or metaphorical and with characteristic diplomacy and ambivalence he answered: "The monks believe in them, but you can't always trust monks" (Interview at Menri monastery on 4/22/2009).

206 Interview with Tenzin Yangtön at Menri monastery on 6/18/2009.

207 Interview with Tenzin Tsultrim at Triten Norbutsé on 2/27/2009.
} 
that addresses this question specifically. As described above, the first section of this volume is a myth-history of the four types of deities of the Nyelam Dé Zhi, towards the end of which it reads:

The four classes of nyen and sadak mixed together and became the inner contents, the sentient beings - the gods, demi-gods, humans, animals, hungry ghosts, hell-beings, and so on...As for the teaching [about] their abodes, the world [is where] sentient beings [of] the six types reside. The lu do not reside as formless gods or gods of the form realm. The lu do not reside in the [realms of the] hungry ghosts or hell-beings. Because of the power of their merit, they reside pervasively in all the rest. ${ }^{208}$

In this case, "all the rest" (phyi ma yo, which could be expanded to phyi ma yo ka), refers to all the realms "after" or "beyond" the form and formless realms, and beyond the hungry ghost and hell-being realms of the desire realm, thereby indicating the animal, human, demi-god, and god realms. However, it also clearly states that the four kinds of deities "mixed" or "joined" together (sbyor ba, which can also mean to copulate, a meaning that also fits in this context) and all six types of sentient beings thus came into existence. Thus, if the sadak and lu and so on do not currently reside in the realms of hungry ghosts and hell-beings - because of the power of their positive merit, an atypically positive assessment of their soteriological status - they are nevertheless genealogically connected to them.

Other sources point to different classifications of the deities, or different emphasis in comparable classifications. Mimaki (2005, pp. 99-101) points out that

\footnotetext{
${ }^{208}$ gnyan dang sa bdag sde bzhi sbyor ba la/ lha dang lha med mi dang byol song yi dags dmyal ba la sogs nang bcud sems can srid/... de dag gnas ris bstan pa ni/ 'jig rten khams ni rig drug sems can gnas/ gzugs med lha dang gzugs khams lha la klu mi gnas/yi dags dmyal ba gnyis la klu mi gnas/ bsod nams dbang gi phyi ma yo la khyab par gnas/ (106.2-5). Note that rig should be rigs and dbang gi should be dbang gis.
} 
an important 14 th century doxographical work ${ }^{209}$ describes lu, nyen, and tö $^{210}$

primarily as demi-gods (Iha ma yin) but also as hungry ghosts (yi dwags), and

contrasts this against typical Buddhist accounts, which describe them as animals.

Mimaki also draws a hesitant but important conclusion from this inconsistency, that

the lu kings may be demi-gods, while the lu peasantry are hungry ghosts. None of

the Nyelam Dé Zhi texts or explicit monk comments make reference to this possible

distinction, but the differing treatment and understanding of both, inside and

outside of ritual contexts, supports a dual status-based classification.

A perspective with regards to origins and residence that none of the monks

or laypeople shared is given in the fragmented Lubum that is also part of the Nyelam

Dé Zhi collection, ${ }^{211}$ and from which, together with the three matching volumes for

the other three deities, substantial parts of the Upper Ritual are drawn. It describes

the lu as deriving from a dragon that fell from the sky, ${ }^{212}$ which then became the

earth, or of parallel prominence as the earth, such that:

The radiance of the lu were the first of what was in the sky - the clouds -

and the winds were their retinue.213

The first among earth foundations was Mt. Meru, which is the body of the lu.

The first among that which grew was vegetation, and that is also the hair of

the lu.

The first among grasses were the ne'u gseng grassy valleys, and that is also

the body hair of the lu.

\footnotetext{
209 bon sgo gsal byed.

210 See the lists on pp. 104-105 for mention of gnyan po and gtod po.

211 Volume 24, pp. 565-602.

212 Or, less likely, they were a treasure that fell from a dragon in the sky - dang po srid pa gnam la bab pa'i gter la/gnam las bab ni 'brug yin te/ (566.3). Note that gnam la bab should be gnam las bab. As will be discussed in the next chapter, the contents of this volume are quite inconsistent, fragmented, sometimes incoherent.

213 I have rendered this as verse despite the variation in syllable counts from segment to segment. Given the shortness of lines and the average two-syllable variance, it is my opinion that this was either more disciplined verse prior to multiple transcriptions and edits or a somewhat unsuccessful attempt at verse to begin with.
} 
The first among elements was air, and this is also the breath of the lu. The first among flooding things was water springs, so this is also the water spring of the sadak and lu.

The first among that which flowed was the water, snow, and rain, so this is also the snow and rain of the sadak and lu.

The first among that which puddled was the ocean, so this is also the abode of the sadak and lu.

This first among solid things was stone, so this is also the bones of the sadak and $l u$.

The first among soft things was water, so this is also the blood of the sadak and lu.

The first among empty things was the sky, so this is also the canopy of the sadak and lu.

The first among surfaces was the earth, so this was also the flesh of the sadak and $l$. $^{214}$

\section{When human affronts are made to the earth and water, then, it is not just that one is}

\section{defiling the abodes of these beings, but assaulting their very bodies:}

In that way, [when] cutting puru wood [at] washing channels, it comes from the ankle bones of the sadak and lu. [When] taking water from the bottom of a valley, it comes from the blood of the sadak and $\mathbf{l u}^{215}$

\footnotetext{
214 de yang klu yi 'od zer la sogs te nam mkha' la snga ba ni sprin legs te/de yang klu yi 'khor rlung legs so// sa gzhi la snga ba ni ri rab legs so/da yang klu yi sku gzugs legs so// skye ba la snga ba na rtsi shing lags te/de yang klu yi dbu skra legs so// bre mo la snga ba ne seng legs so// de yang klu yi yul legs so// 'byung ba la snga ba ni rlung legs te/de yang klu yi lbugs so/skye 'brug la snga bo ni chu mig legs so/de yang sa bdag dang klu yi chu mig legs te/'bab pa la snga ba ni chu kha char legs te/de yangs sa bdag klu yi kha char legs so// 'khyil ba la snga ba ni rgya mtsho legs te/de yang sa bdag klu yi bzhugs gnas legs so// sra ba la snga ba ni brag legs ste/de yang sa bdag klu yi rus pa legs te/snyi ba la snga ba ni chu legs te/de yang sa bdag klu yi khrag legs so// stong dus snga ba la ni gnam legs te de yang sa bdag klu yi bla re legs te/logs su snga bo ni sa gzhi legs te/de yang sa bdag klu yi sha legs te/ (566.4-568.3). Note that there are a number of spelling mistakes or alternate spellings, and also that this subject matter, matching the first of something to the lu and sadak, continues until 571.2 - I chose a small illustrative sampling. It is also unclear why the sadak start to be included with the water springs, through to the end of the section. Though there may be a logical explanation - some connection between earthly features and lu that sadak do not share, or a tacit strategy for illustrating the primacy of lu over sadak - it seems more likely that it is merely a transcription or translation or dictation idiosyncrasy.

215 de ltar las khrus rtsa phu ru shing bcad pa sa bdag dang klu yi re long lad 'bab po/ mda' chu btus dang sa bdag dang klu yi khrag---------'babs so/ (571.3-4). Note that lad should be las, and that there is a section of text explicitly missing or unclear to the scribe, which likely included at least las. I left phu ru untranslated because khrus rtsa phu ru was unclear to Tenzin Tsultrim and all geshés consulted. phu ru, which is most often used to translate the sound of fluttering bird wings, could refer to a type of thorny plant (see 'jig rten mgon po, bka' 'bum (2001) IV 133.5).
} 
Even if the vast majority of monks and laypeople do not know or do not cite this cosmogonic orientation of the lu and sadak, or their equivalence with earthly elements, such textual descriptions help to explain the importance of, or at least enhance the representation of these deities as intimately tied to the earthly exploits of human activity. As such knowledge filters down from those who do read these myth-histories, they help to explain the emphasis on these two deities in particular over the others, though we have to allow also for the possibility that lay concerns and sensibilities filtered up into these texts.

As a further and final complicating factor, these deities can hybridize with each other and with other kinds of deities. It is not uncommon to come upon deities identified as more than one of kind of deity - as with Nyenchen Tangla (gnyan chen thang Iha), who is variously considered a lha, nyen, or lu $\mathrm{u}^{216}$ - or to read about hybrid groups with more than one designation in their name - lu tsen (klu btsan), ${ }^{217}$ lu sin (klu srin),,218 lu drokmo (klu 'brog mo),,219 lu dü (klu bdud),,220 and so on.. ${ }^{221}$

Lu

Of the four deities, it is the lu, which many scholars, both Tibetan and western, traditionally consider a translation in word and concept of the Sanskrit naga, that command a special attention and enthusiasm, from Tibetan ritualists and nonritualists alike. Monks and laypeople at Menri and Triten Norbutsé tell stories about

\footnotetext{
216 See for example Bellezza, 1997, pp. 34-35.

217 Nebesky-Wojkowitz, 1956, p. 309.

218 Nebesky-Wojkowitz, 1956, p. 315.

219 Nebesky-Wojkowitz, 1956, p. 303.

220 Nebesky-Wojkowitz, 1956, p. 386.

221 It should be noted, however, that some combinations, such as lu nyen (klu gnyan) likely use the latter word as an adjective rather than to represent a hybridization of beings.
} 
them, sometimes recounting legends from books, sometimes describing episodes from their upbringing in which lu exacted revenge for infractions against them. Examples include the pollution of a stream or the failure to make offerings on days that are "lu tep" (klu thebs), when the lu emerge from their lairs. As Nyima Özer explained, one can identify lu-inhabited trees even from a distance, and yet the abodes of the sadak, nyen, and tö are not only lesser known but, especially as concern the latter two, are the subject of much deliberation and debate even in the abstract. The Lubum is wildly popular and widely read as well as ritually employed among both Bönpos and Buddhists. In contrast, extremely few monks, including geshés, could speak specifically to the contents of the Sadakbum, Nyenbum, and Töbum that are of equal import - and much greater coherence, though less rich in content - to the Nyelam Dé Zhi and allegedly to the management of these deities in other contexts.

From a practical perspective, part of the reason for the greater significance of lu compared to the other deities is that they control water, so critical to the traditional day-to-day lives of a great many Tibetans, in the sense of engaging directly with water bodies or needing water for agriculture, even if less relevant to those of the monks. ${ }^{222}$ Western scholars and Bönpos alike have suggested that one of many possible reasons that the Buddhists adopted the Bönpo Lubum text was for its efficacy, perceived or otherwise, in rainmaking. ${ }^{223}$ There was thus more tangible, and more immediately relevant, benefit and harm from the lu than others, if only

\footnotetext{
222 Monks drink water, of course, but do not interact with bodies of water.

${ }^{223}$ For the western scholarship side of this, see for example Martin, 2001, p. 411.
} 
because their identification with and relationship to water was clearer, more consistent, and easier to grasp.

An important dynamic in common portrayals of lu that is otherwise not explicitly present in the Nyelam Dé Zhi narratives is that lu tend to be associated with women or the feminine. Karmay 1998 (p. 494) speaks to this femininity as a common trait of lu identification, and places it in opposition to mountain deities, who are more often male and/or associated with the masculine. ${ }^{224}$ Other examples can be found in a hymn in Karmay, 2005, p. 392, and Nagano, 2005, pp. 577 and 596, and in the ubiquitous references across primary and secondary literature to "lumo."225 In the context of the Nyelam Dé Zhi, it is thus significant that in the mandala recitation that connects worldly deities and the Ones Gone to Bliss with cardinal directions, lu are placed with Satrik Ersang, the one feminine deity in the entirety of the ritual, in the east.226

\section{Sadak}

There is very little known Bönpo literature 227 that describes sadak deities in detail comparable to lu. Unlike the lu, which either originate from or express in parallel the Indian naga, the origins of the sadak are of a distinctly Tibetan provenance. Erik Haarh provides the most compelling etymological account in The Yar-lun Dynasty

\footnotetext{
${ }^{224}$ Karmay also notes on the same page that nagas in Indian literature have abundant male identifications and thus the female aspect or its emphasis is Tibetan.

${ }^{225}$ A great deal more information about lu can be found in Mumford, chapter 5 (pp. 93-116), which discusses rites of exchange between the lu and a Buddhist community in Nepal, and via the additional references cited in Nebesky-Wojkowitz, 1956, p. 290n85. There is frankly more information to be found than could reasonably be referenced here, but not all of it is relevant to the communities under discussion - Bönpo, monastic, from diverse geographies - even if a great deal of lu knowledge is shared across Tibetan subcultures.

${ }^{226}$ See pages $129-131$ of the Upper Ritual.

227 As with all assertions of "little known," it is highly likely that there are extensive descriptions in the as-yet-unexamined vastness of untranslated Bönpo texts.
} 
(1969, p. 313), suggesting that the very term sadak is a personification of the more abstract power, often malevolent, of the earth and of the dead, which was referred to previously as sadok ( $s a \mathrm{dog}$ ), meaning "binding the earth." The Sadakbum, a condensed version of which is included in the Nyelam Dé Zhi collection, does not provide much general descriptive information, but rather, and much like a great many sources dealing with sadak, concerns itself mostly with listing a number of specific sadak deities and imploring all of them to heed the words of the Bönpo teachers and actors. The Lubum does have some limited detail, for example describing some of the illnesses that sadak are responsible for, including the thinning or emaciated appearance of one's limbs, ${ }^{228}$ but Nebesky-Wojkowitz suggests that the astrological text Vaidurya Karpo (vaidurya dkar po) is the principle source of information about sadak, ${ }^{229}$ and this may in fact be true, especially in Buddhist contexts, but no Bönpos acknowledged this as their source of information, which is not at all surprising given that it is a Buddhist text authored by the prominent Sanggyé Gyatso (sangs rgyas rgya mtsho, 1635-1705).

Nyen

The diversity and difficulty of monk explanations of nyen is mirrored by the tremendous variety of descriptions in textual sources. The Upper Ritual of the Nyelam Dé Zhi says clearly that "when lu live in the sky, they are called nyen of the realm of space,"230 which is the clearest and most discursive description of nyen among all the volumes of the collection, but the important Affecting Nyen (gnyan

\footnotetext{
${ }^{228}$ See the reference to the Immaculate Lubum on Nebesky-Wojkowitz, 1956, p. 298.

${ }^{229}$ Nebesky-Wojkowitz, 1956, p. 291.

230 klu rnams nam mkha' gnas tsam nas/ bar nang khams kyi gnyan zhez bya/ (107.1)
} 
bcos) volume, recited multiple times over the course of the ritual performance, includes these verses, which situate nyen virtually anywhere:231

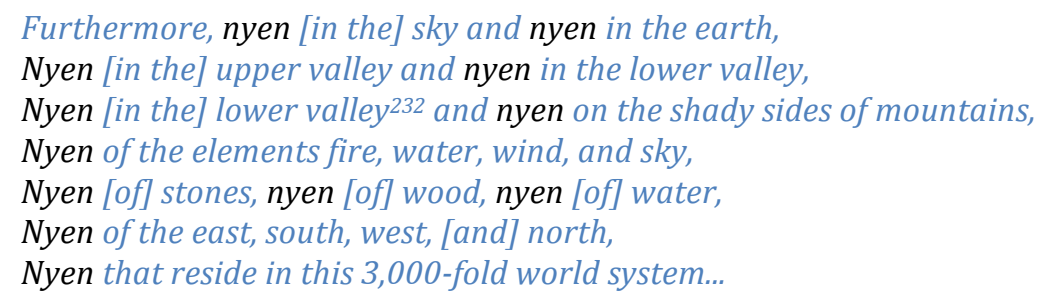

The Nyenbum, which less monks recite or otherwise have intimate knowledge of, also says: "Nyen [of the] sky and nyen [of the] between and nyen [of the] earth" (606.2), makes reference to nyen of mountains, fields, rocks, boulders, meadows, lakes, paths, and trees (607.3-5),233 and then lists a great variety of kinds of mountains and specific (usually mountain) places where they reside, including the "forests of wish-fulfilling trees."234 The first description, placing nyen in the sky or the "between," correlates with aspects of the description in Affecting Nyen and accommodates the identification of nyen as sky-bound lu in the Upper Ritual, but for

${ }^{231}$ gzhan yang gnam gnyan dang ni sa ru gnyen/ phu gnyan dang ni mda' ru gnyan/gda' gnyan dang ni srib su gnyan/ me chu sa rlung nam mkha' 'byung ba'i gnyan/gor gnyan shing gnyan chab gnyan dang / shar lho nub byang phyogs kyi gnyan/stong gsum 'jig rten 'dzam gling 'di la gnas pa'i gnyan/ (246.4-247.1)

232 As you can see in the previous note, "lower valley" is spelled predictably as $m d a^{\prime}$ in the previous line, but then incorrectly as $g d a^{\prime}$ in this line. Nyima Özer assured me that it is supposed to be $m d a^{\prime}$ here as well, repeated because the author wanted to ensure syllable consistency, and presumably did not have another concept that worked as well. Though Nyima Özer dismissed the correct spelling followed by an incorrect spelling as something common to old texts, it seems likely that both were spelled $g d a^{\prime}$ originally and a later scribe corrected the first one to $m d a^{\prime}$, as its meaning was clear in the context of its opposition to $p h u$, while the second one's meaning, so close to the first, was less clear and thus left as is.

233 Note that genitive relationships are reversed in some cases, yielding, for example, both brag gnyan and gnyan gyi pha bong, but I have taken the leap to suggest that even in cases where it is clear that the text is talking about "the boulder of the nyen," it is conveying that nyen live in the places where these features exist. This is admittedly different from the identification of a feature as a primary, bounded abode, but it nevertheless speaks to where nyen can be found and is thus a significant identifier.

${ }^{234}$ dpag bsam ljong shing nags 'tshal la gnas pa'i gnyan (611.4-5). 
those attempting to solidify an identity or definition of nyen deities by abode, especially as they relate to the other three types of deities of the Nyelam Dé Zhi, their ubiquity defies any overly simplistic categorization - as with lu living in water, sadak in soil, nyen in the forests, and tö in the rocks - and in fact the common explanation among informants that nyen inhabited forests is not specifically supported anywhere in the Nyelam Dé Zhi texts aside from this one verse that includes "nyen [of the] trees" (shing gnyan) in a kind of non-descript list, and the "forests of wish-fulfilling trees," which does not point to forests as a habitat as much as it elevates the status of nyen by locating them among wish-fulfilling trees.

Given that this description is deep in a volume that is not recited by all monks and not recited aloud by those monks that do read it as part of the Nyelam Dé Zhi, and given also that this verse is among many others with unusual or otherwise difficult language, it is highly unlikely that this one description has informed the common belief that nyen live in forests. Rather, it is unspecific lore ${ }^{235}$ combined with the placement in the woods of Nyelam Dé Zhi artifacts designated for the nyen that has led quite naturally to the conclusion that this is their primary abode. If at some point in time there had been recognition among Nyelam Dé Zhi administrators that nyen are more commonly situated in the sky/atmosphere or mountains, it was surely deemed impractical or impossible to "place" artifacts in the sky or in non-existent mountains, ${ }^{236}$ and the need to maintain the symmetry of the

\footnotetext{
235 Tenzin Namdak suggested, quite independently of the Nyelam Dé Zhi, that nyen live in forests, and there is certainly plenty of other support for this assertion, as in

236 Triten Norbutsé is on a hillside but there are no mountains in the vicinity.
} 
four directions perhaps suggested that one group of deities would need to receive their gifts from the Nyelam Dé Zhi in the woods behind the temple.

Tö

The tö deities are much less well-known ${ }^{237}$ than the other three, both among scholars and community members at Triten Norbutsé, but it is not entirely uncommon to hear or see them mentioned in the same categories as sadak, lu, and/or nyen - or in larger categories of "local deities" in a variety of sources and in conversation - as a type of sadak or nyen that lives in the rocks. ${ }^{238}$ Aside from the Nyelam Dé Zhi, they can be found in the Zijii ${ }^{239}$ and a variety of other canonical texts, ${ }^{240}$ including their own Töbum, of which there is a condensed version in the Nyelam Dé Zhi. Their relative obscurity compared to the lu and sadak, however, means that their places of residence are typically the only details ever offered with any consistency to identify them.

Some sources do offer trivial details, however. A ritual text for the offering of scorched grain in order to make rain is a typical example of the level of detail around tö deities across texts:

The rock tö [that live in] sandy places [and have] nine eyes,

The sky tö [that have] nine heads... 241

237 As with all assertions of "little known," it is highly likely that there are extensive descriptions in the as-yet-unexamined vastness of untranslated Bönpo texts, and in the knowledge of unmet ritual specialists.

238 All such descriptions almost certainly stem from the canonical Lubum and/or Töbum.

239 See Snellgrove 1967, pp. 10, 17, 78, 88, 92, and 94.

240 See especially the various relevant volumes of the gtad sprug chen mo, as calatogued by Martin and Nagano (2003), starting on page 31.

241 rdo gtod bye ma mig dgu dang: gnam gtod yod pa mgo dgu dang:, from the gsung 'bum of kun bzang nyi ma (1904-1958) in the section titled as drag sngags me 'dus spu gri'i 'khor lo las: sa bdag klu gnyan gtod kyis dgyes bskyed shel tshig 'bul ba bdud rtsi'i char 'bebs, pp. 376.6-377.7 
Such details vary from text to text, however, and they otherwise have no known characteristic attributes, as with the serpentine aspect of lu, and even the suggestion that they might be the ones responsible for rocky landslides or deaths in rocky environments - falling from cliffs and so on - were met by monks with shrugs or counter-arguments that it would probably be sadak who were responsible for landslides. Some sources include them among deities that cause people to go mute, ${ }^{242}$ but there is otherwise no consensus about particular afflictions that the tö are responsible for. ${ }^{243}$

The origin and meaning of the word tö in this context is also uncertain. The verb gtod pa has a number of definitions, including "to make anew," or "to face, entrust, or lean on," 244 all of which could be argued to make sense, especially when put in context of töpo ( $g t o d p o)$, a somewhat common alternate form of tö, in which case a translation might be "entrusted ones," or "those we lean on [for livelihood]," but it is still unclear. Namkhai Norbu suggests "Inflexible Ones" as a gloss or interpretation of the term, ${ }^{245}$ but his understanding of their identity is quite different from the typical, admittedly limited understanding. There is also much

\footnotetext{
242 Nebesky-Wojkowitz, 1956, p. 309, referring to information from various Lubum.

243 Yet another perspective, that of Chogyal Namkhai Norbu in A History of Zhang Zhung and Tibet, claims for tö a larger category that includes the others: "...powerful entities such as lHa, gNyan, Klu, and so on, that we can not distinguish with our senses, are called gTod" (Norbu, 2013, p. 188). This is an unusual perspective, however, that is not attested elsewhere, and it certainly contradicts the treatment of tö in the Nyelam Dé Zhi, as well as an astrological text that Norbu himself translates the dpyad gsum dag rtsis - which lists the sadak, lu, nyen, and tö as equals (Norbu, 2013, p. 215). ${ }^{244}$ This comes from the bod rgya tshig mdzod chen mo: gtod pa - (tha dad pa) 1. btod pa/ gtod pa/ gtod// gsar bzo'am gsar 'dzugs/...srol bzang khag mang sngar med gsar du gtod pa/...2. gtad pa/gtad pa/gtod//1) bcol ba dang/sprod pa/...blo snying brang gsum gtod pa/...las 'gan 'di nga la gtad chog ...ca lag de dag kho rang gi lag par gtad pa yin/...'dod pa can la nor ma ston/ ngan sems can la blo ma gtad/...2) kha bstan pa/...mda' 'ben la gtad nas 'phen pa/...khang pa'i rgyal sgo lho phyogs su gtad/...rkyang lho la shi yang mgo byang la gtad yong/...3) sems rtse gcig tu 'jog pa/...rna ba gtad nas nyon/...mig gtad nas dpe char lta/...dmigs (1050).

245 Norbu, 2013, pp. 40, 78, 81n18, 82.
} 
inconsistency and/or confusion elsewhere in terms of the possible interchangeability of tsen (btsan) and tö, ${ }^{246}$ and gto and gtod. $^{247}$

Given that sadak, lu, and nyen together comprise a common category of worldly deities, the conspicuous absence of tö, or any other deity, points to the need for different taxonomies in different contexts. The tripartite scheme that describes these deities of the landscape and collects them against deities and demons of other natures is a decontextualized compartmentalization of worldly agents and concerns that functions as a broadly deployable explanatory device. The fluidity of each of the three, and especially the nyen, allows lu to inhabit any space at all associated with water, sadak to inhabit the ground, which means essentially any non-aqueous surface, and nyen to exist everywhere else, usually described as one or more of rocks, trees, and air.

Groups of three are also extremely common as an organizational quantity across Bön (and across many traditions). In terms of deities, beyond the sadak lu nyen designation, there are, from above, the very common tripartite schemes of lha above, nyen in the middle, and lu below; lha above, man in the middle, and lu below; lu, nyen, and gyel; lu, tsen, and dü; and so on. There are the three Precious Ones (dkon mchog), the most common grouping of the Ones Gone to Bliss into three -

\footnotetext{
${ }^{246}$ See Nebesky-Wojkowitz, 1956, p. 265: "The sa bdag who dwell in the earth, the klu who dwell in the water, the btsan who reside in the rocks, the gnyan who stay in the intermediary space..."

${ }^{247}$ See Snellgrove, 1967, p. 88 for gto and then p. 92 for gtod, but note also that this was a common confusion on the ground, with monks often offering one or the other in conversation, though this may be a simple spelling confusion.
} 
Tönpa Shenrap, Shenlha Ökar, and Sangpo Bumtri - the body, speech, and mind, and so on. The list could go on for many pages. ${ }^{248}$

The mandalic structure of a ritual like the Nyelam Dé Zhi, however, depends heavily on the symmetry and immutability of the four cardinal, and four intermediate, directions. Groups of three do not lend themselves well to the architecture of such rituals, and yet the members of these groups are critical to ritual concerns and efficacy. The solution has been to expand the three to four, adding, for example, Satrik Ersang to the three Ones Gone to Bliss, and tö to the three sadak, lu, and nyen. Such expansions of established groups explain the heightened uncertainty and slipperiness of the one member compared to the other three, though it has to be acknowledged that a pre-existing ambiguity of character and identity may also be what made them more easily appropriable to these ends. ${ }^{249}$

\section{Conclusion}

Overall, there are a great many cases of shifting identity that illustrate the disagreement or different sensibilities around terms and categories, which stem variously from regional, historical, and individual idiosyncrasies. The high degree of diversity in each of these dimensions, including and especially as exhibited by monks at Triten Norbutsé, suggests that it is impossible to define a normative

\footnotetext{
248 This "rule of three" has many possible origins and motivations, but it is beyond the scope of this project to go into greater detail.

249 This necessarily points to structured mandalic rituals as technologies that grew out of, or on top of, a pre-existing pantheon and organizational structure, which may or may not be appropriate, but which is my assertion nevertheless, based on the increased ambiguity of one member in each of the primary groups of four.
} 
classification scheme even for one (admittedly heterogeneous) community, much less for Bön as a whole, and much less still for Tibetan traditions as a whole.

Nevertheless, the relative lack of ambiguity and inconsistency in perceptions of the Ones Gone to Bliss, with the exception of Satrik Ersang, reflects and reproduces different priorities. This happens both at the literary level - in which very clear, well-established canonical texts like the Ziji and the Zermik provide background and definition for the Ones Gone to Bliss with a consistency, comprehensibility, and preeminence that is missing in the huge diversity of texts that provide background and definition to worldly deities (most of which omit the tö deities altogether) - and at the local cultural level, in which the Ones Gone to Bliss persist across all rituals and are thus much more exposed, and also embody the ideals that the monastic community has been constructed to pursue. This constructed and bounded environment and its ideals are also designed to limit engagement with the kinds of activities that would bring its members into any kind of contact with worldly deities, a bubble that might ordinarily be perforated by their co-dependence on a local laity for provisions and patronage - those whose livelihoods and means of providing for the monastic community entail complex negotiations with such deities. The bubble remains imperforated at Triten Norbutsé, however, because of their urban and exiled situation, a dynamic discussed in more detail in Chapter Six.

Even so, it is not the case at Triten Norbutsé that monks have no contact with laity, and in any case worldly deities remain a critical constituent of their worldview. Pre-monastic experiences, historical and ritual narratives and activities, modern lay 
concerns in the countryside and in Tibet, and even the occasional direct contact between the monastic community and worldly deities, as when building a new structure on a previously undeveloped patch of land at the periphery of the monastery grounds, embed and sustain these deities in the individual and community consciousness.

Perhaps most importantly, confusion and complexity is a quality of the observed field, not of the individual experience. It does not concern monks and laypeople, at any level deeper than a mild curiosity, that agent identities shade one into the next or shift from ritual to text to practice to ritual, and so on, any more than it would concern them that the guest of honor at one birthday celebration is not the guest of honor at another birthday celebration.

In this context, rituals like the Nyelam Dé Zhi, representing historical and cultural layers that community members body forth without conflict but that are ultimately at odds with the community's dominant ideologies - scholarship and the pursuit of transcendence - help to render coherent different and sometimes contradictory identities and experiences. It is through the bounded experience of rituals like the Nyelam Dé Zhi that actors' relationships with the various deities, informed though they may be by a great many familial, regional, historical, and ideological layers, some of which would indeed contradict each other if brought into direct dialogue, maintain their coherence. The ritual event is given a very specific timeframe in the annual calendar and has very clear start points (gathering and construction) and end points (deconstruction and dispersal), inside of which are specific treatments of and claims about deities' identities. While it is clear that 
actors import and export notions of identity to and from these bounded contexts, and while rituals like the Nyelam Dé Zhi have spatially and temporally expansive aspirations, any resulting tensions dissipate in the authoritative, domain-specific language of the ritual, which describes a bounded subset of a larger reality, for specific (if sometimes controversial) ends. Other rituals may describe alternate subsets of reality, highlighting different qualities or incarnations of the same beings for different ends. This would be problematic if a ritual departed dramatically from the most fundamental order - treating a Guest of Reverence as a Guest of Karmic Debts, for example - but this is never the case. Even if it were, the ability of ritual actors to make the experience coherent, whether via active justification and reconciliation or tacit faith in the intention and authority of the articulators, would undoubtedly prevail against the threat of contradiction. 


\section{Chapter Four: Text}

The various volumes in the Nyelam Dé Zhi collection participate in a variety of literary genres, from the modern, purely instructional Manuscript to the archaic nomadic poetry of the Beckoning of Fortune. Some of the volumes - the critical Upper Ritual volume, for example - are mixtures of genres within a single volume, with mundane logistical instructions alongside versified histories alongside aspirational recitational prayers. Many of the volumes could stand on their own as complete rituals or rites, while others, especially those referred to as "small notes" (yig chung), exist only to add richness or breadth or body to rites of the same type elsewhere in the collection. Taken together, the immense diversity of genres, styles, conventions, pedigrees, and contents reveals a ritual cycle of texts that is patched together by a brilliantly synthetic volume (the Manuscript), by sometimes loosely threaded collection of themes, and an alleged common revealer, not to mention a single binding and common root number in the Katen (253). However, the individual sections' content indicates a highly diverse authorship and provenance, even if those origins cannot yet be fully known. ${ }^{250}$

250 Challenges to this particular investigation are discussed in the Sources and Methods section of the Introduction. 


\section{Pönsé Khyunggötsel and the Background of the Nyelam Dé Zhi}

The collection of texts comprising the Nyelam Dé Zhi was allegedly revealed by Pönsé Khyunggötsel ${ }^{251}$ (henceforth referred to as Khyunggötsel) at Mt. Tisé at an unknown date between his birth (1175) ${ }^{252}$ and death (unknown). ${ }^{253}$ An alleged emanation of Drenpa Namkha (DN), ${ }^{254}$ Bönpos generally know very little about Khyunggötsel, with Sangyé Tenzin calling him one of countless important lamas from the history of Bön, impossible to know in his factual entirety. ${ }^{255}$ There is a hagiography for Khyunggötsel, written by Shudkyé Drangsong Gyeltsen Tsültrim²56 of Dolpo at an uncertain time, though there are clues to its date in references to well-known personages such as the famous Nyingmapa treasure revealer Guru Chöwang (1212-1270).257 In addition to featuring difficult and possibly quite old language, spelling, and grammar, the biographical details are scarce, focusing

\footnotetext{
251 dpon gsas khyung rgod rtsal, known by many other names, including khyung rgod rtsal, dbyil ston khyung rgod rtsal, dyil bon khyung rgod rtsal, dbyil ston heruka, dbyil heruka, dpon gsas khyung thog (mostly in Buddhist texts), sprul sku dbyil ston, and dbyil bon rdo rje dpal.

252 Note that Heller, 2007, p. 136 has 1235 as a birth date, based on an unpublished work by Roberto Vitali (see 136n31), but this would not be likely if Azha Lodrö Gyeltsen (1198-1263) was in fact his disciple, though this is not necessarily a given, as discussed below.

253 Karmay, 1972, p. 332.18.

${ }^{254}$ dran pa nam mkha', an 8th century master who is considered by some Bönpos to be the father and by some Buddhists to be the son - of Padmasambhava is one of the most important figures in Bönpo myth-history. It should be noted, however, that while the Treasury cites the lung bstan for evidence that Khyunggötsel was an emanation of DN, Khyunggötsel's hagiography opens by first calling him the prophesied emanation of DN (247.2), then the prophesied emanation of "tshe dbang rigs 'dzin dran pa nam mkha"' (247.6), then the prophesied emanation of "tshe dbang rigs 'dzin" (248.3), and finally, just before the colophon, the prophecied emanation of DN again (274.4). Normally, it would be gramatically and contextually clear that tshe dbang rigs 'dzin is an epithet for DN, but it is widely known that tshe dbang rigs 'dzin was the son of DN, and I could not find this name as an epithet for DN in any other sources. Note also that the text repeats rigs 'dzin rather than rig 'dzin.

255 Interview with Sangyé Tenzin at Menri monastery on 4/16/2009.

256 In the name shud kye drang srong rgyal mtshan, shud kye is the name of the clan. Another part of the text (272.2) refers to him by shud de instead of shud kye, but this would appear to be a transcription or other error. ${ }^{257}$ g+hu ru chos dbang (265.8)
} 
primarily on Khyunggötsel's twilight peregrination through the realms of existence,

where he learns lesson after lesson about karmic consequence. The few key facts

transmitted via the hagiography indicate that Khyunggötsel was from northern

Latö, ${ }^{258}$ firstborn as Dorjépel (rdo rje dpal) to a father named Yilbön Dorseng (dbyil

bon dor seng) - a scholar of Bön and the high teachings ${ }^{259}$ - and a mother named

Gurupmo Gyagarsel (gu rub mo rgya gar gsal). ${ }^{260}$ He grew up in an environment

where he was exposed to Bön and Buddhism, becoming learned in both, ${ }^{261}$ and

eventually taking on disciples of both. ${ }^{262}$ Many Bönpos, Buddhists, and scholars of

other traditions believe he is in fact the same person as the Nyingmapa treasure

revealer Rikdzin Gödem, but the currently alleged dates for both would make this

impossible. 263

258 The text reads la stod byang kyi spyi smad dres khung bya ba yin (248.6)- "A place called Drekhung, the general lower [part] of northern Latö" - but I have not yet been able to find information about this place and thus decided that northern Latö was sufficiently specific for the scope of this project.

259 The text gives rtsug lag, which I'm correcting to gtsug lag, for which there are many definitions, with "high teachings" - from sde snod dam gsung rab - being appropriately unspecific here.

260 The text for this sentence reads yab dbyil bon dor seng bya ba yin// bon dang rtsug lag la mkhas pa cig yod// yum gu rub mo rgya gar gsal bya ba yin// de la sras lcam bral 'ga' 'khrungs pa'i che ba brda'/ yab kyis btags pa'i mtshan rdo rje dpal zhes bya ba yin//(248.7-249.1). His mother's unusual name could also be translated as Gyagarsal, woman from [the] Gurup [clan]. The first part of her name begging to be translated as "Illuminating India" or corrected to bsal to become something like "Turning Away from India," yielding "The woman in the Gurup clan who left India" - suggests, in any translation, a connection to India that cannot be further assessed given the scarcity of information. As for the clan, the btsan lha defines gu rub as rta'i ming, pointing possibly to a clan affiliation with horsemanship of some sort.

261 chung nas dad pa dang nyer len yod pas/bon dang chos dang sman dang rtsug lag la swogs pa la mkhas par sbyang zhing rang gzhan gyi don grub par mdzad do// sku'i tshe stod la ban bon dang rgyal la mang po yod pa'i gnad kyis/ ban de'i phrin las dang / bstan bsrungs 'dze nag gshin rje la swogs la mkhas par bzhugs so// (249.1-249.2). There is obviously more in here than I am choosing to include above.

262 There are a few different places where his dual Bönpo/Buddhist identity is implicit or explicit in his rnam thar, but this reference comes from 272.2 - gzhan yang bon dang chos dang zhu ba'i slob bu mang bar brda'o//.

263 Bönpos at Menri who make this claim refer to Jamgön Kongtrul ('jam mgon kong sprul), whose ris med orientation and agenda casts his identifications in suspicion, especially given the gap between his 19th century work and the time periods in question. Rikdzin Gödem (rig 'dzin rgod kyi ldem 'phru can) has well attested dates of 1337-1409, while the most widely accepted date for Khyunggötsel is 
The hagiography lists Khyunggötsel's principle disciples as Yanggel

Drangsong of Dö, Lopön Gönné of Lhotong, Gomlhajé of Taklung, and Tönpa

Küngapen of Nyaksep ${ }^{264}$ - names that are currently not well-known to Bönpos or

western scholars - while the Treasury lists the much better known Azha Lodrö

Gyeltsen, Dru Dülwa Gyeltsen, Yungdrung Senggé, and Patön Gyelwa Sherap. ${ }^{265}$ It is

suspicious that a much later text would list more illustrious disciples, excluding all

four of the principal disciples from the much earlier hagiography. It is further

suspicious that the text that is frequently cited evidence of the connection between

Azha Lodrö Gyeltsen and Khyunggötsel ${ }^{266}$ was almost certainly not revealed by

Khyunggötsel as one influential publication claims. The commentary on this text by

Azha Lodrö Gyeltsen has been published in a number of places, however, one of

which is the TBMC in Dolanji (1985), which does list Khyunggötsel in the colophon

(p. 833.3). The introduction to this publication also identifies Khyunggötsel as the

revealer, when in fact the text is a replica of another in the Bön Canon that lists

Dangra (dang ra) as the treasure site, which is where the revealer Gyermi Nyiö (gyer

1175 , based in part on references to him and his works in the writings of Azha Lodrö Gyeltsen ('a zha blo gros rgyal mtshan), a purported disciple whose dates are known to be 1198-1263. There is also a prophecy of Yiltön Heruka (dbyil ston he ru ka), to be "known later as khyung rgod rtsal" attributed to the lung bstan in the srid rgyud (Karmay, 1972, p. 196 [80b6]), which is known to have been rediscovered in 1310. Therefore, while it appears that both Khyunggötsel and Gödem revealed both Nyingmapa and Bönpo texts, it seems unlikely that they were one and the same individual. Perhaps Pönsé Khyungtok (dpon gsas khyung thog) was the name by which Bönpos referred to Gödem, making a familial or metaphorical connection to Khyunggötsel. Anne-Marie Blondeau (1984) also did some analysis around this issue, and her conclusions come close to those of Tenzin Namdak, who said in an interview at Triten Norbutsé on 5/26/2009 that Khyunggötsel was in fact also a Nyingmapa tertön with the name Gödem, but it is a different, earlier Gödem, not the famous one. 264 rdod kyi yang ngal drang srong / lho stong kyi slob dpon mgon ne/stag lung gi sgom lha rje/gnyag bseb kyi ston pa kun dga' phan dang bzhi ni bu chen bzhi ru brda'o// (272.1)

265 'a zha blo gros rgyaI mtshan dang bru 'dul ba rgyal mtshan gnyis/stod du dar bar byed pa spa mkhan chen g.yung drung seng ge dang spa ston rgyal ba shes rab gnyis te bzhi'o/(332.25).

266 This is the gsang ba bsen thub - see the text titled Rtsa rgyud chen po gsang ba bsen thub dang de'i 'grel pa rin po che yid bzhin rnam par bkod pa'i rgyan in the Tibetan Sources section of the bibliography. 
mi nyi 'od, 12th century) discovered his texts, and indeed another text confirms that he is the revealer. ${ }^{267}$ This is further complicated by the fact that it is widely believed that Shenchen Luga (996-1035) originally revealed the text, ${ }^{268}$ and that in either case the date would likely have been before Khyunggötsel was born. ${ }^{269}$

Finally, it is noteworthy that this tantra and its commentary stand out as very much unlike any of the other texts attributed to Khyunggötsel. While it is by no means impossible that a teacher would defy expectation to make such a request of his disciple, and, indeed, none of this means that Khyunggötsel could not have requested that Azha Lodrö Gyeltsen write a commentary, as is more commonly asserted, but the facts are tenuous at best. ${ }^{270}$ Regardless, both Khyunggötsel's hagiography and the Treasury make accommodations for lots of disciples, with the latter explicitly describing those who disseminated his teachings, and so we are left to conclude that the disciples listed in the hagiography, highlighted as four among many, proved to be merely less important to posterity than these others.

While the principle concern of the hagiography is a clearly pedagogical one, the narrative of his visit to the various realms of rebirth contains a number of details that illuminate his life and time period. First, there are many places of Bön-Buddhist engagement, overlap, or confusion. For example, upon seeing people boiled in a copper cauldron in a hell-realm, Khyunggötsel first remembers a teacher of the

\footnotetext{
267 Kvaerne, Martin, and Nagano, 2003, p. 345.

268 Karmay, 1972, p. 159n4, and others from Kvaerne, Martin, and Nagano, 2003, p. 345.

${ }^{269}$ Karmay, 1972, p. 159 gives the date 1108 via STNN (sangs rgyas kyi bstan rtsis ngo mtshar nor bu'i phreng ba).

270 This is widely attested and accepted, and yet we should inject a cautionary note here, given that this tantra and its commentary stand out as very unlike any of the other texts attributed to Khyunggötsel. While it is by no means unheard of that a teacher would defy expectation to make such a request of his disciple, it is odd that we thus far know of only this one departure. See below for discussion of his corpus.
} 
"new secret mantra" (gsang sngags gsar ma) tradition, 271 and experiences afflictive emotions that he then tries to dispel by visualizing the Buddha Hevajra ${ }^{272}$ as his tutelary deity. ${ }^{273}$ In strictly Bönpo works, Magyü 274 inhabits the same role as Hevajra, and would certainly be appropriate here, such that the choice of Hevajra can only be meant to, or incidentally does, reflect Khyunggötsel's mixed upbringing. In the next sentence, when Khyunggötsel undoes the benefit from this visualization by experiencing a loving devotion to it, he decides to meditate on the Shinjé of Nyingma, ${ }^{275}$ which works again to dispel the illusions. He has visions of "Joshak" (the Buddha, p. 257.1), goes to see a statue of Avalokiteśvara (jo bo thugs rje chen po, p. 259.7), pays homage to a statue of Tara (sgrol $m a$, p. 266.3), meets the famous Guru Chöwang ( $g+h u$ ru chos dbang, p. 265.8) and the Drukpa Kagyupa Götshangpa (rgod tshang pa,1189-1258),276 and so on. He is asked whether he is a Buddhist or Bönpo (271.6), and gives teachings on both (272.2), clearly moving fluidly between traditions, but at various times he experiences a "devotion to Yungdrung Bön" (g.yung drung gi bon la mos pa, p. 253.4) or a "belief in Bön" (bon la yid ches pa, p. 253.7). This, in its possibly newfound belief and references to the tradition as a whole, as if from the outside, suggests that he was uncertain about whether to engage Bön or Buddhism, or was at least moving back and forth from practice of one to practice of the other. The end of the first, most narrative section of the

\footnotetext{
${ }^{271}$ Khyunggötsel's hagiography, p. 251.5. This refers to the 11th century "new movement" (gsar ma) in Tibet, which was a Buddhist movement.

272 bcom ldan 'das dges dor, which we would normally expect to be dgyes rdor, short for dgyes pa rdo rje.

${ }^{273}$ Khyunggötsel's hagiography, p. 251.6

274 ma rgyud g.sang mchog mthar thug

${ }^{275}$ snying ma'i gzhin rje (251.8), with geshés confirming that snying should be rnying.

276 Khyunggötsel's hagiography, p. 262.3-4
} 
hagiography, however, finds him seeing the snows of Takzik (stag zig) and Zhang Zhung - the alleged birthplace of Bön, and its well-known seat in medieval Tibet, respectively - and affirming his decision to be a Bönpo (p. 266.6-7).

Aside from the Buddhist-Bönpo interactions and tensions, the hagiography includes some details important to the ritual-centric texts, such as the Nyelam Dé Zhi, that Khyunggötsel is credited with revealing. For example, he claims to be knowledgeable of nyen practices (p. 263.3-4), and in fact interacts with one shortly thereafter. At one point he is born into the land of the lu (p. 264.1-2), and, though written more as commentary than as content of Khyunggötsel's life story, the hagiographer makes specific mention of how the tradition passed down through Khyunggötsel has been a great kindness to all for its ability to protect from lu (p. 272.2-3).

Whatever his life span may have been, and there is currently no known evidence whatsoever as to his death date, Khyunggötsel is portrayed as a prolific treasure revealer, revealing by some accounts more than 100 texts over the course of his career. ${ }^{277}$ While there is some variation in the genres of his discoveries, the vast majority are ritual or practical manuals, outlining methods of propitiation, pacification, and banishment for deities like Welsé (dbal gsas), Takla Mebar (stag la me 'bar), Gekhö (ge khod), the mamo ( $m a \mathrm{mo}$ ), and of course the deities addressed by the Nyelam Dé Zhi, amongst many others. A great many of his otherwise ritually focused discoveries have been collected in the various configurations of the Bönpo

\footnotetext{
277 A bibliography for Khyunggötsel is available online at: https://collab.itc.virginia.edu/x/Fx700w.
} 
Kangyur, Tengyur, and Katen, ${ }^{278}$ to the extent that it is highly likely that both large monasteries with a regular ritual calendar and individual specialists in villages will make use of his work at some point over the course of a given year. Despite this, not everyone - and in the case of large monasteries, very few indeed - is aware that Khyunggötsel is the revealer who discovered it.

Of all of Khyunggötsel's discoveries, however, none is more substantial than the Nyelam Dé Zhi. If we were to believe that all texts of the collection were discovered together - and we should not, as discussed below - it would be his most voluminous discovery by several orders of magnitude, and, more importantly, it would be the most mature, systematic ritual discovery of his lifetime, and perhaps of all of Bön history up to that time period.

The proliferation of Bönpo treasure discoveries that began with Shenchen Luga in the 11th century produced a great abundance of texts of all genres, and a great abundance of treasure revealers - this is when the most important canonical texts of Bön appear for the first time in recorded history 279 - but, based on attributions, Khyunggötsel and his Nyelam Dé Zhi stand out among the others as perhaps the foremost institutionalizers of Bönpo ritual. It is true that this institutionalization process, textualizing practices and rituals for posterity and for wider-spread use in villages as well as the temples and monasteries that began to

\footnotetext{
278 Of 102 texts, 23 are in one Kangyur or another, 52 in the Tengyur.

279 Of course, Bönpos assert that Tönpa Shenrap and/or Drenpa Namkha authored and transmitted these texts, but for our purposes it is enough to talk about these texts in terms of their post-discovery pedigree.
} 
appear with Shenchen Luga's disciples in the 11th century ${ }^{280}$ was already well underway and ongoing. For example, the text that is the basis for the Sky Expanse ( $m k h a^{\prime}$ klong) summer ritual at the modern Menri monastery, for example, was allegedly discovered by Ma Sherap Senggé ( $r$ ma shes rab seng ge), who lived very much in the same time period as Khyunggötsel. ${ }^{281}$ But the possibly hundreds of texts, with such a large percentage focused on ritual, and with a great many of those showing a genius for systematization - describing implements in detail, outlining steps, and so on - would confer upon Khyunggötsel a monumental role in the dissemination and enshrinement of a great many of the rituals and practices that are persistently relevant to modern Bönpos, and the Nyelam Dé Zhi would be foremost among them.

There is a very serious issue of attribution, however, that raises this assessment into question. To an extent, all literature from nearly 1,000 years ago, and especially treasure texts, has the problem of author verifiability. Revealers attribute texts to former masters, multiple revealers are credited for certain texts, there is the complexity of Bönpo-Nyingmapa dual identity, and so on. In the case of Khyunggötsel, this difficulty is compounded by a few factors, starting with the ambiguity of his biographical details. Was he really born in 1175 , or later, in the 13th or 14th century? When did he die? What are the dates of his hagiographer? Who were his true disciples? Thus far, we have access only to a handful of texts that

\footnotetext{
${ }^{280}$ Karmay and Nagano, 2003, p. 1. Shenchen Luga would be the most significant institutionalizer, but Kutsa Daö ( $k h u$ tsha zla 'od, b. 1024) was also a major figure of the time, revealing a great many treasure texts, ritual texts among them.

281 Blondeau, 2005, pp. 252-53
} 
provide biographical data, ${ }^{282}$ and modern Bönpo scholars such as Tenzin Tsultrim refer to these same texts. It is likely that more texts will be found and translated that talk about Khyunggötsel, but in the current conditions we rely heavily on relatively recent sources, and on a hagiography of an uncertain time period with scant details.

Another, possibly more modern issue of attribution that is very much applicable to the Nyelam Dé Zhi is the ascription of published collections of texts to a single individual when it is abundantly clear that different texts in the collections have different authors, revealers, or translators. The intention of this ascription may be to highlight the individuals who contributed the most significant or base volume(s) of the collection, but this subtlety is often lost on other bibliographers and average Bönpos, who unknowingly conflate the contributions, and thereby the status, of revealers like Khyunggötsel. Specifically in the case of Khyunggötsel, there are the examples of collections like The Sequential Practices and Yogic Activities [for] Welsé, ${ }^{283}$ which are explicitly attributed to Khyunggötsel - "A collection of Bönpo ritual texts for the propitiation of the tutelary Dbal-gsas/ Rediscovered from their place of concealment by Dpon-gsas Khyung-rgod-rtsal" (title page). Turning to the table of contents shows, however, that only two of the forty-five volumes in the collection are attributed to Khyunggötsel, with many others being attributed to other well-known, possibly much later figures like Nyamé Sherap Gyeltsen (13561415). ${ }^{284}$ There are unattributed volumes that could in fact have been revealed by Khyunggötsel, but even then he would only have been responsible for a fraction of

\footnotetext{
${ }^{282}$ His hagiography, the Treasury, and references from the work of Azha Lodrö Gyeltsen and Jamgön Kongtrul.

283 dbal gsas las rim gyi sgrub pa dang las tshogs bcas, published by TBMC in Dolanji in 1973.

${ }^{284}$ See for example volume 19 - dbal gsas gyi mngon rtogs gsal byed nyi ma'i snying po.
} 
the whole collection. As we'll see below in the section examining the contents of the collection, the same is true for the Nyelam Dé Zhi.

\section{The Contents of the Collection}

\section{Literary Genres}

The different volumes in the collection each have a specific and clear utility in the context of the Nyelam Dé Zhi, but most of them also have clear membership in larger literary genres across Tibetan traditions, whether in terms of the volume as a whole or of constituent components of the volume. Generic designations are largely etic, however, as the vast majority of Bönpos consulted did not think of the Nyelam Dé Zhi volumes in terms of genre aside from Kangyur, Tengyur, Katen, treasure texts, and outer tantra (phyi rgyud). Much work has yet to be done to wrangle Tibetan literary genres into a clear taxonomic scheme, but a few works have begun to make sense of the great diversity of literature across time. Two such works are Tibetan Literature: Studies in Genre, edited by José Cabezon and Roger Jackson (1996), and Samten Karmay's Catalogue of Bönpo Publications (1977).

In the case of the former, which is not intended to be comprehensive, the basic categories are as follows: ${ }^{285}$

- History and Biography

○ Historiography

○ Biography / Hagiography / Myth

- Canonical texts

○ Sūtras

○ Tantras

285 Note that in all the lists that follow I have bolded the categories that are relevant, in one form or another, to the Nyelam Dé Zhi. 
○ Commentaries

- Bönpo literature

$\circ$ Treasure texts

- Philosophical literature

○ Doxography

- Logic

- Debate manuals

- Polemical literature

- "Path"-oriented literature

○ Mental purification (blo sbyong)

- Spiritual instruction texts (gdams ngag)

- Stages of the path (bstan rim).

- Ritual texts

○ Consecration (rab gnas)

- Offerings (mchod pa)

- Sādhana (sgrub thabs)

○ Puja or "stability of life" prayers (zhabs brtan)

The inclusion of Bönpo literature as a separate category within "Canonical texts" is relevant given that the Bönpo canon includes a Kangyur, Tengyur, and Katen, encompassing a huge diversity of texts - essentially anything found at Bönpo monasteries.

To categorize the great diversity of Bönpo publications he encountered, Karmay constructed a different but sometimes overlapping set of categories as follows:

- Sūtras (mdo)

- Tantras and Their Commentaries

- Sādhana (sgrub thabs)

- Guru Sādhana (bla sgrub)

- "Cutting" practices (gcod)

- Great Perfection texts (rdzogs chen)

- Biographies, Chronicles, and Prophecies

- Protector Deities (bka'skyong)

- Worldly Rituals

- Philosophy and Logic 
- Astrology and Astronomy 286

- Medicine

- Stages of the Path (lam rim)

- Afterlife literature ('das $\log$ )

- Consecration (rab gnas)

- Miscellaneous Collections of Liturgical Texts

- Works of the New Bön Tradition

- The Collected Works of Shar rdza bKra shis rgyal mtshan

Within the categories of "ritual," obviously appropriate for an evaluation of the

Nyelam Dé Zhi collection, work has been done to identify additional subcategories.

In different works from the taxonomic ones referenced above, Karmay (1998) and

Cabezon (2009) have attempted to impose structure here as well. For example,

Karmay, on page 141, lists typical everyday rituals, for which there are often

dedicated volumes:

- Marriage rituals

- Ensuring continuation of prosperity

- Prolonging life

- Increasing wealth

- Summoning good fortune

- Averting misfortune

- Assuring good harvest

- Rituals for the dead

He also identifies the following subrites, defined within the "vehicle of prediction" (phya gshen theg pa), that typically comprise these larger rituals, each of which may also have dedicated manuals:

- Divination $(\mathrm{mo})$

- Astrology (rtsis)

- Narrative-Rites (gto)

286 It is important to note that the Nyelam Dé Zhi has much to do with astrology, in terms of these worldly deities having astrological orientations, as evidenced by the inclusion of planets and stars in the lists of deities, and the occasional reference to Kongtsé, known within Bön as the astrologer par excellence, but that the rites therein are not astrological rites per se. In other words, they do not make use of astrological or divinitory methods to make things happen. 
- Diagnoses (dpyad)

Cabezon, on pages 18-19, includes a more expansive list focused more specifically on ritual texts:

- The tantra (rgyud) of a given deity

- History of transmission (lo rgyus)

- Empowerment liturgies

- Sādhanas

- Instructions (gdams ngag)

- Important commentaries on the practice (khrid)

- Retreat manuals

- Torma offering rituals

- Burnt-offering rites

- Consecration liturgies

- Protector-deity practices

- Prayers

- Practical/magical practices (for long life, protection, defeating enemies, etc.)

Cabezon also, on pages 15-16, lists the typical subrites within these rituals, which may or may not be substantial enough in a given tradition or context to comprise volumes of their own:

- Preparations (sta gon)

- Land ritual (sa chog)

- Offerings ( $\operatorname{mchod} p a$ )

- Praise (bstod pa)

- Actual ritual (dngos gzhi)

- Burnt offerings (sbyin sreg)

- Beseeching (gsol bya)

- Beseeching to leave (gshegs su gsol ba)

- Dedication, usually of merit ( $b s n g o b a$ )

- Auspicious (bkra shis)

- Entreating (gsol ba 'debs pa)

- Descent of blessings (byin 'bebs)

Pilfering from these lists, it is possible to construct a generic portrait of the Nyelam

Dé Zhi in the following way: Its canonical designations are Tantra (specifically outer 
tantra, phyi rgyud) and Treasure (gter ma), and it can thus be found, in the known canonical collections, in the Katen (volume 253) and in the Tengyur as indexed by Nyima Tenzin (T83).287 The collection as a whole, and the majority of individual volumes, would also fall under the "worldly rituals" category, which includes many of the everyday rituals Karmay listed - ensuring continuation of prosperity, prolonging life, increasing wealth, summoning good fortune, averting misfortune, and assuring good harvest.

As for individual volumes, there are instructional liturgical manuals (primarily the entirety of volume 1 and portions of volume 6, but virtually every volume has some instructional component, even if just a few lines); offering texts (volumes 3, 5, 22, 23); a volume for auspicious rites (40); practical/magical practices, within which there are cures for worldly ailments and afflictions (the various Cure (nad sel) volumes 16-19, 35-38, as well as the other illness-related volumes $29,30,32,33,39$, and dealing with people fighting in volume 28), "treatments" and banishings for problematic forces and beings (4, 7-11, 15, 31, 41, 43-46), more positive practices such as those that beckon fortune (13-14), and a magical formula text for accomplishing a variety of tasks (12). The Upper Ritual and the four bum volumes, and to a lesser extent the catch-all collection of rites for the last day of the ritual (34), cannot be so easily categorized, however, because they each embody a variety of different genres, in the former cases from mythic narratives to instructions to confession and praise and so on, as well as practical/magical practices. The Upper Ritual and the Treatment (bcos) volumes

287 This has been made available thanks to the work of Per Kvaerne, 1974, p. 46 (120). 
also include almost every one of the subrites listed by Cabezon above. And then there are additional genres of volumes not included in the lists above, such as purification or preparation of the ritual environment (volumes 2, 20) and confession (21)..$^{288}$

As Appendix 2 shows, the preponderance of volumes in the collection as a whole fall into the practical/magical genre, and yet the next chapter will show that only a fraction of those volumes are used in the institutional performance of the ritual at Triten Norbutsé. This splintering between monastic-appropriate and layappropriate stems from a variety of pressures, historical, logistical, and otherwise, some of which will be described below in the section on authorship and origins. Before going into such detail on the contents of the collection, however, it will be helpful to describe briefly the overarching "genres" of treasure texts and outer tantra of which the collection is a member.

\section{Treasure Texts}

Given that the entirety of the collection is considered a treasure text (gter ma), and some individual volumes have colophons that explicitly claim that the preceding text was discovered by Khyunggötsel, the treasure phenomenon within the Bön tradition bears brief scrutiny. To an extent, it is no different from the treasure texts of other traditions, most notably Nyingma. As Janet Gyatso points out in "Drawn from the Tibetan Treasury: The gTer ma Literature," 289 treasure texts on their own do not constitute a unique genre of Tibetan literature. Rather, they are the products

\footnotetext{
288 See Appendix 2 for a list of volumes organized by genre.

289 Gyatso, 1996, pp. 147-148.
} 
of a purported method of revelation that can exhibit as much variation in genre as other methods of revelation or authorship. Across traditions, treasure revelation typically manifests as physical texts unearthed from the ground or from places of concealment in physical structures like temple columns (sa gter) - or as texts that spring forth in the mind of the revealer, planted in their consciousness-continuum by a former master (dgongs gter). While this former master or original author is very often Padmasambhava in the Nyingmapa tradition, the most common concealer among Bönpo treasure texts is Drenpa Namkha. ${ }^{290}$ The default answer among monks at Triten Norbutsé and Menri to the question of who originally wrote a treasure text that a given revealer later discovered is that Tönpa Shenrap taught it and Drenpa Namkha wrote or otherwise directed or propagated it, though in the case of the Nyelam Dé Zhi a few of the texts list other composers, such as Kongtsé, Sertup Gyelwa, and Tönpa Shenrap himself.

Alleged reasons for the original concealment vary widely, from fears of persecution and destruction to wishes to delay a particular teaching or doctrine until a later time, when the people of a particular place or the greater world have evolved an attitude that is capable of receiving and understanding the teachings therein. In the specific case of the Bön treasure tradition, the mind treasure tradition seems to be far more unusual than it is in the Nyingma tradition, and reasons for concealment tend far more towards the former - fear of persecution. ${ }^{291}$

\footnotetext{
290 It is beyond the scope of this project to go into detail about Drenpa Namkha, but it is perhaps relevant to point out that, from an etic perspective, he occupies a very similar role as Padmasambhava in the Bönpo history, including very similar iconography. From an emic perspective, Bönpos consider him the father of Padmasambhava.

291 Kvaerne, 1996, p. 139 suggests this is how the treasure tradition started in Bön, but Samten Karmay (Karmay, 1998, p. 123, confirmed in interview at Menri monastery on 4/22/2009) claims
} 


\section{Outer Tantra}

The whole of the collection of the Nyelam Dé Zhi is classified as "outer tantra" (phyi rgyud). This designation is not conspicuously mentioned by or otherwise attached to any of the original volumes, instead appearing exclusively in the Manuscript, where it is referenced first in the author's introduction, identifying the Nyelam Dé Zhi as outer tantra from among the outer, inner, and secret tantras (2.2). The elements that comprise or are otherwise specific to outer tantra become clearer as the author outlines instructions for different aspects of the ritual and its preparations:

- According to conventions of outer tantric rituals, implements like tormas and ornamented vases and so on, described by Expansive Space, need to be put together (2.4), and are then placed on the dö and maṇdala (14.3).

- Before beginning the main recitational part of the ritual, do preliminaries like the mandala branch practice and so on, according to general conventions of outer tantra (27.4).

The Manuscript thus expects that ritual administrators will have a grasp on what constitutes outer tantric implements and practices, and implies that such implements and practices are key distinguishing features of outer tantra.

In terms of literary pedigree in Bön, there are not many authoritative sources that explicitly address differences between outer, inner, and secret tantra, but as with most of the modern taxonomic teachings, the nine vehicles of Bön, especially as

that all Bönpo treasure texts were concealed out of fear of persecution by the Buddhists, given the Bönpo historical narrative of the fall of Zhang Zhung at the hands of the Tibetan king Trisong Detsen in the 8th century, and the re-emergence of Bön during the Tibetan Renaissance period starting in the 10th and especially 11 th centuries, when the earliest known treasure texts started to appear. Various sources claim different periods of persecution and concealment, including earlier persecution by the Tibetan king Drigum Tsenpo and a later one by the Chinese during the Cultural Revolution (Gyatso, 1996, p. 152), and there is no doubt that prophecies about treasure texts became important in Bön as well, usually involving the Padmasambhava analogue Drenpa Namkha, but historical and modern sources both describe the practical necessity of concealment as the primary motivation. 
articulated in the Ziji - the long biography of Tönpa Shenrap, constitute the locus

classicus. With regards to the different "series" of tantra, the vehicle of the shen of illusion ('phrul gshen theg $p a$ ) in the Ziji, which is named as such because it addresses rituals for managing the afflictions and conditions arising from this "illusory" world, says: 292

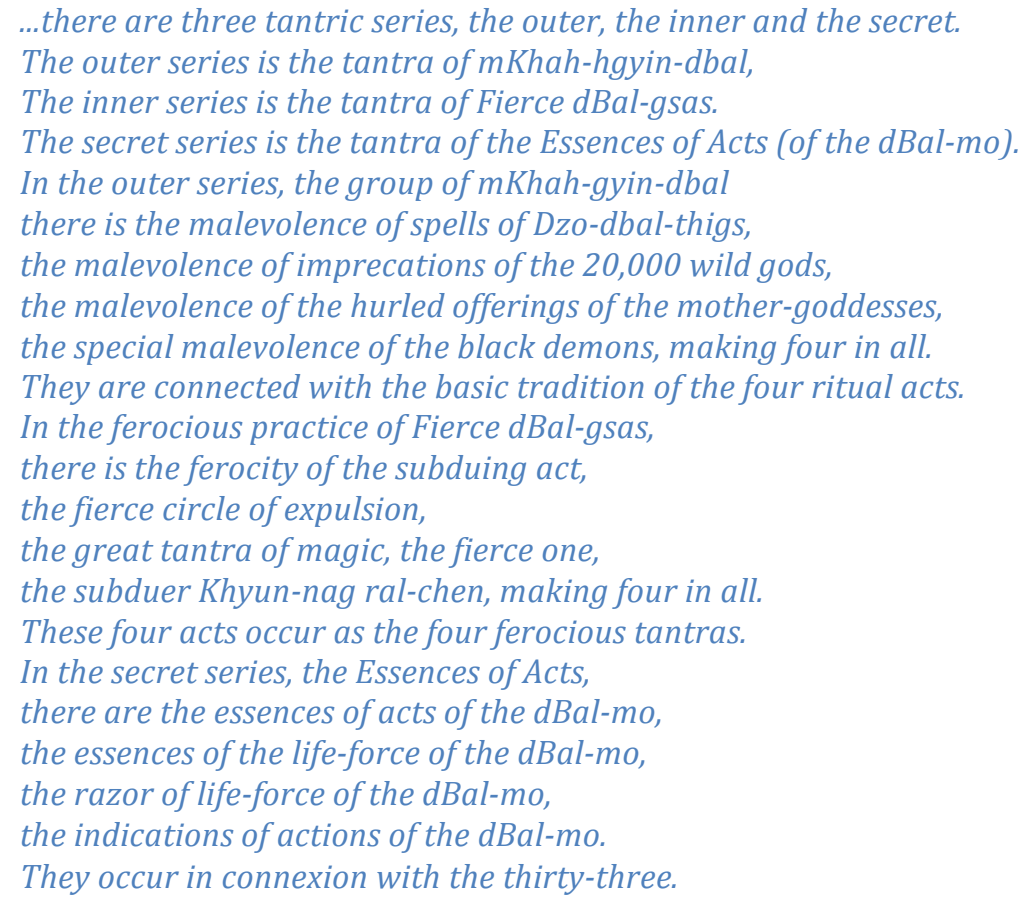

This is in a section that discusses ferocity or wrath (drag po) and associated rituals and practices, and thus the emphasis within these descriptions of the three tantras is on the same, such that the descriptions would seem at first to be of little generalizable value. This is true to an extent, but it nevertheless illustrates the relative concerns and subjects of each, with outer tantra being the only one to address specifically mundane deities like the wild gods (lha rgod), mothergoddesses ( $m a \mathrm{mo}$ ), and black demons (nag po bdud).

292 Snellgrove, 1980, p. 109. 
The text that likely informs the Manuscript, however, and other ritual texts in use at Menri and Triten Norbutsé, and which most immediately informs those monasteries' geshés' understanding of the three kinds of tantras, is the seminal commentary on the root tantric text of the Sangwa Sentup (gsang ba bsen thub). ${ }^{293}$ The latter is a treasure text that is incidentally believed by some to have been revealed by Khyunggötsel, ${ }^{294}$ with the former being one of the most important works written by Khyunggötsel's alleged disciple Azha Lodrö Gyeltsen. In this commentary, Lodrö Gyeltsen includes a section on the topic of "enlightened activity" ('phrin las), in which distinctions between inner, outer, and secret, while not addressed explicitly as a group, are described individually in a variety of contexts. For example, he draws connections between the outer and the world and its inhabitants (snod bcud), the inner and the body and mind (lus sems), and secret and ignorance ( $m a$ rig pa). ${ }^{295}$ In at least three places he discusses how various teachings and practices will dispel enemies and hindrances from the outer, obstacles of conceptual thought from the inner, and the stain of ignorance from the secret. ${ }^{296}$ The monks at Triten Norbutsé understand these designations in ritual contexts in sometimes different ways, a dynamic that stems in part from idiosyncratic conceptualizations and observations of outer tantra throughout the ritual year - to be discussed in more detail in the next chapter. In addition, it derives

\footnotetext{
${ }^{293}$ See the Rtsa rgyud chen po gsang ba bsen thub dang de'i 'grel pa rin po che yid bzhin rnam par bkod pa'i rgyan text in the Tibetan Sources section of the bibliography, referred to henceforth as Commentary.

294 This is not at all certain, however, with most sources attributing it either to Gyermi Nyiö or Shenchen Luga. For a discussion of these latter two, see Kvaerne et al (2003), p. 345, and for reference to Khyunggötsel see Martin, 1997, p. 280, which appears to be referencing a Kangyur volume that describes Khyunggötsel as the revealer of the root tantric text.

295 Azha Lodrö Gyeltsen, Commentary, p. 436.5.

${ }^{296}$ Azha Lodrö Gyeltsen, Commentary, pp. 426.2-3, 435.13-14, 438.13-14.
} 
from the density of detail in Expansive Space, the seminal outer tantric manual, which has so many particulars that nothing in particular stands out as a defining feature or set of features. Nevertheless, it is clear enough from the above the likely foci of literature and rituals with one or the other tantric orientation - outer, inner, or secret. As with the Nyelam Dé Zhi, outer tantra deals with the world and its inhabitants, enemies and hindrances, and specific named worldly deities. Whether or not the articulators and authors of the Nyelam Dé Zhi texts and ritual procedures had any notion of these categories, the author of the Manuscript recognized them as such, from the deities they address, the outcomes they seek, and the implements and procedures that connect the two.

\section{Disaggregating the Collection}

Bönpos who know anything about the textual basis of the Nyelam Dé Zhi, which, at Triten Norbutsé and Menri, is a handful of geshés and the abbots and rinpochés but no one as well as Tenzin Tsultrim - refer casually to the entirety of the collection as if it were indeed revealed by Khyunggötsel alone. The Treasury supports this generalization by including no detail about the revelation of the Nyelam Dé Zhi aside from the location and revealer of the "sa bdag nye lam sde bzhi,"297 when in fact each text or group of texts appears to have a different pedigree. There is no colophon for the collection of forty-six texts that comprise the Nyelam Dé Zhi within the Bönpo Katen, ${ }^{298}$ and which have been aggregated and sometimes bound separately into a single pecha of 1,068 folio faces, though the bound version, published by the "Tritan

\footnotetext{
297 Karmay, 1972, p. 332.18.

298 It is beyond the scope of this project to discuss the organizational and publishing rationale of the challenging Bönpo Katen, but for more information see Karmay and Nagano 2001.
} 
Nurbutse Bon Education Center" in Kathmandu in 1990 includes a forward in English:

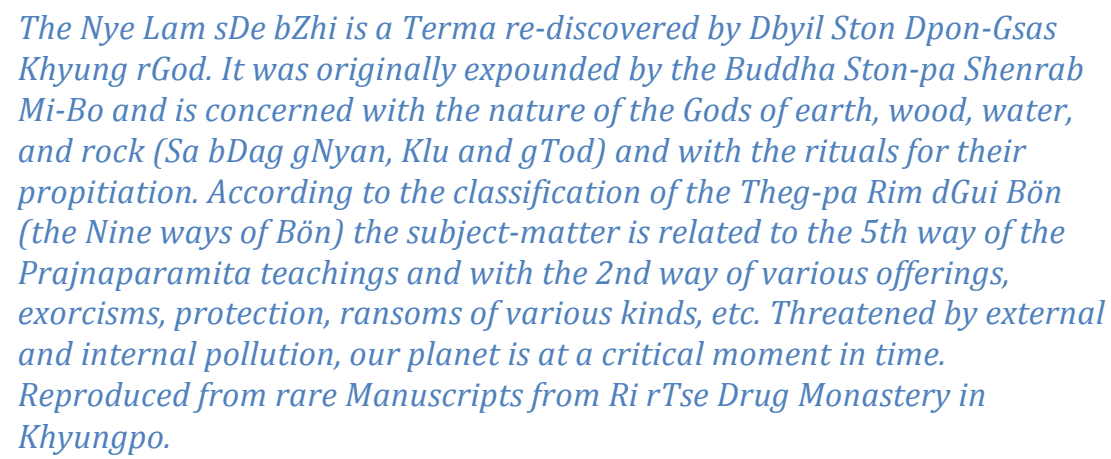

This publication and this forward were done by or otherwise at the behest of Tenzin Namdak, who discovered the manuscripts at the monastery referenced above in 1986, though he states very clearly that he was not the one to compile these different texts into the monolithic Nyelam Dé Zhi collection. Indeed, he and all geshés consulted ${ }^{299}$ make no indication that these different texts may have been compiled by anyone other than Khyunggötsel. Similarly, the first volume, the Manuscript "notes" for the Nyelam Dé Zhi, explicitly written by another author, makes the same general claim about Khyunggötsel having revealed the Nyelam Dé Zhi at Mt. Tisé. ${ }^{300}$ The publisher codified this declaration in the table of contents by giving the title of every volume and putting Khyunggötsel's name by each. Of the forty-six volumes, however, only three have colophons that make any reference to Khyunggötsel - the Five-fold Offering Prayer; ${ }^{301}$ the Preparations for the Auspicious Teachings of Opening the Door, Empowerment, Aspiration Prayers and

\footnotetext{
299 This includes Tenzin Tsultrim, Tenzin Yangtön, Yungdrung Mönlam, and Nyima Özer. 300 Manuscript, p. 19.4

301 nye lam sde bzhi'i mdo las rnam lnga'i smon lam (vol. 23, pp. 551-564)
} 
Accomplishments, and the Completion Stage -- Generating into the Expanse; ${ }^{302}$ and the Abbreviated Treatment, ${ }^{303}$ which has no title page and is referenced by annotation in the published version's table of contents as "(causing [the deities] to go)"..304

Most of the other forty-three texts do not have colophons, or have colophons without any bibliographic information, but five of them do. The first and most significant, requiring a separate evaluation below, is in fact the first volume in the collection, the Mirror that Clarifies the Manuscript of the Nyelam Dé Zhi, ${ }^{305}$ written by Drutsün Drungmu Werzhi ${ }^{306}$ on the eighteenth day of the fifth month of the earth ox year (1889-1890). The other four volumes, with their colophons, are:

- Volume 16, the Cure for Sickness[es] of the Four Lu, Nyen, Sadak, [and Tö]:307 "This cure for the disease[s] of the Nyen was composed by Nyen Bön Tödé Gyelwa..." 308

- Volume 18, the Cure [for] Sadak Sickness: ${ }^{309}$ "The Cure for Sadak Sickness was taught to the Bönpo ${ }^{310}$ [of the] Sadak, Sertup Gyelwa."311 This could suggest that someone else, perhaps Khyunggötsel, is the originator of this text, but there is no indication of this, and in fact the title page of the text reads, "Composed by the great Sadak, Sertup Gyelwa, the Cure [for] Sadak Sickness..." 312

\footnotetext{
302 nye lam sde bzhi'i smad chog sgo dbye dbang bskur smon dngos srub rdzogs rim dbyings su bkyed pa bzhi brtan bkris bcas pa'o (vol. 34, pp. 851-922)

303 bcos mdo (vol. 44, pp. 1043-1052)

304 (gshegs bskyod)

305 nye lam sde bzhi'i zin thu gsal byed 'phrul gyi me long (vol. 1, pp. 1-36)

306 'gru btsun drung mu wer zhi

307 klu gnyan sa bdag bzhi yi nad sal

${ }^{308}$ gnyen gyis[sic] nad sel 'di gnyan bon thod de rgyal bas mdzad pa shin tu legs sto/ (415.1). It is likely that thod is supposed to be $d o d$.

${ }^{309}$ sa bdag nad sel

310 In titles like this, it is reasonable to translate Bönpo further as "priest," or even "tantrika" (sngags pa suggested by Yungdrung Mönlam), but there is much ambiguity about the applied meaning of the term across sources and time periods and thus I am choosing to leave it transliterated.

${ }^{311}$ sa bdag nad sel sa bdag bon po gser thub rgyal ba la gsungs ba mdzad legs sto/ (446.4).

312 sa bdag chen po gser thub rgyal bas mdzad sa bdag nad sel bzhugs pa'i dbus phyogs legs swo//

(429). The grammar shows sa bdag chen po and gser thub rgyal ba in apposition, and I have rendered
} 
- Volume 19, the Shingri Cure: "The Shingri Cure was composed by the aggregate Ones Gone to Bliss and Kongtsé..."

- Volume 35, the Cure for Frog Sickness: "This Cure for Frog Sickness was composed by Kongtsé..."

While volumes 19 and 35 are attributed to Kongtsé 313 and thus do not preclude Khyunggötsel from having revealed them at a later time, volumes 16 and 18 are more problematic. It is possible that Tödé Gyelwa, for example, is also a legendary figure from a time earlier than Khyunggötsel's - corroborating sources are absent but it is impossible to say for certain at this time. Other texts such as the bum volumes are known or believed to have other revealers, in this case Shubön Genyen. ${ }^{314}$

Without making reference to the colophons, from which it is difficult to draw many conclusions, diverse authorship is evident in the highly variable language and writing styles. There are five different styles of handwriting throughout the collection, with three primary styles and a fourth and fifth that appear only for the titling of volumes that were otherwise untitled. ${ }^{315}$ The handwriting is all the same for the contents of the texts, which is to say they show some combination of the three primary styles, with each style intending to connote different performative orientations - one for non-performative instructions or comments, one for melodic and rhythmic verse recitation, and one for non-rhythmic, uttered recitation. Without

\footnotetext{
it as such, but all other references to this individual in other sources show sa bdag gyi bon po gser thub rgyal ba (see for example the rgyud rim by khod spungs pa dbra ston ngag dbang skal bzang bstan pa'i rgyal mtshan, in the bka' 'gyur, p. 217).

313 It is beyond the scope of this work to go into detail about the otherwise interesting figure of Kongtsé (kong tse), who is considered one of the great Bönpo astrological figures from ancient times. Monks do not connect him to Confucius, though they admit he is of Chinese descent, and Karmay (1975) has done some work around this.

314 shu bon dge bsnyen (Karmay, 1972, p. 124).

315 See Figure 3.1 at the end of this chapter for the different styles.
} 
doing a scientific handwriting study, it is nevertheless clear that one scribe

produced all of the texts in the current Nyelam Dé Zhi collection, and that there are

in fact many works by this scribe across the modern Bönpo canonical collections.

One or two individuals then, much later, inserted titles in various places where they

felt such annotations would be useful for quick reference. ${ }^{316}$

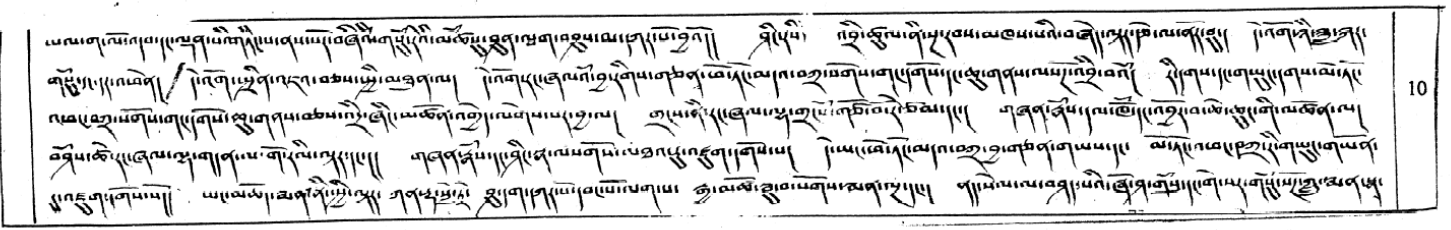

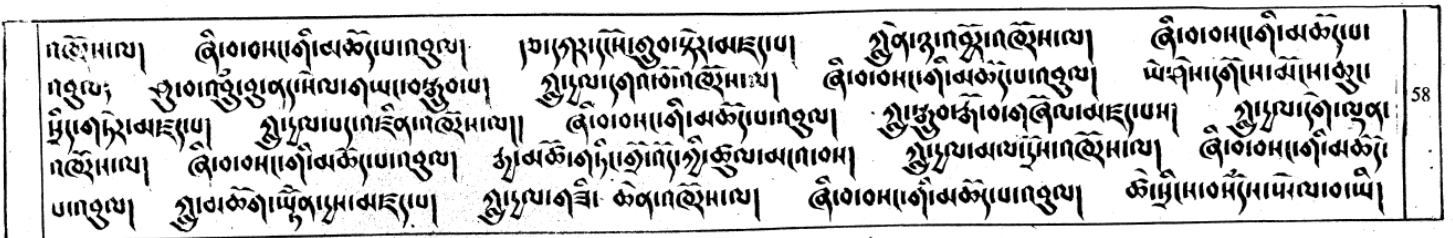

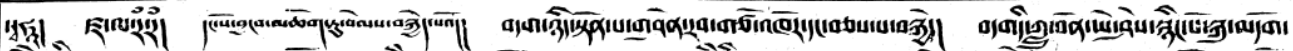

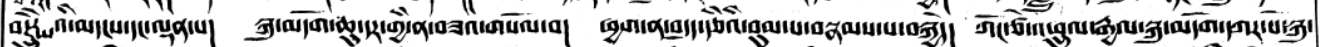

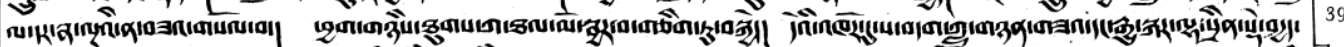

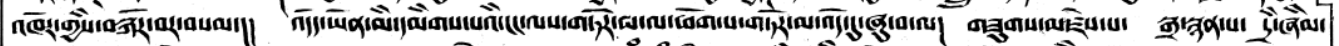

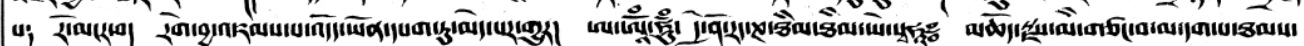

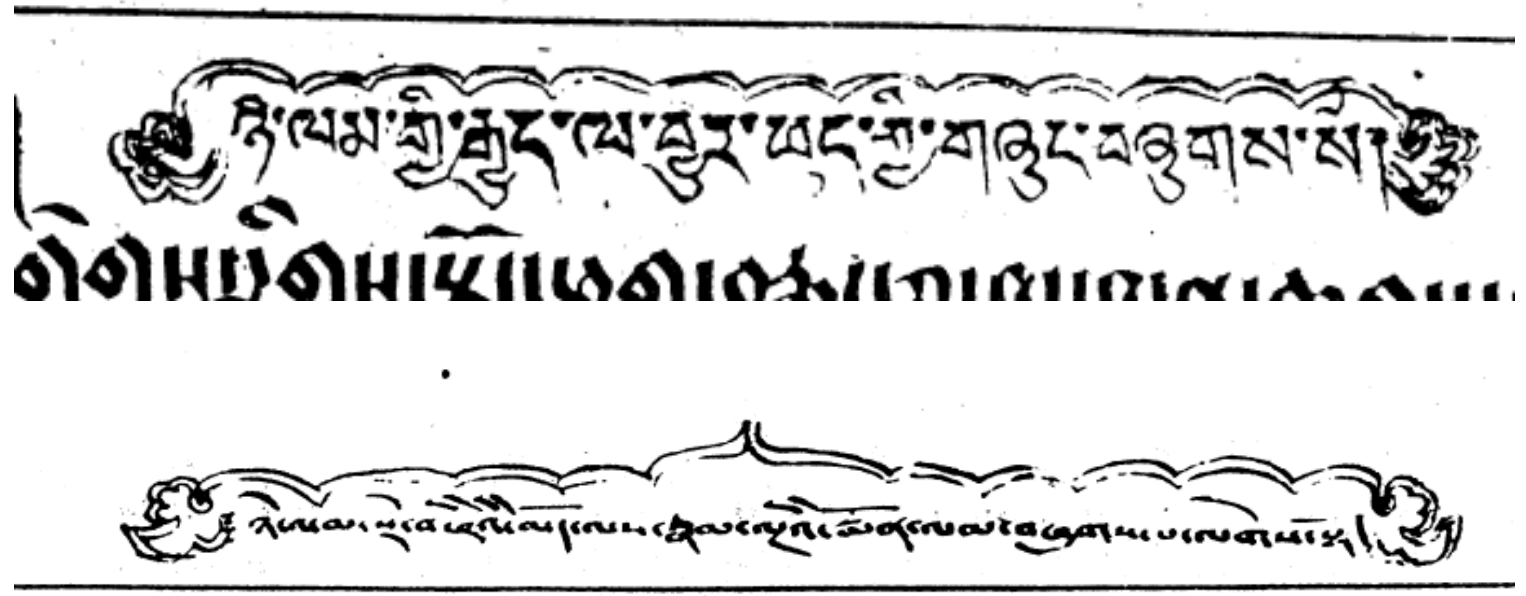

316 The fifth style does share features in common with the primary commentarial style, but there are enough points of departure, including the simple fact of the fifth style's awkward inclusion outside the bounds of the original pages, to suggest a different author. 
Figure 4.1: Handwriting styles 1-5, respectively from top to bottom, with the 1st for instruction/commentary, the 2 nd for verse recitation, the $3^{\text {rd }}$ for visualization, and the $4^{\text {th }}$ and $5^{\text {th }}$ later additions by different scribes for titling and comments.

Despite the common handwriting throughout the textual contents, however, the title pages show a great deal of variation. Seventeen of the forty-six volumes, for example, do not have a title page at all, including only a topic sentence that makes it clear what the volume will be about, or referencing a title in the colophon, or showing an annotation in the fourth or fifth handwriting styles, together with ornamentation clearly meant to re-create the aesthetic of a title page as much as possible in a small space. ${ }^{317}$

In many cases, they are short volumes, sometimes a few pages, hardly warranting a grandiose title page, but there are a number of longer volumes without title pages and shorter volumes with title pages, to the extent that length alone is hardly sufficient to explain the presence or absence of a title page. In cases of prominent and more generalized texts like Affecting Lu (klu bcos), the Lubum, or the Beckoning of Fortune, it is clear that the presence of a title page indicates decontextualization from former contexts or decontextualizability from any given context, almost certainly the former. That is, these are texts that existed prior to the systematization of the Nyelam Dé Zhi collection, imported into the collection to fulfill particular needs. In cases of title-paged volumes highly specific to the Nyelam Dé Zhi - for example, the Manuscript and the Upper Ritual - such prominent and ornate title pages function as banners for the entire collection.

317 See Appendix 8: Notable title page differences across volumes. 
Other cases are less clear. For example, neither the Cow Cure (ba yi nad sel) nor the Royal Retinue Cure (rgyal 'khor nad sel) has a title page, unlike the Frog Cure (sbal pa'i nad sel) and Cure of the Garuda (khyung gi nad sel) volumes, which are otherwise similar in length, format, subject, and generalizability. An explanation for this is that the latter two existed independently at the time the Nyelam Dé Zhi collection was put together, and the former two needed to be improvised or were orally communicated to the scribe. Indeed, many of the untitled volumes are introduced in a very conversational and linguistically consistent manner, suggesting that swaths of the Nyelam Dé Zhi collection, especially the smaller and simpler volumes, may have been dictated in one or a few serial sittings from one lama to one scribe.

Only twenty-five of the forty-six volumes include nye lam sde bzhi in the title, ${ }^{318}$ with one of them actually referring to it as the nye lam rgyal po sde bzhi. ${ }^{319}$ Some embed the title in larger phrases or complete sentences, sometimes with adornments, qualifiers, and so on - bzhugs pa legs, bzhugs pa'i dbus phyogs, or a combination $^{320}$ - while others just list the title of the text and nothing else. ${ }^{321}$ One talks about the $m d o$ of the Nyelam Dé Zhi ${ }^{322}$ while others talk about the gzhung of the Nyelam Dé Zhi, ${ }^{323}$ and one calls it the nye lam gyi rgyud. ${ }^{324}$ One of them, the Sadakbum, stands out from the rest in its use of the zhes bya ba elocutionary device

\footnotetext{
318 Volumes 1-4, 6-11, 13, 20-25, 27, 29-32, 34, 40, 42, and 46. This is a total of 25, or 54\% of the total collection. See Appendix 1 for details about these volumes, and those listed in the notes that follow. 319 Volume 40, the bkra shis shog chung.

320 Volumes $2,3,6-11,13,16-22,24-30,33,35-39,42,43$, and 46 . This is a total of 32 , or $70 \%$ of the total collection.

${ }^{321}$ Volumes 5, 12, 14, 15, 41, 44, and 45.

322 Volume 23, the rnam Inga'i smon lam.

323 Volumes 5, and 7-10.

324 This is volume 4, the nye lam gyi rgyud la byur phud kyi gzhung.
} 
to set the title off from the rest of the title expression. ${ }^{325}$ Otherwise, groups of texts are not necessarily titled in a common style as might be expected. For example, the four 'bum texts of each of the deities:

- $\quad$ All except the Mottled Töbum start with nye lam sde bzhi'i...

- All except the Sadakbum have roughly the same title expression: “...bzhugs pa'i dbus phyogs legs swo//", though the Lubum has legs misspelled as lags (565). The Sadakbum has "...zhes bya ba bzhugs pa'i dbus phyogs so//".

- All title page cosmetics are roughly the same and relatively simplistic except for the Lubum, which is quite a bit more ornate. ${ }^{326}$

- Only the Mottled Töbum includes a "color" classifier in the title. ${ }^{327}$
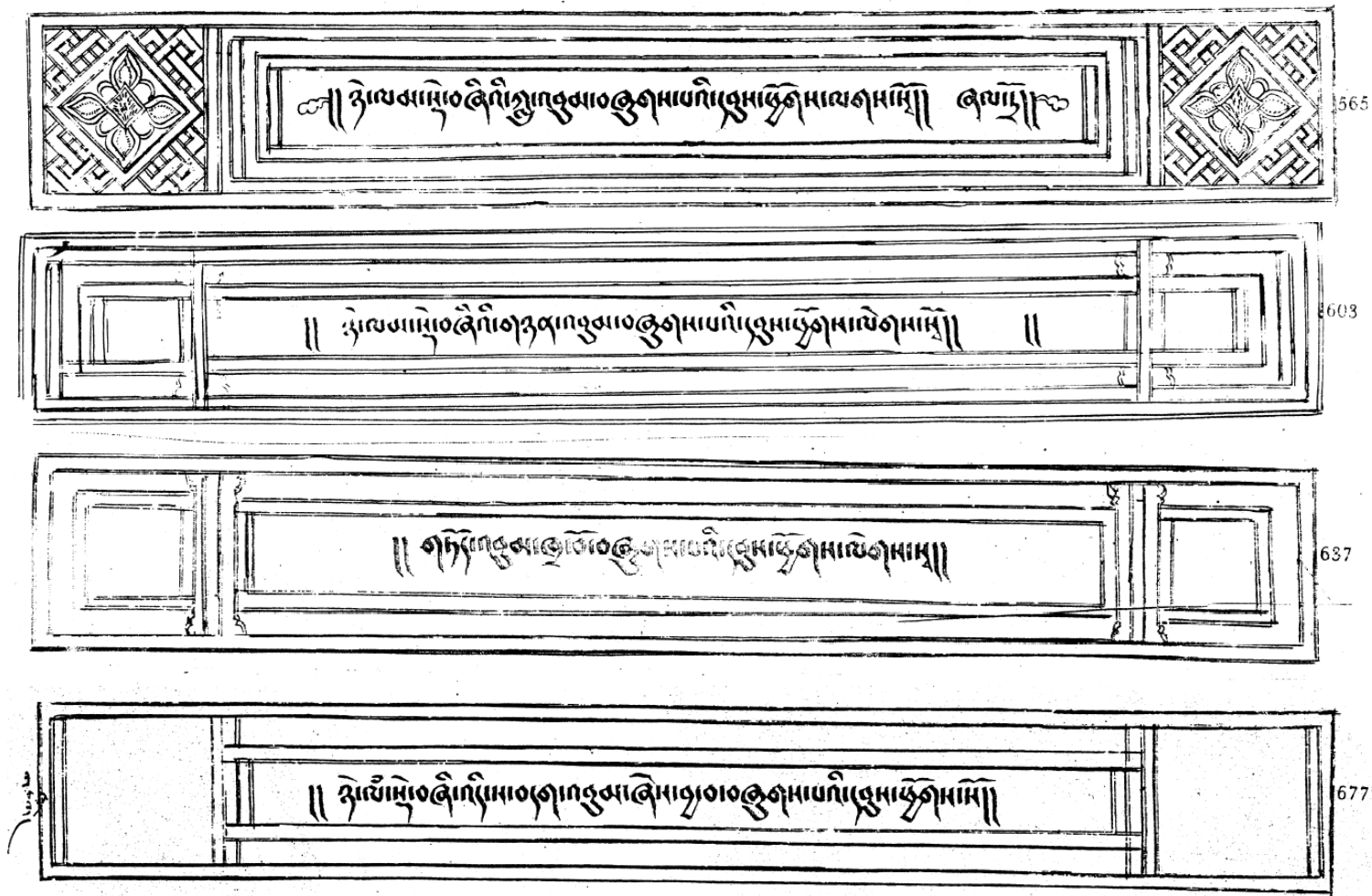

Figure 4.2: The ornate Lubum title page (top), compared to the plain title pages of the other bum texts.

325 Full title expression: nye lam sde bzhi'i sa bdag 'bum zhes bya ba bzhugs pa'i dbus phyogs so (677)

${ }^{326}$ See figure 4.2 for the difference in title page cosmetics.

327 It is common for the 'bum texts of these deities to include a dkar po, nag po, or khra bo designation, especially in the case of the klu. In fact, the Sadakbum does indicate nag po from the language preamble - sa bdag 'bum nag zhes bya'o// (678), but it does not include this in the title, and neither of the other two make any mention of further classifications. 
On their own, these differences might be enough to suggest distinct authorship or at least separate authoring episodes rather than all volumes being discovered at once by the same person, but much of this could still be accounted for by transcription choices, mistakes, and so on over the course of many years. The contents of the texts, however, are as variable in style as the titles. A great diversity of vocabularies, versification, grammatical styles, and subject matter is on display across the volumes, to an extent that unambiguously points to multiple authorship over great periods of time and to the origination of individual or groups of volumes, as independent, or stemming from other collections.

One telling difference in style between texts that may point to time period is the translation of a text's title into one or more languages as a first order of business. In Bönpo texts generally it is common to see translations into one or more of the Zhang Zhung language (zhang zhung skad, the language of the old land of Zhang Zhung), the Language of the Everlasting Gods (g.yung drung lha'i skad, language of the Everlasting Gods), ${ }^{328}$ and Tibetan (bod skad). The Upper Ritual includes a Zhang Zhung language seal and translation of the title - na ga sho ta rag mo sla zhi phu mu mu ye smar ma ho - followed by the Tibetan - klu gnyan gter dang

\footnotetext{
${ }^{328}$ g.yung drung lha'i skad has a lot in common with Sanskrit but is not the same. Nyima Özer said that some people believe it was a language the pre-dated all the others in Asia, and from which Sanskrit and others in the region are derived. For these people, this explains the presence of Sanskrit words and letters - like om - in Bönpo texts that have no alleged connection to India (Interview with Nyima Özer at Menri monastery on 7/12/2009). Tenzin Tsultrim, on the other hand, presents the perspective that g.yung drung lha'i skad was the language of Ölmo Lungring ('ol mo lung ring), the legendary birthplace of Tönpa Shenrap and Bön. As Bönpo scholars learned Sanskrit to prove their aptitude among Buddhist peers, the two similar languages became mixed and confused (Interview with Tenzin Tsultrim at Triten Norbutsé on 5/27/2010).
} 
sa bdag zhi bar byed pa'i mdo zhes bya'o. The Lubum ${ }^{329}$, Töbum, $^{330}$ and Sadakbum ${ }^{331}$

also have titles in the Zhang Zhung language and Tibetan, while the Nyenbum has one in the Language of the Everlasting Gods. ${ }^{332}$ There are a couple of strong similarities between the title translations in the two non-Tibetan languages, however. For example, the name of the deities in the Zhang Zhung language appear to be na ga ra tsa (klu rgyal), ri mo ra tsa (gtod rgyal), and na ga de de (sa bdag),333 while the Language of the Everlasting Gods name is sho ti ra tsa (gnyan rgyal). All translations also seem to use zhi or zhi ba to set off the title (though the Töbum uses zhes). It is abundantly clear that Bönpos consider the Language of the Everlasting Gods and the Zhang Zhung language to be independent languages, and yet it in this case, and others, ${ }^{334}$ they are almost interchangeable, and the choice was made, deliberately or randomly, inside or outside the context of the Nyelam Dé Zhi aggregation, to designate the alternative title in the Nyenbum as the Language of the Everlasting Gods. Authors and scribes operating across time and space within the Bön tradition did not always have a clear or consistent sense of the distinction between the two - certainly many geshés in modern times find the Language of the Everlasting Gods to be inscrutable and most do not know enough about the Zhang

329 zhang zhung skad: mur zangs na ga ra tsa mu la zhi (566.1). Tibetan: sa bdag kra yi bod (566.2). This strange Tibetan title points to the overall very problematic Lubum of the Nyelam Dé Zhi, a topic that will be addressed later.

330 zhang zhung skad: ri mo ra tsa zhes ho. Tibetan: gtod 'bum khra bo zhes bya'o. (638.1) It seems unlikely that the former includes the khra bo designation, given that na ga ra tsa just means klu. 331 zhang zhung skad: na ga de de byo lha zhi ra'o. Tibetan: sa bdag 'bum nag zhes bya'o. (678.1)

332 sho ti ra tsa zhi ba lhan ne hrun (604.1). Immediately following this there is a bod skad du..., as if to introduce a Tibetan title, but then the text just begins, paying hommage to the Ones Gone to Bliss. Though this reads coherently enough, the departure from convention suggests that the Tibetan title was mistakenly omitted.

${ }^{333}$ Based on conversation with a few geshés, na ga de de may translate as "authentic lu," however, so this could be a mistake in the text or an unusual title for sa bdag.

${ }^{334}$ See also Achard, 2004, p. 213, where he refers to a text that was purportedly written in the Language of the Everlasting Gods, which appeared very clearly to be the Zhang Zhung language. 
Zhung language to speak to differences. However, even without specific knowledge of these languages, invocation of their names - one earthly and one celestial reflects different agendas. One establishes a horizontal origin and the other a vertical one. Given that there is nothing about the contents of the Nyenbum that obviously compel setting it apart from the other bum texts in this way, we are left to conclude that, in etic terms, this one text either had a different author and/or time period and/or other subcultural pressures. Alternatively, in emic terms, it appears to suggest that the nyen are the most "heavenly" of the four deities, often residing on mountain tops or the ethereal space above them, often playing critical roles in royal mythology, 335 and so on, such that teachings about them are subtly elevated in this linguistic way, or are otherwise logistically connected to more vertical than horizontal origins.

Besides the four bum texts and the Upper Ritual, there are no other texts in the collection that include this language preamble, which begs questions about other distinguishing features of these five texts. Do they, as a group, come from a different author or authors, different time period or periods? Were they written or re-written or at least re-introduced to accommodate a different audience than the other volumes of the Nyelam Dé Zhi? Were they merely following established literary conventions? It is unlikely that one author in one period would have treated these five texts differently from all the others, further treating one of the five differently from the other four.

335 There are many such myths, but I'm echoing a blanket summary from Karmay, 2009, p. 56. 
The motivation for making reference to these other languages can also only relate to an intended or expected audience. While we have to allow that there may have been scholars and other specialists writing and reading in the Zhang Zhung language at the time, for whom this translation key would have been of practical benefit, it is far more likely that Bönpo authors were following the same convention that, in Buddhist texts, had titles listed first in Sanskrit and then in Tibetan. Referring to the Zhang Zhung language instead of Sanskrit served the obvious purpose of establishing Bönpo origins, while the use of the Language of the Everlasting Gods in the Nyenbum upped the ante, intending to compete with Sanskrit for primacy rather than simply establishing identity. In both cases, the message that these were Bönpo texts was made abundantly clear to a possibly diverse audience that was either expected to make use of the texts or already had.

Further style and content differences among the forty-six volumes of the Nyelam Dé Zhi are evident in the internal ordering of texts. Enumeration within the texts, typically in the colophon, point to some of these volumes as having been part of different collections at one point or another and/or to having comprised their own collection. The Cure volumes, for example, are in the following physical order in the Nyelam Dé Zhi collection:

1. klu gnyan sa bdag bzhi336

2. gtod

3. sa bdag

\footnotetext{
336 This volume actually only deals with lu and nyen, with the sadak addressed in a later volume. The title is thus wrong both in its inclusion of sa bdag and its inclusion of bzhi. Presumably the titler put bzhi there because of the frequency of klu gnyan sa bdag gtod bzhi as an expression, and hopefully not because he considered sa bdag to be two separate syllables, but in any case it should not make reference to anything but lu and nyen.
} 
The colophons for these texts, however, enumerate as follows (respectively in the texts):

1. first (klu, 407.1) and second (gnyan, 415.1)

2. fourth (427.2)

3. third (446.4)

Putting aside the awkwardness of two volumes being condensed into one mistitled volume, it is possible that the gtod and sa bdag volumes merely got swapped when the collection was being put together, but there is no other context in which these four are referenced together that would justify, in the context of the collection, the enumeration of one through four in the first place, and indeed there are four other Cure texts. ${ }^{337}$

Compared to virtually all of the other volumes, there is an obvious difference, and enhanced comprehensibility, in tone and style in the Manuscript due to its recency (c. 1889-1890), which again will be discussed in more detail below, but a few others are on the opposite end of the spectrum. The Twelve Namshé (gnam gshed bcu gnyis, volume 15, p. 389), the Lubum (volume 24, p. 565), and Banishing Rock Ogres (volume 43, p. 1037) are three examples of very different and very challenging volumes.

The Twelve Namshé is only four pages long and is concerned with banishing the demons associated with particular astrological years - tiger, rabbit, snake, and so on - for the benefit of patrons, fellow people in the village, and cattle. In addition to this text's abundance of at least partially Zhang Zhung names, such as re te mgo

\footnotetext{
337 It's important to note that the zin thu does make occasional reference to all four together (see for example 31.2), but not in any particular order.
} 
nyag, kha ste 'gro yug, za re stag skra, and kyas med hol gshen 'grug ghon, ${ }^{338}$ old or obscure words, alternate spellings or misspellings, and particle confusion abound. This last issue points to the clear oral dictation of this volume to a scribe or scribes over the course of potentially many reproductions, who sometimes wrote lo $p a^{\prime} i$ $b_{d u d^{339}}$ (correct, though we might expect lo $b a$ ) and sometimes wrote lo pas bdud ${ }^{340}$ (incorrect), sometimes within one line of the other. This confusion may also help identify the region where this dictation took place, as, for example, the Amdo and possibly the Kham accent would have sufficiently distinguished the two particles in ways an Ü-tsang or Dölpo accent would not. Given what we know about the background of the manuscript, the author of the Manuscript, and Khyunggötsel, Dölpo is the likely context. ${ }^{341}$

The Lubum starts coherently but quickly devolves into a jumble of alternate spellings or misspellings or old or ambiguous words, repeated lines, ${ }^{342}$ and missing words or sentences. ${ }^{343}$ The scribe for this iteration of the volume at least partially understood that there were errors in the text he was drawing from, as there is more than one place in the text where he substituted dashes for what must have been unreadable or blatantly wrong prose. ${ }^{344}$ Tenzin Tsultrim, Samten Karmay, and other geshés believe that this volume was drawn from one of the other more standardized Lubum texts, with layers of transcription errors yielding this barely comprehensible

\footnotetext{
338 These are all listed on 389.1-2. This last name could possibly be split into two names.

339 See 390.1, 390.3

340 See $389.5,390.2,390.3$

${ }^{341}$ It should be noted, however, that this relates more immediately to locations of reproduction than to locations of authorship.

342 See 568.6.

${ }^{343}$ See 569.3 and 571.1 for two such examples.

${ }^{344}$ See for example pages 571.4 and 572.2 .
} 
version, but there is no clear parity with other Lubum manuscripts. No other volumes in the Nyelam Dé Zhi collection have such abundant errors or challenges, and yet there can be no doubt, given the lu's prominence among the four deities of the Nyelam Dé Zhi in Tibetan culture and attitudes, as well as the predominance of lu concerns and detail among the many volumes, that the Lubum is one of the most important texts in the collection.

Instinctively, we would expect this to mean that its accuracy would be a paramount concern among scribes and ritual specialists charged with administering the Nyelam Dé Zhi, and this is indeed true, but not in the way we expect. To take a methodological leap to ritual performance (though a purely textual analysis thereof), the dynamic is much like Kafka's leopard as articulated by Jonathan Z. Smith. ${ }^{345}$ In other words, the vagaries and blunders of repeated transcription have become codified in the ritual corpus to the extent that no one in modern times feels comfortable "correcting" them, and nor are they especially interested in doing so. As will be shown in the next chapter, monks very often do not understand what they're reciting, and narrative coherence, or lack thereof, has no bearing whatsoever on the motivation or efficacy or overall coherence of the ritual itself, which requires the presence of texts, and their alleged pedigrees, far more than it requires anything specific about their contents. ${ }^{346}$

\footnotetext{
345 Smith, 1980, p. 113.

346 This excludes administrative volumes like Manuscript and Upper Ritual, which must be exceptionally coherent and discursive as they provide the framework for the performance of the ritual itself. These are discussed in more detail below.
} 
Banishing Rock Ogres - a volume with instructions for banishing the titular beings (brag srin) as well as lu demons (klu srin) $)^{347}$ - represents two larger dimensions or trends in the Nyelam Dé Zhi collection: Language idiosyncrasies and remedial manuals to be used only when the need arises, and not as part of annual ritual performances. As for language, the translation of this short volume required the assistance of three different geshés ${ }^{348}$ and Drukzé, the Acharya at Menri, to complete, and there are still sections that could use further clarification, in part because of transcription errors and alternate spellings or misspellings, but also because of a different vocabulary than many of the different volumes. Here is an illustrative example:

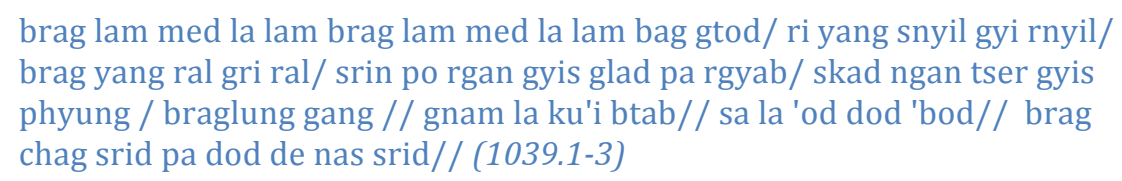

These two lines start with an inadvertent duplication, ${ }^{349}$ and then feature archaic or otherwise distinct poetic styles not present in most of the other volumes of the Nyelam Dé Zhi, ${ }^{350}$ and many alternate spellings or misspellings. ${ }^{351}$ Tenzin Tsultrim is of the opinion that certain genres have different vocabulary or style requirements

\footnotetext{
347 I'm choosing to translate srin as demon because of the common convention of doing so for srin po, even though a more contextually accurate translation might be "spirit," in which case klu srin would not be clearly different from klu on its own. Using "demon" better reflects the author's choice to address klu srin instead of just klu.

348 Tenzin Yangtön, Yungdrung Mönlam, and Nyima Özer

349 brag lam med la lam brag lam med la lam bag gtod should probably be brag lam med la brag la lam bag gtod.

350 Nyima Özer, who is the publisher of bon sgo magazine, which features a great deal of poetry, explains that snyil gyi rnyil, which we understand to be nyil gyis snyil, is the hallmark of pre-modern poetry. The following stanza features this style again with ral gri ral, which we understand to be ral gyis dbral. The only other text in the Nyelam Dé Zhi collection that consistently uses this style is the Beckoning of Fortune (volume 13).

${ }^{351}$ See the previous note, as well as the particle confusion in srin po rgan gyis klad pa rgyab, tser instead of gtser in skad ngan tser, 'od instead of 'o in 'od dod 'bod, and brag chag instead of brag cha.
} 
and that the best writers understood this - the different style does not necessarily mean that Khyunggötsel did not write it. Tenzin Yangtön and Drukzé, on the other hand, all agreed that it seemed like someone besides Khyunggötsel wrote this volume, and possibly at a very different time, though their knowledge of the rest of the volumes in the collection was perhaps less complete than Tenzin Tsultrim's. ${ }^{352}$

The second important dimension that Banishing Rock Ogres illustrates is its remedial orientation. That is, there are a number of texts across the Nyelam Dé Zhi that are self-contained manuals useful only to ritual specialists facing particular and immediate challenges, typically a large-scale illness in the village. This particular volume suggests that the specialist go to wherever the Draksin (brag srin) resides, deploy specific tormas (1037.1-3), and recite a mythical story about a particular rock demon (as well as other characters like Lusin [klu srin], 1037.3-1039.5), and then do the banishing in sometimes supplicatory and sometimes imperative terms (1039.5-1041.4). See Appendix 3 for the names of other volumes that are not used in the ritual because they are similarly oriented (remedial) and self-contained.

None of these volumes are part of the annual ritual as described by the Manuscript and Upper Ritual, which only make casual reference to other kinds of remedial rituals that can be included as needed, nor are they part of the actual performance at Triten Norbutsé, with Tenzin Tsultrim describing such volumes as relevant only to village ritual performances, not those at the monastery. ${ }^{353}$ The

\footnotetext{
352 Interviews with Tenzin Yangtön and Drukzé at Menri monastery on 5/7/2009, with Tenzin Tsultrim at Triten Norbutsé on 5/28/2009.

353 Indeed, Tibetans who remember the Nyelam Dé Zhi being performed in their villages when they were young - primarily Samten Karmay and Tenzin Namdak - say that such smaller scale performances were always occasioned by particular problems with particular beings, usually lu.
} 
inclusion of such volumes in the larger collection, alongside larger institutional organizational volumes like the Manuscript, which ritual specialists in smaller village rituals with remedial intent would not make heavy use of - and may not use at all, or at least certainly did not use prior to its being written in the 19th century points to the great diversity of contexts and use cases that the collection addresses, of which a preventative, annual, institutional performance like that at Triten Norbutsé is but one.

\section{Volumes that Structure the Performance}

\section{The Synthetic Manuscript}

Perhaps the clearest and most comprehensible volume of the collection is the Manuscript, also the most important text in the collection for the institutional performance of the Nyelam Dé Zhi. It was written by Drungmu Werzhi ${ }^{354}$ on the eighteenth day of the fifth month of the earth ox year (1889-1890), with the explicit intention ${ }^{355}$ of making coherent performative sense of the various texts included in the collection. It is split into two principle sections, the ritual preparations $\left(b c a^{\prime}\right.$

\footnotetext{
From interviews with Samten Karmay in Paris, France on 5/31/2011 and with Tenzin Namdak at Triten Norbutsé on 5/26/2009.

354 It has proven quite difficult to locate this individual. Achard (2004, p. xxii) makes reference to him as one of Dechen Lingpa's teachers, with an uncertain death date of 1870, but Alay (2010, p. 124) finds reference to him in a very similar context to that of the Manuscript's colophon (Dechenling) with a possibly comparable teacher (Shetsu Werya [she tsu wer ya]), and the colophon there suggests a composition year of 1887. Dan Martin (2001, p. 138) identifies an individual with the same name who was abbot of Menri monastery in 1662 (via Kvaerne, 1971), but this date obviously places him out of range. Both Alay and Martin point out that his name is the Zhang Zhung translation of g.yung drung rgyal mtshan, an exceedingly common Bönpo name.

355 The full title of the text is the nye lam sde bzhi'i zin thu gsal byed 'phrul gyi me long - The Mirror that Illuminates the Manuscript of the Nyelam Dé Zhi. Note that zin thu is much more commonly zin tho. The origin of this alternate spelling is unknown.
} 
gzhi) and the ritual steps (las rim). ${ }^{356}$ The former concerns itself with basic and sometimes very specific details about the tormas, vases, mandala, offerings, and other implements, as well as instructions for building the dö, and what to recite while undertaking all of these tasks. It points out that texts like the Cure volumes, Banishing Rock Ogres, and so on are only present in the collection for the purposes of actually curing illnesses or dealing with issues that occasioned the ritual, and therefore do not need to be considered for the institutional performance. The latter addresses the main part of the ritual, the recitation, and it specifies what volumes should be used when, places to look for supplementary texts - including the very important Expansive Space, discussed below - and options to do or not do certain parts of the ritual based on resources. ${ }^{357}$ It makes specific reference to sections of the texts, in the form of starting and ending syllables, where one can find the recitations for particular segments of the ritual, and the exact order in which it should all be undertaken.

The majority of recitation instruction centers around the Upper Ritual volume - to be described below - and the supplementary Expansive Space text, which provides not only preparatory details about tormas and other ritual implements, but also the recitations that accompany preparations - dedications, consecrations, and mantric seals - as well as recitations for essential preliminaries like going for refuge and generating bodhicitta, which, significantly, are not present anywhere in the volumes of the Nyelam Dé Zhi itself. While the Manuscript does

\footnotetext{
${ }^{356}$ See Appendix 6 for the complete sa bcad.

357 This is also present in the first part of the text, in various places indicating that certain preparations can be done at different scale - or not done at all - based on the material and time available.
} 
make use of Expansive Space to fill in such important gaps in the Nyelam Dé Zhi, in many cases, as with the blessing of the offering materials, confession, the five-fold offering, and so on, it indicates that recitation should be done from particular sections of both. Within these cases, there are some that feature a high degree of similarity between recitations and some that are quite different, such that it can be difficult at first to discern a rationale for making such consistent use of Expansive Space - many segments of the ritual seem to be quite sufficiently addressed by the Upper Ritual or other Nyelam Dé Zhi volumes. To understand this, it is important to look at both the Upper Ritual and Expansive Space in a bit more detail.

\section{The Upper Ritual}

Before the Manuscript was written, the stod chog was the sole organizational manual for performances of the Nyelam Dé Zhi that spanned more than a single remedial volume. It is split into two main sections, with the first addressing origins, locations, and other descriptive details about the sadak, lu, nyen, and tö. There is a full cosmogonic myth-history of each, starting with the creation of Mt. Meru and their birth from eggs in each of its four intermediate directions. ${ }^{358}$ The second, much longer section, comprising the main body of the text, describes the ways to deal with these deities, ${ }^{359}$ and contains twelve subsections: ${ }^{360}$

1. The "the four continents" (gling bzhi) - the story of the subjugation of the four kinds of worldly deities

2. Preliminary practice steps (sngon du 'gro ba'i las rim)

3. Land-taking (sa blang)

\footnotetext{
${ }^{358}$ See pages $105-107$.

${ }^{359}$ See Appendix 7 for the complete sa bcad.

360 Note that I present the wylie for these as they appear in the text, which includes a number of alternate or erroneous spellings, such as sta bon instead of sta gon, and steg bu instead of stegs bu. See notes below for more detail.
} 
4. Ritual preparations (sta bon) ${ }^{361}$

5. Erecting the platform ${ }^{362}$ (steg bu brtsegs)

6. Casting the lines [of the mandala] (thig gdab)

7. Sending the colored sand [of the mandala] (tshon bkye)

8. Arranging the instruments and ornaments (yo byad dang rgyan bkod pa)

9. Ablution (khrus)

10. Creating boundaries ( $m$ tshams bcad pa)

11. Generating meditative absorption (ting 'dzin bskyed)

12. Invocation (spyan drang $b a$ )

The last section then includes the nine subrites that are common to a great many rituals, from the bcos volumes within the Nyelam Dé Zhi collection, to the generic referents from which Cabezon (2009) constructed his list above. They are:

1. Requesting to remain (bzhugs su gsol ba)

2. Producing delight (dgyes pa bskyed)

3. Prostrations (phyag 'tshal)

4. Confessing misdeeds (sdig pa bshags)

5. Making offerings ( $\operatorname{mchod} p a$ 'bul)

6. Magic sentences and essence [mantras] ('dzab dang snying po)

7. Praise $(s k u$ bstod $)$

8. Enjoining enlightened activity (phrin las bcol ba)

9. Aspiration prayers (sman lam gdab)

With a narrative that describes the occasion and authority for the ritual, instructions for the construction of necessary ritual implements, and a full step-bystep liturgy, the Upper Ritual stands on its own as a complete ritual text. There can be no doubt, in fact, that this volume was used in isolation for small-scale performances of a ritual that may or may not have been called the Nyelam Dé Zhi. Its author purportedly drew from the bum texts for its content, but it makes no reference to them and the bum volumes in the collection do not match up

\footnotetext{
${ }^{361}$ Note that this is usually sta gon or lta gon, as per Cabezon's list of subrites at the beginning of this chapter. The substitution of bon for gon here is a characteristic practice of many authors and teachers.

362 Note that I have not chosen "altar" here, a common translation of stegs $b u$, because it is referring to the dö and not a traditional altar.
} 
consistently with the content of the Upper Ritual. Upper Ritual, in fact, does not make reference to any other texts in the collection, and the Manuscript offers both redundant and extrapolated information about the Upper Ritual's contents, which is sometimes fragmented and missing chunks of content, with the Manuscript additionally to bolstering its various component rites with additional material, in order to transform this relatively simple ritual into one appropriate for larger scale performances that incorporate more institutional concerns, such as clan-affiliated traditions of practice, and more rigorous structure, such as the various tantric preliminaries that it took for granted or otherwise fails to include - going for refuge, generating mind, and so on. ${ }^{363}$ To accomplish these goals the Upper Ritual is supplemented by Expansive Space.

\section{Expansive Space and Other Supplemental Texts}

What the Manuscript of the Nyelam Dé Zhi - and many other rituals and monks refer to as Expansive Space, which translates to "Extended Expanse," is an outer tantric text extracted from the Zermik, the middle-length "biography" of Tönpa Shenrap. Expansive Space is an alias for the fourteenth chapter, Shenrap's teachings on the significance of the eighteen enlightened activities, ${ }^{364}$ and has also been collected into the Katen, where it is known primarily as and within the Collection of Hymns. ${ }^{365}$ More than the name by which it is referenced in the Nyelam Dé Zhi and

\footnotetext{
363 The one exception to this self-containment is the collection of rites to be found in volume 34 (see Appendix 1), which the stod chog references (112.3-5) but does not then include. It is not clear why these are in a separate volume without much of a title and with no explanation within the stod chog to look for them elsewhere. It is possible that the author took for granted that performers would know how to do them, which would speak very clearly to an institutional audience.

${ }^{364}$ le'u bcu bzhi pa/gshen rab kyis 'phrin las bco bryad kyi don bstan pa'i skor (gzer mig, p. 593).

365 bstod tshogs (klong rgyas) - volume 265.
} 
elsewhere, this name points to its genericized utility across liturgies and events of many kinds. A codification of the liturgical traditions of the Dru ('bru) clan, explicitly referred to as the "Dru system"366 - this text provides self-contained, decontextualized "hymns" and instructions for particular formulations of mantras, mudras, visualizations, and ritual implements and ornamentation, alongside verses, that can be used, as illustrated by the Manuscript of the Nyelam Dé Zhi, to fill in ritual gaps and standardize outer tantric rites and addresses in any given system. It also helps to maintain threads of continuity stretching back at least to Nyamé Sherap Gyeltsen - especially important when used to anchor new ritual innovations - and has the added practical benefit of enhanced memorability for monks, who often know many of the hymns well enough not to need to read them. ${ }^{367}$

The Manuscript of the Nyelam Dé Zhi makes heavier use of Expansive Space and its rich contents than some ritual manuals do, however, suggesting that a portion of Nyelam Dé Zhi tormas and vases and other implements be constructed according to Expansive Space, which can be differentiated from those in the Upper Ritual by the former's emphasis on merit-generating implements and uses thereof, and the latter's emphasis on implements used as targeted offerings for specific deities. The Manuscript then directs usage of Expansive Space for the following preliminaries ${ }^{368}$ or for recitations to accompany them:

\footnotetext{
366 'bru lugs. A couple of monks used this term in conversation, and apparently there is a lugs for each clan's ritual styles (gshen lugs and so on, see Lhagyal, 2005, p. 433). The choice to translate lugs as "system" instead of "tradition" in this context is that it designates a sometimes complex array of ritual prescriptions that, while conforming to the entailments of tradition, should not lose its sense of systematicity.

367 More on this below, in the next chapter on text and performance.

368 There are multiple places where it refers to preliminaries in Expansive Space generally, one of which is 30.3 .
} 
- earth[-taking] ritual (sa chog, 21.3)

- blessing (byin brlabs, 21.4)

- boundary-setting, ground-leveling, line-drawing 369

- self-generation (bdag bskyed, 22.3)

- ritual preparations (Ita gon, 22.3)

- various mantric seals ${ }^{370}$

- ablutions (khrus, 23.3)

- downward offerings ${ }^{371}$

- arrangement of ornamentation (rgyan rdzas rnams bkod, 23.7)

- scattering of grain and ornaments ('bru dang me tog gtor, 24.2)

- going for refuge (skyabs su 'gro ba, 24.3,27.5)

- clear realization and front-generation 372

- blessing of offering materials (mchod rdzas byin brlabs, 24.5-25.1)

- invocation (spyan drang, 25.1)

- cleansing the sense faculties (dbang po sgo bsal, 25.5)

- the seven branch practice (yan lag bdun phyag, 26.1)

- confession (bshags pa, 26.2)

- five-fold offerings (rnam lnga, 26.3)

- praise $^{373}$

- generating mind (sems bskyed, 27.5)

Expansive Space is also critical to rites performed at the end of the ritual, ${ }^{374}$ both in

terms of instructions and accompanying recitations:

- confession (bshags pa, 32.1)

- opening the door (sgo dbye, 32.1)

- aspiration prayers (smon lam, 32.3)

- ablution mantras (khrus snying, 32.3)

- empowerment mantras (dbang snying, 32.3)

- movement of the guests (mgron bskyod, 34.1)

- movement of the seat (gdan bskyod, 34.2)

- auspicious blessing (bkra shis, 34.2)

${ }^{369}$ mtshams gcad (21.5, 24.2, 27.5, 30.3), chag chag (22.1), thig gdab (22.1)

${ }^{370}$ See for example A A Ad Om (22.5), A kar A rmad (23.2) for the seals for marking the boundaries of the vase as well as ornamentations and bindings, ablutions, fumigations, and more.

371 mar sbyin $(23.5,26.4)$ - Note that there was disagreement among geshés about whether this was literally "downward gifts" or "butter gifts." In both cases, it was understood that these were generally gifts for "lower" beings, sometimes including butter and sometimes not. It could be that mar is a deliberate play on both the "butter" and "downwards" definitions.

372 mngon rtogs $(24.4,24.5)$, mdun bskyed (24.4)

373 sku bstod (26.5). Note that this is literally "body/form-praising," but I've reduced it just to praise because geshés often talked about it with only implicit reference to $s k u$.

374 rjes bya mthar phyung ba (32.1) 
Many of these instructions to consult Expansive Space alternate with instructions to consult Upper Ritual or other volumes of the Nyelam Dé Zhi collection, such that it is clear that the combined content of the two is what yields the more comprehensive rite - Expansive Space provides more generalized rites and instruction - including elements that speak to the "bodhi" orientation that is of concern to monastics ${ }^{375}$ while the Nyelam Dé Zhi volumes provide versions of the rites or supporting material that specifically target the more lay-oriented concerns of the Nyelam Dé Zhi.

There are some cases, however, where Expansive Space fills in blanks that no volume in the Nyelam Dé Zhi collection addresses. For example, going for refuge (skyabs su 'gro ba) and generating mind (sems bskyed) are nowhere instructed in the Nyelam Dé Zhi volumes themselves, with the Manuscript directing ritual actors to Expansive Space instead, or to unspecified practices associated with outer tantric traditions. ${ }^{376}$ In the case of the former, the Manuscript author explains that refuge and generating mind can be done - in accordance with the four Ones Gone to Bliss or not. 377 The decision is the ritual administrator's to make. The absence of such critical preliminaries can only point to the "folk" orientation of the Nyelam Dé Zhi as a whole, and to its origins as remedial or palliative manuals prior to or concomitant with the more traditionally ethical influences of "new Bön."378

\footnotetext{
375 This idea of orientations is borrowed from Samuel, 1993.

376 dang po ni sngon 'gro man+Da la yan lag sogs phyi rgyud spyi ltar dang/(27.4)

377 skyabs su 'gro ba klong rgyas shog chung ltar/bdag dang 'gro ba: sogs tshang bar btang / nye lam sde bzhi la skyabs sems mi snang yang gong du bder gshegs gtso bzhi la mthun par byas kyang rung ngo /(24.3-4)

378 "New Bön" is a controversial label to describe this most modern incarnation of Bön, which is similar to Nyingma Buddhism, and further away from its purported death ritual roots. For more about this see Bjerken, 2004.
} 
The Manuscript thus instructs supplementary usage of Expansive Space - as well as the usage of some other supplementary texts (see below) - primarily for the very beginning and very end of the larger Nyelam Dé Zhi ritual, with the main section of the ritual furnished by the volumes contained in the Nyelam Dé Zhi. This relay between a more generic liturgical manual like Expansive Space and the main volumes of a specific ritual collection is an exceedingly important dimension to the construction of institutional ritual, whereby a ritual that focuses on whatever deity or deities, or on whatever desired ends and outcomes, can be wrapped in preliminary and secondary rites, prayers, and so forth that address community imperatives for any ritual. These include: Generating the right attitudes, blessing or cleansing or protecting the spaces where the ritual will be performed (including the body and mind) as well as the implements that will be used, and at least at Triten Norbutsé and Menri, maintaining continuity with the traditions of the Dru clan. The Nyelam Dé Zhi, missing instructions in its main volumes for such critical preliminaries as generating mind, is a perfect illustration of the need for such a widely applicable liturgical supplement. As such, it points to the added benefit of ready-made liturgical manuals like Expansive Space. When combined with the textual versification of any prose or orally transmitted subject matter - to make it recitable in the assembly hall - it immediately domesticates, and thus provides access to, any entity or concern, lay or monastic, in a way that dramatically reduces the time of liturgical conceptualization, and increases adoptability, performance consistency, and confidence in efficacy. 
Expansive Space is not, however, the only external text called for in the Manuscript. There are three others that fulfill particular liturgical mandates, providing decontextualized recitation material:

- The Completely Pure (rnam dag, 21.2): This is common short-hand for The Completely Pure Lotus Vastness (rnam dag pad ma klong yangs), a tantric text that is volume 254 of the Katen. Like Expansive Space, it is comprised of many common liturgies, in this case used for ablution and fumigation.

- $\quad$ The Six Vinayas ('dul ba rgyud [drug]) (26.2): The manual(s) of monastic discipline.

- Summoning Fortune [from] the Fount of Existence (srid kyi chu mig g.yang len, 33.4): This is an old ritual for bringing fortune that the Manuscript describes as relevant only to a village performance of the Nyelam Dé Zhi. Even then, it specifies that it should be recited, but it is optional whether to actually do the accompanying ritual. ${ }^{379}$

The latter two are sufficiently explained above, but rites provided by The Completely Pure - primarily ablution and fumigation - are, along with the casting of poison (dug phyung), common to every ritual as preliminary preparations of the ritual environment, implements, and actors. Unlike the casting of poison, which has a dedicated volume in the Nyelam Dé Zhi for addressing its particular needs, preliminary ablution and fumigation are the same across all rituals and thus the Nyelam Dé Zhi excludes any dedicated volumes, and The Completely Pure is used universally.

\section{Conclusion}

It is a testament to the importance of the Manuscript that if it were removed from the collection it would be inordinately difficult to make sense of the rest of the texts

\footnotetext{
${ }^{379}$ grong chog yin na srid kyi chu mig g.yang len brjod la g.yang len byas kyang rung / (33.4)
} 
and use the various volumes in concert to create a coherent ritual experience. From a purely literary perspective, however, this synthetic function of the Manuscript obfuscates more than it clarifies. It is the primary authority suggesting that the whole of the collection is a treasure text, that it was revealed by Khyunggötsel at Mt. Tisé, and that it is all outer tantra. ${ }^{380}$ It combines the various volumes, with instructions that are occasionally so explicit as to quote the starting and ending verses within the sequencing of volumes, into a coherent whole that only flows naturally when the contents of the various texts are not scrutinized.

While pedigrees of most of the other Nyelam Dé Zhi volumes (aside from the bum volumes) are mostly unknown, there is a great variation in titles, in terms of their fundamental presence or absence, aesthetic presentation, phrasing, and explicit assignment, or lack thereof, to the Nyelam Dé Zhi. There is occasionally different handwriting, language translation preambles, ordering schemes that do not cohere with their placement in the collection or relative to each other, duplications, and, above all, highly different content across volumes, with different subject matters, grammars, vocabularies, transcription problems, writing styles, and so on.

This reveals a few important dynamics about the collection and its component volumes, and about the community's relationship to them. First, there is a reverence for transmitted texts - a reverence not present in the community's relationship to performance, at least not for the Nyelam Dé Zhi, as the next chapter

\footnotetext{
380 The outer tantra designation is less obfuscating than the others, but it neglects the point that the klong rgyas provides at least as much material for the performance of outer tantric rituals than the Nyelam Dé Zhi volumes themselves.
} 
will show - that prevents correction or reconciliation of difficult or inscrutable volumes, even in the case of those that are used heavily for preparing and undertaking the ritual performance. This is true also of the aggregation, in the sense that no one, including Tenzin Tsultrim, was willing to say that the duplication of a text in the collection was an error that could or should be corrected in the event of a republication of the collection..$^{381}$

Second, and more relevantly, it shows that many of the volumes were used at some point in isolation. The Upper Ritual is a purely self-contained ritual manual, replete with narrative background and context, craft instructions, and verses. The Treatment volumes and, to a lesser extent, the bum volumes, also have full sets of rites that would allow them to be performed on their own. All of the remedial volumes, which comprise the majority of the collection, at least in quantity of volumes, if not in total number of pages, are self-contained and feature a great diversity of styles and contents that point to diverse authors and origins.

Finally, it shows that the modern collection of Nyelam Dé Zhi volumes is meant to inform and accommodate a variety of performative contexts. The different remedial volumes address problems that would be faced by villagers or nomads or royalty, but not monastics, while the fortune-calling texts and confessions and so forth address all, and those having to do with empowerment and other rigorous preparations are relevant only or mostly to monastic performances.

Despite any obfuscatory qualities of the Manuscript with regards to projects of attribution and origination, there can be no doubt that it illustrates a genius

${ }^{381}$ It is important to note here that this likely relates as much to the perceived infallibilty of high lamas as it does to the reverence for texts and their collections. 
beyond the crafting of a performance out of these particular texts. It shows how to connect a particular ritual or concern to a clan tradition, and how to bring the full inventory of pre-fabricated "swappable" rites to bear on a theme, or on a collection of thematically related texts, to create a coherent, easily learned and performed liturgy that seamlessly incorporates technologies developed over many centuries of ritual articulation - the nine steps of invocation, the five subrites to ensure efficacy (boundary-setting, mantra, mudra, verse recitation, and meditative absorption), and so on - and meets the various mandates of the community's ideology (generating the right attitudes, acting for the welfare of all sentient beings, and so on).

At least, this is the theory and the promise of the unperformed text. What happens when the rites and verses prescribed by the texts are brought to life, embodied by real people in real contexts that may be quite different from those of the texts' composition, is a different story. 


\section{Chapter Five: Performed Text}

Predictably, the portrait of a ritual that the texts convey is different in many respects from the live performance. The Manuscript, as described above, functions as a bridge between the ritual as text and as performance, connecting the dots between common liturgy and that of the Nyelam Dé Zhi, addressing resource limitations and providing options for different communities in different contexts, and clarifying some of the more opaque points of the other texts to create a more coherent experience for ritual actors. It thus has enormous value for the modern institutional performability of the ritual, and yet it cannot overcome all of the challenges and mandates of ritual enactment, at least not as observed at Triten Norbutsé.

The discrepancies between text and performance exist in two primary layers: A superficial phenomenological layer, having to do with aesthetics and logistics, in which textual instructions are not followed or understood, and a deeper signification layer, having to do with purpose, motivation, and meaning, in which the ritual's focus or goal, whether explicit or implicit in the text, does not match a ritual actor's understanding of the focus or goal.

"Superficial," in this case, does not at all mean trivial. Rather, it is a positional designation on an axis of visibility and givenness. Indeed, some ritual theorists posit that strict attention to these phenomenological aspects of ritual - following instructions precisely and in exactly the same way every time, adhering to certain "grammatical" rules regardless of content, "getting it right," and so on - is the 
primary variable that determines ritual success or failure. ${ }^{382}$ While many ritual performances across cultures support this perspective, the performance of the Nyelam Dé Zhi at Triten Norbutsé does not. As an examination of preparatory and performative divergences from the texts, and other performative idiosyncrasies, will show, the success of the Nyelam Dé Zhi performance can only be defined in spite of, not according to, stated ritual goals or expected outcomes on the one hand, or a strict reproduction of or adherence to procedural strictures on the other.

\section{Monk Attitudes Towards the Collection as a Whole}

Before outlining the specific departures from textual instruction or description it is worth examining monks' understandings of the collection as a whole. Monks who were familiar with the Nyelam Dé Zhi and with the works of Khyunggötsel - a small percentage of the total population, to be sure, and mainly geshés - uniformly suggested that the Nyelam Dé Zhi is not among the most important texts with which they have any kind of regular interaction, and is certainly not one of Khyunggötsel's most important revelations. It is true, they say, that the rituals and stories therein are of importance to the Bön tradition overall, and it is true that the Nyelam Dé Zhi collection as a whole is the most voluminous and, at least in that regard, the most impressive of Khyunggötsel's alleged revelations, but the critical point is that

\footnotetext{
382 See Smith (1980, 1993), Staahl (1996), and Humphrey and Laidlaw (1994), among many others, though an important clarification about and recovery from Humphrey and Laidlaw will be offered in the next chapter.
} 
nothing in the collection deals with dzokchen, which they consider the most important literature in their libraries and in their canon..$^{383}$

Even among non-dzokchen texts it is inferior to many, however, because of its orientation and classification as outer tantra. This genre and its larger context within Tibetan literature were described in more detail above, but monastic perspectives understandably differ from those of primary taxonomic texts and secondary research sources. The vast majority of monks consulted understand and agree that the movement from outer to inner to secret is one of increasing interiority and thus sophistication and power, and most of them could explain how this might apply to particular rites within larger rituals - how much emphasis is put on internal versus external offerings, visualizations, and so on - but beyond that explanations of what outer tantra means in a ritual context began to diverge. Here is a representative sampling of answers:

- The simplest difference between inner and outer tantra is that outer doesn't have miraculous manifestations (cho 'phrul), cutting, male and female combination, wrathful offerings, ganapuja offerings, and so on. Outer has different offerings, less wrathful, sometimes burnt offerings. Inner visualizations are more wrathful. And the altar is very different -- outer has more sutric ( $m d o$ ) offerings, pure white usually on the right of the altar, whereas inner is to the left, wrathful, ganapuja, red. The reason for having these two separate is for us, for practice, for different ways of thinking. Outer is more peaceful. ${ }^{384}$

- Inner tantric rituals must have red tormas, while outer tantric rituals almost always have yellow. Secret tantric rituals have both. ${ }^{385}$

\footnotetext{
383 It is somewhat misleading, in terms of perceived importance, that the Nyelam Dé Zhi is included in the Bönpo canon. A great many ritual texts are included in the various canons, and especially in the most recently published Katen, which has a tremendous variety of different texts, themes, and competencies on display, such that, in the words of Samten Karmay, it seems like just about anything that could be found around the monastery was thrown in there (from Interview with Samten Karmay in Paris, France, on 5/31/2011).

384 Interview with Nyima Özer at Menri monastery on 7/18/2009.

385 Interview with Tenzin Yangtön at Menri monastery on 5/14/2009.
} 
- Outer tantra is from the Bön of Cause. Inner tantra is from the Bön of Effect.

- Inner tantra has more drums, whereas outer tantra sometimes does, sometimes does not.

- Outer is for lower deities like the lu and sadak, whereas inner is for higher deities.

- Often the difference is between sutric ritual ( $m$ do chog) and tantric ritual (sngags chog). Rituals like Expansive Space, The Twelve Rituals (cho ga bcu gnyis), The Complete Pure (rnam dag), and the Complete Victory (rnam rgyal) are sutric, while those for deities like Trowo (khro bo), Magyü ( $m a$ rgyud), Meri (me ri), Purba (phur ba) and so on are tantric. The only deity that is in both sutric and tantric is Chamma.

- Outer tantra does not have the collected offerings (tshogs) - the big table of offerings. 386

- Outer tantra practitioners focus mainly on doing things with their body; inner tantra practitioners do body and mind things equally; secret tantra do mind things primarily; the Great Perfection is totally different. ${ }^{387}$

There are indeed many ways to distinguish outer, inner, and secret, some of which were discussed in the previous chapter, and it is thus unsurprising, on one level, that conversations about them would yield such a variety of perspectives. On the other hand, each answer above represents the first, and in most cases, complete response, from a sampling of monks, to the question of what distinguishes outer tantra from other kinds of tantra. Thus, monastic sensibilities about the distinguishing features span aesthetic differences like colors and instruments and quantity, quality, presence, and placement of offerings; taxonomic considerations; ritual addressees (deities) and their relative statuses; emotional valences; and motivational distinctions. Unsurprisingly, answers having to do with taxonomy came from

\footnotetext{
386 Interview with Tenzin Yangtön at Menri monastery on 5/16/2009 and interview with Tenpa Dargyé at Triten Norbutsé on 6/1/2010.

387 Interview with Tenzin Tsultrim at Triten Norbutsé on 3/2/2009.
} 
geshés, while answers such as the different colors of tormas came from both geshés and younger monks.

\section{Issues of Incomprehensibility}

A critical dynamic in the tension between text and performance is that of performer comprehension. A substantial percentage of the monks who are reciting the texts do not understand all of what they are reading, and some understand very little. This is not at all unique to the Nyelam Dé Zhi, but is crucially important to an understanding of ritual mechanics and meaning. Reading and translating the texts, one comes to an understanding of what the ritual is explicitly about, a sense of where it may have come from, and how it works. Aside from the segments of the Manuscript and Upper Ritual used for preparations, however, the majority of the monk performers have never before read the volumes outside of the ritual recitation and even those that have cannot understand a significant percentage of what they are reading, partly because, as described above, a number of the volumes contain archaic language, alternate or erroneous spellings, and transcription errors; partly because many of them are not yet educated enough to understand otherwise "correct" prose; partly because some recitations are explicitly non-discursive, as with mantras or verses in the Zhang Zhung or Everlasting Gods languages; in all cases because ritual recitation proceeds so quickly that there is very little time to construct or consider meaning that is not immediately given, and in all cases because virtually no one claims that it is important for all monks to understand what they are reading. Ritual performance explicitly privileges the act of recitation 
above the content of recitation. Many ritual manuals for a variety of rites specify a number of times that a given verse or mantra or collection of verses or a volume must be recited - calculated as the number of monks reciting the segment in question times the number of repetitions - in order for ritual goals to be achieved. While it could be argued that the content of what is being repeated is what engenders the transformation, or otherwise accomplishes the goals, from a performance perspective, and given the lack of comprehension throughout the ranks of performers, the fact of the recitation is clearly of primary importance.

This is true even - and especially - with the more narrative segments of the Nyelam Dé Zhi. Most ritual participants, even among the elite, have only a vague idea of what the mythic bases of the ritual might be, not having read them (in the Lubum, Nyenbum, and so on) recently or ever. In fact, the only monks who read these particular myths at any time in proximity to the performance are the typically younger, less adept monks who recite them quietly at the periphery of the ritual assembly. Incapable of understanding a large percentage of the archaic language, they are ostensibly charged with this task in order to please the beings that the stories are about. Perhaps most importantly, the majority of the ritual procedures themselves are almost entirely devoid of relevant mythical origins, having been handed down as a kind of generic technology applicable to any end. In this case, it would seem that even the narratives' value is more purely performative than 
transcendental, perhaps arriving closer and closer at such a role as familiarity with its particular dialect recedes. ${ }^{388}$

\section{Phenomenological Divergences}

\section{Crafts and Their Accompanying Recitations}

The first explicit departures of performance from text occur during ritual preparations, which are outlined in the text primarily in the Upper Ritual, but elaborated upon and clarified in the Manuscript. For the performances of the NDLZ observed, the most obvious differences concerned the details of the mandiala and thread crosses, and the timing and order of recitations during and around the crafting of ritual implements.

The monks making the mandiala use both the Manuscript and the book of maṇdala images called Maṇdalas of the Bön Tradition, which includes a drawing of the mandiala for the Nyelam Dé Zhi that is allegedly based on the Manuscript, but which differs in a few key ways, described below, along with the additional differences in the mandiala made for Triten Norbutsé's performance of the Nyelam Dé Zhi.

The Manuscript does hint at the possibility of differences, making explicit reference to "those who say that the mandala need not match the text [exactly]...that

\footnotetext{
388 It should be noted that, as with the other ritual texts, some of the mythic narratives are difficult not only with regards to vocabulary and grammar, but are also missing segments mid-sentence, whether through the patching together of different texts or transcription errors. Regardless, no effort is made to correct them or otherwise make sense of the disjointedness. They are recited as is.
} 
it does not need doors or door ornaments and so on,"389 but it does not endorse or condemn this attitude, instead suggesting that it is up to ones more knowledgeable than the author to decide. While some of the unique flourishes in the outermost layers of the Triten Norbutsé monks' mandiala would turn out to be inconsequential - the style and colors of the foliage in the extreme outside corners, for example staying within the lenient guidelines for adornments of the Manuscript, other discrepancies were much more significant. For example, according to both the Manuscript (5.1-2) and the Upper Ritual (133.4-5), the lotus petals at the center, the seats for the Ones Gone to Bliss, should be in the intermediate directions, but both the picture book and the monks' mandala had them in the cardinal directions. The Manuscript has stūpas beyond the doors (8.1-2), whereas the Upper Ritual (136.34), the picture book, and the monks' mandala have iron roofs, which is especially puzzling given that the picture book claims it took its information from the Manuscript. The picture book has dragon heads and deer and wheels by and above the roofs, but the mandala makers put garuda heads on top instead of the deer and wheel, and no dragon heads, all of which is not specified anywhere in the texts, but which is very similar to a mandala on the opposing page of the picture book.

Tenzin Tsultrim was not at all pleased to see these mistakes, saying loudly, "This is very annoying!" Most of the places where the colors are slightly different or patterns not exactly right were fine, he said, because it can be difficult to work with the sand, and it is not specific in the text, but these other details were very

\footnotetext{
389 ...dkyil 'khor lung mthun ltar mi dgos pa dang dkyil 'khor bris kyang sgo dang sgo brgyan sogs rgyas par mi dgos par smra yang / rang dra blo dman gyi dpon par ma gyur ba'i mkhyen ldan rnams kyi dpyad par mdzod cig// (8.9-9.1)
} 
important indeed. "The gods will not like this mandala," he said. ${ }^{390}$ I asked if this meant the ritual would not work, to which he replied, "No, but it won't work as well. They will still come and listen but they will not be happy." He also made a point of saying that the mistakes the monks made will be washed away soon, as opposed to the mistakes in the picture book, which are major because they are permanent. It is obvious that the monks almost exclusively followed the picture book instead of the text, ${ }^{391}$ but not even that consistently, as with the case of the garuda heads taken from a different maṇala, so that it is clear -- especially through dynamics visible in the video footage -- that when there was some uncertainty, one artist made a decision and the others followed it. There was thus a cascade of divergences, with the Manuscript author - who is not so important, according to Tenzin Tsultrim, because "he's just a lama" - making mistakes or decisions about something that should be different in the Upper Ritual, some of which were replicated by the artist who drew the mandiala for the picture book, who made his own errors or decisions, which were replicated by one or more sand maṇala makers, who then made their own errors or decisions, which were then replicated by the other mandiala makers, such that the final product was substantially different from the original text.

Whether or not the baseline usage of a picture book based on the text as a kind of expedient or proxy to the text constitutes, on its own, a departure from the

\footnotetext{
390 This and what follows is from an interview with Tenzin Tsultrim at Triten Norbutsé on 6/5/2009.

391 One of the mandala makers came in during this interview to serve tea. Tenzin Tsultrim called him over and showed him the mistakes. The monk seemed somewhat unfazed, in part because Tenzin Tsultrim was smiling and laughing. When he left, Tenzin Tsultrim said, "Monks don't read the texts. They can't understand."
} 
"pure" text - and it is very common practice now, across rituals, to rely on the images from the book, if available - the fact that the book does not follow the textual instructions exactly, and the further fact that the monks making the mandala did not precisely follow either the Manuscript instructions or the picture book example, means that the process and result of this maṇala making "performance" depart substantially from the textual instructions, which are otherwise highly detailed and specific.

If the monks are able to understand the instructions - as they generally could, with a few exceptions when the text itself was not entirely clear - and if they all looked at the same image in the picture book, how could there be errors? The primary explanation for this is simply that the construction of these highly detailed maṇdalas is a complex and grueling task, and one for which there is little to no oversight. It is hard to convey the aesthetic complexity of a mandalic image in prose - it would be somewhat like trying to instruct someone how to reproduce a famous painting by describing it in words ${ }^{392}$ - and, while the image in the picture book helps with many of the elements, the fact that it does not accord entirely with the text creates confusion about what to keep and discard. Given that Tenzin Tsultrim and the disciplinarian only make brief visits part way through the construction and different monks work on the maṇala each year - a dynamic discussed in more

\footnotetext{
392 After pointing out that the mandala in the book was not the same as the text, I asked Tenzin Tsultrim why they did not just take a picture of the mandala one year, or video, and then use that as the basis for future years, to which he laughed and replied, "Maybe we will use yours!" I pointed out that the mandala in my pictures is going to be wrong, not a good model for future years, and he said, "I know. We don't need pictures. It's fine."
} 
detail below -there is no one to authoritatively correct mistakes at each turn, and anything learned from the process is not passed on year to year.

None of the other textually prescribed implements, aside from the configuration of the dö, have even a fraction of the textual detail of the mandala, taking for granted that monks will know how to make thread crosses and changbu and torma and wood drawings and so on, instead just specifying the names and quantities of the kinds of each to use, and perhaps a color or image instruction here or there. The reason for this comparative lack of detail is simply that these are generic implements that can be used as they are for virtually any ritual that calls for them. There is thus no substantial textual basis, within the context of the Nyelam Dé Zhi collection, to which to compare the live preparations of these implements.

Tenzin Tsultrim pointed out, however, that the thread crosses for the Nyelam Dé Zhi were not well made, and that the deities would not like them, implying that there was a standard of craftsmanship somewhere outside of the Nyelam Dé Zhi collection that these particular thread crosses did not meet, and yet it was not at all clear where this standard comes from or why monks should have any knowledge of it. Tenzin Tsultrim admitted that he did not teach monks how to make thread crosses, and in fact could not say for sure where each of them might have learned how to make them. The monks themselves explained that they learned how to make basic thread crosses as part of the academic curriculum, along with other basic ritual crafts such as torma-making, but also explained that they were not given special instructions for the refinement of those crafts. The basic how-to knowledge was, in all cases, enough. Some monks showed a natural talent for certain crafts, and 
they would be called upon for special, patron-requested rituals. However, the policy for full-scale institutional rituals that are part of the annual calendar is that monks are rotated in and out of craft responsibilities year to year in order for all of them, over the course of their younger monastic careers, to have had experience making them. The emphasis and importance of this work in this context, then, has much less to do with strict adherence to guidelines for craft excellence or ritual efficacy, and everything to do with general monk education.

Predictably, different monks have different experience with or capacities for understanding the preparatory instructions. Only a portion of the monks ${ }^{393}$ actually read the Manuscript or Upper Ritual prior to the start of recitation with an eye to understanding how to proceed with preparations. The mandala-makers all did this, but for the rest of the crafts it was far more common that a handful of monks would read the texts and then pass on instructions to the rest. This approach engenders much greater efficiency, and is necessary for younger monks who are still learning how to read, and by no means defies any kind of instruction from the text that all members of a community performing this ritual must read and understand the text and all its references. However, it also deepens the chasm, for most monks, between the text and its performative realization. A number of monks did not know what certain implements were called, ${ }^{394}$ or what they were for, ${ }^{395}$ having only been told,

\footnotetext{
393 I did not poll all monks to get an exact percentage, but based on limited interviews and casual conversation, it was obvious that less than $30 \%$ read these volumes for specific instruction around preparations.

394 Wood drawings are the main misunderstood implement, with one monk explaining that they are simply images (gzugs brnyan, meaning simply "image" or "picture"), not wood drawings (shing ris, interview with unspecified monk at Triten Norbutsé on 6/4/2009.)

395 Many monks could or would not tell me what threadcrosses, certain special torma, shingri, and so forth were for. Even Tenzin Tsultrim was not sure what a crystal ball on the altar was for. Note that
} 
for example, how to connect this drawing on paper to this stick, and where to put it. As will be discussed below, this dynamic is very much on display for the recitation as well, where monks are told what to read, primarily by the prayer master, and do so without reading or understanding the directions, and often without understanding what they are reading.

Throughout the preparations, but especially for the mandala, there is another important difference between text and performance, one that is on display for many rituals at both Triten Norbutsé and Menri. ${ }^{396}$ In various places, the Manuscript ${ }^{397}$ and the Upper Ritual ${ }^{398}$ instruct that certain recitations are to accompany the construction of implements. Some of these instructions are upheld as instructed, as in the case of recitation of ablutionary and boundary creation, but in other cases, and again especially in the case of the mandala and the dö, the recitation is disconnected from the construction, in explicit defiance of the instructions. The reason for this is clear enough: the modern institutional performance of these rituals is subject to and restricted by the organizational and logistical pressures of modern monastic infrastructure. That is, the recitation is part of the main ritual liturgy, requiring that certain other parts of the ritual be done first. To follow this instruction exactly would mean to assemble all the monks, do all the necessary preliminaries, and so forth, begin construction of the mandala, do the accompanying recitations, and then wait for the mandala to be done - in this case four days - so

this does not necessarily mean that monks were ignorant of meanings and uses. It is likely that some of them were afraid of giving the wrong answer or did not want to engage in conversation about it.

${ }^{396}$ I use the Medicine Consummation (sman sgrub) ritual at Menri as the primary point of comparison because this dynamic was so overtly on display therein, even without studying the ritual texts, though it is also clear that similar dynamics are on display for many rituals.

397 See in particular 19.3-27.4.

398 See in particular 111.4-145.1 
that the dö can be constructed over the course of one day, after which the liturgy could continue. While this would certainly be possible, it would create dissonance and discontinuity, and be a distraction from the many other things going on at the monastery. One would have to convene the assembly to do part one of the liturgy, wait a number of days, and then continue. This contrasts sharply with the efficiency of having all preparations undertaken at roughly the same time - with implements being crafted, monks getting their texts together and tying up other responsibilities, the monastery being cleaned, and so on - and then gathering everyone together to have a focused recitation of the liturgy over a condensed time period.

This separation of preparation and recitation is but one of many strategies the monks employ to reconcile the textual instructions - often written in a very different time period and, in the case of the remedial manuals, a very different context - and the requirements for performance at a modern monastery. Some ingredients can be difficult to find, with similarly colored or textured ingredients readily available and sufficient as substitutes. ${ }^{399}$ With more monks and more space they would expedite preparations. ${ }^{400}$ Some of the rites that the Manuscript prescribes to be done daily, as in the case of the incense offering (bsang mchod), are only done on one of the days because of lack of time.

\footnotetext{
${ }^{399}$ Nyima Özer and a number of monks explained that they buy whatever they can from markets in Kathmandu and Solan, sometimes using spices or synthetic dyes where they would have traditionally, or as textually instructed, have gathered natural, wild plants and minerals. ${ }^{400}$ As described elseweher, Tenzin Tsultrim explained that if they had more monks and space they would not do the Nyelam Dé Zhi. They would do the Sky Expanse, as Menri does.
} 


\section{Divergence During the Main Liturgy and Recitation}

During the main recitational segment of the ritual, there are phenomenological differences between text and performance at a few additional levels: rites done at different times or with different frequency from textual instructions; dimensions of performance that cannot or are not otherwise communicated in the text, such as melody; and idiosyncratic behaviors among performers.

\section{Particular Rites Done Differently from the Text}

The rites that are done differently than prescribed are departures from instructions in the Manuscript, not from the verses or configuration of verses as presented by the rite volumes themselves. There are a number of examples of this, most of which relate to issues of time or resources. For example, the monks only perform the rites from Expansive Space on the first and last day of the performance, despite the zin thu instructing usage of Expansive Space for a variety of preliminary practices, the maṇdala branches (yan lag), vase arrangement, ornamentation, scattering of grain, and so on for the second day of the performance as well. Tenzin Tsultrim explains that the section of Expansive Space that the Manuscript refers to here is mostly just used when empowerment is necessary, which is "usually"401 not the case for the monks at Triten Norbutsé. The monks do the incense offering (bsang mchod) only on

\footnotetext{
401 There were a number of occasions when Tenzin Tsultrim said that they "usually" do not do this or that rite or detail of the performance - this was also the case with the bya bkru bsrung gsum rite, for example (interview at Triten Norbutsé on 5/30/2009) - and when asked about the circumstances that would lead to the decision to do or not do it, he often just replied that it "depends on whether it is needed," but did not elaborate on the further criteria for necessity, even when pushed, instead looking at me as if it should be obvious, which in the case of empowerment, may be the case - it is necessary when there are monks performing the ritual who have not yet received empowerment in Expansive Space tradition, which does not happen with any regularity, and no one was able to offer specific details about when or why this happens.
} 
the last day, instead of every day as the Manuscript instructs, because it is not as important as other rites, which monks want to be sure to complete.

There are other cases where the Manuscript instructions are less specific and thus rites are done according to the accommodations of a particular performance on a particular day, or as much as is necessary to reach a prescribed total number of recitations. For example, monks always do the vase generation (bum skyed) once on the first day as prescribed, but on following days they do it two or three times, as time allows. The same is true of the mantra recitations in the Offering of Magic Sentences ('dzab sgron). ${ }^{402}$

The content of the rites, however, is not altered under any circumstances, aside from instructions in the Manuscript that draw out certain sections of larger rites to be done at different times from other sections of the rites. Otherwise altering or reconfiguring the verses in recitational volumes would be tantamount to sacrilege, and would threaten the integrity of the ritual as a whole - one of a handful of aspects of the ritual performance that do conform to the stereotypical strictures around absolute fidelity. But these strictures have less to do with concern about ritual integrity as they do with reverence for canonical texts in the community, an attitude that far outweighs the sanctity of performance, especially when that performance has been prescribed in a purely instructional text written by "just a lama." Indeed, accidentally dog-earing a canonical text, as would happen on occasion - though great lengths were taken to carefully wrap and organize texts to prevent this from happening - seemed to cause far greater stress than producing an

402 This volume is also called the snying po sngags kyi yig chung. 
incorrect maṇdala or poorly constructed thread crosses, or falling asleep during recitation.

\section{Performative Dimensions that cannot be Textualized}

There are a variety of dimensions to a performance that cannot be or are not instructed in the texts. The Manuscript and other rites can command musical instrumentation, for example, but they cannot or do not explain how to play them, how long to play them, how to coordinate between them, and so on. The various melodies of recitation required for different kinds of rites, for different kinds of deities, and so forth are another good example. At one level of melodic orientation is that between private recitation and group recitation at large-scale rituals (those where all or most of the monks are required to attend), which necessarily requires different volumes and tones. While no one could give a name to the former, which itself can be different in speed and intonation based on whether a monk is actually "praying" - as with aspiration prayers (smon lam) - or engaged in a more "secular" activity like memorizing texts, the large-scale ritual category was known generally as "great ritual language" (chog chen skad). ${ }^{403}$ Within the latter distinction, however, is a series of smaller distinctions based on 1) type of deity - tutelary deities like the four Ones Gone to Bliss and Takla Mebar (stag la me 'bar) and Purba have a particular melody, for example, 2) type of rite - ablution has a particular melody, as does rites for "opening the door," as does the Nyelam Dé Zhi's Beckoning of Fortune, which is especially unique among rite melodies, to match its unique onomatopoeic language, 3) activities within rites, such as visualization, which has a slower rhythm

403 Interview with Tenzin Tsultrim at Triten Norbutsé on 6/6/2009. 
to assist in the complexity of the process, and a different handwriting to style to make it obvious when the switch should occur, and 4) the verse or prose orientation of the text, with most recitations being in rhythmic verse, requiring the various chant melodies described above, as opposed to narrative prose and other speakable text, evidenced in the texts both by the lack of syllabic fidelity and the different handwriting style. Each of these melodies is in turn constructed from differing combinations of bodily chant strategies, including the deep and powerful kungdar chant produced from the engagement of the stomach and diaphragm, lighter and softer nandar chanting produced by pushing air through the nose, the percussive chaké (lcags skad) sound made by engaging the tongue and the roof of the mouth to create a sound like striking metal, bumbur chanting to create a crescendo effect, and shungdar to create a swelling effect, with tones and volume rising and falling. 404

In most of these cases, and certainly in the case of the examples of music and recitation melodies, the reason for lack of specification in the texts relates on the one hand to the difficulty of discursively describing non-discursive phenomena, and on the other hand to the standardized expectations of monastic skills and knowledge. In the same way that Expansive Space and The Completely Pure provide genericized rites and verses to be reconfigured and deployed as necessary for different rituals, monks learn melodies and instrumentation to be used across rituals with very little intrinsic variation, even if the timing and addressees of each

\footnotetext{
404 Note that most of this information comes from Geshé Q (interview with Geshé Q at Menri monastery on 2/13/2009), who declined to provide full spellings of the names of these chants, though they were casually corroborated, and still not spelled, by Tenzin Yangtön (interview with Tenzin Yangtön on Menri monastery on 5/10/2009). I have yet to locate an authoritative source, including proper spellings, but surely one exists. It is also important to note that the vast majority of monks asked could not explain why there are different melodies, with some saying there was no reason - they were just different. It is clearly an issue that most of them take for granted.
} 
change from context to context. This ensures both that rituals can be easily innovated around new concerns, beings, and so on, and that monks will already be trained in many of the necessary skills to perform any given ritual.

\section{Idiosyncratic Divergences}

Most of the idiosyncratic divergences from the text relate to simply not doing the recitations or accompanying subrites. In the case of the former, there were many monks, especially the younger ones towards the back of the temple, or in the periphery, that fell in and out of recitation because they would occasionally sleep, talk or joke with friends, or otherwise stare out the window or look around. Even with a few breaks built into the proceedings, and the occasional pause afforded by musical interludes, it requires tremendous concentration and energy to keep up with the chant master hour after hour, day after day, especially if you are among the group of monks that cannot understand much of the verses. Nevertheless, the geshés and more advanced monks towards the front of the room can almost never be seen breaking from their recitation.

In the case of not doing subrites, most rites that require concrete, observable, externalized activity - offering and dispersal of tormas, "golden beverage," and so on - are always done. Those that are not always done are those that require understanding of the text in the moment, like visualization, or a greater knowledge of when certain kinds of subrites should be deployed, gleaned from having done many rituals many times, such as mudras. Confirmation of visualization is a matter of self-reporting and thus not reliable, but it is obvious that a number of monks do not do it, whether because they are not reading along with the texts at the time they 
instruct visualizations or because they admit not to doing it. Tenzin Tsultrim and other older monks acknowledge that not all monks do them, and that this is no problem. It is primarily for older or more advanced monks. ${ }^{405}$ The same is true of mudras. When asked about whether the ritual would not be more effective if performers were not more consistent or committed to the various tasks commanded by the texts, the attitude was that it is always better if everyone is doing them, but not especially problematic if they are not.

Other idiosyncratic divergences from the text include some monks leaving during recitation or not attending certain segments and the disciplinarian giving a lecture during one of the breaks about proper care of texts. 406 The evidence suggests that there were other substantial, unspoken differences taking place, in the form of minds wandering or not following instructions, but these all would require selfreporting, and given the more overt departures in this spirit, in the form of sleeping and joking, and so on, and the obvious embarrassment that monks felt around such behaviors, I did not pursue such lines of enquiry.

In some of the above cases, the Manuscript endorses the departure from the primary texts, using or doing whatever works best for the community, and this is indeed one of the Manuscript's primary purposes. Not only does it facilitate the performance of the ritual by listing alternatives or making certain segments optional, but, the Manuscript also explicitly justifies differences between text and performance, not only in the specific dimensions that it addresses, but thematically

\footnotetext{
405 Interview with Tenzin Tsultrim at Triten Norbutsé on 5/25/2010.

406 Tenzin Tsultrim saw my footage of this and simply said, "He does not need to do that" (Interview with Tenzin Tsultrim at Triten Norbutsé on 6/6/2009.
} 
for any aspect of the ritual that is impossible or defeatingly onerous for a particular performative community. As volume one of the ritual collection and thus a canonical text of the Nyelam Dé Zhi, it may be a bit lower in stature than the others that were purportedly revealed by Khyunggötsel in the Tibetan Renaissance period but is at least equal, and perhaps even greater, in stature as the others in terms of practical institutional value. As monk interviews - especially with Tenzin Tsultrim - revealed, any perceived dissonance between text and performance is relegated to trivia - "We don't do that part because we don't have enough monks (or enough time),"407 or "You only do that part if there's sickness in the village."408

All of this begs the question - what is different now, in this context, compared to the context, assumptions, and so on of the text's authorship? Were these rituals written for larger communities of performers with more time and resources? Were they written more in the abstract, without a clear sense of ritual actors and communities? Are there performance dynamics at play in modern, primarily academic-oriented institutions in exile with limited laity that set them apart from the preponderance of other institutions in different time periods that would otherwise engage the performance of the Nyelam Dé Zhi?

Aside from the Manuscript author, who is quite clearly writing primarily for a larger monastic audience, it is difficult to know the volume authors' intentions and sensibilities. Knowing full well that performance, in almost all cases, brings different challenges to and resultant divergences from that prescribed by a textual manual, it is nevertheless clear that text and performance, in the context of the Nyelam Dé Zhi

\footnotetext{
407 Interview with Tenzin Tsultrim at Triten Norbutsé on 2/27/2009.

408 Interviews with Tenzin Tsultrim at Triten Norbutsé on 5/28/2009, 5/29/2009, and 5/30/2009.
} 
volumes, were at one time married more closely than they are now, at least in the ways described above. Certain volumes were independent, performed in isolation or with accompanying rites and texts that are outside the purview of the Nyelam Dé Zhi. Making those volumes fit into a larger scale institutional ritual in exile necessarily yields differences in text and performance.

The bum volumes, for example, have been harvested for offerings, narratives, and so forth, and then combined into the Upper Ritual, minimizing complex relays between texts during the liturgy, reducing redundancy, and creating a more coherent liturgical narrative out of many different segments of different texts that otherwise have no awareness of each other. To ensure fidelity to the original bum texts, however, a collection of monks sit in the periphery of the assembly hall, reading and silently reciting them in their minds. In one sense, this group is satisfying an implicit mandate that the recitational sections of texts be followed exactly during performance - read word for word - but from the perspective of the principle liturgy the texts have been deconstructed and reconstituted to form a quite different ritual. This is not uncommon among ritual compositions - drawing from different sources to construct a liturgy that cohesively addresses the different subjects therein - but in this case this practice is not just for the sake of liturgical enrichment, but also for performance facilitation.

\section{Signification Divergences}

At the deeper level of signification, monks imputed a great diversity of purposes and meanings to the Nyelam Dé Zhi and its various components, only some of which 
matched anything articulated in the texts themselves. The most common

explanations for the performance of the Nyelam Dé Zhi at Triten Norbutsé included:

1. Because Yongdzin Rinpoché says we have to do it.

2. To make it rain.

3. To cure or prevent disease.

4. To send troublemaking beings away.

5. To ensure fortune and prosperity for benefactors, laypeople, and Tibetans everywhere, but especially in Tibet.

6. To apologize for any wrongdoings throughout the past year and promise to be respectful for the coming year, maintaining harmony in the community, both local and global.

7. Because it is tradition to do it every year, and people will be upset if we do not do it.

It is important to note that these are not all exclusive of each other. Generally as one moves down the list, there is a greater likelihood that all the previous explanations are assumed, but that, to the interviewee, there is also a "truer" reason at the root of the decision to perform this ritual. This list also loosely parallels the age and maturity of monks, who start out without any clear sense of why they are participating other than it being a requirement imposed from above, begin to understand or believe the simplest explanations, and gradually mature into more expansive, more sophisticated perspectives. It is an important point, however, that this is a loose generalization - a number of geshés, for example, gave the rainmaking explanation.

Explanations 2-4 reflect common understandings of lu and other worldly deities, as described in an earlier chapter. A number of the volumes do clearly reference these issues - addressing lu directly to ask for rain for agriculture, to ask them not to bring disease, and so on - but virtually any Tibetan asked about the purpose of a ritual addressing the lu would very likely give these answers without 
knowing anything specific about the ritual. It is thus difficult to assess but otherwise clear that some of these answers came from readings and comprehensions of the ritual texts, while some came from common understandings of what lu rituals entail.

Even so, there are clear departures from the texts in terms of who these deities are and what they are responsible for. Much of this has already been discussed in Chapter Two, and some of this simply relates to issues of being unable to comprehend texts, but it is worth reiterating here that the preponderance of monks do not have a clear sense of nyen and tö deities in particular, and only partial understandings of lu and sadak, such that the third answer about benefitting patrons matches essentially all textual descriptions, and the second answer is generally coherent with the texts that describe all of these deities as having possible roles in causing illness, but the first answer is not relevant to any of the deities but the lu. The machinations of the other deities, and the technologies for addressing them, are not well understood by most of the performers, including some of the most elite among them.

When one grafts the list of Nyelam Dé Zhi volumes organized by genre (Appendix 2) onto the list of volumes used in the performance at Triten Norbutsé (Appendix 3), it becomes clear that the vast majority of practical/magical volumes, especially the ones dealing with illness, are not used. Given also that the third explanation regarding the cure and prevention of disease was given mostly by those who had not or could not read the texts - again, especially the volumes on curing various illnesses, which are among the most challenging in the collection - it 
becomes obvious that the institutional performance of the ritual is not oriented at all towards curing, though it does involve some prevention.

For these and other reasons, the sixth explanation - apologizing for wrongdoings and promising to do better next year - has emerged as a common explanation, and the one that has become the "official" purpose of the ritual, as stated on the annual calendar of activities at Triten Norbutsé. There is substantial support for this perspective within the texts, but only in a piecemeal sense, extracting motivations from individual volumes or verses, not in the sense of a coherent articulation of the purpose of performing the overall ritual. In other words, there are clear rites and volumes abundantly associated with confession (both in the Upper Ritual and in the volume dedicated to confession called the Small Note of Confession (bshags pa'i yig chung), and many volumes throughout the collection that include confessional subrites (sdig pa bshags pa, as in the various Treatment volumes) or at least a verse or two about confession, as well as numerous dedications of activities for or towards the benefit of all beings. As with lu, however, the inspiration for this understanding of the ritual comes at least as much from understandings of dö rituals generally, or teachings about the point of the ritual from the more elite in the community, as it does from evaluations of the texts or textual themes themselves.

The last explanation - people will be upset if the ritual is not done as per usual - came only from older geshés and Tenzin Tsultrim. At this level it is essentially inappropriate to compare texts with performance because the reason given have less to do with the goal of the ritual than with the reason to undertake 
the performance of this ritual in this community. It is included here, nevertheless, because it is an important counterpoint to the notion that the reason a ritual is being performed at any given time relates necessarily to the stated goal of the ritual, whether expressed explicitly in the texts or surmised from hints therein. As the conclusion of this chapter and the entirety of the next will show, the community's relationship to the stated goals and beneficiaries of the Nyelam Dé Zhi is anything but obvious, and in fact the most poignant compulsions to institute and maintain the performance of this ritual are markedly divergent from anything to be found in the texts.

What is not represented in these explanations are the more private sentiments regarding the purpose of performing the Nyelam Dé Zhi and other rituals. Most monks have a sense of what an answer should be, especially when the question is asked by someone outside the community whom they think is just trying to make sense of their actions. Pressing them to go deeper, however, often resulted in something resembling the first explanation, that they simply go where and do what they are told. Some would tentatively suggest that doing these performances generated good merit or good karma, or that not doing them would bring bad karma upon the individuals who did it or the whole community. Again, a great many, after being pushed, admitted that they had no idea why they were doing it, or said they were not sure, suggesting that Tenzin Tsultrim and Tenzin Namdak could give better answers.

While these issues would be of general interest and concern to anyone, monks and laypeople alike - at least in the case of being free from disease - the 
monks acknowledge that none of this really applies to them. They do not farm and are not interested in "fortune," though they do have financial needs and "misfortune" can be interpreted in many ways, but more importantly their day-today activities do not bring them in contact with lu and their kind. They rarely build something on new ground, rarely interface with water bodies in the extended area, rarely burn anything that these deities would find offensive, and so on. Thus, while these commonly articulated motivations for the ritual, expressed most often by monks of average learning and age, were in line with explanations given by certain Nyelam Dé Zhi volumes, they were clearly lay-oriented motivations, and yet Triten Norbutsé has an almost non-existent lay population, and the performance of the Nyelam Dé Zhi has on average the same or fewer lay benefactors than rituals that are less lay-oriented.

While it is not at all uncommon for monks and for ritual actors of many traditions to give different answers for the meaning of particular rituals or ritual components, no other event in the Triten Norbutsé calendar commands such a diversity of answers to the fundamental question: "What is the main purpose of doing this ritual?" There are 100,000 offerings ('bum tshogs) rituals to the protectress Sipé Gyelmo and to Drenpa Namkha, both of which are explained comfortably as offerings to important deities and figures for the purposes of protection, merit, and so on. Then there are the memorialization celebrations of Tönpa Shenrap - the founder of Bön - and Nyamé Sherap Gyeltsen, the father of modern Bönpo monasticism. Members of the academic perform rituals to cultivate 
wisdom and knowledge. ${ }^{409}$ There is certainly variation in explanations for these rituals, but interviews with these same monks who were performing the Nyelam Dé Zhi revealed an almost startling consistency by comparison. The persistent relevance to the community and its other activities and overarching ideologies clearly leaves less room for interpretation and reflection than the Nyelam Dé Zhi, which addresses concerns not relevant to these monks' lives, for the benefit of a laity that is not present.

\section{Sources for the Absence of Hegemonic Meaning}

Beyond this severed connection between performers and addressees and beneficiaries, opportunities for divergence from textual explications and implications of the ritual's purpose or goals arise from the ambiguity and sheer quantity of symbols and artifacts used in the construction of the dö and throughout the ritual performance, from the vacuum of meaning created by the lack of comprehension described at the beginning of this chapter, and from the most elite members of the community being conspicuous in their absence from the performance.

Beyond the immediacy of the physical impression that it makes, the dense layering of symbolism, and the obvious interplay of different cultural strands,

\footnotetext{
409 There is also the issue of "celebrations," as when the whole extended community gets involved in the new year celebrations at the time of the Tibetan new year. To an extent, celebrations like this invite a comparable diversity of explanations, but that is primarily because such celebrations are explicitly occasional, not instrumental. In this way, celebrations perhaps even belong in a different heuristic category than rituals like the Nyelam Dé Zhi, at least when trying to understand emic motivations, as memorialization unambiguously follows events, real or metaphorical. Rituals like the Nyelam Dé Zhi, while incorporating narratives of important events that may well have contributed to the establishment of the ritual, are understood to aim towards a particular future outcome, diverse though the understanding of that desired outcome may be.
} 
traditions, and sensibilities in the completed dö - with a great diversity of tormas atop a mandala that is itself a complex map of meaning, atop a mound with its own enormous cosmic significance, surrounded by drawings of wealth and greenery and flora from the monastery environment, everything studded with thread crosses and changbu - is unlike that of any other craft product or ritual implement or monastery feature at Triten Norbutsé and its ritual calendar. It is obvious that different members of the community perceive and receive different degrees of meaning in and from the dö and the attendant components of the Nyelam Dé Zhi, and while there are many rituals of different scale that make use of maṇalas, tormas, thread crosses, and so forth, there is no denying the singularity of this dö among monks' other concerns and activities throughout the year. There is abundant lack of clarity around questions like why mud and greenery are brought into the temple - are they decorations, offerings, ways to make the dö more hospitable to deities of the landscape, representative of the world in the larger structure of the cosmos? How do wood drawings of symbols like men and women, arrows, spindles, yak and other animals work as part of the ritual? Do the thread crosses function as offerings or supports of deities or both or neither? What role do the garudas play, an especially intriguing question for some monks given that there is a large wood drawing of a garuda above and behind the mandala? And so on.

As for lack of comprehension, ritual theorists often point not only to the irrelevance of incomprehension in ritual performance, but to the importance of it. ${ }^{410}$ Discursive narrative or coherent comprehensible verse provokes in the actors and

410 I am referring mostly to Staal (1996) and Humphrey and Laidlaw (1994) here, but there are many others. 
audience a compulsion to take narrative meaning literally, or to impute meaning to the narrative based on interpretation of its metaphors, plot, and so on in the context of either their own lives or the overall performance. Mantras and recitation that are otherwise inscrutable in terms of narrative meaning, whether by their very nature, deliberately obfuscated by the author, written in a different language, or gradually obfuscated over time via transcription problems, confusion, misrepresentations, and the like, all allow for a kind of cognitive disengagement with specific meaningcreation and also, in theory, afford greater emphasis on and attention to the precision of the performance, uncomplicated by any perceived dissonance between recitation subject matter on the one hand and externalized actions on the other.

Caroline Humphrey and James Laidlaw, for example, have put forth a compelling theory that the very designation of "ritual" reveals itself as the most appropriate choice only when actors disagree about the meaning, point, and so forth of what could otherwise be called a practice. ${ }^{411}$ In the case of rituals like the Nyelam Dé Zhi, then, the inscrutability of the texts - even to many geshés, who had to study the texts closely with me to try to understand them, often had to make uncertain but educated guesses about various phrases or words, or simply said they did not know how to understand the text as it was written and recited - is what engenders, or helps to engender, the wide disagreement or multifarious interpretation of the ritual goals and purposes on display among the monk population of Triten Norbutsé.

Does this mean that inscrutability was the agent that transformed a prior practice into the modern ritual that is the Nyelam Dé Zhi? Hardly. Different volumes

${ }^{411}$ Humphrey and Laidlaw, 1994, pp. 12, 151-155. This will be revisited in more detail later. 
exist in the collection at different levels of scrutability and surely have moved closer or further from scrutability over the years, especially during transcription when errors are made or, much more rarely, when something incoherent is noticed and made coherent, whether or not its newfound coherence matches the original coherence. And disagreement over meaning and purpose has a much broader and more complex provenance than difficulty understanding the recitation. Few of the texts give a clear "meaning" for the ritual, and none lay claim to exclusive purposes and goals for the collected ritual as a whole, even if individual volumes may be clear enough in their own purpose. A community performs a ritual for its own reasons. Different explanations and meanings develop among different segments of the community and within an individual's own sensibilities. In this sense, the incomprehensibility of the texts merely results in more expansive opportunities for divergent interpretations.

The absence of the most elite members of the community from the ritual performance can be understood in a variety of ways, but more than anything it devalues the ostensible goals of the ritual, thereby helping to create the vacuum that the rest of the community fills with their own individual or collective intentions. Given that the sixth explanation of the ritual, the opportunity to confess misdeeds and create harmony, is the one propounded by the leaders of the community, their absence also situates and communicates that the most accomplished community members, the leaders and teachers, may be beyond the need for general confession, thereby reinforcing the devotionalist dispositions that are common and necessary in monastic and tantric teacher-disciple relationships, and opening up avenues of 
interpretation for younger monks to consider their own opportunities for confession.

\section{Conclusion}

While every performance necessarily diverges from its textual bases in the process of adding a lived third dimension to its authored two-dimensional instructions, the Nyelam Dé Zhi does so in ways that are both similar to and different from other rituals of the calendar. As with other rituals, the texts themselves can be difficult to comprehend, and thus instruction can come from elsewhere, whether published books depicting mandalas or from other monks who may or may not have read and understood the texts. In either case, a mistake in one place will be propagated throughout the rank and file, limiting its chances of being corrected and augmenting its chances of being further replicated in future years. The small quantity of monks and lack of resources at Triten Norbutsé, especially as compared to a larger monastery like Menri, means that certain rites cannot be done, or cannot be done in the order specified by the texts. Every ritual also has non-discursive elements that are impossible to communicate fully in the text, like music instrumentation and chant melodies, and in any event it is taken for granted that monks will know how to do these things. It is also not uncommon for monks to be sleeping or talking or joking during protracted recitations, and not uncommon for rituals to have a variety of interpretations and explanations regarding their motivations and goals, based on the maturity and accomplishments of the monks and community members who articulate them, and based on the inscrutability of many of the texts. 
The Nyelam Dé Zhi is unique, however, both in its incorporation of dynamics not seen elsewhere and in the heightened degree to which it exhibits some of those that are. Unlike many of the other rituals, there is very little oversight of either the preparations or the recitation. ${ }^{412}$ The disciplinarian does a very cursory check-in during the preparations and is present during the recitation, but his disciplinary style does not address conspicuous idiosyncratic departures from prescribed performances, and none of the other higher status members of the community attend at any time. One of the possible reasons for this, and for disengagement across the board, is that the ritual itself lacks the immediacy of the vast majority of others. It does not fit with typical monastic sensibilities, addressing abundantly lay concerns, in a community where the laity are almost entirely absent, and in any event the texts and the ritual are outer tantra, seen uniformly as less important than inner and secret tantric rituals. While a lack of resources may affect many rituals, it may or may not be the case that they have texts that are as permissive as the Manuscript, which not only makes affordances for specific kinds of flexibility, certain rites that can be dropped or done less often, but which also sets a tone of lax customizability that contributes to an overall attitude of nonchalance regarding proper or improper ways of doing things, and the likelihood or importance of successful outcomes. Lack of concern about outcomes is further communicated and bolstered by the absence of elite community members whose presence would help

412 While there are certainly rituals that are not attended by elite community members, other rituals of this scale were almost always attended at least briefly by such members if they were nearby and healthy, and the same is clearly true of comparable rituals in the literature. See for example Beyer, 1978, p. 75, and Bentor, 1996, p. 213. 
ensure or promote confidence in success, and by the absence of a laity who would experience and evaluate the benefits, or lack thereof, of the performance, or who would at least confer immediacy on its occasion. These conspicuous absences, combined with the absence of comprehension of texts and the absence of concern for this outer tantric, worldly technology that is not especially germane to the dominant monastic ideologies of scholarship and transcendence, creates a vacuum of meaning that opens the door wide for the reappropriation of this performance to other ends. 


\section{Chapter Six: Interpretation}

The landscapes of group identity... around the world are no longer familiar

anthropological objects, insofar as groups are no longer tightly

territorialized, spatially bounded, historically unselfconscious, or culturally

homogeneous. 413

At the end of Chapter Two, I asked the question of why monks continued to engage in a ritual that no one seemed to care about. Beyond describing the elements and experience of the Nyelam Dé Zhi as performed at Triten Norbutsé, the intervening chapters have endeavored to identify the negative space, the ambiguities and ambivalences, that beckon actors, observers, and interpreters, and communities of the same, to bring forth their own meanings and colonize their worlds with them. This final chapter is about the products of that process, which together provide a series of compelling, if incomplete, answers to the question above.

A key factor in the production of these assessments that cannot be ignored are the issues of exile and globalization. Manuel Vazquez, in his insightful analysis of the effects and dynamics of globalization on religious traditions and practice, makes a clarion call for ethnographers to avoid the pitfall of imagining that the "internal dynamics" or the surrounding "religious ecology" of a community that is not utterly isolated are sufficient scopes for understanding it. In this age of heightened globalization, one must assess also the ways in which a given community "emplaces" broader trends in the region and world, while simultaneously contributing to or

413 Appadurai, 1996, p. 48. 
influencing these broader trends. ${ }^{414}$ While it is not appropriate here to assess global trends at the largest scale to see how they may pertain to the community at Triten Norbutsé, it is appropriate, and illuminating, to consider how the performance and community engagement with rituals like the Nyelam Dé Zhi relate to the processes of a culture and community being dislocated and relocated, and to the pressures of an expanded world stage.

This dimension is of paramount importance, given that the community members and tradition have moved and become established in Kathmandu relatively recently, and yet it is a considerable challenge to compare the current environment, traditions, and so forth at Triten Norbutsé to pre-exile environments, for a few reasons. First, the original Triten Norbutsé monastery in Tibet was not a direct precursor to the modern Triten Norbutsé monastery in Kathmandu. Second, even if the exile monastery was a direct reincarnation of the original monastery, the population is necessarily different in exile, with monks coming from all across the Tibetan cultural region and beyond. ${ }^{415}$ Thus, there is no one-to-one import of individuals and traditions that could provide a basis for evaluating dynamics preand post-exile. Nor does any Bönpo or other Tibetan literature - at least, none of the literature yet translated or otherwise available or consulted - describe a performance of the Nyelam Dé Zhi in a comparable institutional context anywhere at anytime in pre-exile Tibet. The only sources available for such an analysis are the

\footnotetext{
${ }^{414}$ The idea of emplacement that Vasquez is referencing here (2003, p. 224) comes from Thomas Gieryn (2000).

415 It must be acknowledged that it was not at all uncommon in Tibet for monks at a given monastery to have come from far and wide, but in exile the boundaries of far and wide have been pushed significantly further, to include essentially the whole world.
} 
ritual texts themselves - the Manuscript, for example, was written in the 19th century, giving a picture, however limited, of how the Nyelam Dé Zhi might have been performed in pre-exile Tibet - and the memories of older monks who observed or participated in Nyelam Dé Zhi rituals prior to fleeing Tibet.

These sources are problematic for reasons that are obvious but worth making explicit nevertheless. In the case of the Manuscript, it is possible to draw conclusions about how the Nyelam Dé Zhi was performed at the time it was written, what the pressures were that compelled a clarification or modification of the original texts, but it is still primarily an instruction manual, a textualized prescription for a performance rather than a documentation of performance itself, which would still be problematic. There is no way of knowing how much pre-exile performances of the Nyelam Dé Zhi that made use of the Manuscript did so with fidelity to its prescriptions. In the case of older monks, their perspective is invaluable, but there are the same reliability problems as any first-hand account, deepened by the great many years that have passed since the time in question. Add to this the infrequency with which these elder monks encountered, much less participated in, performances of the Nyelam Dé Zhi, and the pre-exile traditions prove to be very difficult to capture indeed.

Menri, the other principle Bönpo monastery in exile, does help to provide perspective and data related to exile, however. This was discussed in greater detail in Chapter One, but for now it is sufficient just to reiterate that Menri and Triten Norbutsé, in addition to emphasizing the preservation of traditions that feel more fragile in exile, both have issues of lay (or any) support, both house monks from all 
over the Tibetan cultural region and beyond, both are academic-centric, and both receive a nearly constant stream of international visitors. Menri has a larger built-in Bönpo community in the settlement, is much larger overall - in terms of both structural size and monastic population - and houses the highest ranking lama of the Bön tradition. Triten Norbutsé is less directly connected to the Tibetan government-in-exile and is generally under much less political pressure than Menri. Thus, examining dynamics between and across Menri and Triten Norbutsé will help to illuminate issues that may be the result of exile generally, idiosyncratic to a particular monastery or place or personality, or persistent across space and time.

\section{Conditions for the Inconsequence of Ritual Infidelity}

The nature of the two observed performances of the Nyelam Dé Zhi suggested strongly that fidelity to text or other instructions for, or strictures of, performance was not necessary for success as the community implicitly defined it. Except as an afterthought, ${ }^{416}$ there was often a lack of concern for excellence in preparations and recitations, and an indifference about the likelihood of expected outcomes. Even the very articulation of expected outcomes or value statements regarding the ritual were inconsistent or absent. Tenzin Tsultrim explained that as long as monks have taken refuge and generated the mind set on enlightenment, none of it matters; everyone trusts that the monks have done these two things, nobody questions it,

\footnotetext{
416 I have mentioned and will mention again below some occasions where Tenzin Tsultrim and other monks have expressed some form of regret or displeasure over certain dimensions of the preparations or recitations. While this does communicate concern about certain kinds of fidelity, it was not enough to change behavior from year to year, and I have to consider the possibility that these expressions of concern were more for my benefit than anything else.
} 
and thus whatever they do or do not do in the course of the ritual, whatever they are thinking or not thinking, is all in the service of the greater good, and ultimately does not have a significant effect on the ritual outcome or on individual destinies. ${ }^{417}$ Geshé Q made a similar remark when asked about how one could tell whether a ritual had "worked" or not, whether performers had achieved the ritual's stated goals: "I don't know if it works or not. I just know that, working or not working, it is a good thing to have so many monks together with good intentions."418

These kinds of apologetics help to explain lack of enforcement, and perhaps that lack of enforcement, when combined with the absence of any other kind of repercussions, is a force for the persistent reproduction of lackluster ritual attitudes and performances, but it is not the whole story. The absence of concern for fidelity in the training for or initial execution of preparations and performance, such that the apologetics above would not be necessary, stems from a variety of pressures, foremost among which are those related, in one way or another, to the community's exile situation.

While Jonathan Z. Smith's assessment of the importance of fidelity in performance - "getting it right" - in "The Bare Facts of Ritual" (1980) has proven to be not especially relevant to the performance of the Nyelam Dé Zhi as observed at Triten Norbutsé, his earlier articulation of the connection between accuracy and proximity to the "center" is much more resonant. In Map is not Territory (1978), Smith explains that "getting it right" is most crucial when there is a close correspondence between place and cosmos - when you are at or near the center,

417 This and what follows is from interview with Tenzin Tsultrim at Triten Norbutsé on 2/27/2009. 418 Interview with Geshé $\mathrm{Q}$ at Menri monastery at 6/18/2009. 
where all behavior needs to replicate an ideal model. ${ }^{419} \mathrm{He}$ was referring to mythical archetypes, but as with many ritual theories, the vertical and horizontal dimensions mimic each other, or at least can be found often to parallel each other. The exiled Triten Norbutsé community, especially as it gathers around and conceptualizes the Nyelam Dé Zhi ritual performance, is far from its center. This is true both geographically, in the sense of being disconnected from the homeland and the locus of the Nyelam Dé Zhi's mytho-historic landscapes, formulation, and traditional performances, and ideologically, in the sense that the Nyelam Dé Zhi ritual addresses lay concerns that are barely the purview of this scholastically oriented community.

Indeed, the monks at Triten Norbutsé have too paltry a relationship with the worldly deities to be enthusiastic about a ritual in their honor, or for their negotiation, even if the ethic of the ritual performance is broadened to "harmonize and purify all the spirits of the universe." They are rarely engaged with activities that would interface with them, the best known of the deities - the lu - are known to be more affiliated with, and more of a concern of, the feminine, and their avowed mission as a community is to abandon the worldly.

Related to this is the absence of a laity that would provide occasion and income for ritual performances, as well as greater pressure for positive outcomes, which would in turn put pressure on the quality of the preparations and performance. A very small persistent laity does exist at the perimeter of Triten Norbutsé and scattered throughout the city of Kathmandu, and certain occasions

${ }^{419}$ Smith, 1993, pp. 116-117. 
such as new year celebrations enjoy visits from Bönpos far and wide, but the income from this laity, at least for the occasion of the Nyelam Dé Zhi, is never or rarely enough to cover the costs of the ritual performance itself, much less provide a compelling economic justification for the ritual's persistence year after year. ${ }^{420}$

At the same time, the small-scale laity that does persist in these exile communities, lacking many of their own resources, rely more heavily than ever on the monasteries for their ritual needs. This is especially true at Menri, where, Cech writes, residents who used to do ransom (glud) rituals in the household now just attend ritual exorcisms at Menri. ${ }^{421}$ The picture that emerges is one where the laity look to these monasteries to fulfill their ritual needs and connect to their tradition, offloading the maintenance of some of their own legacy knowledge to a community that prioritizes other pursuits, if only (and it is not only) because the lay support and demand are not substantial enough to justify their doing otherwise. Ritual quality - at least of certain rituals not highly attended or marking major celebrations or related to the dialectics program - can only decline in such an environment, thereby threading communities with the tension between needing to preserve traditions accurately and being able to afford to do so.

There is also a common monastic sentiment, reverberating back and forth between Menri monastery in India and Triten Norbutsé in Nepal, that Menri is the

\footnotetext{
420 On the other hand, this may always have been the case for Menri and some other Bönpo monasteries, even before exile. Cech (1987, pp. 62-63, 138) writes about how many of these monasteries in central Tibet did not have large lay communities to support them, and thus they had to travel far and wide to garner support from other Bönpos. Perhaps many of their rituals therefore have a certain built-in invulnerability to a small laity, and the current situation merely represents an ongoing tradition of not worrying about "getting it exactly right" because they have always worked with less resources for a more limited audience.

${ }^{421}$ Cech, 1987, p. 228.
} 
primary steward of Bönpo traditionalism. It has more monks (including Sangyé Tenzin, the highest ranking Bönpo world-wide), more resources (including a regular funding package from the central Tibetan government-in-exile in Dharamsala that varies in value), ${ }^{422}$ more space, and a bigger immediate laity in the form a Bönpo settlement situated just below the monastery. Monks frequently asked why anyone would study the Nyelam Dé Zhi when they could study the Sky Expanse ritual at Menri, and Tenzin Tsultrim himself admitted that they would do the Sky Expanse at Triten Norbutsé if they had enough monks and space and could otherwise afford it. Rituals at Menri are accordingly larger-scale, more meticulously crafted, and better funded. Sangyé Tenzin is a more mobile and more severe disciplinarian than Tenzin Namdak or the much younger, often traveling abbot of Triten Norbutsé, Tenpa Yungdrung Rinpoché, which also translates to stricter disciplinarian personalities at Menri.

At a more logistical level, it is hard to cultivate excellence in crafts and performance at Triten Norbutsé because each monk's engagement with them is temporary. Aside from the most prestigious figures in ritual performances, such as the chant master and disciplinarian, monks rotate in and out of roles from year to year, and sometimes performance to performance. Monks making the manḍala one year do not make the mandala the following year. There may be some overlap or redundancy between groups of monks responsible for a given responsibility, but the agenda, established originally by Sangyé Tenzin and Tenzin Namdak, is explicitly designed to expose all monks to all duties at some point in their careers, so that they

422 Sangyé Tenzin told in an interview at Menri monastery on 4/16/2009 that the most recent funding totaled 700,000 rupees. 
have at least basic knowledge of and facility with all aspects of ritual logistics. That this agenda trumps one that would match tasks with the monks most skilled at those tasks further reinforces the insignificance of ritual success or outcomes, at least in the traditional sense of trying to accomplish what the ritual is ostensibly undertaken to achieve, and the utility of this and other such rituals for a broader education in Bönpo traditions and traditionalism.

This broader education has as its goal the encoding of Bönpo traditions in monk bodies and non-intellectual actions, thereby ensuring their ongoing maintenance and portability, and also increasing the odds that any given monk will eventually be able to provide the minimum skills necessary for most patronized rituals outside of Triten Norbutsé, which has traditionally been critical to the larger spiritual economy, and had the potential to ensure a monk's ongoing livelihood.

The current absence of excellence in crafts points, however, to a burgeoning dynamic among these scholastic monks wherein the benefits of ritual expertise are outweighed by those of scholastic expertise. It is extraordinary competency in debate and other more typical academic pursuits, and not extraordinary competency in ritual crafts, that will dispose a monk to greater prestige, opportunity, and, eventually, income. ${ }^{423}$ As the academic program increases in sophistication and esteem, especially in an environment with a small, almost absent, lay community, the ritual technologies that may have traditionally been the primary responsibility and income-generator for Bönpo monks are no longer emphasized,

\footnotetext{
${ }^{423}$ One monk who said it would be a "dream" to be a geshé explained that he hoped and expected that it would lead to greater financial stability. Perhaps unsurprisingly, this monk has asked not to be named (Interview with unknown monk at Menri monastery on 2/10/2009).
} 
less frequently requested, and less enthusiastically undertaken. Geshé Q explained that it used to be the case that a patron would request a ritual and monks would vie for the right to perform it and thereby earn some income from it. Now, with the emphasis on scholasticism and the ability for family and patrons to send money relatively easily around the world, no one wants to do it. ${ }^{424}$

There are thus a great variety of pressures preventing a rigorous adherence to textual prescriptions and standards of performance. There is the distance from "centers," both geographically and ideologically; the lay-centric concerns of the ritual and its primary deities, as well as a lack of significant lay presence; a more stringent and capacious stewardship of tradition at Menri, the other principle monastery in exile; and a lack of mastery of ritual skills or engagement due to a rotating educational program and an emphasis on scholastic pursuits above all others.

Perhaps more fundamental than all of these is the simple truth that ritual performances are difficult. Understanding the textual instructions and verses requires a high level of literacy and reflection, if they are possible to understand at all, while recitations require tremendous energy and concentration over prolonged periods of time. It is unreasonable to expect that all monks, especially the younger ones, could sustain perfect fidelity to any particular program hour after hour and day after day.

${ }^{424}$ Interview with Geshé Q at Menri monastery on 2/22/2009. 


\section{Orientation and the Four Chronotopes}

To assist in answering the question of "why then?" and to otherwise provide an organizational framework for articulating the various interpretive levels operative in the community's orientation to the Nyelam Dé Zhi, the analysis that follows makes use of the work of Thomas A. Tweed. In Crossings and Dwellings: A Theory of Religion (2006), Tweed proposes a theory of religion that could best be summarized by a statement from page 54, which says that religions are "confluences of organiccultural flows that intensify joy and confront suffering by drawing on human and suprahuman forces to make homes and cross boundaries." This notion draws also from the work of Jonathan Z. Smith, who wrote that religion is:

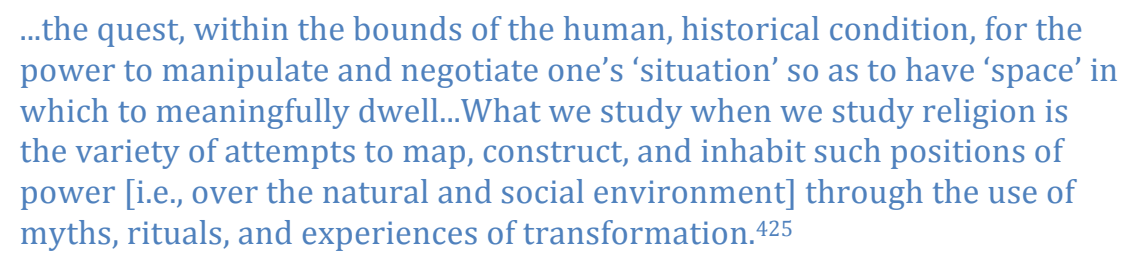

...the quest, within the bounds of the human, historical condition, for the power to manipulate and negotiate one's 'situation' so as to have 'space' in which to meaningfully dwell...What we study when we study religion is the variety of attempts to map, construct, and inhabit such positions of power [i.e., over the natural and social environment] through the use of myths, rituals, and experiences of transformation. ${ }^{425}$

Though Manuel Vazquez talks more pointedly about globalization, he makes a similar argument, when he refers to the role of religion as "a key cultural component in the construction of both new spatio-temporal arrangements and emerging cognitive maps through which individuals and institutions try to locate themselves in the new landscapes..." 426

\footnotetext{
${ }^{425}$ Smith, 1993, p. 291.

426 Vasquez, p. 52, drawing from and expounding upon Nestor Garci Canclini (1995, p. 229), who wrote about deterritorialization and reterritorialization as "the loss of the 'natural' relation of culture
} 
There is much to unpack from these propositions, but for the purposes of understanding the Nyelam Dé Zhi, and ritual on a larger scale, especially in exile, it will suffice to focus on the "making of home" and the "crossing of boundaries" as projects, first and foremost, of orientation, taking also the liberty of substituting ritual for religion in the larger theoretical frameworks. ${ }^{427}$ To illuminate the various dimensions of this crossing and dwelling, Tweed describes religious adherents as mapping, constructing, and inhabiting four chronotopes: ${ }^{428}$
1. Body
2. Home
3. Homeland
4. Cosmos

To paraphrase and extrapolate the summary explication that follows the enumeration of these chronotopes (also on page 97), again substituting ritual for religion, the idea is that a ritualized body functions first and foremost as the "watch and compass" that orients an individual in space and time, regardless of where that individual may be situated. Ritual activity then constructs, purifies, or otherwise transforms foreign spaces into home, and when done at a community level, functions to "negotiate collective identity," both maintaining a connection to a pre-existing homeland and creating a new one in a new space. This process reinforces social hierarchies and possibly creates new ones within the community, while situating

to geographical and social territories and, at the same time, certain relative, partial territorial relocalizations of old and new symbolic productions."

427 In the quote above, Smith points more explicitly to ritual as a tool of negotiation within the larger project of religion, while Tweed (2006) suggests that ritual's role, in part, is to transmit and retransmit tropes of "natal place and social space" that have been "anchored" into "artifacts" (p. 111), and to bring back to the present the religious minds that have traveled to distant pasts and imagined futures (p. 162), a dynamic which will be discussed later, but as will also be shown, the roles he assigns to religion in the context of larger human and cultural experience are conveyable as effectively to ritual in the same context.

428 Tweed, 2006, p. 97. 
them in and regenerating taxonomies of extended community members and "others" outside the community and in the vastness of the cosmos.

As for mechanics, ritual orients bodies in a variety of ways. ${ }^{429}$ It establishes boundaries in, on, and around bodies, designating what must stay within and without, and what can or cannot cross these boundaries, sometimes temporarily for the duration of the ritual, and sometimes more permanently, inscribing its attendant cultural values in the very structure or disposition of the body itself. In the home, ritual directs and orients the bodies residing there or visiting, structuring the interior spaces and the practices and relationships therein. It dresses, adorns, or otherwise marks bodies with symbols and implements that connect individuals to the collective, and the collective to the homeland. Finally, it situates them on a continuum that stretches backwards in time towards, and sometimes all the way to, the origin of the cosmos, often transforming the body into the site of the cosmic, whether via mediumship or via embodied re-enactments of cosmic narratives.

For the community at Triten Norbutsé, then, the Nyelam Dé Zhi ritual reveals itself to be the most engaged orientation-through-boundary-making ritual of the annual calendar. Whereas the vast majority rituals of all scales at Triten Norbutsé include rites at the beginning for the creation of boundaries, those boundaries are set to ensure the integrity of the ritual context for the duration of that performance. In the case of the Nyelam Dé Zhi, the boundaries are set for individuals and for the entirety of the community for the entirety of the year, and then renewed year after year.

${ }^{429}$ All of what follows in this paragraph is a paraphrase and extrapolation of Tweed, 2006, pp. 99103. 
For individuals, the Nyelam Dé Zhi works more than any other ritual at Triten Norbutsé at the boundary between the embodied self and the natural world. Tweed evokes Max Weber to describe experiences at this boundary as encounters with and between "corporeal limitations" and "the world's perfections and imperfections," and the complex experiential intersection of the two in the form of personally impactful natural events, both fortunate and unfortunate, like timely rains on the one hand, and floods and earthquakes on the other. ${ }^{430}$ The Nyelam Dé Zhi, with its negotiation of the perceived agents of the natural world via embodied technologies of appeasement, curation, subjugation, and banishment, is an attempt to seize control of this boundary. It does this by moving agency and accountability across that border, from outside to inside, in the process reducing the terror of the unknown and the unpredictable, and equipping bodies with ritual technologies of orientation that are easily deployed in any new natural environment.

In the larger picture of monastic ritual generally, the physically taxing nature of the performance, requiring protracted periods of upright stillness combined with disciplined recitation, has the effect of molding bodies to match a set of prescribed values. In the academic program at Triten Norbutsé, the relatively boisterous debate-centric scholastic activities that reward animated and forceful comportment, combined with the lack of emphasis on practices like meditation, ${ }^{431}$ has the

\footnotetext{
430 Most of this is from Tweed, 2006, p. 136, though he does not cite Weber directly.

${ }^{431}$ Note that they do meditate, many of them daily, but as Sangyé Tenzin said, this kind of practice is considered more important when your older. In the academic program, it is success in debate that is most important.
} 
potential to undermine efforts to embody monastic decorum in other contexts. ${ }^{432} \mathrm{As}$ an example, during the confrontation with Karmay at Menri, a number of monks stood up and, loudly and forcefully, castigated him for what he had written in The Arrow and the Spindle, to the thunderous applause of monks in the audience. The next day, Tenzin Yangtön ${ }^{433}$ and Geshé $\mathrm{Q}^{434}$ expressed some embarrassment about this on those monks' behalf, saying that such behavior was appropriate for, and in fact highly valued in debate, but was out of line elsewhere. The stultifying atmosphere and demands of recitation-based ritual performance in the assembly hall counteract or balance out these tendencies in much the same way, but to a much greater degree, that being made to sit quietly still in school or church disciplines bodies of other traditions or cultures.

\section{Home}

The Nyelam Dé Zhi, at least at the level of an institutional performance like that undertaken at Triten Norbutsé, is less relevant to the home chronotope in terms of exclusively residential space, but for a monastic community in exile, home is the entire monastic grounds. In a project of home-making at this level, rituals like the Nyelam Dé Zhi are important architectural and orienting forces, in terms of domesticating a previously wild patch of ground to transform space into place, and then structuring the space, time, and socio-behavioral dynamics within.

\footnotetext{
432 See Dreyfus, 2003, p. 35 for support and more detail about this tension.

433 Interview with Tenzin Yangtön at Menri monastery on 4/23/2009.

${ }^{434}$ Interview with Geshé $Q$ at Menri monastery on 4/24/2009.
} 


\section{Orienting to a New Place}

In light of ritual's capacity to orient, it is easy to understand Tenzin Namdak's choice $^{435}$ to include the Nyelam Dé Zhi in the annual calendar of a new monastery being constructed in a new environment, in exile, with an explicit mission of training monks, and easy also to understand how it has now fallen into a kind of disrepair. In a new country, in a new political situation, in a new landscape - and one that had never before been developed for human habitation - the imperatives of environmental orientation were profound. The Nyelam Dé Zhi, a ritual focused specifically on negotiation with land and spaces and elements, was well suited to meet these imperatives. While there are no known detailed records of the performances of the Nyelam Dé Zhi in those early days of the monastery's operation, it is easy to imagine that there was a greater immediacy, and thus fidelity, to the proceedings.

If that immediacy and fidelity are gone now, it is in part because that particular transition-orientation is complete, with the monastery and its community comfortably assimilated into the landscape. Modern activities of the community rarely challenge the boundaries in question to the degree that they would have upon their original establishment, and while the monastery occasionally pushes those boundaries outwards with a new construction project, such expansions are rare or not large-scale. Monks are not involved in the cultivation of land, and are not close enough to an exposed body of water to engage in regular negotiation around its use.

\footnotetext{
435 Note that Tenzin Namdak does not say much about the decision to include the Nyelam Dé Zhi in the annual calendar.
} 
They do not otherwise have significant worldly needs and the laity that do are distant.

Nor have the boundaries been challenged from the outside. Menri experienced a landslide during the construction of their tantric temple that compelled a re-evaluation of boundaries and their negotiation, but Triten Norbutsé has not had such an experience. Perhaps such an event would change the character of the Nyelam Dé Zhi performance, and attitudes around it, if only temporarily. For now, and for many years now, the persistent absence of antagonism in and around these spaces has further prevented any sense of immediacy, or even relevance, in the proceedings.

During the initial orientation of the community but especially afterwards and since, however, the value of the Nyelam Dé Zhi has been mitigated as a force for orientation by its "affective vector" - its popularly understood ethic to be ultimately a sending away, rather than inviting in - at least compared to other orienting rituals. One such ritual is the 100,000-fold offering to Sipé Gyelmo, the great protectress of Bön. As one of the most common and recognizable deities of Bön, it is very likely that rituals for her have always been popular, and indeed people in both the monastic and broader communities often express a great affinity for her. This is evidenced, in part, by a volume of patronage that is, on average, higher than other comparable rituals of the calendar. Every major ritual of the calendar invites patronage, and of the events observed across visits, not one went without at least a few patrons - and most significantly more than that - but there is certainly fluctuation from ritual to ritual. Some of this fluctuation is random, based on how 
many people happen to be visiting the monastery or in the area at the time of the ritual, and how wealthy and/or generous these visitors may be, but there is also no doubt that certain rituals routinely enjoy more patronage than others.

Despite their perennial popularity, rituals for Sipé Gyelmo take on a new urgency in exile, where protection - of the teachings primarily, but also in a broader, encompassing sense - is all the more important in the face of less predictable environs, pressures, and political futures. They are rituals of invitation and cohesion, developing and maintaining community locally and cosmically, sharing wealth and strengthening bonds. With a monastic population haling from a variety of homelands, coming together in exile before dispersing back to these homelands or to other localities where geshés are needed to help install education programs or otherwise provide leadership, and with a laity that consists at least as much of pilgrims - including westerners - as it does of local adherents, the challenge of maintaining community and tradition is especially acute. Sipé Gyelmo, her rituals, and other rituals that are similarly oriented towards protection, strengthening, cohesion, and so on abundantly address this challenge.

Some of these dynamics in exile that augment the immediacy of rituals like the 100,000-fold offering to Sipé Gyelmo would seem to be just as, if not more, relevant to the Nyelam Dé Zhi - negotiating the environment, ensuring prosperous futures in the face of uncertainty, and so on. If the Nyelam Dé Zhi is focused primarily on negotiating with the deities of the landscape, and is ostensibly about "harmonizing all the spirits of the universe," why would it not also be of the utmost significance and utility as a community attempts to settle itself gracefully into a new 
landscape, building new structures, taking from the land, and so on? To an extent, it is. When asked, monks admit that performance of the Nyelam Dé Zhi has "probably" helped to install the monastery and its community into the local environment, and it "may have been especially helpful" during early construction projects, especially during construction of the main monastery buildings.

This admission was never offered without prompting, however. By now, the reasons for this lack of engagement around the Nyelam Dé Zhi, and the reason for the contrast with Sipé Gyelmo, should be mostly obvious, but there are additional dynamics at play here. One is this notion of an "affective vector" of the Nyelam Dé Zhi, from in to out. It is ultimately a banishment rather than an invitation, creating cohesion and harmony among all beings in theory but in practice, or at least in common understandings of practice, sending a great many beings away or at least ensuring they stay on the other side of reinforced boundaries, doing whatever they can to ensure they do not return or cross. While this coheres with a larger project of community cohesion, given that these beings are often problematic when they are present, the already fractured nature of the exile community, which itself was, in a way, "banished," recommends rituals of reconstruction rather than further deconstruction. 436

${ }^{436}$ A conversation over tea with a group of monks at Triten Norbutsé on 5/30/2010 brought this observation to light when I asked them why, if the goal was to have perfect compassion for all beings, they were not embracing these beings and inviting them here for tea. One of the older monks who was visiting Triten Norbutsé from Menri very poignantly responded, "We do invite them here, but it is not for long. I guess they are like us [in exile] - they are invited but only under certain conditions, one of which is that they promise to leave." 
Another reason for the tone of these reactions was that there was a targeted land consecration ritual at the time the monastery was established, ${ }^{437}$ which would have been considered far more effective than the wide-cast net of the Nyelam Dé Zhi, and indeed the general efficacy of the latter is very much in question, or outside of consideration, for many of the monks. Younger monks trust its efficacy, and are eager to connect it to any rainfall around the time of the performance, but the older monks and especially geshés repeatedly explain that it is impossible to verify the success of these rituals, and, again, that there is no reason to try. ${ }^{438}$ Regardless, it is clear that there is evidence, of a sort. It is tacitly understood that the fact that the community as a whole is thriving testifies to the success of rituals like those dedicated to Sipé Gyelmo, while the lack of major natural disasters, sickness, and so on could testify to the success of the Nyelam Dé Zhi. ${ }^{439}$

The respectful, apologetic, but still forceful banishment of the Nyelam Dé Zhi is in indeed one of its distinguishing characteristics among other rituals in the annual calendar at Triten Norbutsé. While plenty of rituals and rites include degrees of this dynamic in order to cleanse, clear, or purify in preparation for other more important activities, no other ritual takes this externalization, or "sending away," as its primary vector. In addition to the 100,000-fold offering to Sipé Gyelmo, celebrations of Tönpa Shenrap and Nyamé Sherap Gyeltsen, the 100,000-fold

\footnotetext{
437 Interview with Tenzin Namdak at Triten Norbutsé on 5/26/2009. He could not or did not provide many details of this ritual, saying only that they would not have built anywhere in the area, especially so close to Swayambuthnath, without performing rituals of propitiation, purification, and boundarymaking.

${ }^{438}$ Note that this lattermost sentiment is not shared by all geshés consulted, but was explicitly stated by Tenzin Tsultrim (Interview at Triten Norbutsé on 2/27/2009) and Tenzin Namdak (Interview at Triten Norbutsé on 5/26/2009).

439 Note that none of this is to discount the daily activities that monks undertake towards similar ends - praying for the health and longevity of teachers, the well-being of the community, and so on.
} 
offering to Drenpa Namkha, the Mawé Senggé (rma ba'i seng ge) wisdom deity

rituals, and new year's festivities are all inspired by or focused on invitation and procurement. Keep the protectors and ancestors and teachers around as much as possible, increase wisdom and insight and merit, and so on. The Nyelam Dé Zhi does include invitation and invocation and merit and such, but the goal is to keep its primary addressees and their minions and their activities at bay for another year. In the case of the more remedial volumes, most of which admittedly have no part in the standard annual performance of the Nyelam Dé Zhi at Triten Norbutsé but which are otherwise part of the ritual's culture, origins, and identity, it is not about keeping beings at bay but about explicitly expelling them from the current environment and doing whatever one can to ensure they do not return.

Incidentally, the upside of this orientation is that the purging of the environment is matched thematically by the purging of self via confession and apology, such that the overall effect of the Nyelam Dé Zhi, again more so than any other ritual of the calendar, is one of renewal. Distracting, polluting, complicating, obstructive forces are evicted from self and surroundings at the time of year, traditionally, when life is renewed from the frozen ground, ${ }^{440}$ and promises are made or renewed for the upcoming year.

While the imperatives for orientation may have softened over time, compelling a softening of rigor and enthusiasm in kind, the ritual nevertheless

440 Traditionally across cultures, rites of renewal coincide with harvest and are thus more common in autumn, but those ceremonies merely mark a different transition in the process of renewal, namely the disintegration and decay of the vitality of the previous year, and its transformation into the sustenance of vitality for the upcoming year. Ceremonies in the spring mark birth rather than death, and as such are more appropriate for forward-looking rites like the institutional version of the Nyelam Dé Zhi, which includes confession and apology and promise as a means to ensure the prosperity of all for the coming year. 
remains threaded into the fabric of the community because, in part, "if we don't do it, people will be upset." 441 The Nyelam Dé Zhi performance (and others of the calendar) has become so embedded in the tacit, baseline orientation of community members that its absence now, in more Tweedian terms, would be dis-orienting. Its orienting function is thus no longer about mapping territory but about reprinting the atlas every year. Given that not much changes from year to year, it would not be disastrous to stop doing so, but anxiety would begin to mount around the possibility of losing one's way, and around losing contact with the homeland (discussed below).

\section{Structuring Time}

In the intervening years between early orientation and modern performance, the Nyelam Dé Zhi has become involved with other kinds of boundary creation and preservation, one of the most conspicuous of which is temporal rather than spatial. Ronald Grimes (2000), like Turner and van Gennep and others, talks about rituals as marking and negotiating transitions, organizing time periods into stages. From this perspective, the Nyelam Dé Zhi, as "the summer ritual," as community members commonly referred to it, oftentimes entirely in lieu of its name, is a force for seasonal and annual orientation. It marks the beginning of summer, when the "lu have thawed from their frozen riverbeds," which follows a couple of months after geshé graduation ceremonies by a couple of months. While there is not quite the same sense of an American school year, with summers off, there is a clear sense among these scholastic monks of pre-summer activity and post-summer activity,

\footnotetext{
${ }^{441}$ Interview with Tenzin Tsultrim at Triten Norbutsé on 6/8/2009.
} 
with the Nyelam Dé Zhi acting as a conspicuous boundary, and thus a kind of agent of transformation, or a transitional rite, between the two. ${ }^{442}$

\section{Structuring Space}

The need for expansive craftwork in preparation for the Nyelam Dé Zhi, with many monks concurrently building thread crosses and molding tormas and building the sand mandala, compels the construction or appropriation of large multi-use spaces that can afford to be dirtied. There are only a couple such places on the entirety of the monastery grounds, and they are conspicuously different from the other structures that are generally oriented either towards engaged ritual and scholastic activity - the two primary temples (including the main assembly hall), the library, and Tenzin Namdak's residence - or towards quotidian residential and operational concerns, such as the residential halls, bathroom houses, kitchen, and shop. These unique spaces are entirely unfurnished and non-descript, with only an occasional cushion or tool brought in for the undertaking of the work to be done there. The mandala commands a more privileged location in the prayer wheel temple, which matches the literary and popular expressions of its importance compared to the other implements, but thread crosses and torma making, as well as the assemblage of wood drawings and greenery and earthen blocks that serve as anchors for the dö, require neutral spaces that are at least temporarily, but often, exempt from the

\footnotetext{
442 There is a temptation here to talk about Turner's rites de passage, but the truth is that the performance itself does not resemble the rituals he theorized about, given that there is no separation, no real liminal space, and thus no reaggregation. The whole thing happens at the "center." There are, however, shades of his theories present in other aspects of the ritual, discussed below.
} 
monastic strictures regarding the cleanliness and order of ritual/scholastic and residential spaces.

These spaces are at the fringes of the monastery grounds but not outside of them, and the behavior of monks within these spaces mirrors, to an extent, the regulatory suspension and, in quasi-Turnerian and van Gennepian terms, the liminality, of the spaces themselves. While it is possible to observe momentary departures from decorum and stricture in any space within and around the monastery at any given time, the torma-making monks and especially the thread cross-making monks conspicuously and persistently exhibited a high-spirited freedom from the same, joking and teasing and laughing heartily. While the thread cross-making could hardly be considered a rite de passage - though it is true that all monks must do it at least once on their way to becoming fully educated - the peripheral location of the space, and the temporary dislocation of monks from stricter spaces and behaviors, and the obvious camaraderie that ensued in this exempt space and time, evoke both Turner's communitas - though without the conspicuous change of status upon their return - and Smith's utopian, ${ }^{443}$ and frankly help to explain the contrast of monks' relative enjoyment of the ritual preparations with the drudgery of the ritual performance.

That the activity in this space is associated with aspects of the ritual that are ostensibly more "popular" or worldly in origin and orientation is no accident. In theoretical Turnerian-Smithian terms it shows a clear assignment of, and relationship and interplay between centered/locative/transcendent and

${ }^{443}$ See Smith, 1993, pp. xi-xv, 67-207. 
peripheral/utopian/worldly modes. In ethnographic terms it reflects this modern community's ambivalent attitudes towards worldly lay-oriented activity (when the laity is not particularly present) and the non-scholastic, which is further reflected in comments about the relative unimportance of this aspect of the ritual and the lack of excellence in its execution, which is as much a result of the lack of oversight as anything else. And yet the work done therein is not outsourced or pushed outside the boundaries of the monastery. It is still important for monks to be stewards of these traditions, facile with their basic forms, and for the community as a whole to define and redefine the perimeters and parameters of their hierarchical arrangement. Such crafts and practices may be less important than other ritual aspects or pursuits, but it is important to exert control over them and to define clearly - even if this clarity is more implicit than explicit - where they fit in relation to everything else, which is "to the side."

The assembly hall - the primary recitation space at the locative/center - on the other hand, is carefully configured according to the needs and hierarchies of rituals like the Nyelam Dé Zhi and the communities that inform and perform them. It is at the highest point of the monastery grounds, with dwellings and other functional spaces below. Altars and statues, as well as other sacred implements (including the dö) at the front give way to two high seats (but one highest) for the most prominent members of the community, followed by the regular rank and file, with seats for the most elite among them, the geshés, situated closest to the front. 


\section{Structuring Relationships and Behaviors}

This structuring of space is mirrored by and/or from social structures, and indeed reflection and reproduction of stratified social hierarchies is a key function of ritual, taking on a particularly unique dimension in the case of the Nyelam Dé Zhi. In this way, it shows itself to be in contrast to Turner's particular observations of communitas, a breakdown of the boundaries constructed by the stricter hierarchical nature of the surrounding culture and community, ${ }^{444}$ and relates to Toni Huber's correction of Turner in his analysis of the reinforcement of social hierarchy among Tibetan pilgrims visiting holy sites. ${ }^{445}$ Rituals like the Nyelam Dé Zhi are intensely hierarchical, with a maṇdala providing temporary abodes of beings in concentric rings of decreasing status, situated at the front of a room that is itself structured very clearly according to status. To the extent that Turner's theory is focused on rituals that take place outside the institutional centers, however, these very different social dynamics in the Nyelam Dé Zhi and its context reveal the very "centered" nature of the ritual, and perhaps the absence of any kind of expected or realized transformation.

The Nyelam Dé Zhi is also somewhat unusual, however, in the sense that the most prominent members of the community are entirely absent, and not by any means necessarily, though sometimes, for reasons of pressing obligation elsewhere. If one of the ways ritual functions is to articulate and reinforce hierarchies, however, it may not be surprising that the ranking members of a community that places an intense emphasis on devotionalism would not need to be present in order to assert

444 Turner, 1986, p. 100.

${ }^{445}$ Huber, 1999, p. 18. 
their status at an event unattended by anyone outside the immediate community. Monks coming into the community are inculcated with the absolute authority and infallibility of their teachers and leaders, a tradition in Bön and Buddhism that stretches back to their origins and beyond, to Indian precursors. At the next level below these principle leaders are the geshés, who generally but more optionally attend the ritual proceedings, and whose status has been firmly established by the award of their degree. The only truly mandatory attendees of the proceedings are those whose communal status is actively, or was until very recently, being negotiated.

The ritual performance thereby communicates, in its social dimension, that the achievement of highest status in the community earns one the "privilege" of not having to attend the proceedings. Tenzin Tsultrim's half-joking acknowledgment that he does not attend because he is "lazy," combined with the obvious toll that roughly twelve hours of ritual activity a day, most of it recitation, for four days, takes on the average monk, suggests that the undertaking of the Nyelam Dé Zhi is a kind of undesirable requirement for the younger or less experienced community members, for whom such rituals - those that are otherwise not entirely relevant to their scholarly career aspirations - are proving grounds of community commitment and potential. Those who refuse to attend, as a small handful do, cease to be upwardly mobile in the community. 446

\footnotetext{
446 It cannot be ignored, however, that those refusing to attend the rituals are likely not on the fasttrack anyway.
} 
Meanwhile, the monks who do attend appropriate a redemptive ${ }^{447}$ place for themselves in a few ways. For the monks who are not in the academic program, instead pursuing the practical education in the practical school, ritual performances are the one communal arena where they excel above all others. Their deeper training and practice in meditation, visualization, and so on, combined with the sense of this opportunity to excel, manifests as a greater resilience and commitment during the recitations. ${ }^{448}$

For all monks, there is a sense that they are now the subduers of potentially destabilizing forces - involving the exercise of great power - and the cultivators of the ideology that their superiors have expressed as the primary goal of the ritual communal, even universal, harmony. Among younger monks, the preponderance of explanations relating to rain-making and preventing illness thus does not reflect merely a more lay-oriented attitude or less complete understanding of the ritual's complexities, but also a seizure of the most recognizable power-conferring elements of the ritual that otherwise cohere with the larger power structure of the community. This is still true in the apology/confession layer, where the power shifts from a command over lower beings to the integration and harmonization of community. The absence of higher lamas implicitly conveys an empowering, redemptive trust in the rest of the community to tend to these at least rhetorically

\footnotetext{
${ }^{447}$ I am using this term deliberately, however loosely, to invoke Catherine Bell's (1992) notion of redemptive hegemony, which describes ritual actors' abilities to assign redemptive places for themselves in relation to sources of power in their community.

${ }^{448}$ Tenzin Tsultrim confirmed the superiority of their performance in an interview on May 15th, 2010.
} 
very important concerns. ${ }^{449}$ As academic monks advance in their careers, they have thoroughly assimilated and taken for granted command over beings like the lu and responsibilities to help maintain harmony, and sources of power begin to shift, towards scholastic accomplishment, degree procurement, and so on. As that shift proceeds, the perceived utility or relevance of the Nyelam Dé Zhi and its performance dissipates.

There is also a sense that they are the caretakers of tradition - a tradition that stretches back many centuries, and which may be all the more important in this respect precisely because it is not as relevant to the primary, immediate concerns of the modern monastic community at Triten Norbutsé, and yet part of the overall project of the preservation of Bön articulated by Tenzin Namdak, who acknowledges that the Nyelam Dé Zhi is possibly but possibly not being done anywhere else at this scale.

\section{Homeland}

Indeed, the most communally poignant function of the Nyelam Dé Zhi, and other rituals at Triten Norbutsé to a lesser extent, are their connection to and re-creation of homeland and homeland traditions. At the most fundamental level, this works because of ritual's ability to encapsulate place, ${ }^{450}$ via the notion that actions have

\footnotetext{
${ }^{449}$ It is important to note that in all of these cases, it is not necessary for monks to recognize the individual rites that relate to controlling lu or cultivating harmony. As explained above, many of them do not understand these recitations and rites explicitly. It is simply enough to have a particular understanding of what the ritual is for, and to be able to articulate this understanding. ${ }^{450}$ Smith, 1993, pp. 83-86 has the most compelling explanation of how this works, though critiques of his work by Thomas (2008), and Grimes (1999) provide illuminating extrapolations and corrections as well.
} 
primacy over place. As Smith described with the Church of the Holy Sepulchre, 451 even an important place can be wrapped up in a ritual bundle that will allow it to be transported. He describes myth as an important part of that bundle, but it is only myth as performed that makes it useful for projects of mobilization. Myth as told without ritual accompaniment fails to re-create, creating distance where it wants to be destroyed, and through the domestication of space, and the transformation into place, ritual dubs the new old and the old new. The Nyelam Dé Zhi, which addresses beings living in the immediate environment as well as all sentient beings, and empowers the surroundings and substances drawn from the same, is a classic example of place packaged and deployed.

In terms of more direct connectivity, the Nyelam Dé Zhi performance both explicitly and implicitly maintains ties to the Tibetan homeland and its people and traditions. The explicit ties appear both in clear statements that "we do the ritual for those still in Tibet," and in answers about the timing of the ritual performance itself - it is done at the beginning of summer because "this is when the lu are thawing from their riverbeds" and can thus receive and be present for the ritual proceedings. When asked about the issue of there not being many water bodies nearby, and none of them froze during the relatively mild winters, monks often replied that the lu and the people with relationships with them were still in Tibet. ${ }^{452}$ Patrons of particular performances were only occasionally located in Tibet, and while monks

\footnotetext{
451 See again Smith, 1993, pp. 83-86.

452 Monks always acknowledged that lu are not just in Tibet, however. They are found throughout the world and beyond, but it is not clear to many of them whether non-Tibetans have any kind of relationship to or knowledge of them, or whether rituals like the Nyelam Dé Zhi would be meaningful and effective for anyone but Tibetans or other Bön adherents.
} 
acknowledged that the patrons were first and foremost among the concerns of the ritual, there was rarely any contact with them aside from seeing their name on the blackboard outside the kitchen and the amount they had given.

Implicitly, the Nyelam Dé Zhi, and many rituals and activities at Triten Norbutsé, are powerful tools of preservation, continuity, and connectedness. Many theorists have described ritual and religion as forces for making close what is distant, whether in vertical or horizontal, spatial or temporal dimensions. ${ }^{453}$ The vertical, as it pertains to the cosmos chronotope, will be discussed below, but there are a number of ways this collapsing of distance happens in the other dimensions. The performance of an earthly, landscape-centric ritual like the Nyelam Dé Zhi, addressing deities allegedly dwelling nearby, would not seem, at first glance, to be very portable. The answers about doing the ritual for those (deities and people) still in Tibet would seem to confirm this. And yet it is undeniable that the performance of this ritual colonizes the surrounding environment with the values of its performers. Local atmospheric phenomena during the ritual are connected to the performance. The mud and greenery are brought into the temple from the surrounding environment, given an important place on the dö and otherwise imbued with specifically Bönpo significance, and then returned to the environment along with other gifts and foods and ritually transformed artifacts, for consumption by local deities. That this theoretically "works" the same way in this exiled environment that it did in the place of its origin, in Tibet, compels the belief that this place is not different from Tibet. Unlike some other rituals in other exiled communities where

453 See for example Latour, 2005 (and Tweed, 2006, p. 158), Humphrey and Laidlaw, 1994, p. 161, and Vasquez, 2003, p. 35. 
the crisis of the difference of their new environment requires an explicit conveyance and reinstallation of a local protector deity, 454 the performance of the Nyelam Dé Zhi subtly expands the boundaries of the homeland to include this place.

The same is true, to an extent, of monasticism and ritual paraphernalia. Tweed (2006) describes how religion marks bodies and spaces with symbols and garb that connect the collective to the homeland (p. 101), and how it anchors natal place in artifacts for transmission via ritual (p. 111). Indeed, the craft components of the Nyelam Dé Zhi are always described in terms of their connection to the origins of the Bön tradition, and in terms of their uniqueness among Tibetan traditions, ${ }^{455}$ such that their significance, even in the context of the ritual performance, seemed to relate far more to this spatio-temporal dimension than to their particular efficacy as a ritual technology.

While the Nyelam Dé Zhi performance does not make use of any particular attire, there can be no doubt that monastic robes evoke homeland, and that, at a more fundamental level, there is a great deal of portability built into monasticism. It has been explicitly designed to set its structure and its members apart from the rest of the environment and community, so as to engage a primarily vertical agenda of transcendence. Much like Smith's Temple of Jerusalem, which was not previously situated in an important place and thus could be reinstalled elsewhere by

\footnotetext{
454 There are many examples of transported protector deities, some of them entirely within Tibet, but an exile example is mentioned by Cabezon (2009, p. 7), in which a particular group of eastern Tibetans in exile in India propitiate the protector deity Machen Pomra ( rma chen spom ra), acknowledging that he has traveled far from his original mountain residence, and has possibly moved permanently to Dharamsala.

455 Such descriptions were, of course, mostly for my benefit as an outsider, but the consistency of such sentiments made it clear that monks conceive of them this way independently too.
} 
reproducing and deploying its "relations of difference,"456 a monastery or group of monks, unless previously situated at a place of profound and unique geohistorical significance, need only re-enact its "setting apart," its "relations of difference," bringing along or re-creating its garb and tools, to re-engage its mission in a new location. The verticality of this mission means also that, at root, the distance is the same no matter where you reside horizontally. 457 The byproduct of this is that monasticism, to the extent that its original forms and relations were themselves products of homeland traditions, is a powerful strategy for homeland mobilization and portability.

In a different sense of collapsing distances, the Nyelam Dé Zhi is an opportunity for the monks at Trite Norbutsé to reduce their distance from an everreceding laity, with whom they had a closer relationship in the homeland. As discussed above, there is by no means a complete absence, but the location of the monastery in Kathmandu, across from Swayambuthnath, in a neighborhood with almost no Bönpo residents, ${ }^{458}$ means that lay engagement is generally confined to special occasions, when adherents visit from elsewhere in the metropolis, country,

\footnotetext{
${ }^{456}$ See Smith, 1987, pp. 83-86.

${ }^{457} \mathrm{An}$ important caveat to this is the possibility that there are greater obstacles to transcendence in some environments than others. In places of little exposure to patrons of any kind, for example, monks may need to engage in more worldly activities to survive than others who might benefit from frequent donations of food and money. But there are always arguments around these kinds of issues, with some suggesting that environments with greater worldly obstacles may in fact be more conducive to spiritual advancement than those without hardships.

458 It is important to note, however, that the Namgyal School for elementary-age children is just down the hill from the monastery, which possibly augments the Tibetanness of the area and increases the exposure of the monastery to potential supporters. No research was done into these possible dynamics, but it is important to mention the school to portray accurately the neighborhood dynamics.
} 
and world. ${ }^{459}$ At other times, lay Bönpos and international tourists will occasionally request a divination or training, for which they will usually make a donation of some sort, or they will sponsor a prolonged bardo ritual for a deceased loved one, for which they will pay according to scale. ${ }^{460}$ From the lay perspective, these are undoubtedly invaluable services, but for the monks the value is questionable. While the monastery is by no means wealthy, options for sending money and goods have improved significantly over the last decade, such that many monks at Triten Norbutsé receive spending money, phones, and other items from family members and friends near and far. This is not a dimension of exile as much as it is one of modernity - though being situated in Kathmandu provides resources that rural Tibet could not - but the relative lack of laity and emphasis on scholasticism further distances monks from these kinds of fee-based services. In interviews, especially with Geshé Q but with others also, it was clear that very few modern monks at Menri or Triten Norbutsé 461 are interested, much less excited, to do these kinds of village

\footnotetext{
${ }^{459}$ Again, this is not an absolute. There are constant visitors from afar, and a couple of lay Bönpos working at local shops or otherwise living in the vicinity of the monastery, but monks barely engage these laypeople and as a group they hardly constitute a supportive laity.

${ }^{460}$ I never witnessed this at Triten Norbutsé but a village man died in Dolanji during one of my stays at Menri (actual death date 12/8/2008), and his family requested that Sangyé Tenzin and a team of monks do the transference of consciousness rite ('pho $b a$ ) and other bardo and death rituals for him. This is an explicitly fee-for-service ritual, at the cost of 700 rupees per hour (about $\$ 13$ at 2008 rates), which means that only the very wealthy can afford to pay for all seven days of the full ritual. Poor families can generally pay only for an hour or two. Sangyé Tenzin would not tell me how much this particular family paid, but he did invite me to come observe the proceedings first-hand. Over the course of a couple of days, many manks took part in the ritual preparations - constructing an altar in the home, crafting tormas, placing water bowls and butter lamps, and so on - and then in the recitations, purification of the body, astrological readings, and more. On day two, Geshé Q told me, "It is so much work when someone dies." Indeed, multiple monk friends and acquaintences of mine talked about how much work these rituals required, and how fatigued they were, having done them more or less around the clock since he died. All other responsibilities were put aside. Sangyé Tenzin told me that many monks do not think they should do these rituals any more, because it costs people so much money and it takes monks away from other duties.

461 Geshé Q said "no monks," (Interview with Geshé Q at Menri monastery on 2/22/2009) which I've corrected to "very few" out of an abundance of caution and because I think he was making a point.
} 
or lay-oriented rituals. Geshé Q said, "It used to be that you had to argue over who would do these rituals, because whoever did the ritual received the money. Now, Holiness has to pick people because no one wants to do it. Everyone is so focused on geshé geshé geshé, and they have sponsors from home and everywhere that give them what they need." 462

While this partially helps to explain the lackluster performance and sentiment around the Nyelam Dé Zhi, it also helps to explain the compulsion to preserve it. In a climate of decreased lay presence, decreased emphasis on and expertise in ritual performance, increased scholastic engagement, and increased pressure on the world stage, but within a community that still relies on donations to fund monastic operations and that has survived throughout history because of lay support, and which can certainly imagine a time in the future when some or all of its members would re-engage with a larger lay community, the Nyelam Dé Zhi serves as a kind of lay-orientation package. The texts speak to the origins, character, and modus operandi of the worldly deities that lay activity engages but which monastic activity avoids, thereby providing insight into lay lifestyles and tensions more generally. The preparations and performance educate them with a bare minimum of technologies to address a great variety of lay issues (all kinds of sickness, drought, fighting, and so on), and the larger collection contains remedial manuals for specific

\footnotetext{
462 Interview with Geshé Q at Menri monastery on 2/22/2009. Geshé Q was careful to point out that the desire for money had nothing to do with simply wanting to accumulate wealth, but that having some spending money was always desirable in these environments where a few rupees could provide bus fare, grocery money, opportunities to treat friends and guests to tea and biscuits, and so forth. I was certainly the beneficiary of more than one cup of tea secretly purchased for me by a monk I only casually knew. This kind of social etiquette is deeply embedded in Tibetan culture throughout the Tibetan cultural region, but I was especially concerned about monks spending what little money they had on me. Geshé $Q$ assured me that many of these monks had no problem affording these cups of tea, but that they would do it even if it was difficult for them to afford.
} 
problems that rarely if ever affect the monastic community (cattle or frog sickness, troublesome rock ogres, and so on), thereby providing them with the resources to address issues that are otherwise outside the domain of their experience and expertise. All of this serves both to memorialize and to maintain their relationship with the laity, past and future, local and abroad, even when the engagement with this memorialization and maintenance is less than enthusiastic.

Beyond the logistics of memorialization and maintenance, the social mechanics of the ritual make attempts to repair social fractures with the laity, and other kinds of fractures, through the substantial rites of confession, apology, and promises, and thus through the payment of "social debts." ${ }^{463}$ No other ritual or event in the annual calendar addresses or involves such a breadth of beings in the local and global communities, and while a number of other rituals involve some form of confession or apology as one or a couple of constitutive rites in a much larger whole, none have motivations that are explained in these terms. ${ }^{464}$ Monks who talk about this particular motivation of the Nyelam Dé Zhi describe it in terms of an "opportunity" (go skabs) to confess and apologize to any beings that may have been harmed or offended by the activities of the community over the past year, thereby creating or fostering harmony in a broader sense. The particular phrasing of this motivation for the Nyelam Dé Zhi, and it was almost always phrased this way, is very telling. It is not just that the ritual itself is comprised of confessional rites that

\footnotetext{
463 See Kratz 1991 for a discussion of this.

${ }^{464}$ As a phenomenon or practice on its own or in a variety of cultural contexts, confession has commanded a great variety of interpretations, many of them stemming from the Catholic sacrament of confession, which is very different in most regards from both the explicit rites and the general motivational sense of confession in the Nyelam Dé Zhi.
} 
do the real "work" of confession, but that the ritual event provides an "opportunity" - it is an appropriate occasion for - the confession of something that has difficulty finding expression in other contexts.

What is this thing that waits for an opportunity to confess? In a general sense, it is possible to talk about cross-cultural compulsions for confession as a kind of curative for guilt, 465 but even if it is true that guilt and confession exist in some form or another in most cultures, the production of guilt and the compulsion and manner of attending to it are highly culturally specific. For the monks at Triten Norbutsé it is an opportunity to reconcile a few fractures in particular. One is the community's preoccupation with scholastic pursuits and rituals that support these pursuits - as with the Mawé Senggé wisdom deity ritual - which carries with it the danger of isolation from their larger context, in terms of their homeland relations and traditions, laity and other sentient beings, and their own tradition's ideologies of altruism and compassionate action. By addressing beings with whom they do not often interface, attending to an issue that is of paramount concern to lay people and Tibetans in Tibet, with whom they also do not often interface, thus compassionately seeking to ameliorate situations that have no benefit for them directly, the monks at Triten Norbutsé repair or prevent social fractures and moral isolation. Other activities help to address these issues - the new year's celebrations, for example, which involve laity from far-flung places and which bring focus, at least at the level of entertainment, to beings of all sorts that are not often addressed throughout the rest of the year - but none have the same sense of repaying a social debt. In other

${ }^{465}$ See Todd's article on the "The Value of Confession and Forgiveness According to Jung" (1985). 
words, given that many monks do not know the names of even the primary beings that the ritual addresses, much less the contents of the texts being recited, it has become clear that the "opportunity" for confession and apology that the Nyelam Dé Zhi engenders, ostensibly for infractions that are mostly irrelevant to monastic activities and sensibilities throughout the year, is being appropriated for a largerscale restoration of relationships that have been severed by exile and by the narrower pursuits of an academic monastery, at least in the minds of the ritual actors.

It is not clear and beyond the scope of the present project to assess whether the performance of the Nyelam Dé Zhi has any real effects on the quality of relationships between those inside and those outside the monastic community. What is important is the sense monks have, vis-à-vis themselves and each other, that they have taken this opportunity to right any wrongs of the past year with people and other entities with whom they do not have regular contact, thereby repairing any fractures that their absence or negligence, or at least their guilt regarding any possible absence or negligence, has created. Doing so, and especially doing so together, decreases their shared sense of isolation and alienation, ${ }^{466}$ with regards to both exile and their narrower pursuits.

\section{Cosmos}

The final crossing or collapsing that happens in the Nyelam Dé Zhi is at a larger scale, bridging the gap between community members and non-community members, the internal and external, the local and the translocal or cosmic.

466 Todd (1985) details how this works in terms of connections between confession and guilt. 
Humphrey and Laidlaw quote J. Jaini as saying, "Ritual...is the enjoyment of what is beyond us, until devotion becomes ecstasy and we feel that we are what we considered to exist outside us, that we are one with the goal, and that the ideal is realized within ourselves." ${ }^{467}$ In the intended transcendent sense of this observation, there can be no doubt that this dynamic is at play in the theory and structure of the Nyelam Dé Zhi and many Bönpo rituals similarly configured. At various stages of the liturgy are visualizations of powerful transcendent figures like the four priests of the four groups of worldly deities, followed by a shift to firstperson recitation, with verses that have ritual performers identifying entirely with, and being empowered by, these cosmic agents and their narratives, commanding masses of beings to do their bidding. The mandala is to be transformed into a divine palace and the dö into the axis of, and eventually the entirety of, the cosmos, offered up, with all the other offerings, both real and visualized, to higher beings.

This is the theory, and in one sense, this collapsing of distance, this crossing the cosmos, does serve the purposes of ideological orientation on the ground at Triten Norbutsé. Rituals like the Nyelam Dé Zhi create a place where all the various agents of the world and cosmos are made accessible. Monks then have the opportunity in the assembly hall to discover and fashion their personal relationship with these deities, in the form of engagement or disengagement with visualizations and offerings and other rites targeting particular deities. Even when they are not able to engage at such levels, as with younger monks, there is a persistent repetition of names of higher deities throughout the liturgy, some of which are heard only in

${ }^{467}$ Humphrey and Laidlaw, 1994, p. 161. 
ritual contexts, such that these names become associated with very specific (ritual) aesthetics, tonalities, behaviors, times of year, and so forth. In other words, dominant and obscure cosmic figures alike are externalized in ritual, especially in outer tantra, well beyond their typical artistic representation, in a way that allows monks not only to observe them, but, in the case of more adept monks, to feel what it is like to be them. In the case of the Nyelam Dé Zhi and other subjugatory rituals, then, these relationships with the higher deities are designed to engage and orient monks upwards in their ideological world, cultivating a sense that they are closer now to the transcendent than they are to the worldly, and that the latter is to be actively and repeatedly rejected and dispelled. The ritual performance proves or encourages or, in most cases, since older and more adept monks need not attend the ritual performance, provides the training grounds for this mastery over worldly concerns, both literally and figuratively. Outer tantra is the natural choice for this project, as it is the most worldly in its orientation, the most externalized, most explicit, and most relatable and accessible of the three tantric traditions, all important dynamics for younger and less experienced monks needing to cross the boundaries between lay and monastic, worldly and transcendent.

\section{Globalization and the World Stage}

While there are many reasons for monks' preoccupations with the procurement of a geshé degree, one of them is a sense of competition with Buddhists on the world stage. There has always been a need for patronage, but the acutely felt anti-Bön 
polemics from Buddhists throughout history ${ }^{468}$ take on a new urgency in exile and in modern times, and around the world, where the Buddhists arrived much earlier than the Bönpos. Much of the vitriol directed towards Karmay in the confrontation at Menri, for example, stemmed from a persistent sense of inferiority and of the need for redemption. More than one monk expressed deep sadness that Bönpos have been under attack from the outside for so long, and now they were under attack by one of their own, an ex-geshé, who was telling the whole world that their religion was based on lies. When it was just Buddhists, people could say there was some kind of agenda, but why would they not believe a Bönpo who said these things? ${ }^{469}$

For these Bönpos, then, with purported origins as the pre-Buddhist folk religion of Tibet, there is a profound ambivalence stemming from the mounting tension within Bön, vis-à-vis the larger Tibetan cultural and world context, between scholastic sophistication and traditional stewardship. The tensions between Buddhists and Bönpos - as exemplified by attitudes and activities at Triten Norbutsé and Menri - are magnified on the world stage, with Bönpos engaged in a project of combatting polemics that paint them as shamans or practitioners of black magic, ${ }^{470}$ and proving that they are as philosophically rich and high-minded and disciplined as a tradition as anyone, while simultaneously asserting their primacy among Tibetan

\footnotetext{
468 There are many sources for anti-Bön polemics, a couple of which are Martin 1997 and van Schaik 2013, but also countless examples on the ground of how these polemics are felt, in conversation with monks at Menri and Triten Norbutsé.

469 Interview with Geshé Q at Menri monastery on 4/25/2009.

470 There are many sources for this, including Martin 1997 and van Schaik 2013, but also from countless conversations on the ground at these monasteries, where monks strenuously express this being the case.
} 
traditions via an explicit ownership and stewardship of the very ritual traditions that invite such polemical derogation in the first place.

This is further complicated by the fact that many members of the world cultures that have engaged with Bön in recent years - especially Russians and eastern Europeans - find their way to Bön because of its purported ancient origins and its purported expertise with and negotiation of ancient, chthonic forces. Given that these foreign adherents tend to be relatively wealthy and otherwise committed to helping Bön however they can, it behooves Bönpos to meet these new adherents in their overlapping domains of interest and expertise, which, again, are the domains that have been thoroughly polemicized. ${ }^{471}$

With all of this in mind, it is not surprising that the Triten Norbutsé administrators - primarily Tenzin Namdak and Tenzin Tsultrim, in this case - would see the importance and value of preserving a ritual like the Nyelam Dé Zhi, but that the performance itself would be lackluster, reflecting not only an irrelevance to academic monks' daily prioritized activities, but also an active distancing from polemical lightning rods, towards the more strongly felt imperative of scholastic sophistication.

This is further complicated still, however, by the fact that the pressures and allure of the larger world have also changed the character of monastic populations, their personalities and careers. To an extent, this is the result of different sensibilities between different generations, with Sangyé Tenzin and Tenzin Namdak often speaking wistfully about how monks and others used to be more economical -

${ }^{471}$ This is obvious on the ground, but is also discussed in terms of Bönpo apologetics in Zeff Bjerken's illuminating article "Exorcising the Illusion of Bön 'Shamanism”' (2004). 
taking the bus and train instead of private cars ${ }^{472}$ - and more patient - for example, nobody does the 100 circumambulations around holy mountains before preliminary practices anymore, and many of them do not even do the preliminaries, "some not even wanting to prostrate!"473 While the geshé degree program for Bönpos has increased in duration in recent years from nine years to thirteen years (at Triten Norbutsé) or fifteen years (Menri) ${ }^{474}$ in order to improve educational parity with Buddhist geshés, overall the requirements for these programs are shrinking. The reason for these reductions in requirements, and in patience, is that there is a competing drive to get out into the world and travel and teach and learn other things. ${ }^{475}$ Again, some of this can be attributed to a natural evolution of sensibilities and other pressures of the modern world, but there can be no doubt that dislocation and relocation to a thriving hub (in the case of Triten Norbutsé), with all the access and resources it affords, not to mention the dramatically increased influx of international visitors and money, has changed the character of monk sensibilities and careers. ${ }^{476}$

\footnotetext{
472 I witnessed plenty of monks taking trains and buses - most of them, in fact. I believe Sangyé Tenzin, in this case, meant to say that a few monks generally hire cars instead of taking trains or buses, and that even when they can afford to do this they should choose the more economical, humbler option. He was surprised and delighted when I told him that I always bussed and trained through India. "You would be a very good monk," he said. (Interview with Sangyé Tenzin at Menri monastery on $12 / 15 / 2008$.)

${ }^{473}$ Interview with Sangyé Tenzin at Menri monastery on 5/21/2009.

474 These were the numbers given to me from Sangyé Tenzin on 5/21/2009, but he emphasized that the duration of the program is always under consideration to ensure the optimal education for monks, and thus the number of years may have changed since, or soon will.

475 Sangyé Tenzin and Tenzin Namdak both expressed this dynamic, but they had somewhat different personal reactions to it. Tenzin Namdak was especially concerned about it, very hesitant to let monks learn English, for example, because he knew that this would eventually take them away from the monastery and their responsibilities there. Sangyé Tenzin laments the passing of more "traditional" values, but otherwise seems to condone worldliness to a larger extent.

476 An additional example of this was the Menri monk Tenzin Nyima, who for a while was the principle videographer for all monastic activities, using a very expensive camera that was provided by a donation for the Zhang Bod Documentation initiative of the Bön Foundation. He was decidedly
} 


\title{
Conclusion
}

\begin{abstract}
The present episode of globalization, with its relentless dialectic of homogenization and heterogenization, heightens paradox and complexity and forces us to pay close attention to how institutions generate change, even when they do not expressly intend it. 477
\end{abstract}

Taken together, the above perspectives reveal the immense complexity of what is at stake in the decision to perform a ritual, how the performance is undertaken, how it relates to other activities and imperatives inside and outside the monastery, and why it is maintained year after year, even in shifting conditions that persistently threaten one sense of the ritual's relevance, only to replace it with another. What can appear as contradictions in the Nyelam Dé Zhi - drawing boundaries while crossing them in an attempt to maintain an ethic of harmony and wholeness, subjugating beings and apologizing for doing so at the same time, moving away from the laity and lay concerns while apologizing for doing so at the same time, seeking redemption in the curation of a tradition that the community has deprioritized, and so on, points to the incredible diversity of performers - monks of all ages, backgrounds, sensibilities, and ambitions - and of competing tensions that these Bönpos in exile are negotiating. They are simultaneously attempting to situate themselves comfortably in a new place, merging old home and new home in the ritual crucible; to correct Buddhist polemics in order to prove their scholastic

unenthusiastic about being a monk, in part, he said, because he has seen so many Hollywood movies and met so many international film crews at Menri that he thought he could parlay his photography skills into some kind of film job in the US. We became Facebook friends and in the years since I have seen that he in fact left Menri to live as a layman in first Delhi and then Dharan, Nepal, though it is not clear what he is doing with his time.

477 Vasquez, 2003, p. 196. 
sophistication and viability as an independent world tradition; to equip themselves with the knowledge and the means to go out and succeed in the larger world while preserving and re-creating as many elements of their tradition and their homeland in exile as possible; and to preserve their primacy among Tibetan traditions via the ongoing cultivation of otherwise decontextualized rituals like the Nyelam Dé Zhi and similar activities with pre-modern aesthetics, which also provide opportunities for engagement with new sources of patronage around the world. 


\section{Conclusion}

This study has referred many times now to Caroline Humphrey and James Laidlaw's The Archetypal Actions of Ritual (1994), in which can be found a theory of ritual centered on the idea that the operative mechanism behind ritual behavior is a "ritual commitment," which is an attitude characterized by the irrelevance of the actor's intentions or thoughts, with all focus directed towards performing stipulated, elemental ritual acts. These acts originally had clear and dominant meanings and functions, but they were "practices" at that time. Ritualization is the process of objectifying such practices and ascribing different and new meanings to them, such that a custom or practice does not become ritual until people disagree about the meaning. The space created between and through these different meanings and the irrelevance of actors' thoughts and intentions is vast and fertile. It is in this space that ritual actors can plant and cultivate the seeds of cultural creation and re-creation, even when cultural contexts and needs are in flux and sometimes at odds with former contexts and needs.

Though the emphasis of Humphrey and Laidlaw's theory on getting things right is somewhat misleading - the barrier to qualifying for "right" is very low - the crux of the idea helps us to see that the Nyelam Dé Zhi as performed at Triten Norbutsé is in transition from practice to ritual. It is a kind of prequel to the rituals they describe, illustrating the ways that practice begins to lose its relevance and immediacy, inviting new interpretations and justifications to fill the void. This shift is evident in many aspects of the Nyelam Dé Zhi ritual and performance and 
surrounding context, but perhaps none as plainly as the disuse of "practical" volumes in the collection. Though Tenzin Tsultrim and others have never used these practical manuals, and have never seen them used, they allow for the possibility that they could still become useful one day, in which case it will be a great blessing to have them at hand in the collection. But if such a need ever does come to pass, it will be a different performance from the one done at the beginning of summer every year. In Humphrey and Laidlaw terms, it will be a practice again, and not a ritual, because no one will disagree about its meaning or purpose, and all involved performers, patrons, and observers - will be looking for very specific outcomes. This possibility, remote though it may be, points to an important dimension not discussed elsewhere, or not discussed enough, and that is that context is paramount. Beyond the diversity of volumes and ethics and ideologies on display in the Nyelam Dé Zhi volumes, and the inconsistencies present in and around the collection and its performance, it is the exiled monastic setting of the ritual, and especially its periodicity, that render it inert as a practice. The decision to include it in the annual calendar was partly a practical one in the earliest days and years of the monastery's founding, but the decision to keep doing it indefinitely, "our summer ritual from the 12 th to the 16 th of the 4 th month," dramatically changed its character and utility. There was no longer any understood reason to do it, aside from the purported occasion of lu thawing from river beds, which was not understood by all and lacked relevance in this new temperate climate anyway, and aside from the notion that the monastic calendar and lifestyle is driven by periodic, recurring events, such that the Nyelam Dé Zhi is "just something we do every year." 
The very question of "Why are you doing this?" was perplexing to many monks, and it is easy to understand why. Observing this culture and these performances from the outside, one is incessantly trying to make sense of what is happening, what is motivating behavior, where it is all going, and so on. If someone were to do the same for us, with our traditions - "Why do you celebrate Halloween given that you are not a farmer and otherwise have nothing to do with harvest?" we would find it difficult to give an answer besides "It's just something we do every year."

Yet, we know there is a rich history behind our own traditions. We know they are peopled with legendary figures real and imagined, and with events and practices that are irrelevant to or outmoded in our modern lives. We know there are tremendous shifting and evolving narratives, as well as pervasive inconsistency across the sources of our traditions and our own thoughts and actions around them. But we do not experience contradictions, or we at least do not experience them as problematic. Every now and then a curtain is pulled away - "What does the Easter Bunny have to do with the resurrection of Jesus?" - and we laugh at ourselves and our traditions and humanity, and then we move on, dropping another hard-boiled egg in a bowl of purple dye.

Inconsistency is a word that is too often used to denigrate. The truth is that inconsistency is everywhere, in all of our traditions and behaviors, and without it cherished human phenomena like culture and innovation would perish. To the degree that institutionalization tries to limit it, it also creates conditions for much 
larger contradictions and inconsistencies, as the chaos of the world repeatedly collides with attempts at its transcendence.

For the monastic community at Triten Norbutsé, then, this rich, productive space that some may refer to as inconsistency but which is also a prerequisite for the production and reproduction of culture, is everywhere, including within and among its most conspicuously institutionalized elements. The canon is "a mess." The texts comprising the Nyelam Dé Zhi, its instructions and verses, are incomplete or contradictory or incomprehensible. The mandala and thread crosses constructed for the performance are not consistent with instructions or with other standards of quality. Many of the deities addressed by the ritual are unknown or inconsistent in their identity, shifting characteristics and orientations and designations from ritual to ritual and context to context. Performers are sometimes reciting, sometimes asleep or goofing around, and sometimes absent. The monks themselves are from a great many different places, with different backgrounds and relationships, speaking different languages, having arrived somewhat recently in a new environment. In exile, many people, geshés and lamas and foreigners and others, are coming and going at all times. Even the ideologies and priorities of the community - scholastic sophistication, traditional stewardship, procurement of patronage, combating polemics - can be contradictory, and are always in tension.

In this environment, like many environments, there is a cascade of inconsistency, for which the incorrect mandala is maybe the best metaphor, with each level of inconsistency begetting another level of inconsistency, and creating a culture of acceptance in the process. Even the Manuscript, the most institutional and 
well-organized of all the components of the complex web of the Nyelam Dé Zhi, endorses doing a great many things "only if you want to or can." Some may look upon this as a liability, but for these Bönpos working in shifting contexts it gives them tremendous flexibility, to change priorities - for example, to adjust the academic program - to re-use and re-interpret texts and rituals and traditions to keep up with a rapidly changing world, and to find their place in it.

As life moves on and they move out further into the world, and new generations of monks arrive at the monastery who have never been to Tibet, rituals like the Nyelam Dé Zhi, if nothing else, and there is a great deal else, as I hope to have shown, keep them anchored to the home from which they have been exiled. In the words of Ronald Grimes: 478

These ceremonial occasions inscribe images into the memories of participants, and they etch values into the cornerstones of social institutions. Effective rites depend on inheriting, discovering, or inventing value-laden images that are driven deeply, by repeated practice and performance, into the marrow.

478 Grimes, 2000, p. 5. 


\section{Appendices}

\section{Appendix 1: Annotated List of Volumes in the Nyelam Dé Zhi Collection}

Note that volumes are reproduced here as they appear in the collection, even when they include unusual, possibly wrong, spellings. Major differences are addressed in the annotation. I've also chosen to include "The Nyelam Dé Zhi's..." or "From the Nyelam Dé Zhi..." when present because it is revealing of which volumes may or may not have been produced or titled or transcribed together, or other issues of diverse authorship. Finally, I've included "[Khyunggötsel]" as the revealer and "[c. 13th century]" as the time period for any volumes that do not specifically attribute the revelation to him but which are assumed to have been revealed by him.

\begin{tabular}{|c|c|}
\hline Index & 1 \\
\hline Pages & $1-36$ \\
\hline Title & nye lam sde bzhi'i zin thu gsal byed 'phrul gyi me long \\
\hline Translation & The Mirror that Clarifies the Manuscript of the Nyelam Dé Zhi \\
\hline Author & Drutsün Drungmu Werzhi ('gru btsun drung mu wer zhi) \\
\hline Year & c. $1889-1890$ \\
\hline Colophon & $\begin{array}{l}\text { 'jigs rten bde byed rgyu yi bon mchog nye lam sde bzhi'i bca' gzhi dang / 'don 'grig gi } \\
\text { zin thu mdo tsam 'di ni/ sdong rig sngags 'chang sad wer gyis bskur phyir/ thos bsam } \\
\text { kyi shes rab chung zhing bsgom bsgrub kyi don la le lo dang btang snyoms su gyur pa'i } \\
\text { 'gru btsun drung mu wer zhi'i sa glang hor zla lnga pa'i gral tshes bco brgyad 'du gnas } \\
\text { brag dkar lha lung gis mdun zhol g.yung drung bde chen gling du g.yung drung rnams } \\
\text { 'joms bsgrubs pa'i thun mtshams su bris pa/ yig cha gang la'ang myong rtogs med pa'i } \\
\text { rkyon gyi tshad gsum gyi bsgrub byas dben pa'i nyes 'gal du gyur srid smra dbang } \\
\text { mkhas grub tshogs la bshags shing / dge bas 'gro kun sgrib gnyis rnam par byang zhing } \\
\text { tshogs gnyis yongs su rdzogs pa'i rgyu ru gyur cig// }\end{array}$ \\
\hline $\begin{array}{l}\text { Colophon } \\
\text { Translation }\end{array}$ & $\begin{array}{l}\text { As for this brief Manuscript of ritual preparations and appropriate recitations of the } \\
\text { Nyelam Dé Zhi [of] the supreme Bön that is the producing cause of bliss in the world, } \\
\text { it was ordered by Dongrik Ngakchang Sewer [and] was written the eighteenth day of } \\
\text { the fifth month of the earth ox [year] by [me], Drutsün Drungmu Werzhi, who am of } \\
\text { small learning and wisdom, and lazy and indifferent with regards to meditation, at } \\
\text { Dechenling, at the base and in front of the religious center Drakar Lhalung, during the } \\
\text { practice breaks of the Yungdrungnam Jom. I confess to the group of skilled ones the } \\
\text { possibility that, in any of the texts, there were faults that do not meet the proof of the } \\
\text { three [kinds of] valid cognition, resulting from [my] not having experience and } \\
\text { understanding. By [its] virtue, may the two pollutions of all beings be purified, and } \\
\text { may it turn into the cause of the complete exhaustion of the two accumulations. }\end{array}$ \\
\hline Summary & $\begin{array}{l}\text { Instructions for ritual preparations and otherwise making use of the rest of the } \\
\text { volumes and supplementary texts to craft a performance of the Nyelam Dé Zhi. }\end{array}$ \\
\hline
\end{tabular}




\begin{tabular}{|l|l|}
\hline $\begin{array}{l}\text { Used in } \\
\text { Performance }\end{array}$ & No, but critical to planning the ritual performance. \\
\hline
\end{tabular}

\begin{tabular}{|l|l|}
\hline Index & 2 \\
\hline Pages & $37-49$ \\
\hline Title & nye lam sde bzhi'i dug phyung \\
\hline Translation & The Drawing of Poison of the Nyelam Dé Zhi \\
\hline Revealer & [Khyunggötsel] \\
\hline Year & [c. 13th century] \\
\hline Summary & $\begin{array}{l}\text { Verses for the standard preliminary rite of using "poisonous" smoke and ash to drive } \\
\text { away wicked spirits and otherwise purify the environment. }\end{array}$ \\
\hline $\begin{array}{l}\text { Used in } \\
\text { Performance }\end{array}$ & Yes \\
\hline
\end{tabular}

\begin{tabular}{|l|l|}
\hline Index & 3 \\
\hline Pages & $51-88$ \\
\hline Title & nye lam sde zhi'i bsang mchod \\
\hline Translation & The Incense Offering of the Nyelam Dé Zhi \\
\hline Revealer & {$[$ Khyunggötsel] } \\
\hline Year & [c. 13th century] \\
\hline Summary & $\begin{array}{l}\text { Verses for a typical incense offering rite, specified by the Manuscript to be done } \\
\text { every day, but done by the monks at Triten Norbutsé just once on the last day of the } \\
\text { ritual. }\end{array}$ \\
\hline $\begin{array}{l}\text { Used in } \\
\text { Performance }\end{array}$ & \begin{tabular}{l} 
Yes \\
\hline
\end{tabular}
\end{tabular}

\begin{tabular}{|l|l|}
\hline Index & 4 \\
\hline Pages & $89-94$ \\
\hline Title & nye lam gyi rgyud la byur phud kyi gzhung \\
\hline Translation & The Scriptures that Drive Away Misfortune in the tradition of the Nyelam \\
\hline Revealer & {$[$ Khyunggötsel] } \\
\hline Year & [c. 13th century] \\
\hline Summary & $\begin{array}{l}\text { A preliminary rite, done on the first day only, for preparing the ritual environment, } \\
\text { drawing wicked beings and forces into a specially molded torma on a plate and then } \\
\text { casting it away. }\end{array}$ \\
\hline
\end{tabular}




\begin{tabular}{|l|l|}
\hline $\begin{array}{l}\text { Used in } \\
\text { Performance }\end{array}$ & Yes \\
\hline
\end{tabular}

\begin{tabular}{|c|c|}
\hline Index & 5 \\
\hline Pages & $95-98$ \\
\hline Title & bum pa skyed pa \\
\hline Translation & Generation of the Vase \\
\hline Revealer & [Khyunggötsel] \\
\hline Year & [c. 13 th century] \\
\hline Summary & $\begin{array}{l}\text { A common, short, visualized vase offering rite, done once on the first day of the ritual, } \\
\text { two or three times all the rest of the days, depending on time. }\end{array}$ \\
\hline $\begin{array}{l}\text { Used in } \\
\text { Performance }\end{array}$ & Yes \\
\hline
\end{tabular}

\begin{tabular}{|l|l|}
\hline Index & 6 \\
\hline Pages & $99-176$ \\
\hline Title & nye lam sde bzhi'i stod chog \\
\hline Translation & The Main Ritual of the Nyelam Dé Zhi \\
\hline Revealer & [Khyunggötsel] \\
\hline Year & [c. 13th century] \\
\hline Summary & $\begin{array}{l}\text { This is arguably the most important volume of the collection, containing narratives } \\
\text { about the origins of the four types of worldly deities and their subjugation, followed } \\
\text { by the ritual preparations and preliminary rites and recitation that are particular to } \\
\text { the Nyelam Dé Zhi, as opposed to a number of the other volumes and all of the } \\
\text { supplemental texts, which could be used across rituals. Its verses are recited in their } \\
\text { entirety each day of the ritual performance. }\end{array}$ \\
\hline $\begin{array}{l}\text { Used in } \\
\text { Performance }\end{array}$ & \begin{tabular}{l} 
Yes \\
\hline
\end{tabular}
\end{tabular}

\begin{tabular}{|l|l|}
\hline Index & 7 \\
\hline Pages & $177-214$ \\
\hline Title & nye lam sde bzhi'i klu bcos bgrubs \\
\hline Translation & The Nyelam Dé Zhi's Lu Treatment Practice \\
\hline Revealer & [Khyunggötsel] \\
\hline Year & [c. 13th century] \\
\hline Summary & Alongside the Upper Ritual, these Treatment volumes are the most important in the \\
\hline
\end{tabular}




\begin{tabular}{|l|l|}
\hline & $\begin{array}{l}\text { collection, comprising the main body of the daily liturgy. Each one addresses the } \\
\text { titular group of deities, calling various prominent members by name, and engaging } \\
\text { them via a standardized group of ten subrites: invocation (spyan drangs), requests to } \\
\text { reside (bzhugs su gsol), bringing them under control (dbang du bsdud), generating } \\
\text { delight (dgyes pa bskyed), prostrations (phyags 'tshal), confession (sdig ba bshags), } \\
\text { offerings (mchod pa 'bul), drawing out the essence (mantras, snying po drangs), } \\
\text { offerings of praise (sku bstod mchod pa 'bul), and enjoining enlightened activity } \\
(\text { phrin las bcol). }\end{array}$ \\
$\begin{array}{l}\text { The verb bcos pa can have a number of meanings, most relevantly to "overcome" or } \\
\text { "treat," such that these titles could be glossed as "curing afflictions related to lu." }\end{array}$ \\
\hline $\begin{array}{l}\text { Used in } \\
\text { Performance }\end{array}$ & Yes \\
\hline
\end{tabular}

\begin{tabular}{|l|l|}
\hline Index & 8 \\
\hline Pages & $215-252$ \\
\hline Title & nye lam sde bzhi'i gnyan bcos \\
\hline Translation & The Nyelam Dé Zhi's Nyen Treatment \\
\hline Revealer & [Khyunggötsel] \\
\hline Year & [c. 13th century] \\
\hline Summary & See description for volume 7 above. \\
\hline $\begin{array}{l}\text { Used in } \\
\text { Performance }\end{array}$ & Yes \\
\hline
\end{tabular}

\begin{tabular}{|l|l|}
\hline Index & 9 \\
\hline Pages & $253-292$ \\
\hline Title & nye lam sde bzhi'i gtod bcos \\
\hline Translation & The Nyelam Dé Zhi's Tö Treatment \\
\hline Revealer & [Khyunggötsel] \\
\hline Year & [c. 13th century] \\
\hline Summary & See description for volume 7 above. \\
\hline $\begin{array}{l}\text { Used in } \\
\text { Performance }\end{array}$ & Yes \\
\hline
\end{tabular}

\begin{tabular}{|l|l|}
\hline Index & 10 \\
\hline Pages & $293-330$ \\
\hline Title & nye lam sde bzhi'i sa bdag bcos \\
\hline
\end{tabular}




\begin{tabular}{|l|l|}
\hline Translation & The Nyelam Dé Zhi's Sadak Treatment \\
\hline Revealer & {$[$ Khyunggötsel] } \\
\hline Year & {$[$ c. 13th century] } \\
\hline Summary & See description for volume 7 above. \\
\hline $\begin{array}{l}\text { Used in } \\
\text { Performance }\end{array}$ & Yes \\
\hline
\end{tabular}

\begin{tabular}{|l|l|}
\hline Index & 11 \\
\hline Pages & $331-354$ \\
\hline Title & nye lam sde bzhi'i bcos mdo la klu gnyan sa bdag cha lag \\
\hline Translation & The Lu, Nyen, Sadak Supplement for the Treatment Scriptures of the Nyelam Dé Zhi \\
\hline Revealer & [Khyunggötsel] \\
\hline Year & [c. 13th century] \\
\hline Summary & $\begin{array}{l}\text { This contains four sections of nad sel rites - cures for illness - related to the four } \\
\text { kinds of worldly deities. It is a remedial text, to be done only when sickness related to } \\
\text { these deities has been identified and needs to be treated. As such, it is never done as } \\
\text { part of the annual Nyelam Dé Zhi ritual. }\end{array}$ \\
\hline $\begin{array}{l}\text { Used in } \\
\text { Performance }\end{array}$ & No \\
\hline
\end{tabular}

\begin{tabular}{|l|l|}
\hline Index & 12 \\
\hline Pages & $355-362$ \\
\hline Title & snying po sngags kyi yig chung \\
\hline Translation & A Short Section of Essence Mantras \\
\hline Revealer & [Khyunggötsel] \\
\hline Year & [c. 13th century] \\
\hline Summary & $\begin{array}{l}\text { This is a series of mantras for a variety of purposes - reconciliation with the various } \\
\text { deities, addressing the garudas, and so on. It is read aloud once on the first day and } \\
\text { twice on all following days of the ritual performance. }\end{array}$ \\
\hline $\begin{array}{l}\text { Used in } \\
\text { Performance }\end{array}$ & Yes \\
\hline
\end{tabular}

\begin{tabular}{|l|l|}
\hline Index & 13 \\
\hline Pages & $363-382$ \\
\hline Title & nye lam sde bzhi'i g.yang 'bod lo bsdom 'dod yon shel tshig bsngo ba bcas \\
\hline
\end{tabular}




\begin{tabular}{|l|l|}
\hline Translation & $\begin{array}{l}\text { The Nyelam Dé Zhi's Calling Fortune, together with Binding [Deities of the] Years } \\
{[\text { and] the Dedication of Scorched Grain and Sensory Pleasures }}\end{array}$ \\
\hline Revealer & {$[$ Khyunggötsel] } \\
\hline Year & [c. 13th century] \\
\hline Summary & $\begin{array}{l}\text { This is a text of rites for improving worldly conditions, calling for phywa and g.yang, } \\
\text { both of which roughly translate to fortune or prosperity, and for other agricultural } \\
\text { and livelihood benefits. There is a clear nomadic (or sa ma 'brog) legacy in the } \\
\text { content and style, and many of the monks admit to a particular lack of } \\
\text { comprehension around this challenging volume. Nevertheless, it is recited twice } \\
\text { every day of the performance. }\end{array}$ \\
\hline $\begin{array}{l}\text { Used in } \\
\text { Performance }\end{array}$ & Yes \\
\hline
\end{tabular}

\begin{tabular}{|l|l|}
\hline Index & 14 \\
\hline Pages & $383-388$ \\
\hline Title & srid kyi chu mig g.yang blan \\
\hline Translation & Beckoning Fortune [from] the Fount of Existence \\
\hline Revealer & {$[$ Khyunggötsel] } \\
\hline Year & {$[$ [. 13th century] } \\
\hline Summary & $\begin{array}{l}\text { A small volume of recitations for beckoning a variety of kinds of fortune - merit, } \\
\text { wealth, and so on - explained by the Manuscript as appropriate for village versions of } \\
\text { the Nyelam Dé Zhi, but not for the monastery. }\end{array}$ \\
\hline $\begin{array}{l}\text { Used in } \\
\text { Performance }\end{array}$ & No \\
\hline
\end{tabular}

\begin{tabular}{|l|l|}
\hline Index & 15 \\
\hline Pages & $389-392$ \\
\hline Title & gnam gshed bcu gnyis \\
\hline Translation & The Twelve Namshé \\
\hline Revealer & {$[$ Khyunggötsel] } \\
\hline Year & [c. 13th century] \\
\hline Summary & $\begin{array}{l}\text { Recitations for banishing the demons of each of the animal years, used for remedial } \\
\text { purposes when astrological divination has determined that these deities are } \\
\text { responsible for local misfortune. It is a short but arcane text with unusual words and } \\
\text { names, some of which are clearly of Zhang Zhung origin. }\end{array}$ \\
\hline $\begin{array}{l}\text { Used in } \\
\text { Performance }\end{array}$ & No \\
\hline
\end{tabular}




\begin{tabular}{|l|l|}
\hline Index & 16 \\
\hline Pages & $393-416$ \\
\hline Title & klu gnyan sa bdag bzhi yi nad sel \\
\hline Translation & The Cure of the Four [Groups of Deities, Including the] Lu, Nyen, and Sadak \\
\hline Revealer & [Khyunggötsel] \\
\hline Year & [c. 13th century] \\
\hline Colophon & gnyen gyis (gyi) nad sel 'di gnyan bon thod de rgyal bas mdzad pa shi na tu legs s+ho// \\
\hline Colophon & $\begin{array}{l}\text { This medicine of the Nyen was composed by Nyen Bön Tödé Gyelwa. May it be } \\
\text { extremely elegant! }\end{array}$ \\
\hline Summary & $\begin{array}{l}\text { Though the title suggests the contents will address the four groups of deities, and } \\
\text { including the sadak, it in fact addresses only the lu and nyen, providing verses and } \\
\text { rites to invite and appease and send them away. The subrites consist of a subset of } \\
\text { the ten typical subrites included across many rites, including the Treatment volumes } \\
\text { above. } \\
\text { The colophon is just for the nyen part of the text, and identifies Nyen Bön Tödé } \\
\text { Gyelwa as the composer. Not much information about this figure is readily available, } \\
\text { but it seems likely he could be the same as Bagor Dödé Gyelwa (ba gor dod de rgyal } \\
\text { ba), in Karmay, 1972, pp. 42, 46, and possibly the same as Bagor Vairocana, aka } \\
\text { Vairocana, aka Bagor Hé Dö (ba gor he dod, Karmay, 2007, p. 34, though this is } \\
\text { technically the name of Bagor Vairocana's father). } \\
\text { It may or may not be done in village performances, but is not done at Triten } \\
\text { Norbutsé. }\end{array}$ \\
\hline $\begin{array}{l}\text { Used in } \\
\text { Performance }\end{array}$ & \begin{tabular}{l} 
No \\
\hline
\end{tabular} \\
\hline
\end{tabular}

\begin{tabular}{|l|l|}
\hline Index & 17 \\
\hline Pages & $417-428$ \\
\hline Title & gtod kyi nad sel \\
\hline Translation & The Cure of the Tö \\
\hline Revealer & [Khyunggötsel] \\
\hline Year & [c. 13th century] \\
\hline Summary & $\begin{array}{l}\text { Much like the previous volume but addressing tö deities, providing verses and rites } \\
\text { for inviting, propitiating, and sending them away. Though there is no proper } \\
\text { colophon, it does say, on 418.1, that it was composed by Tö Bön (gtod bon). This } \\
\text { could be Tö Bön Bati Sungnyen. It may or may not be performed in village } \\
\text { performances, depending mostly on whether tö have been identified as the source of } \\
\text { a given malady. }\end{array}$ \\
\hline $\begin{array}{l}\text { Used in } \\
\text { Performance }\end{array}$ & No \\
\hline
\end{tabular}




\begin{tabular}{|l|l|}
\hline Index & 18 \\
\hline Pages & $429-446$ \\
\hline Title & sa bdag nad sel \\
\hline Translation & The Sadak Cure \\
\hline Revealer & [Khyunggötsel] \\
\hline Year & [c. 13th century] \\
\hline Colophon & sa bdag nad sel sa bdag bon po gser thub rgyal ba la gsungs ba bzad legs s+ho// \\
\hline $\begin{array}{l}\text { Colophon } \\
\text { Translation }\end{array}$ & $\begin{array}{l}\text { The Sadak Treatment, a composition of teachings to the Sadak Bönpo Sertup Gyelwa. } \\
\text { May it be elegant! (Note that the title has an agentive particle where the colophon has } \\
\text { an allative la don, in the former case making it clear that he was the composer.) }\end{array}$ \\
\hline Summary & $\begin{array}{l}\text { Much like the previous volume but addressing sadak deities, providing verses and } \\
\text { rites for inviting, propitiating, and sending them away. In the colophon and on the } \\
\text { title page it says that it was composed by Sadak Chenpo Sertup Gyelwa (title)/Sadak } \\
\text { Bönpo Sertup Gyelwa (colophon). It may or may not be performed in village } \\
\text { performances, depending mostly on whether sadak have been identified as the } \\
\text { source of a given malady. }\end{array}$ \\
\hline $\begin{array}{l}\text { Used in } \\
\text { Performance }\end{array}$ & \begin{tabular}{l} 
No \\
\hline
\end{tabular}
\end{tabular}

\begin{tabular}{|l|l|}
\hline Index & 19 \\
\hline Pages & $447-456$ \\
\hline Title & shing ris nad sel \\
\hline Translation & The Tablet Drawing Cure \\
\hline Revealer & {$[$ Khyunggötsel] } \\
\hline Year & [c. 13th century] \\
\hline Colophon & shing ris nad sel 'di bder gshegs 'dus pa dang kong tses mdzad pa legs so// \\
\hline $\begin{array}{l}\text { Colophon } \\
\text { Translation }\end{array}$ & $\begin{array}{l}\text { This Wooden Tablet Cure was composed by the Ones Gone to Bliss [Sangwa] Düpa } \\
\text { and Kongtsé. May it be elegant! }\end{array}$ \\
\hline Summary & $\begin{array}{l}\text { This is a collection of verses and instructions for a rite that makes use of an adorned } \\
\text { wooden tablet as a seat for the sadak, lu, nyen, planets, and stars. These last two are } \\
\text { somewhat common inclusions in especially the unperformed volumes, but across the } \\
\text { collection, pointing to the astrological connections between these deities and rites. } \\
\text { Kongtsé is considered one of the most important, legendary astrologists, and appears } \\
\text { occasionally in various volumes. His connection with Sangwa Düpa here is a little } \\
\text { unusual, however, such that Tenzin Tsultrim suggested perhaps that Sangwa Düpa } \\
\text { was Kongtsé's tutelary deity. }\end{array}$ \\
\hline $\begin{array}{l}\text { Used in } \\
\text { Performance }\end{array}$ & \begin{tabular}{l} 
No \\
\hline
\end{tabular}
\end{tabular}

Index

20 


\begin{tabular}{|l|l|}
\hline Pages & $457-484$ \\
\hline Title & nye lam sde bzhi yi khrus dgu \\
\hline Translation & The Nine Ablutions of the Nyelam Dé Zhi \\
\hline Revealer & {$[$ Khyunggötsel] } \\
\hline Year & [c. 13th century] \\
\hline Summary & $\begin{array}{l}\text { A collection of ablution rites and verses to be performed in village versions of the } \\
\text { ritual. There are ablutions in the monastic performance, but they come directly from } \\
\text { the Upper Ritual. Of note in this volume is the abundance of visualization, especially } \\
\text { around the hairs of the body. }\end{array}$ \\
\hline $\begin{array}{l}\text { Used in } \\
\text { Performance }\end{array}$ & No \\
\hline
\end{tabular}

\begin{tabular}{|l|l|}
\hline Index & 21 \\
\hline Pages & $485-508$ \\
\hline Title & nye lam sde bzhi yi bshags pa'i yig chung \\
\hline Translation & The Nyelam Dé Zhi's Small Section of Confession \\
\hline Revealer & [Khyunggötsel] \\
\hline Year & [c. 13th century] \\
\hline Summary & $\begin{array}{l}\text { These verses and rites compound the confessional tone of the overall ritual that has } \\
\text { been otherwise established via verses of confession in the Upper Ritual. The } \\
\text { difference is that the confession in the Upper Ritual is directed towards the Ones } \\
\text { Gone to Bliss and other higher beings, while these are directed towards the lu and } \\
\text { worldly deities. These verses are recited once the first day of the ritual and twice } \\
\text { every other day. }\end{array}$ \\
\hline $\begin{array}{l}\text { Used in } \\
\text { Performance }\end{array}$ & Yes \\
\hline
\end{tabular}

\begin{tabular}{|l|l|}
\hline Index & 22 \\
\hline Pages & $509-550$ \\
\hline Title & nye lam sde bzhi'i mchod pa 'bul ba'i yig chung \\
\hline Translation & The Nyelam Dé Zhi's Small Section of Making Offerings \\
\hline Revealer & [Khyunggötsel] \\
\hline Year & [c. 13th century] \\
\hline Summary & $\begin{array}{l}\text { Similar to the last volume, this extra set of verses for the making of offerings } \\
\text { accompanies offering verses in the Upper Ritual, with these directed more towards } \\
\text { the worldly deities. Also like the last volume, it is recited once on the first day and } \\
\text { twice every other day. }\end{array}$ \\
\hline $\begin{array}{l}\text { Used in } \\
\text { Performance }\end{array}$ & Yes \\
\hline
\end{tabular}




\begin{tabular}{|l|l|}
\hline Index & 23 \\
\hline Pages & 551-564 \\
\hline Title & nye lam sde bzhi'i mdo las rnam Inga'i smon lam \\
\hline Translation & $\begin{array}{l}\text { The Aspiration Prayer of the Five-Fold Offering, from the Scriptures of the Nyelam Dé } \\
\text { Zhi }\end{array}$ \\
\hline Revealer & Khyunggötsel \\
\hline Year & c. 13th century \\
\hline Colophon & $\begin{array}{l}\text { dbyil ston khyung rgod rtsal gyis gshen rab zhal bzhugs dus kyi gter ti se gangs la dngos } \\
\text { grub brnyed//ma pang mtsho 'gram zhal yang bshus/ shog ser kha dras nyi shu la nye } \\
\text { lam sde bzhi'i bcos mdo/ zhal yang bshus so 'gro don rgya lag phyed par shog rim la } \\
\text { thogs med kyis zhal nas bshus so// }\end{array}$ \\
\hline $\begin{array}{l}\text { Colophon } \\
\text { Translation }\end{array}$ & $\begin{array}{l}\text { Yiltön Khyunggötsel found the accomplishment at Tisé that was a treasure during the } \\
\text { lifetime of Shenrap. It was copied at some point on the banks of Mapangtso. The } \\
\text { Abbreviated Treatment of the Nyelam Dé Zhi was copied at some point into twenty } \\
\text { yellow scroll copies. It was copied from the mouth of Tokmé in stages continually, for } \\
\text { the benefit of all beings.479 }\end{array}$ \\
\hline Summary & $\begin{array}{l}\text { These are verses and rites for five-fold offerings, for village performances only. Of } \\
\text { note is the rare rediscovery colophon that specifically attributes the revelation to } \\
\text { Khyunggötsel, and a couple of pages of narrative mythology on pages 561-563. }\end{array}$ \\
\hline $\begin{array}{l}\text { Used in } \\
\text { Performance }\end{array}$ & \begin{tabular}{l} 
No \\
\hline
\end{tabular}
\end{tabular}

\begin{tabular}{|c|c|}
\hline Index & 24 \\
\hline Pages & $565-602$ \\
\hline Title & nye lam sde bzhi'i klu 'bum \\
\hline Translation & $\begin{array}{l}\text { The Lubum of the Nyelam Dé Zhi (I have chosen not to translate 'bum for any of these } \\
\text { volumes since it is convention to refer to them untranslated, but it generally means } \\
\text { the "collected [teachings about] lu," with 'bum translating literally to 100,000.) }\end{array}$ \\
\hline Revealer & [Khyunggötsel] \\
\hline Year & [c. 13th century] \\
\hline Summary & $\begin{array}{l}\text { This and the following three bum volumes are purportedly condensed versions of the } \\
\text { larger canonical bum texts of the same names, which exist in many editions across } \\
\text { collections. They include stories about the lu and other worldly deities, naming a } \\
\text { great many illustrious kings and others to be called upon to assist in the proceedings, } \\
\text { and contain instructions for performing rituals that address them. Tenzin Tsultrim } \\
\text { explains that much of the main liturgy in the Upper Ritual and elsewhere is derived } \\
\text { from the 'bum texts, though the present volume is so disjointed, full of transcription } \\
\text { errors and/or lost sections and difficult language, that it is unlikely that this } \\
\text { particular volume provided much of use to the main liturgy. This is not the case with } \\
\text { the other worldly deity bum volumes, which are much clearer and more readable, } \\
\text { likely reflecting later authorship. Regardless, each of the volumes are "silently }\end{array}$ \\
\hline
\end{tabular}

${ }^{479}$ Note that this translation is incomplete. 


\begin{tabular}{|l|l|}
\hline & $\begin{array}{l}\text { recited" - read in the minds of - monks seated in the periphery of the assembly hall, } \\
\text { as many times as possible every day of the ritual, collectively amounting to many } \\
\text { thousands of times. }\end{array}$ \\
\hline $\begin{array}{l}\text { Used in } \\
\text { Performance }\end{array}$ & Yes \\
\hline
\end{tabular}

\begin{tabular}{|l|l|}
\hline Index & 25 \\
\hline Pages & $603-636$ \\
\hline Title & nye lam sde bzhi'i gnyan 'bum \\
\hline Translation & The Nyen Bum of the Nyelam Dé Zhi \\
\hline Revealer & [Khyunggötsel] \\
\hline Year & [c. 13th century] \\
\hline Summary & See the notes for volume 24 above. \\
\hline $\begin{array}{l}\text { Used in } \\
\text { Performance }\end{array}$ & Yes \\
\hline
\end{tabular}

\begin{tabular}{|l|l|}
\hline Index & 26 \\
\hline Pages & $637-676$ \\
\hline Title & gtod 'bum khra bo \\
\hline Translation & The Piebald Tö Bum \\
\hline Revealer & [Khyunggötsel] \\
\hline Year & [c. 13th century] \\
\hline Summary & $\begin{array}{l}\text { See the notes for volume 24 above. Of note here is the title, which is the only one of } \\
\text { the bum volumes to include a color designation, a typical taxonomic scheme } \\
\text { employed for the canonical versions of these bum texts. }\end{array}$ \\
\hline $\begin{array}{l}\text { Used in } \\
\text { Performance }\end{array}$ & Yes \\
\hline
\end{tabular}

\begin{tabular}{|l|l|}
\hline Index & 27 \\
\hline Pages & $677-736$ \\
\hline Title & nye lam sde bzhi'i sa bdag 'bum \\
\hline Translation & The Sadak Bum of the Nyelam Dé Zhi \\
\hline Revealer & [Khyunggötsel] \\
\hline Year & [c. 13th century] \\
\hline Summary & See the notes for volume 24 above. \\
\hline $\begin{array}{l}\text { Used in } \\
\text { Performance }\end{array}$ & Yes \\
\hline
\end{tabular}




\begin{tabular}{|c|c|}
\hline Index & 28 \\
\hline Pages & $737-784$ \\
\hline Title & $\begin{array}{l}\text { gangs rgyal ti tse'i gter ma nye lam sde bzhi'i bcos mdo'i cha lags sde bzhi'i mi dang } \\
\text { 'gras bsdum }\end{array}$ \\
\hline Translation & $\begin{array}{l}\text { The Reconciliation of Fighting Among People [Because] of the Four Types [of Worldly } \\
\text { Deities], a Supplementary Text of the Treatment Scriptures of the Nyelam Dé Zhi, a } \\
\text { Treasure Text of Gangyel Tisé. }\end{array}$ \\
\hline Revealer & [Khyunggötsel] \\
\hline Year & [c. 13th century] \\
\hline Summary & $\begin{array}{l}\text { These are verses and rites that address the four worldly deities and others in much } \\
\text { the same way as the Treatment and other volumes, but with the primary intent of } \\
\text { smoothing over any discord in the community that has been divined to be the result } \\
\text { of interference on the part of the worldly deities. It is a remedial volume that is only } \\
\text { performed in villages, and then only when such divinations have yielded such results. }\end{array}$ \\
\hline $\begin{array}{l}\text { Used in } \\
\text { Performance }\end{array}$ & No \\
\hline
\end{tabular}

\begin{tabular}{|l|l|}
\hline Index & 29 \\
\hline Pages & $785-800$ \\
\hline Title & nye lam sde bzhi'i klu gnyan sa bdag gtod bzhi'i dal bkyag \\
\hline Translation & The Nyelam Dé Zhi's Lifting the Maṇdala of the Four - Lu, Nyen, Sadak, and Tö \\
\hline Revealer & [Khyunggötsel] \\
\hline Year & [c. 13th century] \\
\hline Summary & $\begin{array}{l}\text { This is a rite done on the last day of the monastic performance to suppress afflictions } \\
\text { of the mind, and it involves fumigating the mandala in the direction of each of the } \\
\text { four kinds of deities in turn and reciting verses. }\end{array}$ \\
\hline $\begin{array}{l}\text { Used in } \\
\text { Performance }\end{array}$ & Yes \\
\hline
\end{tabular}

\begin{tabular}{|l|l|}
\hline Index & 30 \\
\hline Pages & $801-820$ \\
\hline Title & nye lam sde bzhi'i rgyud las nad mda' phyung ba \\
\hline Translation & From the Nyelam Dé Zhi Tantra, Drawing Out the Arrow [of] Illness. \\
\hline Revealer & [Khyunggötsel] \\
\hline Year & [c. 13th century] \\
\hline Summary & $\begin{array}{l}\text { These are verses and rites to cure one or more people of "thorn" disease caused } \\
\text { specifically by nyen, with the rite creating effigies (ngar mi) to draw out the spikes of } \\
\text { pain. It is not done as part of the monastic performance, and only remedially in the } \\
\text { village when people are afflicted with this condition. }\end{array}$ \\
\hline
\end{tabular}




\begin{tabular}{|l|l|}
\hline $\begin{array}{l}\text { Used in } \\
\text { Performance }\end{array}$ & No \\
\hline
\end{tabular}

\begin{tabular}{|c|c|}
\hline Index & 31 \\
\hline Pages & 821-832 \\
\hline Title & nye lam sde bzhi'i byad kha bzlog pa'i mar mnan \\
\hline Translation & The Nyelam Dé Zhi's Suppressive Rite that Reverses Curses \\
\hline Revealer & [Khyunggötsel] \\
\hline Year & [c. 13 th century] \\
\hline Summary & $\begin{array}{l}\text { Verses and rites that address a variety of curses from a variety of deities, making use } \\
\text { of a variety of ransoms }(g l u d) \text { and other implements. This is a remedial text, not for } \\
\text { use in the temple, and in the village only when such curses have been identified as } \\
\text { operative in some current affliction. }\end{array}$ \\
\hline $\begin{array}{l}\text { Used in } \\
\text { Performance }\end{array}$ & No \\
\hline
\end{tabular}

\begin{tabular}{|c|c|}
\hline Index & 32 \\
\hline Pages & $833-842$ \\
\hline Title & nye lam sde bzhi'i sri'u gso ba'i mar mnan bcas ga bstan pa'o \\
\hline Translation & The Nyelam Dé Zhi's Suppressive Rite that Heals Children \\
\hline Revealer & [Khyunggötsel] \\
\hline Year & [c. 13 th century] \\
\hline Summary & $\begin{array}{l}\text { Rites for healing children who have been sickened from the activity of nefarious } \\
\text { deities, and for relatives of children who have died from the same. It is a remedial } \\
\text { text, not done in the temple, and in the village only when the need has been } \\
\text { identified. }\end{array}$ \\
\hline $\begin{array}{l}\text { Used in } \\
\text { Performance }\end{array}$ & No \\
\hline
\end{tabular}

\begin{tabular}{|l|l|}
\hline Index & 33 \\
\hline Pages & $843-850$ \\
\hline Title & god bcod pa'i mar mnan \\
\hline Translation & The Suppressive Rite that Eliminates Misfortune \\
\hline Revealer & {$[$ Khyunggötsel] } \\
\hline Year & {$[$ c. 13 th century] } \\
\hline Summary & $\begin{array}{l}\text { A collection of verses with accompanying rites that address various misfortune- } \\
\text { causing beings, called gödré (god 'dre }), \text { gösi }(g o d \text { sri } \text {, and so on. It is a remedial text } \\
\text { for nomads and villagers experiencing threats to their livelihood, not performed in } \\
\text { the temple. }\end{array}$ \\
\hline
\end{tabular}




\begin{tabular}{|l|l|}
\hline $\begin{array}{l}\text { Used in } \\
\text { Performance }\end{array}$ & No \\
\hline
\end{tabular}

\begin{tabular}{|c|c|}
\hline Index & 34 \\
\hline Pages & $851-922$ \\
\hline Title & $\begin{array}{l}\text { nye lam sde bzhi'i smad chog sgo dbye dbang bskur smon dngos srub rdzogs rim } \\
\text { dbyings su bkyed pa bzhi brtan bkris bcas pa'o }\end{array}$ \\
\hline Translation & $\begin{array}{l}\text { The Nyelam De Zhi's Preparations for the Auspicious Teachings of Opening the Door, } \\
\text { Empowerment, Aspiration Prayers and Accomplishments, and the Completion Stage - } \\
\text { - Generating into the Expanse }\end{array}$ \\
\hline Revealer & [Khyunggötsel] \\
\hline Year & [c. 13 th century] \\
\hline Colophon & $\begin{array}{l}\text { dbyil bon khyung rgod kyi/gshen rab zhal bzhugs dus kyi gter/ti se gangs la dngos } \\
\text { drub brnyes/ma pang mtsho 'gram zhal kyang bshus/ shog ser kha dras nyi shu la/ nye } \\
\text { lam sde bzhi'i bcos mdo 'di yi zhal kyang bshus/'gro don rgya lag phyed par shog/ hri } \\
\text { pa la thogs med kyis zhus/thogs med phyag rgya bris/bdal gyi bdag gi zhal bshus te/ } \\
\text { 'bru bsdus cung zad dag bkrol nas dag par bris pa'o// }\end{array}$ \\
\hline $\begin{array}{l}\text { Colophon } \\
\text { Translation }\end{array}$ & $\begin{array}{l}\text { Yilbön Khyunggö found the accomplishment at Tisé Gang that was a treasure during } \\
\text { the lifetime of Shenrap. It was copied at some point on the banks of Mapangtso. This } \\
\text { Abbreviated Treatment of the Nyelam Dé Zhi was also copied at some point. It was } \\
\text { done by hand continually, for the benefit of [all] beings. Hripala Tokmé requested it. } \\
\text { Tokmé Chakgya wrote it. The lord of Del made a copy. It was subsumed into the Dru } \\
\text { [clan] and commented on a bit, and was then completely written. }{ }^{480}\end{array}$ \\
\hline Summary & $\begin{array}{l}\text { A kind of catch-all volume for a variety of rites to be done once on the last day at the } \\
\text { end of the ritual, including: opening the door (sgo dbye ba), empowerment (dbang } \\
\text { bskur } b a \text { ), aspiration prayers (smon lam btab pa), attaining achievements (dngos grub } \\
\text { nod pa), assigning vows (dam tshig chag pa) }{ }^{481} \text {, arranging into place (gnas su bskyod } \\
\text { pa), and beseeching an auspicious support (gzhi brten bkra shis gsol ba). }\end{array}$ \\
\hline $\begin{array}{l}\text { Used in } \\
\text { Performance }\end{array}$ & Yes \\
\hline
\end{tabular}

\begin{tabular}{|l|l|}
\hline Index & 35 \\
\hline Pages & $923-934$ \\
\hline Title & sbal pa'i nad sel \\
\hline Translation & The Frog Cure \\
\hline Revealer & [Khyunggötsel] \\
\hline Year & [c. 13th century] \\
\hline
\end{tabular}

${ }^{480}$ Note that this translation is incomplete, and also the resemblence between this text and 23, which suggests they were probably composed or colophoned at roughly the same time or place, though there are enough spelling differences that it would not have been the same scribe at the same time. ${ }^{481}$ Note that in the stod chog, this is referenced as dam tshig bgo ba, which has a clearer sense of bestowing or giving than chag $p a$, which communicates "breaking." 


\begin{tabular}{|l|l|}
\hline Colophon & ru sbal nad sel 'di/ kong tse 'phrul gyi rgyal pos mdzad pa legs so// \\
\hline $\begin{array}{l}\text { Colophon } \\
\text { Translation }\end{array}$ & This turtle cure was composed by Kongtsé, King of Illusion - may it be elegant! \\
\hline Summary & $\begin{array}{l}\text { Note that it says "frog" in the title and "turtle" in the colophon. In any event, these are } \\
\text { verses not for the curing of diseased amphibians but for protecting humans from the } \\
\text { diseases themselves. It is a remedial text for use in villages, not in the temple. }\end{array}$ \\
\hline $\begin{array}{l}\text { Used in } \\
\text { Performance }\end{array}$ & No \\
\hline
\end{tabular}

\begin{tabular}{|l|l|}
\hline Index & 36 \\
\hline Pages & $935-956$ \\
\hline Title & rgyal 'khor nad sel \\
\hline Translation & Cure [for] the King [and His] Retinue \\
\hline Revealer & {$[$ Khyunggötsel] } \\
\hline Year & [c. 13th century] \\
\hline Summary & $\begin{array}{l}\text { Verses and rites to heal a sick king and any of his followers when they are afflicted } \\
\text { with illness stemming from the activity of worldly deities. It is of course not } \\
\text { performed in the monastic version of this ritual, and given the rarity of kingdoms in } \\
\text { the modern world, perhaps not performed in any contemporary contexts. This disuse } \\
\text { is evident in the language and organization of the text, which is very unclear and } \\
\text { inconsistent. }\end{array}$ \\
\hline $\begin{array}{l}\text { Used in } \\
\text { Performance }\end{array}$ & No \\
\hline
\end{tabular}

\begin{tabular}{|l|l|}
\hline Index & 37 \\
\hline Pages & $957-970$ \\
\hline Title & ye shes khyung gi nad sel \\
\hline Translation & The Wisdom Garuda Cure \\
\hline Revealer & {$[$ Khyunggötsel] } \\
\hline Year & [c. 13th century] \\
\hline Colophon & $\begin{array}{l}\text { khyung chen nad sel 'di gshen rab khyung du sprul nas sa bdag klu gnyan la sogs sde } \\
\text { brgyad gong gnon gyi tshul du mdzad pa rdzogs so// }\end{array}$ \\
\hline $\begin{array}{l}\text { Colophon } \\
\text { Translation }\end{array}$ & $\begin{array}{l}\text { This Great Garuda Cure was composed by Shenrap, having emanated as a garuda, as a } \\
\text { way of suppressing [from] above482 the eight types [deities] such as the sadak, lu, and } \\
\text { nyen. }\end{array}$ \\
\hline Summary & Verses and rites for the invocation of the five garudas to assist in the curing of illness \\
\hline
\end{tabular}

482 Note that gong gnon can be found in a number of text titles, many of them involving garudas and/or the sde brgyad. Dan Martin also cites a definition for gong non from Tenzin Namdak (bzo rig 78): gong non zhes pa dbyibs gru bzhi mtha' rgyan dang dkyil du dga' 'khyil gyi ri mo sogs yod pa che rab cig zur ltebs byas te gos kyi phyi yi thog nas bgos te bsdams pa zhig yod pa la 'dod do snyam. 


\begin{tabular}{|l|l|}
\hline & in the village. As a remedial text it is not done in the temple. \\
\hline $\begin{array}{l}\text { Used in } \\
\text { Performance }\end{array}$ & No \\
\hline
\end{tabular}

\begin{tabular}{|l|l|}
\hline Index & 38 \\
\hline Pages & $971-984$ \\
\hline Title & ba yi nad sel \\
\hline Translation & The Cattle Cure \\
\hline Revealer & {$[$ Khyunggötsel] } \\
\hline Year & [c. 13th century] \\
\hline Summary & $\begin{array}{l}\text { Remedial verses and rites to cure cows of illness caused by machinations of nefarious } \\
\text { entities, and to prevent them from jumping to people. Done only in the village. }\end{array}$ \\
\hline $\begin{array}{l}\text { Used in } \\
\text { Performance }\end{array}$ & No \\
\hline
\end{tabular}

\begin{tabular}{|l|l|}
\hline Index & 39 \\
\hline Pages & $985-1004$ \\
\hline Title & bya bkru bsrung gsum \\
\hline Translation & Activity, Ablution, and Protection \\
\hline Revealer & [Khyunggötsel] \\
\hline Year & [c. 13th century] \\
\hline Summary & A remedial volume recited only in the village, mostly for treatment of leprosy. ${ }^{483}$ \\
\hline $\begin{array}{l}\text { Used in } \\
\text { Performance }\end{array}$ & No \\
\hline
\end{tabular}

\begin{tabular}{|l|l|}
\hline Index & 40 \\
\hline Pages & $1005-1016$ \\
\hline Title & bkra shis shog chung \\
\hline Translation & A Small Paper [on] Auspiciousness \\
\hline Revealer & {$[$ Khyunggötsel] } \\
\hline Year & [c. 13th century] \\
\hline Summary & $\begin{array}{l}\text { A short collection of verses and instructions, mostly focused on the showering of } \\
\text { grain, that comprise the auspicious rites common to the closing ceremonies of } \\
\text { virtually every ritual. This is the last rite on the last day of the performance. }\end{array}$ \\
\hline
\end{tabular}

483 Note that this explanation comes from Tenzin Tsultrim (interview at Triten Norbutsé on $5 / 30 / 2009$ ), and I have not translated it to corroborate. 


\begin{tabular}{|l|l|}
\hline $\begin{array}{l}\text { Used in } \\
\text { Performance }\end{array}$ & Yes \\
\hline
\end{tabular}

\begin{tabular}{|l|l|}
\hline Index & 41 \\
\hline Pages & $1017-1020$ \\
\hline Title & gshegs bskyod (aka klu rnams bskyod pa) \\
\hline Translation & Causing to Go (Causing the Lu to Go) \\
\hline Revealer & [Khyunggötsel] \\
\hline Year & [c. 13th century] \\
\hline Summary & $\begin{array}{l}\text { Done in the temple on the last day of the performance, just before the auspicious } \\
\text { rites, to send the deities away. }\end{array}$ \\
\hline $\begin{array}{l}\text { Used in } \\
\text { Performance }\end{array}$ & Yes \\
\hline
\end{tabular}

\begin{tabular}{|l|l|}
\hline Index & 42 \\
\hline Pages & $1021-1036$ \\
\hline Title & klu gnyan sa dag bzhi' dal bkyag \\
\hline Summary & This is a duplicate of volume 29. \\
\hline
\end{tabular}

\begin{tabular}{|c|c|}
\hline Index & 43 \\
\hline Pages & $1037-1042$ \\
\hline Title & brag srin bkar ba \\
\hline Translation & Banishing Rock Ogres \\
\hline Revealer & [Khyunggötsel] \\
\hline Year & [c. 13th century] \\
\hline Summary & $\begin{array}{l}\text { A remedial set of verses and rites done only in the village or wherever trouble is } \\
\text { being made by a rock ogre/demon, presumably in the form of landslides, falling } \\
\text { rocks, and so on. It is a challenging and incomplete text, with both mythic narrative } \\
\text { and recitational verse components. }\end{array}$ \\
\hline $\begin{array}{l}\text { Used in } \\
\text { Performance }\end{array}$ & No \\
\hline
\end{tabular}

\begin{tabular}{|l|l|}
\hline Index & 44 \\
\hline Pages & $1043-1052$ \\
\hline Title & bcos mdo (aka gshegs bskyod) \\
\hline Translation & The Abbreviated Treatment (aka Causing to Go) \\
\hline Revealer & [Khyunggötsel] \\
\hline
\end{tabular}




\begin{tabular}{|l|l|}
\hline Year & [c. 13th century] \\
\hline Summary & $\begin{array}{l}\text { Like the other gshegs bskyod volume above, this is done on the last day of the ritual to } \\
\text { send deities away. }\end{array}$ \\
\hline $\begin{array}{l}\text { Used in } \\
\text { Performance }\end{array}$ & Yes \\
\hline
\end{tabular}

\begin{tabular}{|l|l|}
\hline Index & 45 \\
\hline Pages & $1053-1056$ \\
\hline Title & nad 'dre bkar ba'i bca' thabs \\
\hline Translation & Preparatory Methods for Banishing Demons of Illness \\
\hline Revealer & [Khyunggötsel] \\
\hline Year & [c. 13th century] \\
\hline Summary & $\begin{array}{l}\text { A remedial set of verses to be done only in village settings when the need arises. No } \\
\text { one at the monastery has ever done or seen this and many other of the nad sel rites } \\
\text { done. }\end{array}$ \\
\hline $\begin{array}{l}\text { Used in } \\
\text { Performance }\end{array}$ & No \\
\hline
\end{tabular}

\begin{tabular}{|l|l|}
\hline Index & 46 \\
\hline Pages & $1057-1067$ \\
\hline Title & spar khams lo bdud bkar ba \\
\hline Translation & Banishing Demons [of] the [8] Trigrams 484 \\
\hline Revealer & [Khyunggötsel] \\
\hline Year & [c. 13th century] \\
\hline Summary & $\begin{array}{l}\text { More remedial verses and rites to be done to banish the twelve demons responsible } \\
\text { for a variety of afflictions. This volume has a strong astrological orientation, making } \\
\text { reference to Kongtsé and the Chinese. }\end{array}$ \\
\hline $\begin{array}{l}\text { Used in } \\
\text { Performance }\end{array}$ & No \\
\hline
\end{tabular}

${ }^{484}$ I have emended spar khams to spar kha, which makes much more sense here. 


\section{Appendix 2: List of Volumes According to Genre, Ordered by Quantity, Descending}

Texts and indices in [brackets] are too diverse to include in one category, or are misleading in that they may accomplish similar goals with different tone/strategies and thus might be better situated in a different category.

\begin{tabular}{|c|c|}
\hline Volume & Index \\
\hline \multicolumn{2}{|l|}{ Practical/Magical Practices (30) } \\
\hline \multicolumn{2}{|l|}{ Cures for ailments or afflictions (14) } \\
\hline klu gnyan sa bdag bzhi yi nad sel & 16 \\
\hline gtod kyi nad sel & 17 \\
\hline sa bdag nad sel & 18 \\
\hline shing ris nad sel & 19 \\
\hline mi dang 'gras bsdum & 28 \\
\hline klu gnyan sa bdag gtod bzhi' dal bkyag & 29 \\
\hline nad mda' phyung ba & 30 \\
\hline sri'u gso ba'i mar mnan & 32 \\
\hline god bcod pa'i mar mnan & 33 \\
\hline sbal pa'i nad sel & 35 \\
\hline rgyal 'khor nad sel & 36 \\
\hline khyung gi nad sel & 37 \\
\hline ba yi nad sel & 38 \\
\hline bya bkru bsrung gsum & 39 \\
\hline \multicolumn{2}{|c|}{ Treatments and "banishings" for problematic beings (13) } \\
\hline byur phud kyi gzhung & 4 \\
\hline [klu bcos] & [7] \\
\hline [gnyan bcos] & [8] \\
\hline [gtod bcos] & [9] \\
\hline [sa bdag bcos] & [10] \\
\hline klu gnyan sa bdag cha lag & 11 \\
\hline gnam gshed bcu gnyis & 15 \\
\hline byad bzlog & 31 \\
\hline [gshegs bskyod] & [41] \\
\hline brag srin bkar ba & 43 \\
\hline [bcos mdo] & 44 \\
\hline nad 'dre bkar ba & 45 \\
\hline spar khams lo bdud bkar ba & 46 \\
\hline \multicolumn{2}{|l|}{ Beckoning fortune (2) } \\
\hline g.yang 'bod & 13 \\
\hline srid kyi chu mig g.yang blan & 14 \\
\hline \multicolumn{2}{|l|}{ Other (1) } \\
\hline 'dzab sgron & 12 \\
\hline \multicolumn{2}{|l|}{ Offerings (4) } \\
\hline bsang mchod & 3 \\
\hline bum pa skyed pa & 5 \\
\hline mchod pa 'bul ba'i yig chung & 22 \\
\hline mdo las rnam lnga'i smon lam & 23 \\
\hline \multicolumn{2}{|l|}{ Assorted - 'bum (4) } \\
\hline klu 'bum & 24 \\
\hline gnyan 'bum & 25 \\
\hline
\end{tabular}




\begin{tabular}{|l|l|}
\hline gtod 'bum khra bo & 26 \\
\hline sa bdag 'bum & 27 \\
\hline Liturgical/Instructional Manuals (2) & 1 \\
\hline zin thu & 6 \\
\hline stod chog & \multicolumn{2}{|l|}{} \\
\hline Purification/Preparation of Environment (2) & 2 \\
\hline dug phyung & 20 \\
\hline khrus dgu & 21 \\
\hline Confession (1) & 21 \\
\hline bshags pa'i yig chung & 40 \\
\hline Auspiciousness (1) & \\
\hline bkra shis shog chung & 34 \\
\hline Other (1) & \\
\hline sgo dbye dbang bskur smon lam & \\
\hline
\end{tabular}




\section{Appendix 3: List of Volumes According to Inclusion in the Performance at Triten Norbutsé}

\begin{tabular}{|c|c|}
\hline Used in performance (22) & \\
\hline zin thu & 1 \\
\hline dug phyung & 2 \\
\hline bsang mchod & 3 \\
\hline byur phud kyi gzhung & 4 \\
\hline bum pa skyed pa & 5 \\
\hline stod chog & 6 \\
\hline klu bcos & 7 \\
\hline gnyan bcos & 8 \\
\hline gtod bcos & 9 \\
\hline sa bdag bcos & 10 \\
\hline 'dzab sgron & 12 \\
\hline g.yang 'bod & 13 \\
\hline bshags pa'i yig chung & 21 \\
\hline mchod pa 'bul ba'i yig chung & 22 \\
\hline klu 'bum & 24 \\
\hline gnyan 'bum & 25 \\
\hline gtod 'bum khra bo & 26 \\
\hline sa bdag 'bum & 27 \\
\hline klu gnyan sa bdag gtod bzhi' dal bkyag & 29 \\
\hline sgo dbye dbang bskur smon lam & 34 \\
\hline bkra shis shog chung & 40 \\
\hline gshegs bskyod & 41 \\
\hline Not used in performance (23) & \\
\hline klu gnyan sa bdag cha lag & 11 \\
\hline srid kyi chu mig g.yang blan & 14 \\
\hline gnam gshed bcu gnyis & 15 \\
\hline klu gnyan sa bdag bzhi yi nad sel & 16 \\
\hline gtod kyi nad sel & 17 \\
\hline sa bdag nad sel & 18 \\
\hline shing ris nad sel & 19 \\
\hline khrus dgu & 20 \\
\hline mdo las rnam lnga'i smon lam & 23 \\
\hline mi dang 'gras bsdum & 28 \\
\hline nad mda' phyung ba & 30 \\
\hline byad bzlog & 31 \\
\hline sri'u gso ba'i mar mnan & 32 \\
\hline god bcod pa'i mar mnan & 33 \\
\hline sbal pa'i nad sel & 35 \\
\hline rgyal 'khor nad sel & 36 \\
\hline khyung gi nad sel & 37 \\
\hline ba yi nad sel & 38 \\
\hline bya bkru bsrung gsum & 39 \\
\hline brag srin bkar ba & 43 \\
\hline$b \cos m d o$ & 44 \\
\hline nad 'dre bkar ba & 45 \\
\hline spar khams lo bdud bkar ba & 46 \\
\hline
\end{tabular}




\section{Appendix 4: Unpublished Manuscript of a Teaching Document on the Subject of Tormas, by Geshé Tsultrim Tenzin}

Received at Triten Norbutsé monastery in Kathmandu, Nepal, on June 1st, 2009. Note that this is a partial transcription of the full document, stopping at the middle of page 10. The original document continues for another 3.5 pages, but the content was not relevant to include so it is left out.

g.yung drung bon gyi gzhung lugs ltar gtor ma'i lo rgyus dang dgos pa phran tsam brjod pa/

dge bshes tshul khrims bstan 'dzin/(sgom grwa'i mkhan po)

rang re bod kyi rig gnas dang lo rgyus ni shin tu rgya che la gting ring ba khungs ldan gyi yig cha'i rgyab brten yod pa zhig yin pa ngos 'dzin zhu 'os/'on kyang khungs ldan gyi yig cha de dag mi lo stong phrag mang po'i nang du dus kyi gnyan 'phrang dang 'gal rkyen du mar 'phrad pa'i rkyen gyis mkhas pa phal gyi bcos bslad mang drags pa dang / dus rabs brgyadpa tshun chad lo rgyus smra ba po rnams kyis dngos gnas bod kyi lo rgyus kyi phugs gang la thug yod pa'i tshul rnams bshad pa nyung drags pa dang / yang 'ga' zhig gis sngon ma'i lo rgyus de dag sbas ci thub dang bskung ci thub gnang ste 'khyog bshad kho nar byas pa'i dbang gis sngar byung bod kyi lo rgyus tshad ldan gsha' ma zhig ston mkhan nyung shas las byung med/

dngos gnas bod kyi lo rgyus tshad ldan tshul mthun zhig bshad bsam mkhan yod na grub mtha'i phyogs lhung spangs te rang phyogs dang gzhan phyogs gnyis su ma phyes pa'i sgo nas bod rang la yod pa'i rgyal rabs dang lo rgyus kyi yig cha gang yod dag la spyan ras rab tu yangs par byas te dpyad pa tshul mthun zhig gnang na/ lo ngo stong phrag mang po'i sngon du bod rang la rig pa'i gnas chen po lnga dang de 'brel rgyal rabs lo rgyus phun sum tshogs pa phugs rtsa brtan po khyim mtshes rgyal khab khag la ngom rin chog pa rtsa chen zhig rnyed mi srid pa ga la yin/de lta bu'i lo rgyus spus dag cig rnyed par byed pa la gtso bo dus rabs brgyad pa'i yar sngon gyi rgyal rabs lo rgyus khag la 'tshol bsdu zhib tshags gnang dgos pa ni gal chen zhig yin/deng sang rgyal phyi nang gi mkhas dbang mang dag cig gis bod kyi rgyal rabs dang lo rgyus rnams la gzigs dpyad nan po gnang ste ljags rtsom yang mi nyung ba zhig spel dang spel bzhin pa yin na'ang / de'i nang du dus rabs brgyad pa'i yar sngon gyi bod kyi lo rgyus dang rgyal rabs tshul mthun zhig bshad mkhan ni nyung shas tsam las byung mi 'dug/chos phyogs su mkhas pa phal mo che mang dag zhig gis srong btsan sgam po'i yan la bod yul du rig pa'i gnas che ba nang don rig pa sogs yod pa phar zhog/yig rigs tsam yang med par mun pa 'thug po'i khrod du bod mi rmongs pa kho na'i lam lugs ci yang mi shes pa ba lang dang phag pa lta bur(2) ngos 'dzin gnang ste/ bod kyi lo rgyus smras pa ni rgyal rabs sum cu'i ring gi yab mes gong ma rnams la sma phab ste skyon brjod byas pa ma zad/bod mi spyi yongs la gyon gud ha cang tshab chen gtong ba ni blo gros kyi spyan ras yangs pa'i mkhas pa rnams kyis gzigs na mthong rgyu yod pa las 'dir rgyas par mi gleng /

rgyu mtshan der brten kho bos skabs 'dir bod rgyal thog ma gnya' khri btsad po'i sku dus su zhang zhung nas bod du dar ba'i g.yung drung bon gyi gto chog gi phyag len du 
ma zhig yod pa'i nang nas gtor ma'i lo rgyus dang dgos pa phran tsam zhig 'chad par bya ba yin/

spyir gtor ma bca' yas dang cho ga phyag len gyi skor 'di lo rabs ches mang po'i sngon nas da bar bod dang de 'brel hi ma la ya'i ri rgyud du ban bon gnyis ka'i phyogs su dar khyab ha cang chen po byung nas yod pa 'di khyim mtshes rgyal khab gzhan dang mi 'bra bar zhang bod kyi thun min chos dang 'brel ba'i rig gzhung zhig yin par ngos 'dzin zhu 'os/ 'on kyang dar tshul lam byung khungs kyi dbang du byas na/ chos pa'i gtor ma'i phyag len gyi skor 'di dus rabs brgyad pa'i nang / O rgyan gyi mkhas grub chen po gu ru rin po che bod la phebs te gsang sngags kyi chos sde du ma phab bsgyur gnang ba nas bzung 'go btsugs pa zhig yin shas che zhing / bon po'i gtor ma'i skor 'di ni gtso bo bod rgyal gnya' khri'i dus su zhang zhung gi mkhas dbang dam pa nam mkha' snang ba mdog can bod yul du phebs te/ gsang sngags spyi spungs zhi khro rnams dang dbal chen ram pa'i skor rnams zhang skad las bod skad du bsgyur ba nas sngags kyi cho ga'i phyag len de nas dar 'go tshugs pa yin 'dug cing / cho ga'i phyag len yod phyin chad gtor ma'i lag len yod dgos pa ni chu dang nya bzhin gnas pa yin/ lhag tu bod rgyal gnyis pa mu khri btsan po'i dus su bod mi rnams kyi sku rim zhabs brtan gnang yas dang / gsang sngags cho ga'i phyag len gnang phyogs skor dar khyab ha cang chen po byung yod pa ni g.yung drung bon gyi lo rgyus khag rnams kyis ra sprod nus/de yang 'dir dpe mtshon tsam du kha gsal go bde'i lung zhig drangs na/ya ngal gyi gdung rabs 50 las las spyod dag pa gshen gyi las la spyod/gshen nam mkha' snang ba mdog can la/spyi spungs bon skor zhus nas spyod/ sku gshen dag gtsang ya ngal tshe co gsum gyi (gyis) mdzad/ yul la snga ba yar lung sog kha btab/ mkhar la snga ba byi ba stag rtse brtsegs/ rgyal la snga ba gnya' khri btsan po yin/gshen la snga ba ya ngal tshe co gsum/ bon la snga ba spyi spungs gsang ba'i skor zhes dang /.sgrung lde'u bon gsum gyi gtam 450 las gshen chen po nam mkha'i snang ba'i mdog can de ni spyi spungs sngags sems gnyis ka'i brgyud pa'i khungs shig yin par gsal la/ de'i dus du bod na bon yongs su grags pas slob dpon chen po de 'dra ba zhig bod na bzhugs bzhin par spyi spungs sngags sems kyi skor ma(3) dar ba'i rgyu mtshan ci zhig yod/ ces dang / yang de nyid 451 las rgyal po gnya' khri'i dus tsam nas/zhang zhung las chad pa'i rgyal khab cig gsar du btsugs pa dang /..dus mnyam du bod kyi tha snyad byung yod pa 'dra bas bon ni bod las kyang snga bar bshad la/ skabs der bod na gshen chen po nam kmha' snang ba'i mdog can bzhugs yod par brten/de dus kyi bon rnams kyi snying po spyi spungs kyi skor 'di dag yin pa shes thub/ces gsungs pa ni mkhas pa chen po'i gdams ngag lo rgyus kyi gnad mthong ba'i gtam zhig yin par sems so/

gtor ma'i ngo bo ji ltar dgos pa/

gtor ma zhes pa'i tha snyad 'di ni lo ngo stong phrag mang po'i sngon du bod la dar khyab che shos gras kyi chos phyogs kyi ming tshig cig chags yod/bod mi chol kha gsum gyi dmangs khrod du sku rim zhabs brtan gyi ched du ban dhe dang bon po rnams kyis phyag len gnang yas kyi gtso bo zhig kyang red/gtor ma zhes pa'i tha snyad 'di gang 'dra yin nam snyam nas hob tu bsam mno zhig btang ba yin na rgyu mtshan gang yang med pa 'dod rgyal kho na'i ming zhig red 'dug snyam pa 'byung las che na yang / don du rjes grub kyi ming rgyu mtshan chen po zhig tu snang ba ni/ mkha' 'gro rin chen phreng ba'i rgyud 290 las mi 'dzin yongs su gtong bas gtor/ kun la 
snyoms shing khyab pas ma/ zhes dang / de las cung zad gsal kha ston zhing go stabs bde ba ni/ ka ba nag po man ngag rtsa ba'i rgyud 111 las de nas chags med kun la khyab pas gtor/thugs rje gdung ba yongs la 'dzin pas ma/ma chags thugs rje'i gtor ma chen po dgye (bkye)/zhes gsungs pa'i tshig des gtor ma'i go don rgya che la gting zab pa rgyu mtshan dang ldan pa zhig mtshon thub/de yang gtor ma gtong mkhan sgrub pa po rang nyid dang rgyu sbyor ba yon gyi bdag po sogs kyis mchod rdzas la ser sna dang 'jungs gegs kyis dri ma spangs te mchod yul rnams la dad pa dang mos gus kyi gzhi bzung / sbyin yul rnams la byams dang snying rje'i sgo nas mgron bzhi kun la khyab par 'bul zhing gtor ba'i rdzas shig yin pas na byed 'brel las tshig dngos rdzas la sbyar ba zhig red/

gtor ma'i dbyibs/

gtor ma'i dbibs ni/gsang sngags gtor ma'i gal byang 271 las/ zhi rgyas dbang drag tshul du bzhengs pa ni/ zhi ba zlum po phyogs med 'bur du brgyas (rgyas)/lhun 'thug byin che rjid (brid) dang ldan/ shes rab kyi rtse mo dod pa/byang chub kyi sku sha brgyas (rgyas) pa/bsam gtan gyi zhabs bzhi (gzhi) brtan pa/(4) tshul khrims kyi rkyed (rked) pa spung ba (spungs pa) bya/ rgyas pa rin chen tshul du gru bzhi bya/ dbang ni zlas (zla) gam tshul du 'gug (gug) chags bya/drag po zur gsum tshul du nyams dbal brgyas (rgyas) par bya/ zhes dang / de yang 272 las brjid ldan byin chags rin chen spungs pa'i tshul/ rtse mo thar lam shul 'dren yin pas 'phra ba rno/'phrag pa dbang dang byin rlabs yin pas zlum la brgyas (rgyas)/ rkyed (rked) pa rin chen spungs pa yin pas spung (spungs) la brjid/ rtsa ba zil gnon 'gro 'dul yin pas bde' (bde la) rgya che bar bya'o/ zhes dang / phags skos sen rjes ya yo song ba ni/glo bur ye 'grog ('grog) bar chod ldang ba'i gnad zur la chad gol the ka song ba ni/ bka' chad bar chad bsod nams yi chad yong ba'i gnad/de ltar ma yin legs par 'cha (bca')/zhes gsungs pa Itar gtor ma'i dbyibs ji ltar dgos pa'i tshul rgyu mtshan dang 'brel ba'i sgo nas gsal bar gsungs zhing / de yang gtor ma tha dag gi dbyigs de ltar nges pa ma yin na yang gtso che ba'i sgo nas zhi ba'i gtor ma zlum po dang / rgyas pa'i gtor ma gru bzhi/ dbang gi gtor ma zla gab/drag po'i gtor ma zur gsum tshul du dgos shing / de dag la rtse mo 'phra la rno ba/'phrag pa zlum zlum yod pa/ rked pa sbom la brjid ldan rtsa ba cung zad rgya che ba sa la bzhag bde ba dgos/gtor ma la sen rjes dod pa dang / ya yo 'bar 'bur kong kong chag gas/zur thed du song ba yin na/ rten 'brel gyi gnad 'chug pa dang sgrub gshen dang sbyin bdag rnams la glo bur gyi nad ldang zhing dge la bar chad yong ba dang / bsod nams dma' zhing yid mi bde ba 'byung ba yin pas de ltar ma song ba legs par bca'dgos/

gtor ma'i rgyu/

gtor ma'i rgyu ni/ rkun rgyu dang / ham 'phrog/btsog chos su ma song ba'i dngos rdzas spus dag cig dgos la/ de yang gtor ma tsam du ma zad mchod rdzas kun la nges can du dgos pa yin/gtor ma dngos su bca'yas ni/ nas dang / 'bras/gro/so ba/mon sran te 'bru lnga'i phye ma la/ bzang drug/rtsa brgyad/sman sgrub/rin chen sna lnga sogs bsres la gtor mkhan sgrub gshen gyi phyag mdzug gis yi ge dpa' bo 'bru lnga/ phyi rgyud ltar OM yaM raM maM khaM dang / nang rgyud ltar na a OM $h+' u M$ raM dza ste sde tshan gnyis po gang rung zhig bris la bde bar gshegs pa rigs lngas byin 
gyis rlabs pa'i 'du shes bzung dgos pa yin/zlog gtor 'ga' zig la rang res srog ma bcad pa'i khrag dang mnyam por sbrus te bca' dgos pa yang yod/(5)

gtor ma'i bdye ba/

gtor ma'i dbye ba ni/lha yi rten gtor dang / rmad byung bskang gtor/ mgron bzhi'i mchod gtor/ skyin tshab glud gtor dang lnga yi nang du gtor ma phal cher 'dus pa yin/

lha yi rten gtor

de'i dang po lha yi rten gtor ni/yi dam lha sogs kyi 'khor sa'i rten nam/sgrub gshen gyis yi dam ha yi rten dang brten pa'i dkyil 'khor sgom pa'i dmigs rten yin/ de yang gtor ma'i gal byang 228 las/gtor gzhong ni/ zhi rgyas dbang drag gang yin pa'i gzhal yas dang / gzhung so sor bshad pa ltar/brgya (rgya) che la dpang mtho ba/ nyams dga' la yid du 'ong ba ste/de'i nang du las so so'i khri gdan mdzes pa'i steng du/gtor sdong ni/ zhi rgyas dbang drag gi lha gang yin pa de'i sku mdog phyag mtshan gdan khri rgyan dang cha lugs rdzogs par sgom/zhes gsungs pas/gtor ma dmigs rten du bzung ste yi dam lha yi rten dang brten a'i dkyil 'khor ji ltar sgom pa'i tshul rob tsam zhig des shes par nus/

rmad byung bskang gtor/

rmad byung bskang gtor ni/gtor gzhong dbus kyi ri rab mtshon byed bang rim bzhi ldan dgos la de'i nang du gtor ma ni gzhung gang la zhugs pa'i gtor zin ltar ma nor ba legs par bca' zhing de yang kun la dgos pa'i bya rigs sna tshogs dang / gcan gzan dang / ri dwags/g.yung dwags/ chu gnas las sogs pa'i gzugs brnyan sna tshogs pa zan dpar gdab pa'am/ ris su bris pa'i shing khra dang nam mkha' rgyang bu bkra shis rtags brgyad rin chen nor bdun sogs gang 'byor bshams/de la tshang rgyung 'jig rten nam snod bcud kyi bkod pa du mar dmigs te mgron bzhi rnams la phul bas/yi dam lha dang srung ma'i thugs kyi dam tshig nyams pa bskang ba'i thabs mchog tu gyur pa yin/

drag po'i zlog gtor/

drag po'i zlog gtor ni/ mdos ra'am gtor gzhong bang rim gang dgos gzhung rang rang gi lha gtso 'khor gyi grangs dang bstun te de'i nang du/gtor zin ltar zlog gtor gang dgos bca' zhing mthar tsang thur skyer pa'i shing thur brgya rtsa brgyad btsugs/de'i phyi rim du zlog khrab ces phur pa khro bcu'i zhal thang dgod/de yang yi dam lha drag por 'khros pa'i sku la me ri dang me dpung 'bar ba phyag na mtshon cha sna tshogs bsnams pa zhal nas grag po'i sngags(6) 'dzab sgrob pa du mar dmigs te sgom pas/ spyir sangs rgyas kyi bstan pa dang sems can gang dag la gnod par byed pa'i 'tshe can/ sgos sgrub pa po'i thar lam la bar chod byed pa dang / rgyu sbyor ba yon gyi bdag po'i lus ngag yid gsum la 'tshe bar byed pa'i gzugs can gyi dgra/gzugs med kyi bgegs/ mi mthun log pa'i phyogs thams cad phyir bzlog pa'am med par bzo byed kyi thabs shig go/ 
mgron bzhi'i mchod gtor/

mgron bzhi'i mchod gtor ni/sngags phyi pa ltar na/srid zhu'i mgron ni skyon kun zad yon tan kun ldan spangs rtogs mthar thug pa'i rnam pa thams cad mkhyen pa'i bde bar gshegs pa'am/yi dam rnams dang sa bcu gang rung thob pa'i g.yung drung sems dpa' rnams yin la/de la gtso bo rnams Inga'i mchod pa ste/ mar me dang / yon chab/ spos/zhal zas/me tog bcas yin la/de'i dang po ni/'bru mar dang / til mar/rtsi mar gyi mar me dang / shel sgong dang / me long sogs gang 'byor/don du gzugs kyi mchod pa'i mtshon byed yin/ yon chab ni/ nam mkha'i char chu dang / rgya mtsho'i 'khyil chu/ ba dkar gyi 'o ma sogs 'o chu gtsang ma gang 'byor/spos ni ga pur dang / tsan dan/ A ka ru/rgya spos/spang spos/brag spos sogs dri zhim spos sna tshogs tshad/me tog ni/sa gtsang ma las skyes pa'i dug rigs min pa'i me tog sna tshogs pa'o/ zhal zas ni/ dkar gtor zlum po la shes rab dang tshul khrims ting nge 'dzin gyi bslab pa mtshon byed du/rim bzhin rtse mo rno la 'phrag pa can/sked pa lhun 'thug la byin chags pa/ zhabs gzhi brtan la rgya che ba/ de la dkar rgyan gyis rnam pa mdzes shing yid du 'ong ba grangs bdun las mi nyung bar dgos/der ma zad ka ra bu ram sbrang rtsi dang zho dang chur ba 'o ma shing thog la sogs sha khrag min pa'i dri zhim ro bzang gis zas sna tshogs tshad ni zhal zas yin/dkar hrug ces zhal zas chung du zhig la dkar gsum mngar gsum me tog gis brgyan pa/dkar chab dang lhan du lha yi grangs dang bstun te 'bul srol yod/sngags phyi pa'i lugs la/ sha khrag rigs lha la rtsa ba nas 'bul mi rung zhing / sgrub pa po rang gis kyang 'di'i cho ga lag tu len pa'i skabs su/ sha khrag za ba dang lag len byed pa sogs spangs te/lus ngag yid gsum dag pa'i las la 'jug dgos/'o na srid zhu'i mgron nam bde bar gshegs pa de dag la mchod pa'i don gang yin zhe na/legs spyod smon lam 511 las/bdag dang mtha' yas sems can gyi/ bag chags sgrib pa bsal ba dang / bsod nams tshogs chen rdzogs pa'i phyir/ bder gshegs lha la 'bul lags na/ thugs rje dang ni dam tshig gi/ gnyis med don gyis bzhes su gsol/ zhes gsungs/ de ltar mchod pa rnam Inga phul bas/ rigs drug tu skye ba'i las dang (7) bag chags bcas pa'i sdug bsngal sogs dag pa'i rkyen du 'gyur ba dang / bsod nams kyi tshogs rdzogs shing / slad nas kyang mchod pa dang sbyin pa'i 'phro skyong ba'i yon tan can du 'gyur ba'i dgos pa rgya chen po yod/

yon tan gyi mgron ni/

sangs rgyas kyi bstan pa skyong ba'i bka' srung bon skyong rnams dang / 'jig rten gyi dpal mgon lha dbang rgya byin/ klu rgyal gtsug na dang / 'jog po/ lha min thang bzang las sogs pa dkar phyogs dge ba la dad cing / sems can gzhan la mi 'tshe ba'i lha klu mthu stobs dang ldan pa gang dag rnams so/de la rang mthun gyi gtor ma dkar bshos 'dab zhi pa gsum lhan du bsgrigs pa la dkar mngar sman 'bru me tog gis brgyan $\mathrm{pa} /$ dkar chab dang mnyam du 'bul/de la mchod pa'i dgos pa ni/spyir sangs rgyas g.yung drung bon gyi bstan pa bsrung zhing sems can gyi bde skyid spel ba dang / sgos su sgrub pa po'i thar lam gyi bar chod zhi ba dang / skabs bab kyi sbyin bdag la bsod nams kyi legs tshogs spel ba'i ched yin/

lan chags kyi mgron ni 
sems can gzhan la gnod cing 'tshe bar byed pa'i gdug sems can gyi lha 'dre rnams te/ de yang bdud dang / rgyal po/gshing rje/ bgegs/ klu/gnyan/sa bdag/gtod/btsan/ ma mo/gnod sbyin/lto phye/grul 'bum/ mi 'om ci/sha za/ro lang/'byung po rnams so/de la mchod pa'i rdzas ni/dkar bshos 'dab gsum pa can sum bsgrigs sman 'bru me tog gis brgyan pa dang dkar chab bcas so/mchod po'i don ni/ kun dbyings 218 las/zhe sdang gdug pa'i tshogs bor la/ byams pa'i tshul gyis mchod yon longs/ zhes dang / gnod pa'i sems ni zhi gyur cig/snang srid 'jig rten mtha' dag kun/ khyed kyi thugs rjes bskyang du gsol/ bstan pa yongs su bsrung du gsol/ bsam pa yid bzhin 'grub par mdzod/ces gsungs pas/de la rang mthun gyi mchod yon phul bas/thugs rab tu dgyes te gdug rtsub kyi mtshan ma yongs su zhi nas byams sems kyi blo dang ldan pa dang / snang srid kyi dga' bde bskyed cing sangs rgyas kyi bstan pa bsrung ba'i dgos pa yod/

\section{sning rje'i mgron ni/}

kha rje dbang thang dman pa'i rigs drug gi sems can te/dmyal ba/yi dwags/byol song / mi/ lha min/ lha dang zas gos btung ba sogs kyis dbul ba'i gsugs med bar do'i sems can rnams so/de la bsngo ba'i rdzas ni/chang bu bdun tshar ram/de las rgyas par 'dod na/ mi dang bya gcan ri g.yung chu gnas sogs kyi gzugs (8) brnyan zang ba min pa sna tshogs dang / dri ro mi zhim pa sna tshogs dar zab sna tshogs pags rigs sna tshogs snam phrug sna tshogs pa'i dras ras rnams gtor zin ltar go rim ma nor bar legs par bsgrigs te cho ga'i tshig bshad kyis brda sprod dmigs pa ting 'dzin gyis 'dod pa'i yon tan phun tshogs su bsam nas bsngo dgos/ bsngo ba'i don ni kun dbyings 219 las/ rigs drug bar do'i sems can gyi/dbang po lnga yi spyod yul du/ bdud rtsi'i char du 'beb gyur cig/ ces dang / rang rang sdug bsngal myur zhi nas/ thar pa'i go 'phang thob par shog/ ces gzungs pas/sgrub gshen gyis ting 'dzin dang snying po tshig bshad dang gsum gyi sgo nas bsngos pas/ sems can de dag gis 'dod pa'i yon tan gang 'dod du longs su spyod de/ mthar thar pa dang bde ba'i go skabs 'thob pa'i dgos pa yod/

nang rgyud gsang ba sngags lugs ltar/ srid zhu'i mgron ni/ 'gro ba'i mgon po skyabs rje drin can rtsa ba'i bla ma brgyud pa dang bcas pa dang / byin rlabs thams cad kyi rtsa ba yi dam zhi khro'i lha tshogs/ dngos grub kun 'byung gi bdag nyid ma sring ye shes mkha' 'gro rnams dang / de bzhin du gang smros ltar gyi yon tan gyi mgron dang / lan chags kyi mgron/ snying rje'i mgron de rnams la 'bul rgyu'i dngos rdzas ni/ 'dod 'jo 'khri shing las gsungs pa ltar mdor bsdus te bshad na/gtor ma dang / rnam brgyad/sman/ rak+ta/ tshogs dang lnga ru dgos shing /

de yang gtor ma ni/ dbyibs zur gsum rtse rgyal brjid ldan la/ sha khrag snying gsum rus pa dang bcas pa brgyan pa dang / de'i sha ni/ rngam pa dgu yi ltag sha zhes gsugs pas/ mi rgod dang / dom nag/'phar ba/stag/chu srin/gsa'/spyang khu/seng ge/ gzig dang dgu yi sha de rnams la pha dgu gdung ba'i stag sha zhes brjod/khrag ni/ gdung ba stong gi snying khrag ces gsungs kyang / mkhas pa'i zhal shes la dgu ru ngos 'dzin gnang ba ni/sre mong bu stor dang / dred mo tshang ma/ wa mo stang 'gyu/ hor khra tshang $\mathrm{ma} /$ sram chen gong rdul/ brag dbyi tshang $\mathrm{ma} / \mathrm{ce}$ spyang tshang $\mathrm{ma} /$ byi la mjug can/gung rgod tshang ma dang dgu yi khrag de rnams la ma dgu gdung ba'i snying khrag ces bya/snying ni gdug pa dgu yi tsi ta zhes gsungs pas/seng 
phrug dang / dom bu thugs dkar/'phar chung / khra chung / nya mo/gangs dbyi/ spyang phrug/stag phrug/ra rog gi tsi ta de rnams la bu dgu gdug pa'i tsi ta zhes bya'o/ de rnams thams cad tshang pa'am yang na gang rnyed rnams gsang sngags bskyed rdzogs la mnga' bsnyems pa'i nus ldan gyi sngags pa gzugs phung tshogs su bsgyur rnam shes lha ru dgog nus pa'i grub pa thob pa'i rig 'dzin/dper na/dbal bon Itag la me 'bar dang / bla chen dran pa nam mkha' lta bu yin na/ gang smros kyi sha khrag snying gsum rus pa (9) dang bcas pa mchod pa'i rdzas su longs spyod pa ma gtogs/ 'gro ba phal gyis sha khrag de dag mchod pa'i rdzas su bshams mi rung ba sang sngags kyi lung du ma las gsungs 'dug pas tho cho dang ras chod du ma song ba gal che/

sgrub gshen phal gyis gong smros sha khrag gi tshab tu nyon mongs kun slongs kyis srog ma bcad pa'i g.yag kham pa gser mig gi sha khrag snying gsum la thams cad tshang zhes 'dod 'jo 'khri shing 35 las gsungs so/de yang ma 'byor na sems can dud 'gro lta bu nad gtsang mas shi ba'am/ tshe zad las kyis shi ba'i sha khrag rnams gtor rdzas su bzhag dgos yod/de yang rdzas Inga rin chen sgron ma'i rgyud 147 las/spang ba ni 'byung ba ma nyams pa'i srog bcad pa dang / nyams pa'i dbugs 'phrog pa rku 'phrog las sogs pa dang / bson (gson) po'i phugs mi gtsang ba dang / shi gnyen (nyes kyi) gyi bsngos bskal la sogs pa/ khyi spyang gcan zan (gzan) las sogs pa mche ba can gyi zas 'phro dang / rme mon (dme mug) dang 'gags 'bogs ('bag 'bogs) nad rims can (gyi) sha las sogs pa dang / zhes gsungs so/

rnam brgyad ni/gong bshad kyi mar mer dang / spos/ zhal zas/ yon chab gang rung / me tog bcas/ de steng sgra yi mchod pa rnga gshang dung gling sogs sgra snyan sna tshogs/ reg bya'i mchod pa dar zab sna tshogs/gar gyi mchod pa lus dang lag pa'i rnam 'gyur sna tshogs/gter gyi mchod pa gser g.yu lassogs rin chen sna tshogs rnams mtshan ldan lha mo brgyad kyi phyag tu bsnams pa'i gzugs brnyan zan dpar ram bris gzugs gang lcogs rnams so/

sman mchod ni/gtso bo dam rdzas rtsa ba lnga ste/dri chen dang / dri chu/ byang sems / (pho yi thig le) rak+ta/ (mo yi mngal khrag) mang sa'am gsang sha gal chen/ (bud med khyi rta ba glang ma he sogs zhes ma rgyud 281 las gsungs so/) dang lnga dngos su rung min ni sgrub gshen gyi rtogs pa la rag las shing / rtogs pas ma 'chun na/de'i tshab tu sman lnga ni/ byang sems kyi tshab tu cu gang / dri chen tsan dan dkar po/dri chu la spos dkar/ rak+ta la si ng+hu ra'am gur gum/gsang sha la A ru gser mdog dang lnga yi steng rtsa ba brgyad de/go yu dang / tsan dan dmar po/ shing tsha/gur gum/li shi/ge sar/ga pur/dza'+' ti dang brgyad gtsos pa'i dug rigs min pa'i sman sna tshogs tshad la rig 'dzin gong mas byin gyis brlabs pa'i sman sgrub kyis 'phrad bstsal la bshams dgos/ de yang dam rdzas rtsa ba lnga ni 'jig rten pa rnams kyis btsog pa blta sa'i gtso bo yin pa dang / gdongs rtogs khyad par can gyi sngags pas rang rgyud kyi btsog 'dzin de dag lta bas zil gyis mnan te/ dngos po de dag ting nge 'dzin gyis dam (10) rdzas su byin gyis brlabs te longs su spyad pas rang rgyud kyi nad Inga bsal ba dang longs spyod 'phel ba sogs kyi dgos pa khyad par can du ma dang ldan te/ 
'gu ya 527 las 'du ba'i nad lnga bsal ba ni/ dri chen dag gi (gis) dug nad gsal/(bsal/) dri chus rlung thabs nad gsal (bsal) lo/ ma (mang) sam bdze nad bsal ba dang/ pad ma rag tas mthor bsnyon sel/g.yung drung sems kyis tshad nad sel/rtsang (gtsang) dmes (dme'i) rtog pa sbyangs pa yin/ rtsa (gtsang) dang dme bar 'dzin pa yi/ rtog pa sbyangs ba'i phyir du blang / thun mong dgos pa rnam lnga ni/dri chen zos na longs spyod 'phel/dri chu chungs ('thung) na rngang (gdangs) skad snyan/ rag ta 'thung na lta mdog sdug ma (mang) sa zos na mthu chen 'gyur/byang sems zos na sku tshe ring / zhes so/sman mchod phul ba'I dgos pa ni/rlung mkhris bad kan 'du ba'i nad rnams kyi gnyen po ni sman yin la/ sman de dag la stong nyid rtogs pa'i lta bas zin pa'i sgo nas yar dkon mchog la mchod pas sgrub gshen rang rgyud la tshogs gsog cing sgrib gnyis sbyong ba dang / mar rigs drug la byin pas nad bsal ba tsam du ma zad nad de dag gi rgyu nyon mongs pa dug gsum te/'od chags dang / zhe sdang / gti mug rnams bsal ba'i thabs mchog tu gyur pa zhig yin pa ste/bsregs chog chen mo 640 las/sman rnam pa lnga'i mchod pa phul ba'i yon tan gyis na tsha'i sdug bsngal las thar nas/ bdud rtsi rgya mtsho ltar ldan par gyur cig ches dang / gshen gyi mdel thung 209 las/ bdud rtsi lnga dad ldan pa ste/dag cing gtsang mar bshams pa yi/gtsang ma sman gyi ril bu 'di/ nyon mongs nad rnams bsal ba'i phyir/ zhes gsung so/ 


\section{Appendix 5: Unpublished Manuscript "Tapiritsa" (ta pi hri tsa) by Tsultrim}

Tenzin

A Bönpo explanation of tormas, maṇạalas, deities, and more, used by Tenzin Tsultrim to educate monks and other interested parties.

Received at Triten Norbutsé monastery in Kathmandu, Nepal in May 2009.

\section{Handwritten "colophon"}

sgrub grwa'i mkhan ming 'dzin pa tshul khrims bstan 'dzin nas nyi hong nang gi 'grem ston khang gi ched du dus rabs nyer gcig pa'i sa glang lor bris/

\section{Table of contents (corresponds to PDF pages, not included)}

- deities

- rje ta pi hri tsa: 1

- yum chen shes rab byams ma: 1

- rdzogs sku gshen lha 'od dkar: 2

- kun bzang rgyal ba 'dus pa: 2

- ston pa gshen rab mi bo: 3

- ston pa khrigtsug rgyal ba: 3

- gshen rab rnam par rgyal ba: 3

- dbal bon stag la me 'bar: 4

- bstan srung ye shes dbal mo: 4

- bon nyid tog nam: 5

- che mchog shal nam: 6

- rgyal mo zhal nam: 6

- srid rgyal dus drug zhal nam: 7

- ru sbal khong nam: 8

- man+dala: 8

- gtor par: 9

- gtor par che ba'i rnam grangs: 11

- gtor par chung ba'i rnam grangs: 13

- zhwa dkar khyung lding ma: 13

- dkar mo rtse rgyal: 14

rje ta pi hri tsa

rje ta pi hri tsa ni zhang zhung snyan rgyud kyi bla ma 'ja' lus nyer bzhi pa tshe spungs zla ba rgyal mtshan gyi slob ma zhig yin/ (dus rabs brgyad pa) khong gi tshe spungs zla rgyal gyi mdun nas rdzogs pa chen po zhang zhung snyan rgyud bka' rgyud skor bzhi dang nyams rgyud gsang sngags me ri bcas khrid lung lag len dang bcas pa zhus nas/gangs ti si'i byang rgyud stag thabs seng ge'i brag la lo dgu'i bar bsgom pas 'ja' 
lus 'phos chen gyi sku bsnyes te kun tu bzang po dngos su gyur/rjes su zhang zhung snang zher lod po la rdzogs pa chen po zhang zhung snyan rgyud kyi gdams pa bzhag par dgongs nas thog mar khye'u rnyed legs bya ba sprul nas smer phyug po'i zhabs tog bsgrubs/de nas snang zher lod po la zhang zhung snyan rgyud yongs su rdzogs pa gsungs nas skal ldan gyi 'gro don grub pa bcas so/

spa btsun bstan rgyal seng ge dpal bzang gis mdzad pa'i brgyud pa'i bla ma'i rnam thar las gsal/

yum chen shes rab byams ma

yum chen shes rab byams ma ni rdzogs sku gshen lha 'od dkar gyi thugs nyid bon sku las sprul pa'i longs spyod rdzogs pa'i lha mo zhig yin la/ phyag g.yas pas dug lnga'i nad sel gyi thabs byams pa chen po'i brdar bdud rtsi'i bcud kyi bltam pa'i gser bum bsnams pa/g.yas pas gar stabs kyis snang srid kyi yin lugs mngon sum gsal ba'i shes rab rig pa'i ye shes kyi brdar U dum wa r'i me tog gi rtse la me long 'khyil ba/spyan gsum ldan pa'i khams gsum gyi 'gro bar brtse bas gzigs pa'i don mthon pa bcan so//

g.yung drung tshul khrims kyis mdzad pa'i mngon rtogs thar lam gsal byed dang / stag la'i thugs sprul dbra ston drung mu'i gter ma lha mo byams ma'i gcig bsgrub las gsal/[2]

rdzogs sku gshen lha 'od dkar

rdzogs sku gshen lha 'od dkar ni ston pa gshen rab mi bo'i sprul gzhi'i lha longs spyod rdzogs pa'i sku de yin la/ lha de nyi zla pad ma'i gdan la bzhugs pas pad mas skyon gyi ma gos pa mtshon/ nyi mas bon nyid ma bcos thig le nyag gcig rtogs pa'i shes rab stong pa nyid mtshon/zla bas brtse ba chen po'i bdag nyid thabs snying rje chen po mtshon/ phyag gnyis mnyam bzhag mdzad de cha lugs lnga ldan du bzhugs pas dug Inga gnas su dag pa'i ye shes lnga'i bdag nyid spros bral bon sku'i ngang las ma g.yos par ting nge 'dzin gyi sgo nas sa thob 'phags pa rnams la bon gyi 'khor lo bskor ba'i don mtshon pa bcas so/

shar rdza rin po che'i lha gnyen shel sgong dang rig 'dzin nyi mas mdzad pa'i bka' lung rgya mtsho'i mchan 'grel las gsal/

kun bzang rgyal ba 'dus pa/

kun bzang rgyal ba 'dus pa ni rdzogs sku gshen lha 'od dkar ye shes Inga ldan sku Inga tshangs pa'i brda rtags zhal lnga phyag bcu pa'i sku bzhengs pa yin la phyag dang po gnyis bon sku thig le nyag gcig las g.yo ba med pa'i brda rtags mnyam bzhag thugs khar sbrel zhing thabs shes mtshon byed A dang mas brgyan pa'i nyi zla 'dzin pa dang / de'i 'og g.yas pa gsum gyis nub pa med pa dang 'gyur ba med pa dang 'gyur ba med pa sprul pa thogs pa med pa'i brda rtags rgyal mtshan dang g.yung drung 'khor lo bsnams pa dang / g.yon pa gsum gyis gsal stong gnyis su med pa dang thugs rjes 'gro la gzigs pa ngan song thar par 'dren pa'i brda rtags mda' gzhu dang zhags pa lcags 
kyu bsnams pa dang / tha ma gnyis kyis srid zhi'i mtha' gnyis gnon cing 'gro ba rnams byams pas skyobs pa'i brda rtags sa gnon gyi phyag rgya mdzad pa bcas so/

'a zha blo gros rgyal mtshan gyis mdzad pa'i zhi ba A gsal las gsal/[3]

ston pa gshen rab mi bo/

ston pa gshen rab mi bo ni rdzogs sku gshen lha 'od dkar las sprul pa'i mchog gi sprul sku dang g.yung drung bon srol 'byed pa po yin la ston pa de'i cha lugs la rdzogs sku'i cha lugs dang rgyal po'i cha lugs rab byung gi cha lugs dang gsum yod pas 'di ni rdzogs sku'i cha lugs so/ bzhugs tshul ni phyag g.yas pa sa gnon gyi phyag rgya mdzad pas srid pa 'khor ba dang zhi ba myang 'das kyi mtha' gnyis khegs shing khams gsum zil gyis gnon pa'i don mtshon/g.yon pa mnyam bzhag mdzad pas thugs nyid ma bcos bon sku las g.yo ba med pa'i don mtshon/ phyag na g.yung drung chag shing bsnams pas g.yung drung bon mdo sngags rdzogs gsum 'chad pa'i slob dpon zhig yin pa'i don mtshon/g.yung drung chag shing ni mdo las/log lta'i gnya' ba gcog pas chag thar la drang por bkri bas shing / zhes gsungs/ mtshon don ni g.yung drung gnyis kyis mdo sngags gnyis kyi don mtshon bar gyi lcum bzhogs kyis gnas lugs byang chub sems su la bzla ba'i rdzogs pa chen po'i don mtshon pa bcas so/

sprul sku blo ldan snying po'i snyan rgyud mdo dri med gzi brjid dang slob dpon bstan 'dzin rnam dag rin po ches mdzd pa'i g.yung drung chag shing gi rnam bshad las gsal/

ston pa khri gtsug rgyal ba/

ston pa gshen rab mi bo dgung lo sum cu so gcig la drang srong legs ldan rgyal ba'i mdun nas khyim spang rab tu byung ste mtshan la ston pa khri gtsug rgyal ba zhes bya la 'di ni rab byung gi cha lugs te pad zhu dang rmadgos rmad 'og stod 'gag smad shams bcas gsol yod/

gshen rab rnam par rgyal ba/

gshen rab rnam par rgyal ba ni mu khyud gdal ba'i mtsho gling du rgya kong rtse 'phrul rgyal gyis gsas khang dkar nag bkra gsal bzhengs pa'i skabs su bdud srin gyis bar chod brtsoms pas de zlog pa'i ched du [4]ston pa gshen rab mi bo'i sprul pa yi dam gyi sku bzhengs pa zhig yin/ de'i mtshon don ni/ ma rig 'khrul ba'i bgegs kyi g.yul las rnam par rgyal ba'i rtags zhi ma khro bo'i tshul bstan pa dang / Ita ba bla med mkha' la rdzogs shing mtha' dgu'i spros pa las rgyal ba'i rtags phyag g.yas nam mkha'i dbyings su gdengs ba dang / pha rol phyin pa klong du rdzogs shing ma rig rga shi'i dgra las rgyal ba'i rtags phyag g.yon sa gzhi'i dkyil du phabs pa bcas so/

go lde 'phags pa'i gter ma rgya nag legs tang rmang pos bsgrig pa'i zhang zhung ma'i mchod gzhug nges pa'i thig le las gsal/

dbal bon stag la me 'bar/ 
dbal bon stag la me 'bar ni dug lnga'i dpung rgod pa'i dun cho'i tshogs rnams 'dul ba'i don du ston pa gshen rab mi bo'i phrin las las sprul pa'i yi dam lha zhig yin/lha de'i mtshon don ni/ byad dang rbod gtong 'jom zhing log lta'i sde bsreg pa'i rtags me ri 'bar ba'i dkyil na zhengs pa dang / srin po ru tra'i tshogs rnams brgyal zhing g.yo ba'i rtags sypan gsum bsgrad pa dang / srung zlog bsad pa'i las la thogs pa med pa'i rtags phyag na gser gyi 'khor lo dang ral gri dgu bsnol bsnams pa dang / 'jig rten gyi dregs pa 'dul zhing dpal rtsal ldan pa'i rtags bdud kyi g.yang gzhi dang stag shams gsol ba dang / mngan sems dang gdug sems rtsad nas 'byin zhing dun cho'i gnod byed las rgyal ba'i rtags ge shan pho mo'i gdan la 'gying ba bcas so/

dbyil ston gyi gter ma spu gri dmar po'i sgrub gzhung las gsal/

bstan srung ye shes dbal mo/

bstan srung ye shes dbal mo ni g.yung drung bon gyi bstan pa srung ba'i ched du yum chen shes rab byams ma drag po'i sku bzhengs pa'i srung ma zhig yin/ mtshon don ni/ mkha' 'gro'i brda rtags zhabs g.yas bskum [5]g.yon rkyang ste bzhengs pa dang / g.yung drung bon gyi bstan pa bshig cing 'gro la 'tshe ba can dang / sgrub gshen gyi thar lam la bar chod byed pa'i tshogs rnams bsgral ba'i brda rtags phyag g.yas pas ral gri nam mkha' la phyar ba dang / bstan pa 'dzin skyong spel gsum byed pa'i skyes bu rnams kyi tshe srog sring zhing grogs byed pa'i brda rtags bdud rtsi'i bum pa bsnams pa dang / dug Inga dang dug gsum gyi nyes pa'i tshogs kun 'joms pa'i brda rtags rma bya'i thul pa sku la gsol ba bcas so/

gshen chen klu dga'i gter ma ye shes dbal mo'i bskul pa las gsal/

bon nyid tog nam/

bon nyid tog nam ni bon sku mtshon byed yin pas snang gshen theg pa'i gzhung lugs su gtogs pa'i mkha' klong gsang ba'i mdos chen lag len byed pa'i skabs su mkho zhing de yang mdos ni snang srid snod mcud kyi bkod pa yongs rdzogs mtshon byed yin zhing bon nyid tog nam ni de rnams bon sku stong pa chen po'i rol rtsal las byung ba shes dgos pa dang / zhi ba'i lha tshogs kyi rten gyi ched du bed spyod byed dgos pa yin/ de yang dkyil dbus kyi mig ris kyis ye shes thig le nyag gcig mtshon/de'i rgyab 'ja' ris bskor ba'i sngon pos bon sku'i ngo bo skye med stong pa ka dag gi don mtshon/de'i rgyab 'ja' ris spros pa'i dkar pos de'i rnam pa lhun grub chen po'i don mtshon/ de'i rgyab ser po dang ngon po dmar po ljang khu dkar po rnams kyis rim bzhin du me long ye shes dang bya grub ye shes sor rtogs ye shes mnyam nyid ye shes stong nyid ye shes bcas kyi don mtshon/ de'i rgyab 'ja' ris kyis bon sku'i thugs rje'i 'od zer gyis 'gro ba kun la khyab pa'i don mtshon/mthar bya spu brgyan pas de'i phrin las phyogs med du bkye b'i don mtshon pa bcas so/

rma ston shes rab seng ge'i gter ma stong rgyung gis mdzad pa'i no bwe ka'i lag len dang / spyi rgyug mdos mchong rin chen phreng ba'i zil gnon las gsal/[6]

che mchog zhal nam/ 
che mchog gam gtso mchog zhal nam ni yi dam gtso mchog mkha' 'gying gi rten yin zhing mkha' klong gsang ba'i mdos chen lag len byed pa'i skabs su lha sring sde brgyad zil gnon gyi ched du bed spyod dgos pa dang / de yang dkyil dbus mig ris kyis ye shes spyan mtshon/de'i rgyab 'ja' ris bskor ba'i mthing khas zhal dbus dang sku mdog mtshon/mdun gyi dmar pos yum mkha' la gdug mo mtshon/de'i rgyab 'ja' ris spros pa'i g.yas dkar po dang g.yn dmar pos zhal g.yas dang zhal g.yon mtshon/de'i rgyab 'ja' ris kyis tshad med gzhi'i 'od zer phyogs bcur khyab pa'i don mtshon/phyi nang rim pa gsum yod pas sku gsung thugs gsum mtshon/snam skud phyi nang gnyis drangs pas ye shes lha mdun rgyab med pa'i don mtshon/mthar bya spu brgyan pas zhi rgyas dbang drag gi phrin las kyis gdul bya thar pa'i lam la bkri ba'i don mtshon pa bcas so/

rma ston shes rab seng ge'i gter ma stong rgyung gis mdzad pa'i no bwe ka'i lag len dang / spyi rgyug mdos mchong rin chen phreng ba'i zil gnon las gsal/

rgyal mo zhal nam/

rgyal mo'am srid rgyal zhal nam ni g.yung drung bon gyi bstan srung gtso mo ma mchog srid pa'i rgyal mo'i rten yin zhing mkha' klong gsang mdos lag len byed pa'i skabs su srid pa'i rgyal mo'i dmigs rten gyi ched du bed spyod dgos/de yang dkyil dbus kyi mig ris kyis sprul pa thogs pa med pa'i lhun grub kyi spyan mtshon/de'i rgyab 'ja' ris spros pa'i mthing nag gis dbus zhal dang sku mdog mtshon/de'i rgyab 'ja' ris spros pa'i g.yas dkar po dang g.yon dmar pos g.yas zhal dang g.yon zhal mtshon/ de'i rgyab 'ja' ris kyis rgyal ba gshen rab mi bo'i bstan pa la nyams len gnang ba'i skyes bu rnams la ma ltar byams pas skyong zhing grogs byed pa'i don mtshon/ snam ris phyi nang gnyis su drangs pas nyin mtshan rtag tu [7]g.yung drung bon gyi bstan pa la bya ra byed pa'i don mtshon/ mthar bya spu brgyan pas bstan dgra sgrol ba'i phrin las la thogs pa med pa'i don mtshon pa bcas so/

sman ri'i khri 'dzin nyer gsum pa nyi ma bstan 'dzin gyis mdzad pa'i mkha' klong gsang ba'i mdos chen gyi bca' thabs gsal byed nyi 'od dang / slob dpon bstan 'dzin rnam dag rin po che'i bka' 'bum pod lnga pa'i nang dpe ris las gsal/

srid rgyal dus drug zhal nam/

srid rgyal dus drug zhal nam ni g.yung drung bon gyi bstan srung gtso mo ma mchog srid pa'i rgyal mo gtso 'khor dang bcas pa'i rten yin la/ srid pa'i rgyal mo'i bskang mdos lag len byed pa'i skabs su rgyal mo sprul pa dang bcas pa spyan 'dren sa'i rten du bed spyod byed dgos pa yin/de yang dkyil dbus kyi mig ris kyis sprul pa thogs pa med pa'i lhun grub kyi spyan mtshon/de'i rgyab 'ja' ris brgyan pa'i mthing khas zhal dbus mtshon/ de'i rgyab stod g.yas dkar pos g.yas zhal dang g.yon dmar pos g.yon zhal mtshon/smad kyi ljang nag gis sku mdog mtshon/de'i rgyab ser ljang dmar sngo bzhis ne slas rgyal mo dang li mun rgyal mo tshangs stang rgyal mo ting nam rgyal mo bcas mtshon/de'i rgyab gru gsum bsnol ma'i dbyibs can nag po dang sngon po dkar po ser po dmar po smug po bcas kyis dus drug sprul pa'i khro mo drug mtshon/ 
de'i rgyab dkar sngon dmar gsum mnyam du sgrul te bskor bas gze gyad byin gsum mtshon/ mthar bya spu brgyan pas bstan pa'i dgra bgegs sgrol ba'i phrin las la thogs pa med pa'i don mtshon pa bcas so/rma ston shes rab seng ge'i gter ma stong rgyung gis mdzad pa'i no bwe ka'i lag len dang / 'or sgom phug pa'i dngos grub srid rgyal nang bskang chen mo las gsal/[8]

ru sbal khong nam/

rus sbal khong nam ni skye 'gro thams cad brten pa'i gzhi ma phyi rig pa'i 'byung khungs tshang rgyung 'jig rten chags pa'i sten gnas 'byung ba lnga yi bdag po ma ha+'a gser gyi rus sbal gyi rten yin pas 'byung rtsis sam nag rtsis dang mdos kun la gal gnad che ba'i dngos rdzas shig yin/ de yang 'go bo lho dang mjug ma byang du bstan nas gan rgyal du 'dug pa'i steng du dbang chen gser gyi sa gzhi chags/ de la 'byung ba chen po bzhi dang lo skor bcu gnyis spar kha brgyad sme ba dgu gza' chen brgyad rgyu skar nyer brgyad bcas dang mdor na 'byung bas ma bsdus pa gang yang med la 'byung bas bsdus pa thams cad kyi brten gnas sam bdag por gyur pa'o/

sprul sku blo ldan snying po'i snyan rgyud mdo dri med gzi brjid las bstan pa rin chen rab tu brtan pa'i mdo dang shi+'a la da+ha+'a rdzas mdzad pa'i nag rtsis kyi sgo 'byed 'phrul gyi lde mig las gsal/

man+dala (mandala)

chags tshad ldan pa'i man+dala ni g.yung drung bon lugs 'dzin pa rnams kyis mchod pa'i gtso bor bed spyod gnang ba'i dngos rdzas shig yin/ de yang tshang rgyung 'jig rten gyi bkod pa mtshon byed de rlung me chu sa'i dkyil 'khor rim par brtsegs pa'i steng du gser gyi sa gzhi gdal ba de'i steng ba tshwa can gyi rgya mtsho chags/ de'i steng gling bzhi dang gling phran grub ste shar gling steng du bum pas brgyan pa dang / byang gling gru bzhir dpag bsam ljon shing nub gling zlum por 'dod 'jo ba mo lho gling sog dbyibs nor bus brgyan pa bcas dang / gling phran gling rang rang gi dbyibs mtshungs gnyis re dang / gling bar rgya mtsho'i nang du chu gnas sna tshogs rrtse zhing rol ba'i tshul dang / de'i steng mchod pa rnam brgyad spros pa'i lcags ris stong gsum pa mthar thug gi 'jig rten mtshon/ de'i steng rdzas brgyad spros pa'i lcags ris stong gnyis pa bar ma'i 'jig rten mtshon/ de'i steng rnam lnga spros pa'i lcags ris stong dang po spyi phud kyi 'jig rten mtshon/[9] de'i steng gru bzhi bang rim bzhi ldan la mkhar gyis brgyan pa des ri rgyal lhun po dang rnam rgyal khang bzang mtshon/ mtshams gzhir byang shar bdud byang nub gnod sbyin lho nub phya lho shar nyi pang sad bcas kyi gnas mtshon/nang gi tshom bus mchod pa'i rdzas bsam mtha' yas pa mtshon pa bcas so/

slob dpon bstan 'dzin rnam dag rin po ches mdzad pa'i man+dala rnam bshad rgyas pa las gsal/

gtor par/ 
gtor par ni gson po'i gto dang mdos sogs sku rim gang dgos dang shi bo'i dge bskul gsang sngags kyi bsnyen sgrub bcas la gal gnad che b'i gzugs brnyan sna tshogs brkos pa'i bon po 'i phyag cha zhig yin/de yang lag len gyi skabs su gtor ma'i ngos la par rgyab ste bed spyod byed dgos pa yin/ bed spyod byed stangs mi 'dra ba dper na rnam Inga dang rnam brgyad rnam dgu sogs sde tshan dang po'i rigs rnams mchod rdzas zhes mgon skyobs byed pa'i lha rnams la mchod pa'i dmigs rten gyi ched dang / mi nor yul mkhar dang bya gcan rig.yung sogs sde tshan gnyis pa'i rigs rnams mdos la mkho ba'i mchod rdzas dang sbyin rdzas zhes lha srin sde brgyad dang rigs drug gi sems can rnams la brngan yon 'bul ba'i dmigs rten dang / nam mkha' dang rigs drug gi sems can rnams la brngan yon 'bul ba'i dmigs rten dang / nam mkha' dang ljang bu ni lha rten dang mchod rdzas sbyin rdzas sku glud kyi rten sogs du ma bed spyod byed srol yod/gtor ma zur gsum dbu gsum thod bcig sogs sde tshan gsum pa'i rigs rnams lha rten dang / sde tshan bzhi pa'i mkhar gyi rigs rnams mkhar dang khang pa'i dmigs rten gyi ched du mchod rdzas dang sbyin rdzas ci rigs su bed spyod byed dgos/ gto la mkho gal che ba'i spar kha dang sme ba lo skor sogs sde tshan lnga pa'i rigs rnams sa bdag sogs mi ma yin gyi rten dang /'chi bdag bdud lnga lha bu 'chi bslu dang bla bslu byed pa'i skabs su 'chi ba'i bslu yon 'bul sa'i bdud kyi rten dang / pho tong ni pho glud dag mo tong mo glud bu tong phru gu'i glud gshen bon rang glud ni gsang sngags sgrub pa po'i sku glud dang / g.yung drung dang 'khor lo pad ma rin chen rnams ni gtor ma'i phyogs mtshon byed/[10] nya bo ni sems can rnams la gnod 'tshe gtong ba dang / thar lam la bar chod byed pa g.yung drung bon gyi bstan pa bshigs pa'i dgra bgegs kyi rten bcas bed spyod byed srol mi 'dra ba du ma yod/

sde tshan dang po

rnam lnga dang / rnam brgyad rnam dgu bkra shis rtags brgyad rin chen nor bdun rgyal mtshan 'phan gdugs rnga gshang dung gling rtsal chen stobs lnga rin chen 'bru yi mi ring 'brang rgyas zhal dkar sum tsho ri rab gling dbu/

sde tshan gnyis pa/

mi nor yul mkhar nam mkha'ljang bu bya rigfs gcan gzan g.yung dwags chu gnas go khrab mtshon cha gnam la 'phur dgu bar la 'grim dgu sa la 'dzul bcu gzugs 'gros sna tshogs 'brang rgyas nag po 'brang rgyas dgu mig 'brang rgyas dkar po 'brang rgyas khra bo g.yag lug ra rta bya khyung khyi gtshod gna' ba byi'u sha ba chu bya gzugs 'gros nsa tshogs lug thog bya bab btsan bya 'ug pa/

sde tshan gsum pa

gtor ma zur gsum dbu dgu thod bcing gtor ma gru bzhi gdong lnga thod bcing mkhar thog gtor ma zlum po dbu gsum thod bcing gtor ma zur gsum dbu gsum thod bcing gtor ma zhi rgyas drag gsum thod bcing gtor ma zlum po ril bu bzhi btags thod bcing gtor ma dbu gsum ral bsnol thod bcing gtor ma zur gsum thod bcing mkhar thog gtor ma zur gsum thod bcing gtor ma gru bzhi thod bcing gtor ma gru bzhi khram ris can thod bcing gtor ma zur gsum thod bcing thugs sprul 'brug khyung seng gsum/ 
sde thsan bzhi pa[11]

mkhar thog nor bu mkhar thab mkhar thog brtsegs can/

sde tshan lnga pa/

sme ba dgu spar kha bryad lo skor bcu gnyis klu mo klu bdud sna khrid mched lnga

ngar mi bya mgo ngar mi sbal mgo ngar mi sbrul mgo 'chi bdag bdud lnga btsan dmar po/

gtor par che ba'i rnam grangs

1. rnam lnga

2. rnam brgyad

3. rnam dgu

4. bkra shis rtags brgyad

5. rin chen nor bdun

6. rgyal mtshan 'phan gdugs

7. rngagshang dung gling

8. mi nor yul mkhar

9. rtsal chen stobs lnga

10. pho tong mo tong bu tong

11. nam mkha' ljang bu

12. ri rab gling dgu

13. gshen bon rang glud

14. 'brang rgyas zhal dkar sum tsho

15. mkhar thog nor bu

16. g.yung drung

17. 'khor lo

18. pad ma

19. rin chen

20. gtor ma zur gsum dbu dgu thod mcing (mkha' 'gying lha mo)

21. $\quad$ gtor ma gru bzhi gdong lnga thod bcing (dus yum lha mo)

22. mkhar thog gtor ma zlum po dbu gsum thod bcing (bka'gsang lha mo)

23. gtor ma zur gsum dbu gsum thod bcing (bde 'gro gsang yum)

24. gtor ma zhi rgyas drag gsum thod bcing (rgyal mo rnam gsum)

25. $\quad$ gtor ma zlum po ril bu bzhi btags thod bcing (rdzu 'phrul sman bzhi)

26. gtor ma zur gsum ral bsnol thod bcig (sgra bla'i rgyal mo)

27. gtor ma zur gsum thod bcing (ma bdud)

28. mkhar thog gtor ma zur gsum thod bcing (mi bdud)

29. $\quad$ gtor ma gru bzhi thod bcing (dmag dpon)

30. $\quad$ gtor ma gru bzhi khram ris can thod bcing (gshin rje)

31. gtor ma zur gsum thod bcing (grad btsan)

32. mkhar thab/

sme ba dgu/[12] 
33. gcig dkar

34. gnyis nag

35. sum 'thing

36. bzhi ljang

37. Inga ser

38. drug dkar

39. bdun dmar

40. brgyad dkar

41. dgu smug

spar kha brgyad/

42. $\quad l i$

43. khon

44. dwa

45. khen

46. kham

47. gin

48. $\quad$ in

49. zon/

50. mkhar thog nor bu

51. mkhar thog brtsegs can

52. g.yag

53. $\quad \operatorname{lug}$

54. ra

55. rta

56. bya khyung

57. khyi

58. 'brang rgyas nag po

59. ' 'brang rgyas dgu mig

60. 'brang rgyas dkar po

61. 'brang rgyas khra bo/

lo skor bcu gnyis/

62. byi ba

63. glang

64. stag

65. yos

66. 'brug

67. sbrul

68. rta

69. lug

70. sprel

71. bya 
72. khyi

73. phag

74. gtsod

75. gna'ba

76. bya rigs

77. bya rigs

78. bya rigs

79. bya rigs

80. gcan

81. gzan

82. gcan gzan

83. gcan gzan

84. gcan gzan

85. ri dwags

86. ri dwags

87. ri dwags

88. ri dwags

89. g.yung dwags

90. g.yung dwags

91. g.yung dwags

92. g.yung dwags

93. hcu gnas

94. rin chen 'bru yi mi ring

95. byi'u

96. khyi

97. bya te

98. sha ba chu bya

99. nya'o

100. klu mo

101. klu bdud/

sna khrid mched lnga/

102. gza' bdud mgo dgu

103. 'gor ba nag po

104. gshin rje

105. dmag dpon

106. brag

btsan/

107. ngar mi bya mgo

108. ngar mi sbal mgo

109. ngar mi sprul mgo 
'chi bdag bdud lnga/[13]

110. ma rig 'khrul pa'i bdud

111. phrag dwogs lus len gyi bdud

112. nga rgyal gzugs brnyan kyi bdud

113. 'dod chags nyon mongs kyi bdud

114. zhe sdang las btsan gyi bdud/

115. gnam la 'phur dgu

116. bar la 'grim dgu

117. sa la 'dzul bcu

118. gzugs 'gros sna tshogs

119. gzugs 'gros sna tshogs

120. gzugs 'gros sna tshogs

121. gzugs 'gros sna tshogs

122. gzugs 'gros nsa tshogs

123. lug thog bya bab

124. thugs sprul

125. 'brug khyung seng gsum

126. go khrab mtshon cha

127. btsan dbar po

128. btsan bya 'ug pa/

gtor par chung ba'i rnam grangs

1. rnam Inga

2. rnam brgyad

3. rnam dgu

4. rgyal mtshan 'phan gdugs

5. rin chen nor bdun

6. rnga gshang dung gling

7. nya'o

8. lug thog bya bab

9. g.yung drung

10. 'khor lo

11. pad ma

12. rin chen

13. rtsal chen stobs Inga

14. pho tong mo tong bu tong

15. nam mkha' ljang bu

16. ri rab gling dgu

17. 'dab bzhi sum tsho

18. klu mo

19. klu bdud/

zhwa dkar khyung lding ma/ 
zhwa 'di ni zhwa dkar g.yung drung bon zhes bon gyi grub mthar mtshan gdags gzhi'i zhwa zhig ste gzhi ma phying bal dang phyi g.yog ras kyis mthus/de'i mtshon don ni/ gzhi ma phying dkar gyis bon nyid dri med ka dag gi don dang / phi g.yong dkar pos rang bzhin lhun rdzogs kyi don/ rgyab phyogs tshur la gzhol bas bon la mos gus byed pa'i don/ mtha' ras dmar pos bstan pa me ltar 'bar ba'i don/ mtha' char nag pos bdud srin bskal mthar bskrad pa'i don/gser gyi g.yung drung gis g.yung drung bon la 'gyur ba med pa'i don mtshon pa sogs mdor na zhwa 'dir che ba'i yon tan brda don bco brgyad gsungs yod/

bod shes rig las khung nas 2005 lor dpar skrun zhus pa'i bod zhwa brgya'i ngo sprod las zhal bshus pa'o/[14]

dkar mo rtse rgyal

zhwa 'dir mkhas zhwa dkar mo rtse rgyal yang zer zhing mkhas pa'i rtsod grwa 'grib dus dang gsang sngags kyi las thog sogs la 'jug skabs gsol ba yin/ rgyu phying bal gyi nang 'tshang la phyi g.yog ras dkar bya dgos/mtshon don ni/ rgyab nas gzhol zhing mdun nas dgye bas bon la mos shing 'khor bar yid ldog pa'i don dang / dpral ba'i nor bu rtse gsum dang mtha' ras dmar pos thar smin grol gsum gyi don rdzogs shing dbal mo'i ma tshogs las la 'khor a'i don/ nang sha dmar pos gsang sngags khro tshogs rdzogs pa'i don mtshon pa sogs yin/

bod shes rig las khung nas 2005 lor dpar skrun zhus pa'i bod shwa bryga'i ngo sprod las zhal bshus pa'o/ 


\section{Appendix 6: The table of contents (sa bcad) for the Manuscript (zin thu)}

\begin{tabular}{|c|c|c|c|}
\hline Index & Page & Section (Wylie) & Section (English) \\
\hline 1 & 2.3 & bca'gzhi & preparations \\
\hline 1.1 & 2.4 & $\begin{array}{l}\text { phyi rgyud kyi cho ga spy mthun ltar } \\
\text { klong rgyas gi gtor ma dang bum pa } \\
\text { rgyan sogs tshogs par bsag tshul spyir } \\
\text { gcig go/ }\end{array}$ & $\begin{array}{l}\text { a general manner of gathering into a } \\
\text { collection the tormas, ornamented } \\
\text { vases, etc. of Expansive Space in } \\
\text { accordance with rituals of the outer } \\
\text { tantras }\end{array}$ \\
\hline 1.2 & 2.4 & nye lam sde bzhi dngos & the actual Nyelam Dé Zhi \\
\hline 1.2 .1 & 3.1 & dkyil 'khor bri tshul & the manner of drawing the mandala \\
\hline 1.2 .2 & 9.1 & $\begin{array}{l}\text { rdzas bsags dang bca' gzhi shor 'byung } \\
\text { ngo }\end{array}$ & $\begin{array}{l}\text { material collection, ritual } \\
\text { preparations, and incidentals }\end{array}$ \\
\hline 1.2.2.1 & 9.2 & shing ris dang tsi shing gnyis ka'i rgyu & $\begin{array}{l}\text { reasons for [needing] both shingri and } \\
\text { tsishing }\end{array}$ \\
\hline 1.2.2.2 & 12.2 & rang $m$ thun gyi gtor $m a$ & tormas suited to each \\
\hline 1.2.2.3 & 15.4 & shor 'byung bshad pa & explanation of incidentals \\
\hline 2 & $\begin{array}{l}(2.3) \\
19.3\end{array}$ & las rim & steps \\
\hline 2.1 & 20.5 & ‘don 'grigs tsam bkod pa & arranging brief suitable recitations \\
\hline 2.1 .1 & 21.1 & $\begin{array}{l}\text { sngon 'gro'i tshul du dbu 'dzug klong } \\
\text { rgyas dang sbrag pa'i lugs }\end{array}$ & $\begin{array}{l}\text { the way to connect Expansive } \\
\text { Space with the beginning, in the way } \\
\text { of preliminary practices. }\end{array}$ \\
\hline 2.1 .2 & 27.4 & dngos gzhi & the main section \\
\hline 2.1.2.1 & 27.4 & $\begin{array}{l}\text { sngon 'gro mandala yan lag sogs phyi } \\
\text { rgyud spi ltar }\end{array}$ & $\begin{array}{l}\text { preliminary practices, mandala yenlak } \\
\text { [practices], and so on, according to } \\
\text { general outer tantra }\end{array}$ \\
\hline 2.1.2.2 & 30.1 & $\begin{array}{l}\text { zhor 'byung nad pa'i rim 'gro lta bu la } \\
\text { nad sel dgos na/ de'i 'don 'grig la sngon } \\
\text { 'gro dang dngos gzhi'o/ }\end{array}$ & $\begin{array}{l}\text { an incidental - the preliminaries and } \\
\text { main section for preprations }\end{array}$ \\
\hline 2.1 .3 & 32.1 & rjes bya mthar phyung ba'i rim pa & $\begin{array}{l}\text { stages of casting [things] out at the } \\
\text { end }\end{array}$ \\
\hline & 35.3 & & [colophon - see Appendix 1] \\
\hline
\end{tabular}




\section{Appendix 7: The table of contents (sa bcad) for the Upper Ritual (stod chog) volume}

\begin{tabular}{|l|l|l|l|}
\hline Index & Page & Section (Wylie) & Section (English) \\
\hline 1 & 100.3 & & $\begin{array}{l}\text { [Origin, location, reasons for the four } \\
\text { groups of worldly deities] }\end{array}$ \\
\hline 2 & 107.5 & & [How to deal with the deities] \\
\hline 2.1 & 108.4 & & [Subjugation myth] \\
\hline 2.2 & 111.4 & sngon du 'gro ba'i las rim & preliminary practice steps \\
\hline 2.3 & 112.4 & sa blang & taking the land \\
\hline 2.4 & 118.5 & lta bon & ritual preparations \\
\hline 2.5 & 127.2 & steg bu brtsegs & building the platform \\
\hline 2.6 & 128.3 & thig gdab & casting the lines [of the mandala] \\
\hline 2.7 & 133.3 & tshon bkye & sending the colors [of the mandala] \\
\hline 2.8 & 136.5 & yo byad dang rgyan bkod pa & $\begin{array}{l}\text { arranging the instruments and } \\
\text { ornaments }\end{array}$ \\
\hline 2.9 & 145.2 & khrus & ablution \\
\hline 2.10 & 146.4 & mtshams bcad pa & creating boundaries \\
\hline 2.11 & 148.2 & ting 'dzin byed & generating meditative absorption \\
\hline 2.12 & 153.1 & spyan drang ba & invocation \\
\hline 2.12 .1 & 156.2 & bzhugs su gsol ba & requesting to remain \\
\hline 2.12 .2 & 157.2 & dgyes pa bskyed & producing delight \\
\hline 2.12 .3 & 157.5 & phyag 'tshal & prostration \\
\hline 2.12 .4 & 160.5 & sdig pa bshags & confessing misdeeds \\
\hline 2.12 .5 & 161.4 & mchod pa 'bul & making offerings \\
\hline 2.12 .6 & 163.3 & 'dzab dang snying po & $\begin{array}{l}\text { magic sentences and essences } \\
\text { (mantras) }\end{array}$ \\
\hline 2.12 .7 & 163.3 & sku bstod & praise \\
\hline 2.12 .8 & 174.1 & phrin las bcol ba & enjoining enlightened activity \\
\hline 2.12 .9 & 175.3 & smon lam gdab & making aspiration prayers \\
\hline & & & \\
\hline
\end{tabular}




\section{Appendix 8: Notable title page differences across volumes}

- Volume 4, the byur phud (89): The title is written into the first line of the first page of the text in the fourth handwriting style.

- Volume 5, the bum bskyed (95): The title is written in the commentarial handwriting on the first page as a topic sentence. ${ }^{485}$

- Volume 12, the 'dzab sgron or snying po sngags gyi yig chung (355):486 The second title is present in the colophon. ${ }^{487}$

- Volume 14, the srid kyi chu mig g.yang blan (383): The title is written in the commentarial handwriting on the first page. ${ }^{488}$

- Volume 15, the gnam gshed bcu gnyis (389): The title is written in the commentarial handwriting on the first page. ${ }^{489}$

- Volume 19, the shing ris nad sel (447): The title is referenced in the commentarial handwriting on the first page, ${ }^{490}$ but is written more officially in the fourth handwriting style as a title above the bounds of the original folio page. ${ }^{491}$

- Volume 23, the rnam Inga'i smon lam (551): The title is written above the bounds of the original folio page in the fifth handwriting style. ${ }^{492}$

- Volume 32, the mar mnan (833): The title is written in the commentarial handwriting as the first sentence on the first page. ${ }^{493}$

- Volume 33, the god bcod mar mnan (843): The title is referenced in the first line of the first page, written in the commentarial handwriting, ${ }^{494}$ and included above the bounds of the original folio page in the fourth handwriting style, and with different spelling. ${ }^{495}$

\footnotetext{
485 de nas bum pa bskyed pa ni// (95.1)

486 The published version of this lists 'dzab sgron as the "short title," but this abbreviation is not referenced anywhere in the volume itself.

487 snying po sngags kyis[sic] yig chung bstan pa'o/(362.4)

488 srid kyi chu mig g.yang blan yin pa'o// (383.1)

${ }^{489}$ gnam gshed bcu gnyis dbu'o// (389.1)

490 shing ris nad sel bca' thabs bstan/ (447.1)

${ }^{491}$ shing ris nad sel bzhugs pa'i dbu yi khangs pa bde zhing yang pa bzhugs swo//(447)

492 nye lam sde bzhi'i mdo las rnam lnga'i smon lam bzhugs pa legs sto/ (551)

493 de nas nye lam sde bzhi'i sri'u gso ba'i mar mnan bcas ka bstan pa'o/ (833)

494 de ni nye lam sde bzhi'i god kha bcad pa'i mar mnan bcas ka la/ (883.1).

495 god ka bcod pa'i mar mnan bzhugs so// (883). Note the god ka bcod instead of god kha bcad in this title.
} 
- Volume 36, the rgyal 'khor nad sel (935): The title is written in the fourth handwriting style above the original folio page. .96

- Volume 38, the ba yi nad sel (971): The title is referenced on the second line of the text, written in the commentarial handwriting, ${ }^{497}$ and is included above the original folio page in the fourth handwriting. 498

- Volume 40, the bkra shis shog chung (1005): The title is written in the commentarial handwriting as the first line of the first page. 499

- Volume 41, the gshegs bskyod (1017):500 The title, different from the short title, is referenced in the first line of the first page, written in the commentarial handwriting. 501

- Volume 43, the brag srin bkar ba (1037): The title is referenced in the first line of the first page,, 02 and is written in the fifth handwriting style above the original folio page. 503

- Volume 44, the bcos mdo (1043): The title is referenced in the colophon, written in the commentarial handwriting. ${ }^{504}$

- Volume 45, the nad 'dre bkar ba (1053): The title is referenced in the first line of the first page, written in the commentarial handwriting. 505

- Volume 46, the spar khams lo bdud bkar ba (1057): The title is referenced in the first line of the first page, written in the commentarial handwriting, 506 and also written above the original folio page in the fifth handwriting style.507

\footnotetext{
496 rgyal 'khor nad sel bzhugs so: (935). Note that this is very different from the introduction of the text itself, which reads klu'i sgrub pa chen po'i nang nas sel ba'i thabs bstan pa'o/(935.1).

497 ba yi nad sel 'di gsung pa'o/ (971.2)

498 ba yi nad sel bzhugs so/ (971)

499 nye lam rgyal po sde bzhi'i mdo la bkris kyi shog chung legs/(1005.1)

500 This is the short title given in the published index, but this would appear to be a mistake, at least in terms of the spelling of the second word.

501 da ni klu rnams bskyed de 'di skad do// (1017.1)

502 de nas brag srin bkar ba'i bcas thabs la/ (1037.1)

503 prag[sic] srin bkar ba bzhugs so/(1037)

${ }^{504}$ nye lam sde bzhi'i bcos mdo 'di/ (1052.1)

505 da ni nad 'dre bkar ba'i bca' thabs// (1053.1)

506 de nas nye lam sde bzhi'i spar khams lo bdud bkar ba'i yas rnams bsags/(1057.1)

507 nye lam sde bzhi'i spar khams lo bdud bkar ba bzhugs so/(1057)
} 


\section{Bibliography}

\section{Tibetan Sources}

'a zha blo gros rgyal mtshan (1198-1263). [c. 13 ${ }^{\text {th }}$ century] 1985. Rtsa rgyud chen po gsang ba bsen thub dang de'i 'grel pa rin po che yid bzhin rnam par bkod pa'i rgyan. Dolanji, India: Tibetan Bönpo Monastic Center.

Blo ldan snying po (1360-1385/1407). [c. 14th century] 1975. Phyi rgyud cho go bcu gnyis kyi skor. Dolanji, India: Tashi Dorji.

Btsan lha ngag dbang tshul khrims. 1996. Brda dkros gser gyi me long. Beijing, China: mi rigs dpe skrun khang.

Dpon gsas khyung rgod rtsal (1175-?). [c. 12 $2^{\text {th }}$ century] 1990. Sa bdag nye lam sde bzhi. Kathmandu, Nepal: Tritan Nurbutse Bon Education Centre.

Dpon gsas khyung rgod rtsal (1175-?). [c. 12 $2^{\text {th }}$ century] 1973. Dbal gsas las rim gyi sgrub pa dang las tshogs bcas. Dolanji, India: Tibetan Bönpo Monastic Center.

Drang rje btsun pa gser mig (1024?-1091?). [c. 11 th century] 1965. Mdo gzer mig. New Delhi, India: Tenzin Namdak.

Drang srong rgyal mtshan tshul khrims. [c. 13 ${ }^{\text {th }}$ century?] 1972. Dpon gsas kyi rnam thar. In T. Namdak, Sources for a History of Bön.

Karma lha 'brug rgyal. 1996. Phywa dang g.yang gi ming la rags tsam dpyad pa. In Krung go'i bod kyi shes rig, 2nd issue of the year 1996, pp. 48-63.

Kun bzang nyi ma (1904-1958). 2001?. Rdzong gter kun bzang nyi ma'i gsung 'bum, section titled drag sngags me 'dus spu gri'i 'khor lo las: sa bdag klu gnyan gtod kyis dgyes bskyed shel tshig 'bul ba bdud rtsi'i char 'bebs. Shar rgyal ba dung dkar dgon.

Shu bon dge bsnyen gtsug phud (?). 1977. Gtsang ma klu 'bum chen mo. Dolanji, India: Tibetan Bönpo Monastic Center.

Tshul khrims bstan 'dzin. 2009. G.yung drung bon gyi gzhung lugs Itar gtor ma'i lo rgyus dang dgos pa phran tsam brjod pa. Unpublished manuscript, received by Jed Verity at Triten Norbutsé monastery in June, 2009.

Tshul khrims bstan 'dzin. 2009. Ta pi hri tsa. Unpublished manuscript, received by Jed Verity at Triten Norbutsé monastery in May, 2009. 


\section{Interviews}

Note that this is not a complete account of all conversations, but rather a list of the interviews that produced relevant, citable information. Much of the otherwise valuable information came from more casual conversations with unnamed monks and community members.

Acharya Drukzé

5/7/2009. Personal interview at Menri monastery.

Bsod nam grags pa

6/6/2009. Personal interview at Triten Norbutsé monastery.

Bstan 'dzin rnam dag [Tenzin Namdak]

5/26/2009. Personal interview at Triten Norbutsé monastery.

Bstan 'dzin yang ston [Tenzin Yangtön]

$2 / 5 / 2009$. Personal interview at Menri monastery.

$4 / 23 / 2009$. Personal interview at Menri monastery.

5/10/2009. Personal interview at Menri monastery.

5/14/2009. Personal interview at Menri monastery.

5/16/2009. Personal interview at Menri monastery.

$5 / 27 / 2009$. Personal interview at Menri monastery.

$6 / 18 / 2009$. Personal interview at Menri monastery.

Bstan pa dar rgyas

$2 / 17 / 2009$. Personal interview at Triten Norbutsé monastery.

$6 / 1 / 2010$. Personal interview at Triten Norbutsé monastery.

Geshé Q

$2 / 13 / 2009$. Personal interview at Menri monastery.

$2 / 22 / 2009$. Personal interview at Menri monastery.

$4 / 24 / 2009$. Personal interview at Menri monastery.

$4 / 25 / 2009$. Personal interview at Menri monastery.

$6 / 18 / 2009$. Personal interview at Menri monastery.

G.yung drung smon lam [Yungdrung Mönlam].

$5 / 12 / 2009$. Personal interview at Menri monastery.

Lung rtogs bstan pa'i nyi ma [Sangyé Tenzin]

$12 / 15 / 2008$. Personal interview at Menri monastery.

$4 / 16 / 2009$. Personal interview at Menri monastery.

$5 / 21 / 2009$. Personal interview at Menri monastery.

$4 / 22 / 2009$. Personal interview at Menri monastery.

Nyi ma 'od zer [Nyima Özer]

$2 / 16 / 2009$. Personal interview at Menri monastery.

$7 / 12 / 2009$. Personal interview at Menri monastery.

$7 / 18 / 2009$. Personal interview at Menri monastery.

10/3/2013. Personal correspondence.

Samten Karmay

4/22/2009. Personal interview at Menri monastery. 
5/31/2011. Personal interview in Paris, France.

Tshul khrims bstan 'dzin [Tenzin Tsultrim]

$2 / 27 / 2009$. Personal interview at Triten Norbutsé monastery.

$3 / 2 / 2009$. Personal interview at Triten Norbutsé monastery.

$3 / 3 / 2009$. Personal interview at Triten Norbutsé monastery.

$5 / 25 / 2009$. Personal interview at Triten Norbutsé monastery.

$5 / 28 / 2009$. Personal interview at Triten Norbutsé monastery.

$5 / 29 / 2009$. Personal interview at Triten Norbutsé monastery.

$5 / 30 / 2009$. Personal interview at Triten Norbutsé monastery.

$6 / 5 / 2009$. Personal interview at Triten Norbutsé monastery.

$6 / 6 / 2009$. Personal interview at Triten Norbutsé monastery.

$6 / 8 / 2009$. Personal interview at Triten Norbutsé monastery.

$5 / 15 / 2010$. Personal interview at Triten Norbutsé monastery.

$5 / 16 / 2010$. Personal interview at Triten Norbutsé monastery.

$5 / 25 / 2010$. Personal interview at Triten Norbutsé monastery.

$5 / 27 / 2010$. Personal interview at Triten Norbutsé monastery.

Unknown

$2 / 10 / 2009$. Personal interview at Triten Norbutsé monastery.

$6 / 4 / 2009$. Personal interview at Triten Norbutsé monastery.

6/7/2009. Personal interview at Triten Norbutsé monastery. 


\section{Secondary Sources}

Achard, J. L. (2003). "Contribution aux nombrables de la tradition Bön po: l'Appendice de bsTan 'dzin Rin chen rgyal mtshan à la Sphère de Cristal des Dieux et des Démons de Shar rdza rin po che." Revue d'Etudes Tibétaines, 4, 78-146.

Achard, J. L. (2004). Bonpo Hidden Treasures. Boston, MA: Brill.

Achard, J. L. (2008). Enlightened Rainbows: The life and works of Shardza Tashi Gyeltsen. Boston, MA: Brill.

Alay, Josep Lluis. (2010). "The Forty Magical Letters - A 19th c. AD Manuscript from Hor on Bon po Scripts", Revue d'Etudes Tibétaines, no. 19, Octobre 2010, pp. 119-132.

Appadurai, A. 1996. Modernity at Large: Cultural Dimensions of Globalization. Minneapolis, MN: University of Minnesota Press.

Aziz, B. N., \& Kapstein, M. (Eds.). (1985). Soundings in Tibetan Civilization. New Delhi, India: Manohar Publications.

Bell, C. (1988). "Ritualization of Texts and Textualization of Ritual in the Codification of Taoist Liturgy." History of Religions, 27(4), 366-392.

Bell, C. (1992). Ritual Theory, Ritual Practice. New York, NY: Oxford University Press.

Bell, C. (2001). "Acting Ritually: Evidence from the Social Life of Chinese Rites." In R. K. Fenn (Ed.), Blackwell companion to sociology of religion (pp. 371-387). Oxford, UK Malden, Mass: Blackwell Publishers.

Bell, C. (2009). Ritual: Perspectives and Dimensions--Revised Edition. New York, NY: Oxford University Press.

Bellezza, J. V. (1997). Divine Dyads: Ancient Civilization in Tibet. Dharamsala, India: Library of Tibetan Works and Archives.

Bellezza, J. V. (2005). Spirit-mediums, Sacred Mountains and Related Bon Textual Traditions in Upper Tibet. Boston, MA: Brill.

Bentor, Y. (1996). Consecration of Images and Stūpas in Indo-Tibetan Tantric Buddhism. Boston, MA: Brill.

Bentor, Y. (2000). "Interiorized Fire Rituals in India and in Tibet." Journal of the American Oriental Society, $120(4)$, 594-613.

Beyer, P. (1994). Religion and Globalization. London, England: Sage.

Beyer, S. (1978). The Cult of Tara. Berkeley, CA: University of California Press.

Bjerken, Z. (1998). "Cracking the Mirror: A Critical Genealogy of Scholarship on Tibetan Bon and the 'Canonical' Status of The Crystal Mirror of Doctrinal Systems." The Tibet Journal, 23(4), 92107.

Bjerken, Z. (2004). "Exorcising the Illusion of Bön 'Shamanism': A Critical Genealogy of Shamanism in 
Tibetan Religions." Revue d'Etudes Tibétaines, 2004(6), 4-59.

Blezer, H. (2005). "The 'Bon' dBal-mo Nyer-bdun(/brgyad) and the Buddhist dBang-phyug-ma Nyerbrgyad: A brief comparison." In S. G. Karmay \& Y. Nagano (Eds.), New Horizons in Bön Studies (pp. 117-178). Osaka: National Museum of Ethnology.

Blondeau, A. M. (1984). "Conférence de Mme Anne-Marie Blondeau." École pratique des hautes études, Section des sciences religieuses, 97(93), 107-112.

Blondeau, A. M. (1986). "Conférence de Mme Anne-Marie Blondeau." École pratique des hautes études, Section des sciences religieuses, 99(95), 100-107.

Blondeau, A. M. (1987). "Conférence de Mme Anne-Marie Blondeau." École pratique des hautes études, Section des sciences religieuses, $100(96)$, 74-81.

Blondeau, A. M. (1989). "Conférence de Mme Anne-Marie Blondeau." École pratique des hautes études, Section des sciences religieuses, 102(98), 110-116.

Blondeau, A. M. (1990). "Questions préliminaires sur les rituels mdos." In F. Meyer (Ed.), Tibet. Civilisation et société. Colloque organisé par la Fondation Singer-Polignac à Paris, les 27, 28, 29 avril 1987, Paris, Fondation Singer-Polignac / Éditions de la Maison des Sciences de l'homme, 1990 (pp. 91-107).

Blondeau, A. M. (1998a). "Conférence de Mme Anne-Marie Blondeau." École pratique des hautes études, Section des sciences religieuses, 111(107), 133-136.

Blondeau, A. M. (1998b). "La controverse soulevée par l'inclusion de rituels bon-po dans le Rin-čhen gter-mjod.” In H. Uebach \& J. L. Panglung (Eds.). Tibetan Studies: Proceedings of the 4th Seminar of the International Association for Tibetan Studies, Schloss Hohenkammer, Munich 1985, vol. 2 (pp. 55-68). Munich, Germany: Kommission für Zentralasiatische Studien, Bayerische Akademie der Wissenschaften.

Blondeau, A. M. (1999). "Conférence de Mme Anne-Marie Blondeau." École pratique des hautes études, Section des sciences religieuses, 112(108), 109-112.

Blondeau, A. M. (2005). "The mKha' klong gsang mdos: some questions on ritual structure and cosmology." In S. G. Karmay \& Y. Nagano (Eds.), New Horizons in Bön Studies (pp. 249-287). Osaka: National Museum of Ethnology.

Bolle, K. W. (1990). "Review: Imagining Ritual." History of Religions, 30(2), 204-212.

Boudewijnse, B. (2006). "Ritual and Psyche." In J. Kreinath (Ed.), Theorizing Rituals: Issues, Topics, Approaches, Concepts (pp. 123-131). Boston, MA: Brill.

Cabezón, J. I. \& Jackson, R.R. (Eds.). (1996). Tibetan Literature: Studies in Genre. Ithaca, NY: Snow Lion Publications.

Cabezon, J. I. (Ed.). (2009). Tibetan Ritual. New York, NY: Oxford University Press.

Cantwell, C. (2005). "The Earth Ritual: Subjugation and Transformation of the Environment." Revue d'Etudes Tibétaines, 7, 4-21.

Canzio, R. O. (1985). "Aspects of Ceremonial Behavior in Bön-po Monastic Life." In B. N. Aziz (Ed.), Soundings in Tibetan Civilization (pp. 42-53). New Delhi, India: Manohar Publications. 
Cech, K. (1987). The Social and Religious Identity of the Tibetan Bönpos, with Special Reference to a North-West Himalayan Settlement (Doctoral dissertation), University of Oxford.

Cech, K. (1992). "A Religious Geography of Tibet According to the Bon Tradition." In S. Ihara \& Z. Yamaguchi (Eds.), Tibetan studies: Proceedings of the 5th Seminar of the International Association of Tibetan Studies, Narita 1989, vol. 2 (pp. 387-392). Narita, Japan: Naritasan Shinshoji.

Dagkar, N. N. (1994). "The System of Education in Bönpo Monasteries from the Tenth Century Onwards." In P. Kvaerne (Ed.), Tibetan Studies: Proceedings of the 6th Seminar of the International Association for Tibetan Studies, Fagernes 1992 (pp. 137-143). Oslo, Norway: The Institute for Comparative Research in Human Culture.

Dagkar, N. N. (1997). "sTag-gzig and Zhang-zhung in Bon Sources." In E. Steinkellner et al (Eds.), Tibetan Studies II: Proceedings of the 7th Seminar of the International Association for Tibetan Studies, Graz 1995 (pp. 687-700). Vienna, Austria: Verlag der Österreichischen Akademie der Wissenschaften.

Dagkar. N. N. (1998). "The Early Spread of Bön." The Tibet Journal, XXIII(4), 4-27.

Davidson, R. M. (2005). Tibetan Renaissance: Tantric Buddhism in the Rebirth of Tibetan Culture. New York, NY: Columbia University Press.

Denwood, P. (1983). "Notes on Some Tibetan Bonpo Rituals." In P. Denwood \& A. Piatigorsky (Eds.), Buddhist Studies Ancient and Modern, Collected Papers on South Asia (No. 4, pp. 12-19). London, England: Curzon Press.

Douglas, M. (1966). Purity and Danger. New York, NY: Routledge.

Dreyfus, G. (2003). The Sound of Two Hands Clapping: The Education of a Tibetan Buddhist Monk. Berkeley, CA: University of California Press.

Eliade, M. (1954). The Myth of the Eternal Return: Cosmos and History. Princeton, NJ: Princeton University Press.

Franke, A. H. (1924). "gZer-myig, A Book of the Tibetan Bön-pos." Asia Major, 1, 305-346.

Franke, A. H. (1926). "gZer-myig, A Book of the Tibetan Bön-pos." Asia Major, 3, 321-339.

Franke, A. H. (1927). "gZer-myig, A Book of the Tibetan Bön-pos." Asia Major, 4, 161-239, 450-481.

Franke, A. H. (1928). "gZer-myig, A Book of the Tibetan Bön-pos." Asia Major, 5, 7-40.

Franke, A. H. (1930). "gZer-myig, A Book of the Tibetan Bön-pos." Asia Major, 6, 299-314.

Franke, A. H. (1949). "gZer-myig, A Book of the Tibetan Bön-pos." Asia Major, 7, 163-188.

Canclini, N. G. (1995). Hybrid Cultures: Strategies for Entering and Leaving Modernity. Minneapolis, MN: University of Minnesota Press.

Gardner, A. (2006). "The Sa Chog: Violence and veneration in a Tibetan soil ritual." Études mongoles et sibériennes, centrasiatiques et tibétaines, 36-37, 283-323.

Garrett, F., Erlich, A., Field, N., Hazelton, B., \& King, M. (2013). "Narratives of Hospitality and Feeding in Tibetan Ritual." Journal of the American Academy of Religion, 81(2), 1-25. 
Gellner, D. N. (1999). "Religion, politics, and ritual. Remarks on Geertz and Bloch." Social Anthropology, 7, 135-153.

George, M. K. (1998). "Jonathan Z. Smith's To Take Place: Toward Theory in Ritual After 20 Years." Journal of the American Academy of Religion, 66(2), 283-312.

Giddens, A. (1990). The Consequences of Modernity. Cambridge, MA: Polity.

Gieryn, T. F. (2000). "A Space for Place in Sociology." Annual Review of Sociology, 26, 463-496.

Gill, S. (1998a). "No Place to Stand: Jonathan Z. Smith as Homo Ludens, The Academic Study of Religion Sub Specie Ludi." Journal of the American Academy of Religion, 66(2), 283-312.

Gill, S. (1998b). "Territory." In M. C. Taylor (Ed.), Critical Terms for Religious Studies. Chicago, IL: University of Chicago Press.

Goldstein, M. C. (1998). "The Revival of Monastic Life in Drepung Monastery." In M. C. Goldstein \& M. T. Kapstein (Eds.), Buddhism in Contemporary Tibet (pp. 15-52). Los Angeles, CA: University of California Press.

Goldstein, M. C. \& Kapstein, M. T. (Eds.). (1998). Buddhism in Contemporary Tibet. Los Angeles, CA: University of California Press.

'Gos, L. G., \& Roerich, G. (1949). The Blue Annals. Calcutta: Royal Asiatic Society of Bengal.

Grimes, R. L. (1999). "Jonathan Z. Smith’s Theory of Ritual Space." Religion, 29, 261-273.

Grimes, R. L. (2000). Deeply into the bone : re-inventing rites of passage. Berkeley, CA: University of California Press.

Gyatso, J. (1993). "The Logic of Legitimation in the Tibetan Treasure Tradition." History of Religions, 33(2), 97-134.

Gyatso, J. (1994). "Guru Chowang's Gter 'byung chen mo: An early survey of the treasure tradition and its strategies in discussing Bon treasure." In P. Kvaerne (Ed.), Tibetan Studies: Proceedings of the 6th Seminar of the International Association for Tibetan Studies, Fagernes 1992 (pp. 275-287). Oslo, Norway: The Institute for Comparative Research in Human Culture.

Gyatso, J. (1996). “Drawn from the Tibetan Treasury: The gTer ma Literature. ” In J. I. Cabezón \& R. R. Jackson (Eds.), Tibetan Literature: Studies in Genre (pp. 147-169). Ithaca, NY: Snow Lion Publications, 1996.

Haarh, Erik. (1969). The Yar-Lun Dynasty. Copenhagen: G.E.C. Gad's Forlag.

Harth, D. (2006). "Ritual and Other Forms of Social Action." In J. Kreinath (Ed.), Theorizing Rituals: Issues, Topics, Approaches, Concepts (pp. 15-36), Boston, MA: Brill.

Hecht, R. D. (2008). "'Rites Require Rights': J. Z. Smith's 'To Take Place: Toward Theory in Ritual' after 20 Years Space, Place, and Lived Experience in Antiquity Consultation." Journal of the American Academy of Religion, 76(3), 790-805.

Held, D., McGrew, A., Goldblatt, D., \& Perraton, J. (1999). Global Transformations: Politics, Economics, and Culture. Palo Alto, CA: Stanford University Press. 
Heller, A. (2007). "Preliminary remarks on the Manuscripts of Gnas Gsar dgon pa in Northern Dolpo (Nepal)." In A. Heller \& G. Orofino (Eds.), Discoveries in Western Tibet and the Western Himalayas: Essays on History, Literature, Archeology and Art presented at a Panel of the 10th Seminar of the International Association for Tibetan Studies, Oxford 2003 (pp. 129-150), Boston, MA: Brill.

Heller, A. \& Orofino, G. (Eds.). (2007). Discoveries in Western Tibet and the Western Himalayas: Essays on History, Literature, Archeology and Art presented at a Panel of the 10th Seminar of the International Association for Tibetan Studies, Oxford 2003. Boston, MA: Brill.

Huber, T. (1999). The Cult of Pure Crystal Mountain. New York, NY: Oxford University Press.

Huber, T. (Ed.). (1999). Sacred Spaces and Powerful Places in Tibetan Culture. Dharamsala, India: Library of Tibetan Works and Archives.

Humphrey, C. \& Laidlaw, J. (1994). The Archetypal Actions of Ritual. Gloucestershire, UK: Clarendon Press.

Ishii, H. (2005). "Bon, Buddhist and Hindu life cycle rituals: A comparison." In S. G. Karmay \& Y. Nagano (Eds.), New Horizons in Bön Studies (pp. 359-382). Osaka: National Museum of Ethnology.

Jagchid, S. (1970). "Why the Mongolian Khans Adopted Tibetan Buddhism as Their Faith." In C. Chiehhsien \& S. Jagchid (Eds.), Proceedings of the Third East Asian Altaistic Conference (pp. 10828). Taiwan: Guo li Taiwan da xue.

Kapstein, M. (1985). "Religious Syncretism in 13th Century Tibet: The Limitless Ocean Cycle." In B. N. Aziz (Ed.), Soundings in Tibetan Civilization (pp. 358-371). New Delhi, India: Manohar Publications.

Karmay, S. G. (Ed.). (1972). The Treasury of Good Sayings: A Tibetan History of Bön. London, England: Oxford University Press.

Karmay, S. G. (1975). "A 'gZer-mig' Version of the Interview between Confucius and Phyva Ken-tse lan-med". Bulletin of the School of Oriental and African Studies, University of London, 39(3), 562-580.

Karmay, S. G. (1977). A Catalogue of Bonpo Publications, Tokyo, Japan: Toyo Bunko.

Karmay, S. G. (1998). The Arrow and The Spindle. Kathmandu, Nepal: Mandala Book Point.

Karmay, S. G. (2005). The Arrow and The Spindle, Vol. II. Kathmandu, Nepal: Mandala Book Point.

Karmay, S. G. (2007). The Great Perfection. Boston, MA: Brill.

Karmay, S. G. (2009). "Tibetan Indigenous Myths and Rituals with Reference to the Ancient Bön Text." In J. I. Cabezon (Ed.), Tibetan Ritual (pp. 53-68). New York, NY: Oxford University Press.

Karmay, S. G. \& Nagano, Y. (Eds.). (2001). A Catalogue of the New Collection of Bönpo Katen Texts. Osaka, Japan: National Museum of Ethnology.

Karmay, S. G. \& Nagano, Y. (Eds.). (2003). A Survey of Bönpo Monasteries and Temples in Tibet and the Himalaya. Osaka, Japan: National Museum of Ethnology. 
Karmay, S.G. \& Nagano, Y. (Eds.). (2005). New Horizons in Bön Studies. Osaka, Japan: National Museum of Ethnology.

Kertzer, D. (1989). "Review: To Take Place: Toward Theory in Ritual by Jonathan Z. Smith." Anthropological Quarterly, 62(1), 45-46.

Kind, M. (2002). "Abducting the Divine Bride: Reflections on Territory and Identity among the Bonpo Community in Phoksumdo, Dolpo." In K. Buffetrille \& H. Diemberger (Eds.), Territory and Identity in Tibet and the Himalayas, Proceedings of the Ninth Seminar of the International Association for Tibetan Studies, Leiden 2000, vol. 9 (pp. 271-288). Boston, MA: Brill.

Klein, A. C. (2005). "Authenticity, effortlessness, delusion, and spontaneity in The Authenticity of Open Awareness and related texts." In S. G. Karmay \& Y. Nagano (Eds.), New Horizons in Bön Studies (pp. 192-223). Osaka, Japan: National Museum of Ethnology.

Kloppenborg, R. \& Hanegraaff, W. J. (Eds.). (1995). Female Stereotypes in Religious Traditions. Boston, MA: Brill.

Kohn, R. J. (2001). Lord of the Dance: The Mani Rimdu Festival in Tibet and Nepal. Albany, NY: State University of New York Press.

Kratz, C. A. (1991). "Amusement and Absolution: Transforming Narratives during Confession of Social Debts." American Anthropologist, New Series, 93(4), 826-851.

Kreinath, J., Snoek, J., \& Stausberg, M. (Eds.). (2006). Theorizing Rituals: Issues, Topics, Approaches, Concepts. Boston, MA: Brill.

Kvaerne, P. (1971). "A Chronological Table of the Bön po: The Bstan Rcis of Ñi Ma Bstan 'Jin." Acta Orientalia, 33, 88-135.

Kvaerne, P. (1972). "Aspects of the Origin of the Buddhist Tradition in Tibet." Numen, 19, 22-40.

Kvaerne, P. (1974a). "The Canon of the Tibetan Bönpos (1)." Indo-Iranian Journal, 16(1), 18-56.

Kvaerne, P. (1974b). "The Canon of the Tibetan Bönpos (2)." Indo-Iranian Journal, 16(2), 96-144.

Kvaerne, P. (Ed.). (1994). Tibetan Studies: Proceedings of the 6th Seminar of the International Association for Tibetan Studies, Fagernes 1992. Oslo: The Institute for Comparative Research in Human Culture.

Kvaerne, P. (1996). “The Literature of Bon.” In J. I. Cabezón \& R. R. Jackson (Eds.), Tibetan Literature: Studies in Genre (pp. 138-146). Ithaca, NY: Snow Lion Publications.

Kvaerne, P. (2001). The Bon Religion of Tibet. London, England: Serindia.

Kvaerne, P. (2005). "The study of Bön in the West: Past, present and future." In S. G. Karmay \& Y. Nagano (Eds.), New Horizons in Bön Studies (pp. 7-20), Osaka, Japan: National Museum of Ethnology.

Kvaerne, P., Martin, D., \& Nagano, Y. (Eds.). (2003). A Catalogue of the Bön Kanjur. Osaka, Japan: National Museum of Ethnology.

Latour, B. (2005). "Thou Shall Not Freeze-Frame - or How not to Misunderstand the Science and Religion Debate." In J. D. Proctor (Ed.), Science Religion and the Human Experience (pp. 27 48). New York, NY: Oxford University Press. 
Lessig, F. D. \& Wayman, A. (1968). Mkhas Grub Rje's Fundamentals of the Buddhist Tantras. The Hague: Mouton.

Lhagyal, D. (2005). "Bönpo family lineages in Central Tibet." In S.G. Karmay \& Y. Nagano (Eds.), New Horizons in Bön Studies, 2005, (pp. 429-508). Osaka: National Museum of Ethnology

Littleton, C. S. (1988). "Review: To Take Place: Toward Theory in Ritual by Jonathan Z. Smith." American Anthropologist, 90(3), 769.

Littlewood, R. A. (1988). "Review: To Take Place: Toward Theory in Ritual by Jonathan Z. Smith." Review of Religious Research, 30(2), 207-208.

Lopez, D. S., Jr. (Ed.). (1995). Curators of the Buddha: The Study of Buddhism under Colonialism. Chicago: University of Chicago Press.

Lopez, D. S., Jr. (1998). Prisoners of Shangri-La: Tibetan Buddhism and the West. Chicago: University of Chicago Press.

Lopez, D. S., Jr. (Ed.). (2002). A Modern Buddhist Bible: Essential Readings from East and West. Boston: Beacon.

Mack, B. (2008). "Social Locations." Journal of the American Academy of Religion, 76(3), 782-789.

Makransky, J. (1996). “Offering (mChod pa) in Tibetan Ritual Literature. ” In J.I. Cabezón \& R. R. Jackson (Eds.), Tibetan Literature: Studies in Genre (pp. 312-330). Ithaca, NY: Snow Lion Publications.

Martin, D. (1994a). Mandala Cosmogony. Wiesbaden: Harassowitz Verlag.

Martin, D. (1994b).“Tibet at the Center: A Historical Study of Some Tibetan Geographical Conceptions Based on Two Types of Country-lists Found in Bon Histories." In P. Kvaerne (Ed.), Tibetan Studies: Proceedings of the 6th Seminar of the International Association for Tibetan Studies, Fagernes, 1992, vol. 1 (pp. 517-532). Oslo, Norway: Institute for Comparative Research in Human Culture.

Martin, D. (1997). "Beyond Acceptance and Rejection? The Anti-Bon Polemic Included in the Thirteenth-Century Single Intention (Dgong-gcig Yig-cha) and Its Background in Tibetan Religious History." Journal of Indian Philosophy, 25(3), 263-305.

Martin, D. (1998). “Drung, De'u and Bön: Narrations, Symbolic Languages and the Bön Tradition in Ancient Tibet by Namkhai Norbu, translated into English from Italian by Andrew Lukianowicz [review article]." The Tibet Journal, 23(4), 108-119.

Martin, D. (1999). "'Ol-mo-lung-ring, the Original Holy Place." In T. Huber (Ed.), Sacred Spaces and Powerful Places in Tibetan Culture (pp. 258-301). Dharamsala, India: Library of Tibetan Works and Archives.

Martin, D. (2001). Unearthing Bön Treasures. Boston, MA: Brill.

McMahan, D. L. (2008). The Making of Buddhist Modernism. New York: Oxford University Press.

Mills, M. A. (2003). Identity, Ritual, and State in Tibetan Buddhism. New York, NY: Routledge Curzon. 
Mimaki, K. (2005). "A Preliminary comparison of Bönpo and Buddhist cosmology." In S. G. Karmay \& Y. Nagano, New Horizons in Bön Studies (pp. 89-116). Osaka, Japan: National Museum of Ethnology.

Mumford, S. R. (1989). Tibetan Lamas and Gurung Shamans in Nepal. Madison, WI: University of Wisconsin Press.

Nagano, Sadako. (2005). "Sacrifice and lha pa in the glu rot festival of Reb-skong." In S.G. Karmay \& Y. Nagano (Eds.), New Horizons in Bön Studies (pp. 567-649). Osaka, Japan: National Museum of Ethnology.

Namdak, T. (Ed.). (1972). Sources for a History of Bön. Dolanji, India: Tibetan Bönpo Monastic Centre.

Namdak, T., Nagano, Y.\& Tachikawa, M. (2002). Mandalas of the Bon religion: Tritan Norbutse collection, Kathmandu. Delhi, India: Saujanya Publication.

Nebesky-Wojkowitz, R. (1956). Oracles and Demons of Tibet. London, England: Oxford University Press.

Norbu, C. N. (2013). A History of Zhang Zhung and Tibet, Volume One: The Early Period. Berkeley, CA: North Atlantic Books.

Norbu, N., Clemente, A. (Ed., Trans.), \& Lukianowicz A. (Trans.). (1995). Drung, Deu, and Bön. Dharamsala, India: Library of Tibetan Works and Archives.

Ortner, S. B. (1995). "The Case of the Disappearing Shamans, or No Individualism, No Relationalism." Ethos, 23(3), 355-390.

Patton, K. C. \& Ray, B. C. (Eds.). (2000). A Magic Still Dwells. Berkeley, CA: University of California Press.

Pelgen, U. (2005). "Kharamshing: An antidote against evil." In S. G. Karmay \& Y. Nagano (Eds.), New Horizons in Bön Studies (pp. 671-683). Osaka, Japan: National Museum of Ethnology.

Phillips, B. L. (2004). Consummation and Compassion in Medieval Tibet: The Mani bka'-'bum chen-mo of Guru Chos-kyi dbang-phyug (Doctoral dissertation), University of Virginia.

Ramble, C. (1995). "Gaining Ground: Representations of Territory in Bon and Tibetan Popular Tradition," The Tibet Journal 20(1), 83-124.

Ramble, C. (1999). "The Politics of Sacred Space in Bön and Tibetan Popular Tradition." In T. Huber (Ed.), Sacred Spaces and Powerful Places in Tibetan Culture (pp. 3-33). Dharamsala, India: Library of Tibetan Works and Archives.

Ramble, C. (2005). "The secular surroundings of a Bonpo ceremony: Games, popular rituals and economic structures in the mDos rgyab of Klu-brag monastery (Nepal)." In S. G. Karmay \& Y. Nagano (Eds.), New Horizons in Bön Studies (pp. 289-316). Osaka, Japan: National Museum of Ethnology.

Ramble, C. (2007). The Navel of the Demoness: Tibetan Buddhism and Civil Religion in Highland Nepal. New York, NY: Oxford University Press.

Ray, B. C. (1977). "Sacred Space and Royal Shrines in Buganda." History of Religions, 16(4), 363-373. 
Ray, B. C. (1991). "The Koyukon Bear Party and the "Bare Facts" of Ritual." Numen, 38(2), 151-176.

Robertson, R. (1992). Globalization: Social Theory and Global Culture. London, England: Sage.

Rossi, D. (1994). "The Nine Ways of the Bonpo Tradition: An Oral Presentation by a Contemporary Bonpo Lama." In P. Kvaerne (Ed.), Tibetan Studies: Proceedings of the 6th Seminar of the International Association for Tibetan Studies, Fagernes, 1992, vol. 2 (pp. 678-681). Oslo, Norway: Institute for Comparative Research in Human Culture.

Rossi, D. (1999). The Philosophical View of the Great Perfection. Ithaca, NY: Snow Lion Publications.

Samuel, G. (1993). Civilized Shamans: Buddhism in Tibetan societies. Washington, DC: Smithsonian Institute Press.

Schremph, M. (2002). "The Earth-Ox and the Snowlion." In T. Huber (Ed.), Amdo Tibetans in Transition: Society and Culture in the Post-Mao Era, Proceedings of the Ninth Seminar of the International Association for Tibetan Studies, Leiden 2000, vol. 5 (pp. 147-171). Boston, MA: Brill.

Schrempf, M. (2005). "Victory banners, social prestige and religious identity: Ritualized sponsorship and the revival of Bon monasticism in Amdo Shar-khog." In S. G. Karmay \& Y. Nagano (Eds.), New Horizons in Bön Studies (pp. 317-357). Osaka, Japan: National Museum of Ethnology.

Schrempf, M. (2006). "Hwa shang at the Border: Transformations of History and Reconstructions of Identity in Modern A mdo." JIATS, 2, 1-32.

Schuh, D. (1995). "Investigations in the history of the Muktinath Valley and Adjacent Areas, Part 2." Ancient Nepal,138, 5-54.

Segal, R. E. (2006). "Myth and Ritual." In J. Kreinath (Ed.), Theorizing Rituals: Issues, Topics, Approaches, Concepts (pp. 101-121). Boston, MA: Brill.

Skorupski, T. (1981). “Tibetan g-Yung-Drung Bon Monastery at Dolanji.” Kailash, 8(1-2), 25-43.

Smith, J. Z. (1980). "The Bare Facts of Ritual." History of Religions, 20(1/2), 112-127.

Smith, J. Z. (1992). To Take Place: Toward Theory in Ritual. Chicago, IL: University of Chicago Press.

Smith, J. Z. (1993). Map is not Territory. Chicago, IL: Chicago University Press.

Snellgrove, D. (1980). The Nine Ways of Bon: Excerpts from Gzi-brjid. Boulder, CO: Prajñâ Press.

Sørensen, P. K. (Ed.) 1994. Tibetan Buddhist Historiography: The Mirror Illuminating the Royal Genealogies. An Annotated Translation of the XIVth Century Chronicle rGyal-rabs gsal-ba'i melong. Wiesbaden: Harrassowitz Verlag.

Staal, F. (1996). Ritual and Mantras: Rules without Meaning. Delhi, India: Motilal Banarsidass.

Stein, R. A. (1959). Recherches sur l'épopée et le Barde au Tibet. Paris, France: Presses Universitaires de France.

Stein, R. A. (1972). Tibetan Civilization. Palo Alto, CA: Stanford University Press.

Szerb, J. (1990). Bu ston's History of Buddhism in Tibet, Critically Edited with a Comprehensive Index. Beiträge zur Kultur- und Geistesgeschichte Asiens, no. 5. Vienna: Österreichischen Akademie 
der Wissenschaften.

Tachikawa, M. (2005). "Mandala visualization and possession." In S. G. Karmay \& Y. Nagano (Eds.), New Horizons in Bön Studies (pp. 227-247). Osaka, Japan: National Museum of Ethnology.

Tamding, T. (1998). "Buddhism and Bon." Bulletin of Tibetology, 2, 7-12.

Taylor, M. C. (Ed.). (1998). Critical Terms for Religious Studies. Chicago, IL: University of Chicago Press.

Thomas, C. M. (2008). "Place and Memory: Response to Jonathan Z. Smith on To Take Place, on the Occasion of Its Twentieth Anniversary." Journal of the American Academy of Religion, 76(3), 773-781.

Todd, E. (1985). "The Value of Confession and Forgiveness According to Jung." Journal of Religion and Health, 24(1), 39-48.

Tucci, G. (1980). The Religions of Tibet (G. Samuel, Trans.). Berkeley, CA: University of California Press, 1980.

Tucci, G. (1999). Tibetan Painted Scrolls. Rome, Italy: La Libreria dello stato.

Turner, E. (1996). The Hands Feel It. DeKalb, IL: Northern Illinous University Press.

Turner, V. (1986). The Forest of Symbols: Aspects of Ndembu Ritual. Ithaca, NY: Cornell University Press.

Tweed, T. A. (2006). Crossings and Dwellings: A Theory of Religion. Cambridge, MA: Harvard University Press.

van Schaik, S. (2013). "The naming of Tibetan religion: Bon and Chos in the Tibetan imperial period." Journal of the International Association for Bön Research, 1, 2013.

Vasquez, M. A. (2003). Globalizing the Sacred: Religion Across the Americas. New Brunswick, New Jersey: Rutgers University Press.

Wangyal, T. \& Klein, A. C. (2006). Unbounded Wholeness: Dzogchen, Bön, and the Logic of the Nonconceptual. New York, NY: Oxford University Press.

Weitzman, S. (2008). "Reopening the Gates of J. Z. Smith's Temple: To Take Place in the Light of New Historicism." Journal of the American Academy of Religion, 76(3), 766-773.

Yamaguchi, S. (2005). "Khri-brtan Nor-bu-rtse Bön monastery in Kathmandu." In S. G. Karmay \& Y. Nagano (Eds.), New Horizons in Bön Studies (pp. 551-564). Osaka, Japan: National Museum of Ethnology. 